\title{
IgA GLYCOSYLATION IN IgA NEPHROPATHY
}

Thesis submitted for the degree of

Doctor of Philosophy

at the University of Leicester

Alice Allen BSc Hons (London) MSc (London)

Department of Medicine

University of Leicester

September 1995 
UMI Number: U543801

All rights reserved

\section{INFORMATION TO ALL USERS}

The quality of this reproduction is dependent upon the quality of the copy submitted.

In the unlikely event that the author did not send a complete manuscript and there are missing pages, these will be noted. Also, if material had to be removed, a note will indicate the deletion.

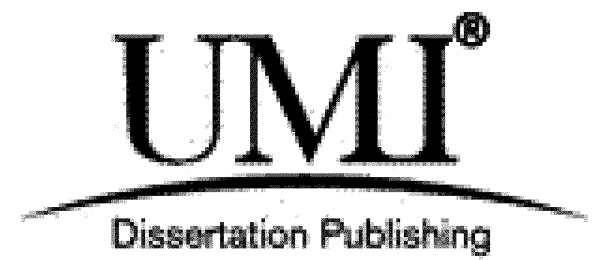

UMI U543801

Published by ProQuest LLC 2015. Copyright in the Dissertation held by the Author.

Microform Edition (c) ProQuest LLC.

All rights reserved. This work is protected against unauthorized copying under Title 17, United States Code.

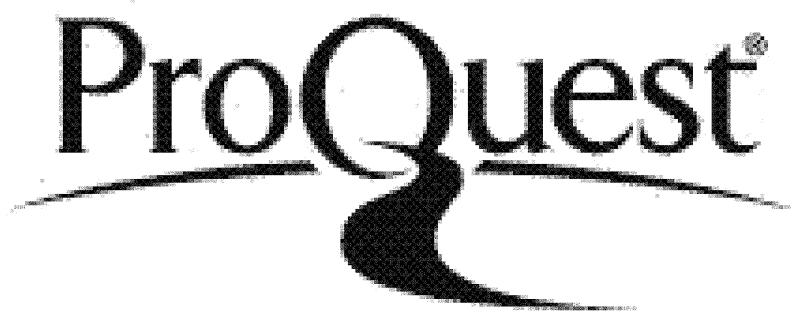

ProQuest LLC

789 East Eisenhower Parkway

P.O. Box 1346

Ann Arbor, MI 48106-1346 
(5) 


\title{
IgA GLYCOSYLATION IN IgA NEPHROPATHY
}

\author{
Alice Allen, Department of Medicine, University of Leicester
}

\begin{abstract}
$\operatorname{IgA}$ nephropathy (IgAN) is a common glomerulonephritis characterised by deposition of $\operatorname{IgA} 1$ in the glomerular mesangium. The underlying abnormality lies within the $\operatorname{IgA}$ system rather than the kidney, and modest irregularities of IgA biology have been described, but the mechanisms involved in IgAl deposition and glomerular injury remain elusive. A few reports have suggested an abnormality of the carbohydrate component of IgAI in IgAN. These studies sought to confirm and further characterise the putative glycosylation defect and to identify its biochemical basis.

Lectin binding assays were developed and used to analyse the $\mathrm{N}$ - and $\mathrm{O}$-linked glycans of IgAl in IgAN and controls. No gross abnormality of $\mathrm{N}$-glycosylation was detected in IgAN, though these studies were subject to technical limitations. IgA1 in IgAN displayed significantly increased binding to lectins with affinity for $\mathrm{O}$-linked $\mathrm{N}$-acetylgalactosamine (GalNAc) as compared to controls. One explanation for this finding is reduced terminal galactosylation of the O-linked sugars of $\operatorname{IgA1}$. A novel assay was developed to measure the functional activity of $\beta 1,3$ galactosyltransferase $(\beta 1,3 \mathrm{GT})$, the enzyme responsible for $\mathrm{O}$-galactosylation, in cell lysates. In IgAN, peripheral blood B cells appeared to show significantly lower $\beta 1,3 \mathrm{GT}$ activity than controls, and this was inversely proportional to GalNAc expression of serum IgAl as measured by lectin binding.
\end{abstract}

These studies confirm an abnormality of O-linked glycosylation of serum IgA1 in IgAN, which may be attributed to low B cell $\beta 1,3 \mathrm{GT}$ activity. Altered O-glycosylation of IgAl may be relevant to the pathogenesis of $\operatorname{IgAN}$. 
For my family and my friends

With my love

and especially, for Howard 


\section{ACKKNOWLEDGRIMENT}

I am grateful to Professor John Walls and Drs John Feehally, Kevin Harris and Graham Warwick for giving me the opportunity to carry out this work in the Department of Nephrology, Leicester General Hospital, and for their encouragement and support.

These studies were partially funded by a Discretionary Grant from the Foundation for Nephrology.

All the practical work described herein was carried out by myself, with the following exceptions. Some of the blood samples were collected by my colleagues; Lorna Layward originally developed and evaluated the ELISA systems; and Pete Topham helped me with the seemingly endless Ficoll separations for Chapter 8. I am also indebted to Dr Helen Griffiths of the Department of Molecular Toxicity, Leicester University, who first introduced me to the use of lectin binding assays for IgG glycosylation analysis.

This work would not have been possible without the cheerful cooperation of everyone who gave their blood for the experiments, and I am indebted to them all, especially to the two young men who passed out cold on the lab floor in the process - that was beyond the call of duty. I am also very grateful to the various people who collected blood samples for me. This sometimes involved travelling long distances at antisocial hours to ensure that they were in the lab first thing in the morning, and I am aware that I was not always in the best of tempers when I received them. I apologise to anyone who felt that I did not fully appreciate their efforts!

My inexorable, if haphazard, drift towards a career in medical research has been fuelled at various stages by Brian Gardiner, Bob Elliot, Derek Millard and Robin Sheppard, who each shared with me an irresistible fascination and enthusiasm for their respective branches of the biological sciences. The work forming this thesis was inspired by a memorable lecture (or would it be better called a performance?) by Ivan Roitt at the Middlesex Hospital in 1991. 
I have been in the Department of Nephrology at Leicester for just under six years, and began my first glycosylation experiments three years ago. This period of my life has been scattered with a number of traumatic life events, but it has been an extremely happy and fulfilling time nonetheless. I wish to thank all the colleagues who have helped to make this so; I'm not going to try to name them all in case I erroneously omit someone, but everyone should consider themselves duly acknowledged. My fellow incumbents of Lab 1 were Steve Harper and Chris Burton, with whom $I$ have shared the agony, ecstasy and hilarity that is research, and whose friendship and support I value very deeply. Several people, who probably know who they are, were particularly supportive at various times when I needed them. As I finish writing my thesis, Chris and Iza are embarking upon the early stages of theirs, and I wish them the very best of luck. Most of all, my appreciation goes to John Feehally, for being the best boss and supervisor I could ever wish for.

Among the greatest benefits I have gained from this work are my numerous acquaintances in the nephrological community worldwide, many of whom have become beloved friends. Without their interest and enthusiasm I would probably have gone to live on a mountain in Peru or under a Caribbean palm tree by now ... I'm not sure whether to thank you all or not!

Thanks are most definitely due to Rob, for keeping me fit and de-stressed with some wonderful classes, one or two of which even went according to plan (what plan?), and to all the other Squash Leicester aero-enthusiasts and skiers, with whom I spent a great deal of the time I wasn't working, for a lot of fun, laughter and good times.

Howard, Craig and Chas - The Razors - provided me with a counterbalancing obsession while I wrote this thesis, as the people around me are no doubt aware. The writing may be over now, but I've still got the rhythm and blues ...

And finally, I want to express my deep gratitude to my parents, who have helped and supported me in countless different ways. 


\section{INDEX}

ABBREVIATIONS 1

CHAPTER ONE IgA Nephropathy 3

Part 1 : The clinical syndrome of IgA nephropathy 4

1.1 Introduction 4

1.2 Epidemiology and Immunogenetics 4

1.3 Clinical Features 5

1.4 Pathology 6

1.4.1 Renal biopsy 6

1.4.2 Characteristics of mesangial IgA 7

$\begin{array}{lll}1.5 & \text { Treatment } & 7\end{array}$

Part 2 : Pathogenesis of IgA nephropathy 8

1.6 Animal models of IgAN 8

1.7 IgAN as a disease of the IgA system 9

1.8 Serum IgA 9

1.9 Production of $\operatorname{IgA}$ in $\operatorname{IgAN} \quad 10$

1.9.1 Lymphoid tissue 10

1.9.2 Response to immunisation 10

1.9.3 In vitro $\operatorname{IgA}$ production $\quad 10$

1.9.4 Other immunoglobulin isotypes in $\operatorname{IgAN} \quad 11$

1.9.5 Site of origin of mesangial IgA in IgAN 12

1.10 Clearance of circulating $\operatorname{IgA} \quad 13$

1.11 IgA antigen specificity in IgAN 13

1.11.1 Exogenous antigens $\quad 14$

1.11.2 Autoantigens 14

1.12 Physical abnormalities of the IgA molecule in IgAN 15

1.13 Functional abnormalities of $\operatorname{IgA}$ in $\operatorname{IgAN} 16$

1.14 Pathogenesis of IgAN: mechanisms of mesangial IgA $\begin{array}{ll}\text { deposition and glomerular injury } & 17\end{array}$ 
1.14.1 Mechanisms of mesangial IgA deposition

1.14.2 Initiation of glomerular injury

2.1 Introduction 22

2.2 Classification of protein glycosylation 22

2.2.1 Monosaccharides occurring in mammalian glycoproteins 22

2.2.2 Glycan linkages to the amino acid chain 23

2.2.3 Sialylation of core glycans 25

2.2.4 Immunoglobulin glycosylation 25

2.3 Functional aspects of protein glycosylation 29

2.3.1 General principles 29

2.3.2 The roles of the carbohydrate components of IgG and IgA 30

2.4 Glycosyltransferases 32

2.5 Glycosylation and disease 33

2.5.1 General considerations 33

2.5.2 Autoimmune rheumatoid disease 34

2.5.3 Tn polyagglutinability syndrome 35

$\begin{array}{lll}2.5 .5 & \text { IgA nephropathy } & 37\end{array}$

$\begin{array}{lll}2.6 & \text { Lectins } & 38\end{array}$

2.6.1 Lectins with specificity for components of $\mathrm{N}$-linked glycans $\quad 38$

2.6.2 Lectins with specificity for O-linked glycans $\quad 39$

2.6.4 Drawbacks of using lectins to analyse glycoproteins 41

Tables 
3.1 Subjects 48

3.1.1 Patients 48

3.1.2 Controls 48

3.2 Consumables 48

3.3 Serum samples 49

3.4 Ammonium sulphate and polyethylene glycol precipitation of serum 49

3.4.1 Ammonium sulphate precipitation 49

3.4.2 Polyethylene glycol precipitation 50

3.5 Enzyme linked immunosorbent assay (ELISA)

3.5.1 Primary antibodies 50

3.5.2 Washing 51

3.5.3 Blocking 51

3.5.4 Standards and samples $\quad 51$

3.5.5 Secondary antibodies 51

3.5.6 Development 52

3.5.7 Results 52

3.6 Protein assay 53

3.7 Sephadex columns 53

3.8 Sodium dodecyl sulphate polyacrylamide gel electrophoresis (SDS-PAGE) 54

3.8.1 Gel preparation $\quad 55$

3.8.2 Sample preparation $\quad 55$

3.8.3 Electrophoresis 55

3.8.4 Gel staining 55

3.9 Western blotting 56

3.9.1 Electrophoretic transfer 56

$\begin{array}{lll}3.9 .2 & \text { Staining } & 56\end{array}$ 
3.10 Purification of IgA1 57

3.10.1 Affinity purification of $\operatorname{IgA} 1$ on jacalin agarose $\quad 58$

3.11 Sequential purification of IgA1 and C1inh from serum 58

3.12 Purification of IgG 59

3.12.1 Preparation of composite column 59

3.12.2 Evaluation of composite column 59

3.12.3 IgG purification $\quad 60$

3.13 Purity of protein preparations 60

3.14 Preparation of detergent-solubilised cell lysates 61

3.14.1 Density gradient centrifugation of peripheral blood mononuclear cells 61

3.14.2 Separation of cell populations with magnetic beads 62

3.14.3 Purity of separated cell populations 63

3.14.4 Lysate preparation $\quad 64$

3.15 Statistical analysis $\quad 64$

Tables $\quad 65$

$\begin{array}{ll}\text { Figures } & 69\end{array}$

CHAPTER FOUR Development of Enzyme-linked Lectin

Binding Assays $\quad 75$

$\begin{array}{lll}4.1 & \text { Introduction } & 76\end{array}$

4.2 Lectin binding assays using purified IgA1 and IgG samples $\quad 77$

4.2.1 Basic Method 77

4.2.2 Sample denaturation 78

4.2.3 Lectin binding of sequential jacalin eluates $\quad 80$

4.3 Inhibition of lectin binding with monosaccharides 81

4.3.1 Method 81

4.3.2 Results 82

4.3.3 Conclusions $\quad 82$ 
4.4 IgA lectin binding assays on antibody-coated immunoplates

4.4.1 Evaluation of plate saturation and non-specific binding

4.4.2 Basic method for lectin binding assays on anti-IgA coated plates

4.4.3 Results of lectin binding assay on anti-IgA coated plates

4.4.4 Conclusions on lectin binding assays on anti-IgA coated plates

Figures

CHAPTER FIVE N-linked glycosylation of IgA1 and IgG in IgA nephropathy

5.2.2 IgA1 and IgG sample preparation 104

$\begin{array}{lll}5.2 .3 & \text { Lectin binding assay } & 104\end{array}$

5.2.4 Calculation of the results 105

5.3 Results 105

5.3.1 IgG glycosylation in rheumatoid arthritis 105

5.3.2 Comparison of the lectin binding patterns of IgAl and IgG 106

5.3.3 Variation of lectin binding by $\operatorname{IgAl}$ and $\operatorname{IgG}$ with age

5.3.4 Comparison of N-linked glycosylation of $\operatorname{IgA1}$ and IgG in IgAN and controls 
$\begin{array}{lll}5.4 & \text { Conclusions } & 107\end{array}$

$\begin{array}{lll}\text { 5.5 Discussion } & 107\end{array}$

Tables 110

Figures 113

CHAPTER SIX O-linked glycosylation of IgA1 and C1 inhibitor in IgA nephropathy

6.1 Introduction 120

6.2 Materials and Methods 121

6.2.1 Subjects 121

6.2.2 IgAl and Clinh sample preparation 121

6.2.3 Lectin binding assays 121

6.2.4 Calculation of the results 122

$\begin{array}{lll}6.3 & \text { Results } & 122\end{array}$

6.3.1 General observations on lectin binding to O-linked moieties

6.3.2 O-linked glycosylation of $\operatorname{IgA} 1$ in $\operatorname{IgAN}$ and controls

6.3.3 O-linked glycosylation of $\operatorname{IgA} 1$ and $\mathrm{C}$ linh in IgAN and controls $\quad 124$

$\begin{array}{lll}6.4 & \text { Conclusions } & 125\end{array}$

$\begin{array}{lll}\text { 6.5 Discussion } & 126\end{array}$

Tables 131

$\begin{array}{ll}\text { Figures } & 135\end{array}$

CHAPTER SEVEN Development of a novel system for $\beta 1,3$ galactosyl transferase activity in cell lysates 
7.2 Materials and Methods 142

7.2.1 Preparation of the acceptor 142

7.2.2 Preparation of a standard cell lysate 144

7.2.3 $\beta 1,3 \mathrm{GT}$ assay 144

7.2.4 Evaluation of the $\beta 1,3 \mathrm{GT}$ assay 145

$\begin{array}{lll}7.3 & \text { Results } & 149\end{array}$

7.3.1 Evaluation of the acceptor 149

7.3.2 Evaluation of $\beta 1,3$ GT assay 149

7.4 Conclusions 152

7.5 Discussion 153

Tables $\quad 157$

$\begin{array}{ll}\text { Figures } & 163\end{array}$

CHAPTER EIGHT Leucocyte $\beta 1,3$ galactosyl transferase activity in IgA nephropathy

$\begin{array}{lll}\text { 8.1 Introduction } & 170\end{array}$

8.2 Materials and Methods 172

$\begin{array}{lll}\text { 8.2.1 Subjects } & 172\end{array}$

$\begin{array}{lll}\text { 8.2.2 Samples } & 172\end{array}$

$\begin{array}{lll}8.2 .3 & \beta 1,3 G T \text { assay } & 173\end{array}$

8.2.4 Lectin binding of serum $\operatorname{IgA1} \quad 174$

$\begin{array}{lll}\text { 8.2.5 Statistics } & 174\end{array}$

$\begin{array}{lll}8.3 & \text { Results } & 175\end{array}$

8.3.1 $\beta 1,3$ GT activity in unfractionated PBMC lysates 175

8.3.2 $\beta 1,3 \mathrm{GT}$ activity in peripheral blood $\mathrm{B}$ cell, $\mathrm{T}$ cell and monocyte populations in IgAN and controls 175

8.3.3 Lectin binding of $\operatorname{IgA} 1$ and ammonium sulphate precipitate samples

8.3.4 Relationship between $B$ cell $\beta 1,3 G T$ activity and lectin binding of serum IgA1 
$\begin{array}{lll}\text { 8.4 Conclusions } & 177\end{array}$

$\begin{array}{lll}\text { 8.5 Discussion } & 177\end{array}$

Tables 180

$\begin{array}{ll}\text { Figures } & 185\end{array}$

$\begin{array}{lll}\text { CHAPTER NINE } & \text { Discussion } & 190\end{array}$

9.1 Summary of the thesis 191

9.2 Technical limitations of the studies 192

9.2.1 IgAl isolation 192

9.2.2 Lectin binding assays 194

9.2.3 Sialylation 194

9.3 Interpretation of the findings 194

9.3.1 Functional consequences of abnormal IgAl

O-glycosylation 195

9.3.2 Mechanism of abnormal IgA1 O-glycosylation 197

9.4 Final conclusions 199

$\begin{array}{llr}\text { APPENDIX I } & \text { Ethical Committee Approval } & 200 \\ \text { APPENDIX II } & \text { Buffers and Solutions } & 202 \\ \text { APPENDIX III } & \text { Suppliers } & 211 \\ \text { APPENDIX IV } & \text { Publications and Presentations arising from } & \\ & \text { this work } & 213 \\ \text { REFERENCES } & & 217\end{array}$




\section{ABBREVIATIONS}

\begin{tabular}{|c|c|c|c|}
\hline $\begin{array}{l}\text { AC } \\
\text { ANCA }\end{array}$ & $\begin{array}{l}\text { Amaranthus caudatus lectin } \\
\text { Anti-neutrophil cytoplasmic } \\
\text { antibody }\end{array}$ & $\begin{array}{l}\text { HBSS } \\
\text { H chain }\end{array}$ & $\begin{array}{l}\text { Hank's balanced salt solution } \\
\text { Heavy chain }\end{array}$ \\
\hline $\begin{array}{l}\text { AP } \\
\text { ASGPR }\end{array}$ & $\begin{array}{l}\text { Alkaline phosphatase } \\
\text { Asialoglycoprotein receptor }\end{array}$ & HEPES & $\begin{array}{l}\text { N-[2-hydroxyethyl]-N'-[2- } \\
\text { ethanesulphonic acid] }\end{array}$ \\
\hline Asn & Asparagine & $\mathbf{H P}$ & Helix pomatia lectin \\
\hline $\mathbf{A U}$ & Arbitary units & HRP & Horseradish peroxidase \\
\hline$\beta 1,3 G T$ & $\beta 1,3$ galactosyltransferase & HSP & Henoch Schönlein purpura \\
\hline$\beta 1, \mathbf{4 G T}$ & $\beta 1,4$ galactosyltransferase & IC & Immune complex \\
\hline BSA & Bovine serum albumin & Ig & Immunoglobulin \\
\hline C1inh & C1 inhibitor & $\operatorname{Ig} \mathbf{A N}$ & Immunoglobulin A \\
\hline CIC & Circulating immune complex & & nephropathy \\
\hline $\begin{array}{l}\text { CD } \\
\text { CH1-3 }\end{array}$ & $\begin{array}{l}\text { Cluster of differentiation } \\
\text { Domains of the }\end{array}$ & J chain & $\begin{array}{l}\text { Immunoglobulin joining } \\
\text { chain }\end{array}$ \\
\hline & $\begin{array}{l}\text { immunoglobulin heavy chain } \\
\text { constant region }\end{array}$ & $\begin{array}{l}\text { L chain } \\
\text { Man }\end{array}$ & $\begin{array}{l}\text { Light chain } \\
\text { Mannose }\end{array}$ \\
\hline CL & $\begin{array}{l}\text { Immunoglobulin light chain } \\
\text { constant region }\end{array}$ & $\begin{array}{l}\text { MBP } \\
\text { 2-ME }\end{array}$ & $\begin{array}{l}\text { Mannose binding protein } \\
\text { 2-mercaptoethanol }\end{array}$ \\
\hline cpm & Counts per minute & $\mathbf{m I g A}$ & Monomeric IgA \\
\hline $\mathbf{C V}$ & Coefficient of variation & $\min$ & Minutes \\
\hline DAB & Diaminobenzidine & $\mathbf{n}$ & Number \\
\hline DI $\mathrm{H}_{2} \mathrm{O}$ & Deionised water & NeuGc & $\mathrm{N}$-glycolyl neuraminic acid \\
\hline DME & $\begin{array}{l}\text { Dulbecco's modified Eagle } \\
\text { medium }\end{array}$ & $\begin{array}{l}\text { NeuNAc } \\
\text { NS }\end{array}$ & $\begin{array}{l}\mathrm{N} \text {-acetyl neuraminic acid } \\
\text { Not significant }\end{array}$ \\
\hline EC & Erythrina cristagalli lectin & OD & Optical density \\
\hline EDTA & $\begin{array}{l}\text { Ethylene diamine tetra } \\
\text { acetic acid }\end{array}$ & OPD & $\begin{array}{l}\text { 1,2-phenylenediamine } \\
\text { dihydrochloride }\end{array}$ \\
\hline ELISA & $\begin{array}{l}\text { Enzyme linked } \\
\text { immunosorbent assay }\end{array}$ & $\begin{array}{l}\text { p } \\
\text { PAGE }\end{array}$ & $\begin{array}{l}\text { Probability } \\
\text { Polyacrylamide gel }\end{array}$ \\
\hline $\mathbf{F}\left(\mathbf{a b} \mathbf{b}^{\prime}\right)$ & Fragment (antigen binding) & & electrophoresis \\
\hline Fc & Fragment (crystalline) & PBMC & Peripheral blood \\
\hline $\mathbf{F c} \alpha / \gamma \mathbf{R}$ & $\mathrm{Fc} \alpha / \gamma$ receptor & & mononuclear cell \\
\hline FCS & Fetal calf serum & PBS & Phosphate buffered saline \\
\hline Fuc & Fucose & PEG & Polyethylene glycol \\
\hline $\mathbf{G}_{\mathbf{0}}$ & Agalactosyl & pIgA & Polymeric IgA \\
\hline Gal & Galactose & PNA & Peanut agglutinin; Arachis \\
\hline GalNAc & $\mathrm{N}$-acetyl galactosamine & & hypogaea lectin \\
\hline Glc & Glucose & Pro & Proline \\
\hline GIcNAc & $\mathrm{N}$-acetyl glucosamine & PS & Penicillin/streptomycin \\
\hline GSSG & Oxidised glutathione & $\mathbf{r}$ & Coefficient of regression \\
\hline h & Hours & $\mathbf{R A}$ & Rheumatoid arthritis \\
\hline HA & Helix aspersa lectin & RT & Room temperature \\
\hline
\end{tabular}


Secretory component

SID Standard deviation

SDS Sodium dodecyl sulphate

Ser Serine

SIgA Secretory IgA

TBS Tris buffered saline

TEMED N,N,N',N'-tetramethyl ethylenediamine

Thr Threouine

TINT Tumour necrosis factor

TnPS Tn polyagglutinability

TV syndrome

Triticum vulgaris lectin

UIDP-Gal Uridine-5'-

diphosphogalactose

$\mathrm{V}_{\mathrm{H}} \quad$ Variable region of

immunoglobulin heavy chain

$V_{L} \quad$ Variable region of

$\mathbb{V} \quad$ immunoglobulin light chain

Vicia villosa lectin

Xyl Xylose 


\section{CHAPTER ONE}

IgA Nephropathy 
Part 1 : The clinical syndrome of IgA nephropathy

\subsection{Introduction}

In the late 1960 's the French pathologist Jean Berger described a form of glomerulonephritis characterised by the deposition of $\operatorname{IgA}$ and $\operatorname{IgG}$ in the glomerular mesangium (Berger 1967, Berger 1969). The condition was initially known as Berger's disease but is now more commonly referred to as $\operatorname{IgA}$ nephropathy $(\operatorname{IgAN})$.

The diagnosis of IgA nephropathy is made by the histological demonstration of predominant $\operatorname{IgA}$ deposition in the glomerular mesangium by immunological staining of a renal biopsy specimen. The presence of mesangial IgA is sometimes secondary to, or associated with, various systemic disease states. These include systemic lupus erythaematosus, liver or biliary tract disease, spondylarthropathies, gluten-sensitive enteropathy and dermatitis herpetiformis, and Henoch Schönlein purpura (HSP). The latter condition is a widespread IgA associated vasculitis characteristically presenting with purpuric rash and glomerulonephritis. It shares many features in common with IgAN, and it is still a subject of debate as to whether it is in fact a more extensive manifestation of the same pathological entity (Waldo 1988).

Primary IgAN, in which mesangial IgA deposition occurs without evidence of any systemic disease, is reported to be the most common glomerulonephritis in countries where diagnostic renal biopsy is routinely practised (d'Amico 1987, van Es 1992). Most of the studies presented in this thesis were conducted on patients with this common, idiopathic form of $\operatorname{IgAN}$.

\subsection{Epidemiology and Immunogenetics}

IgA nephropathy presents most frequently in the second and third decades of life, and is approximately 3 times more common in males than females, though this figure varies in different populations (Emancipator 1985, d'Amico 1987, Schena 1990a). The prevalence of IgAN has marked geographical variation. It accounts for some $30 \%$ of diagnostic renal biopsies in Asia, 
$12 \%$ in Australia, $10 \%$ in Europe, and just 5\% in the USA (Schena 1990a). North American figures show marked differences according to racial origin; Native Americans having a very high incidence, with the white population being comparable to Europeans, while the condition appears rare in black Americans (Jennette 1985). The incidence of IgAN is partly related to the frequency of renal biopsy as a diagnostic tool; areas with an aggressive approach to health screening picking up the most cases (d'Amico 1987, Emancipator 1989, Feelally 1989). It has been estimated that IgAN provides some $10 \%$ of the world's dialysis population (d'Amico 1987).

A few reports of familial clustering in IgAN (Levy 1993), the findings of IgA abnormalities in healthy relatives of IgAN patients (Schena 1993a, Schena 1993b), and the observed racial variations in its incidence, have lead to the search for genetic links. Attempts to identify HLA associations have failed to demonstrate any striking linkages. HLA-B35 may be an independent risk factor for progression, and there have been reports of associations with DQ loci (Berthoux 1993, Moore 1993). Partial complement deficiencies, or certain phenotypes of complement components may be associated with the clinical expression of $\mathrm{IgAN}$ in some populations (Wyatt 1990, Wyatt 1991). The inconsistencies of the overall picture suggest that if a specific gene is involved, it will be in linkage disequilibrium with some of the genes reported to display weak associations, and has yet to be discovered.

\subsection{Clinical Features}

IgAN typically presents in young adults, though it may occur at any age (Emancipator 1985, d'Amico 1987). Most patients present either with asymptomatic urinary abnormalities, or with episodic macroscopic haematuria. These are sometimes considered to represent different subgroups of the disease (d'Amico 1988). Among asymptomatic patients, microscopic haematuria is the most common feature at presentation, with many also having proteinuria. When episodes of macroscopic haematuria are seen they are self-limiting and recurrent, and are often associated with upper respiratory tract or gastrointestinal infections, or with physical exertion.

Progression is often slow, but as more patients are followed over the course of many years, it is increasingly recognised that a significant proportion, maybe $20 \%$, will reach end stage renal 
failure, and many more develop impaired renal function and hypertension (d'Amico 1988). Some patients present with severe proteinuria or the nephrotic syndrome, hypertension, and renal insufficiency; these patients typically progress much more rapidly to end stage renal failure. Clinically, degree of proteinuria is the only parameter which has been shown to predict outcome (d'Amico 1988)

\subsection{Pathology}

\subsubsection{Renal biopsy}

Morphologically, most IgAN biopsies at diagnosis have some mild to moderate glomerular matrix expansion and mesangial proliferation, with mesangial electron dense deposits on electron microscopy. However, the biopsy findings vary widely, from apparently normal glomerular morphology, through focal segmental and endocapillary proliferative lesions, to crescent formation and sclerosis (Emancipator 1985, d'Amico 1987). Progression is generally accompanied by glomerular sclerosis, interstitial fibrosis, and vessel changes, rather than by increased severity of proliferative lesions (d'Amico 1987).

The diagnosis of IgAN is an immunohistological one, requiring demonstration of predominant IgA deposits within the glomerular mesangium. However, other proteins are often co-deposited, the most frequent being other immunoglobulins and alternate pathway complement components. IgG and/or IgM are seen with the IgA in some $75 \%$ of biopsies, and the deposits stain more strongly for $\lambda$ light chain than for $\kappa$. Nearly all biopsies show positivity for $\mathrm{C} 3$ and components of the alternate and terminal pathways of complement, but $\mathrm{Clq}$ staining is very low. This is consistent with the poor ability of IgA to activate the classical pathway.

In a study of 180 IgAN biopsies, no relationship was found between mesangial codeposition of any of these proteins and severity of the disease (Jennette 1988). Immune deposits may be seen in the capillary walls in IgAN, and this feature correlates with a more severe form of the disease. 


\subsubsection{Characteristics of mesangial $\operatorname{Ig} \mathbb{A}$}

Despite an early report suggesting otherwise (Andre 1980), there is now general agreement that mesangial IgA is of the IgAl subclass, and that it is at least partly polymeric. Mesangial IgA is J chain associated, and has the capacity to bind secretory component (SC) (Bene 1982), though $\mathrm{SC}$ itself is not found in the deposits. In comparison to normal serum $\operatorname{Ig} \mathrm{A}, \operatorname{Ig} \mathrm{A}$ eluted from the mesangium in IgAN has restricted anionic charge, and $\lambda$ light chain is over-represented (MelegSmith 1990b).

\subsection{Treatment}

Ignorance of the basic pathological processes involved in IgAN hinder attempts to design appropriate treatment strategies, while the heterogeneity of the patient groups and the extended time course over which the disease develops make analysis of the efficacy of treatment difficult to interpret. The relatively benign nature of the disease in many patients, with the uncertainty of which individuals will progress, make aggressive treatment strategies ethically questionable.

A number of approaches have been tried. Attempts to minimise exposure to dietary antigens implicated in some theories of the pathogenesis of IgAN have included dietary restrictions (Coppo 1986b) and drugs which reduce mucosal permeability (Bazzi 1992), with no long term benefit. Phenytoin (Clarkson 1980, Coppo 1984) and plasmapheresis (Lai 1987a) have been used to lower serum IgA levels, again with disappointing results. Since IgAN is an immunological disease, and the renal injury is an inflammatory one, immunosuppressive strategies have been tried, including corticosteroids alone (Furuse 1985, Lai 1986) or in combination with azathioprine (Andreoli 1989, Woo 1991), and cyclosporine A (Lai 1988a). These appear to be of benefit to a subgroup of patients with severe or rapidly progressive disease (Schena 1990b), but long term treatment with such agents is undesirable. Other strategies designed to reduce the severity of glomerular injury include the use of urokinase (Miura 1989) and eicosapentanoic acid (fish oil), the latter reported as having promising results by some authors (de Caterina 1994), but not by others (Benuett 1989). 
Part $2:$ Pathogenesis of $\operatorname{IgA}$ mephropathy.

\subsection{Animal models of IgAN}

One of the major limiting factors in IgAN research has been the lack of a good animal model of the disease. Renal IgA deposition can be induced in mice by injection of antigen and specific IgA antibody (Montinaro 1991), or with repeated injection of dextran in Freund's complete adjuvant (Gonzalez-Cabrero 1990), to produce large circulating IgA-ICs which lodge in the glomerulus. A similar effect can be achieved with exposure to mucosal antigens such as gluten (Coppo 1992) and the murine respiratory Sendai virus (Jessen 1992), though drugs to suppress "oral tolerance" may be required before systemic IgA-ICs appear (Gesualdo 1990). Chronic alcohol ingestion in rats also leads to renal $\operatorname{IgA}$ deposition, but this appears to be secondary to liver damage (MelegSmith 1990a). The IgA deposits seen in these models are usually benign, and further manipulation is required to produce renal damage (Montinaro 1991, Jessen 1992). Spontaneous development of "IgAN" has been described in ddY mice (Wakui 1989), with IgG and IgA anti-histone antibodies appearing after 40 weeks of age, and the model probably has more in common with a lupus-like syndrome than human $\operatorname{IgAN}$.

The study of animal models has provided information about the role of true antigen-antibody complex associated nephropathy, and about the progression of immunologically mediated glomerular disease (Scivittaro 1993). However, unlike these manipulated rodent models, there is no clear role for a specific antigen in human $\operatorname{IgAN}$, which appears to have a much more complex pathology than a purely IC-mediated syndrome. The relevance of all models of IgAN suffers from the disparities between the human and animal $\operatorname{IgA}$ systems. Rodents have only one IgA subclass which is more similar to human IgA2 than IgA1, while lagomorphs have $13 \operatorname{IgA}$ subclasses. The compartmentalisation and handling of systemic and mucosal IgA differs between humaus and other species (Mestecky 1988). It is therefore very difficult to extrapolate conclusions drawn from animal models of IgAN to the human disease. 
There is considerable evidence that the basic abnormality in $\operatorname{IgAN}$ lies within the $\operatorname{IgA}$ immune system and not the kidney. It is well recognised that $\operatorname{IgA}$ deposits will recur in the graft in a substantial proportion of IgAN transplant recipients (Berger 1975, Berger 1988, Marcen 1991). There have also been reports of the disappearance of $\operatorname{IgA}$ deposits from $\operatorname{IgAN}$ kidneys inadvertently transplanted into non-IgAN patients (Sanfilippo 1982, Silva 1982). A wealth of data exists describing numerous abnormalities in various aspects of the IgA system in patients with IgAN.

\subsection{Serum $\operatorname{IgA}$}

It has long been appreciated that mean serum IgA levels in cohorts of IgAN patients are higher than control values, and, individually, about half of the patients have moderately high serum IgA levels (Mustonen 1981, Delacroix 1983, Tomino 1984, d'Amico 1987, d'Amico 1988, Emancipator 1989). This is accounted for by the IgA1 subclass; most studies finding normal IgA2 levels (Delacroix 1983, van den Wall Bake 1988a). Levels of polymeric $\operatorname{IgA1}(\mathrm{pIgA}$ ), and IgAcontaining immune complexes (IgA-IC) are also reported to be higher in IgAN than control populations (Lopez Trascasa 1980, Mustonen 1981, Delacroix 1983, Newkirk 1983, Tomino 1984, Czerkinsky 1986, Jones 1988, Schena 1989a, Jones 1990). $\lambda$ light chain in serum IgA is increased in IgAN (Chen 1991, Lam 1991), and the IgA appears to be more negatively charged than that of controls (Monteiro 1988, Harada 1989). These anomalies all reflect the characteristics of mesangial IgA in IgAN, which appears to be predominately polymeric $\operatorname{IgA} 1 \lambda$, and anionic in comparison to total serum IgA. Recently, it has been demonstrated that normal $\operatorname{Ig} A 1 \lambda$ is more anionic than $\operatorname{Ig} A 1 k$, and that the apparently higher negative charge of serum IgA1 in IgAN can be accounted for by the reduced $\kappa / \lambda$ ratio (Lai 1994).

There has been much interest in attempting to identify reasons for the raised serum IgA observed in IgAN. There are two possible mechanisms for this; increased production, or decreased clearance. They are not necessarily mutually exclusive. 
There is a great deal of evidence for selective overactivity of the IgA immune system in IgAN, obtained both from in vivo and in vitro experiments.

\subsubsection{Lymplooid tissue}

Data from peripheral blood cells is often conflicting (Egido 1987). Some studies show generally increased T or B cell activation (Rothschild 1984, Antonaci 1989, Magyarlaki 1990, Yano 1992), while others demonstrate upregulation of various IgA-specific activation markers (Sakai 1982, Bannister 1983, Endoh 1983, Casanueva 1986, Sakai 1989, Yasumoto 1989, Fortune 1992). Other studies report no difference in surface markers between IgAN and controls (Cosio 1982, Linne 1985); the clinical state of the patient at the time of study may influence these findings (Feehally 1986, Lai 1987b).

Immunohistological studies of tonsil (Bene 1991b, Harper 1995a) and bone marrow (van den Wall Bake 1988b, Harper 1994b, Harper 1995b) have shown increased IgA-, IgA1- and pIgAproducing plasma cells in these tissues, while the production of pIgA in the duodenal lamina propria appears to be low in IgAN (Harper 1994a).

\subsubsection{Response to immunisation}

Several attempts have been made to study the activity of the IgA system in vivo by following the course of an immune response after exposure to antigen. Exaggerated $\operatorname{IgA}$ responses are usually reported (Endoh 1984, Pasternack 1986, Fortune 1992), with pIgA and the IgA1 subclass predominating (Feehally 1987, van den Wall Bake 1989, Layward 1992).

\subsubsection{In vitro IgA production}

There have been numerous studies of cultured peripheral blood lyomphocytes in $\operatorname{IgAN}$. Many show upregulated in vitro IgA production, both spontaneously (Bannister 1983, Hale 1986, 
Schena 1986, Djukanovic 1991, Kameda 1991) and after mitogen stimulation (Egido 1982, Hale 1986, Djukanovic 1991). There have also been many attempts to elucidate which cell type is responsible for this upregulation. There is evidence for intrinsic B cell overproduction of $\operatorname{Ig} A$ (Cagnoli 1985, Hale 1986, Egido 1987, Allen 1994a, Layward 1994b), and for both reduced Tsuppressor activity and increased IgA specific Thelper activity (Egido 1983, Cagnoli 1985, Sakai 1989, Yasumoto 1989, Casanueva 1990, Jones 1991, Kameda 1991). More recently, some studies have begun to investigate the role of cytokine networks in the increased $\operatorname{IgA}$ production in IgAN. IL-2 production and $\Pi-2$ receptor expression by $C D 4+T$ cells are increased in cultured peripheral blood cells in IgAN (Lai 1988b, Lai 1989, Schena 1989b). Cultured lymphocytes have also been shown to secrete more IL-4 (Lai 1991) and TNF $\alpha$ (Lee 1994). Molecular techniques have demonstrated increased expression by peripheral blood mononuclear cells of mRNA for TGF $\beta$ and IL-6 (de Caestecker 1993), and by CD4+ T cells mRNA for TGF $\beta, \Pi-2$ and IL-5 (Lai 1992).

Overall, an intrinsic tendency to overproduce $\operatorname{IgAl}$ is evident in $\operatorname{IgAN}$; this is demonstrated by both $\mathrm{T}$ and $\mathrm{B}$ cells and does not appear to be related to any particular antigen.

\subsubsection{Other immunoglobulin isotypes in $\operatorname{Ig} \mathrm{AN}$}

In comparison to the general agreement on increased $\operatorname{IgA1}$ activity in $\operatorname{IgAN}$, the data on other immunoglobulin isotypes is more variable. Serum IgG and IgM levels are usually found to be normal (Feehally 1986, Schena 1986, Yasumoto 1989, Lam 1991). In vitro production of these isotypes is more variable, sometimes being normal (Egido 1983, Feehally 1986, Yasumoto 1989, Allen 1994a), while other studies found differences (Casamueva 1986, Hale 1986, van den Wall Bake 1988a, Djukanovic 1991). These differences may be related to the clinical state of the patient at the time of study, with active disease producing a general upregulation of immune cell activity (Cosio 1982, Schena 1986). Vaccination with a variety of antigens results in normal IgM and total IgG responses (Endoh 1984, van den Wall Bake 1989, Layward 1993b, Layward 1994a). A few studies have investigated IgG subclass production in IgAN, and found abuormalities, mostly relating to IgG2 (Monteiro 1989, Rostoker 1989, Layward 1993a). 


\subsubsection{Site of origin of mesangial $\operatorname{Ig} \mathbb{A}$ in $\operatorname{Ig} \mathbb{A N}$}

Since immunoglobulin production does not occur within the glomerulus, mesangial $\operatorname{IgA}$ must arrive via the circulation. There are two distinct arms to the human IgA system; mucosal and systemic. The mucosal IgA system produces approximately equal proportions of the $\operatorname{IgA1}$ and IgA2 subclasses, most of which is $J$ chain-containing polymer. Indeed, $J$ chain is mandatory for active secretion of $\operatorname{IgA}$, since it binds to an epithelial receptor, the polymeric immunoglobulin receptor, which then mediates transcytosis to the mucosal surface and remains an integral part of the secretory IgA molecule, in this context referred to as secretory component (SC). In contrast, systemic $\operatorname{IgA}$ is mostly monomeric, and the IgAl subclass predominates. Regulation of the two sides of the IgA system appears to be separate, with characteristic distributions of cells producing each type in different locations. Secretory IgA is produced in vast quantities at mucosal surfaces, and represents a first line of defence in external secretions, aggregating and neutralising potential pathogens and toxins. Systemic $\operatorname{IgA}$ is produced primarily by the bone marrow, and though it is present in serum in relatively high concentrations, it was originally considered as somewhat inert, perhaps with an anti-inflammatory role. However, it has now become clear that circulating IgA plays an active role in the systemic immune response; effective IgA responses are elicited by exposure to antigen, with the development of immunological memory analogous to that seen with $\mathrm{IgG}$, and $\mathrm{IgA}$ can activate the alternative pathway of complement. Specific IgA receptors are expressed by various immune cells such as lymphocytes, monocyte/macrophages and neutrophils, ligation of which leads to cell activation and triggering of effector functions. (Mestecky 1987, Mestecky 1988, Childers 1989, Kerr 1990).

There has been considerable debate over the years as to which of the two arms of the IgA system is responsible for the production of mesangial $\operatorname{IgA}$ in $\operatorname{IgAN}$. Its physical characteristics are somewhat contradictory in this respect; the observation that it is of the $\operatorname{IgAl}$ subclass favouring a systemic origin, while its polymeric nature arguing for the mucosal system. The well documented descriptions of episodes of macroscopic haematuria closely following upper respiratory tract infections also supported a mucosal origin. Increased numbers of $\operatorname{IgA}$-positive cells in tonsils has been demonstrated in IgAN (Garcia-Hoyo 1987, Bene 1988, Nagy 1988, Bene 1991b, Kawaguchi 1993, Harper 1995a). The finding of a characteristic localisation of IgA1 in 
tonsillar follicular dendritic cells in $\operatorname{IgAN}$ suggests an active immune response to antigen complexed with IgA1 (Kusakari 1992). However, it is not clear that tonsil is strictly a mucosal lymphoid tissue. One study showed that raised serum and salivary levels of secretory $\operatorname{IgA}$, suggesting mucosal activation, were not restricted to $\operatorname{Ig} A N$, but were also found in other primary glomerulonephritides (Rostoker 1992). Studies on duodenal lamina propria show that mucosal IgA production IgAN is normal (Hené 1988), or even downregulated (Harper 1994a). By contrast, there is strong evidence for specific upregulation of $\mathrm{pIgAl}$ production in the bone marrow (vau den Wall Bake 1988b, Harper 1994b, Harper 1995b). Studies of various aspects of serum and secreted $\operatorname{IgA}$ also support an abnormality restricted to the systemic $\operatorname{IgA}$ system in IgAN (Marx 1989, Rostoker 1990, Layward 1992, Layward 1993b, Layward 1993c). These studies suggest that the systemic $\operatorname{IgA}$ system in $\operatorname{IgAN}$ is overproducing $\operatorname{pIgA} 1 \lambda$, the very type seen raised in the serum and deposited in the mesangium, and that this is the branch of the IgA system from which mesangial $\operatorname{IgA}$ is derived.

\subsection{Clearance of circulating $\operatorname{Ig} \mathbb{A}$}

Raised circulating IgA and IgA-IC levels may result from some failure of the normal clearance mechanisms. The major route of serum IgA catabolism is via the liver (Tomana 1988). Studies of the functioning of this system in IgAN have provided conflicting results; one finding no abnormality (Rifai 1989), and another demonstrating reduced clearance of IgA (Roccatello 1993). Another route of clearance of serum IgA is via the reticuloendothelial system, the cells of which take up immunoglobulins and $\mathrm{ICs}$ via specific $\mathrm{Fc}$ and $\mathrm{C} 3 \mathrm{~b}$ receptors. A study of the function of this system in IgAN demonstrated reduced efficiency (Nicholls 1984). Thus the increased serum levels of $\operatorname{IgA}$ in various forms may not be due to increased production alone, but also to reduced clearance. This may in turn lead to deposition of excess IgA in other sites such as the mesangium; a mechanism which is certainly operational in IgAN secondary to liver disease (Feehally 1988).

\subsection{1 $\operatorname{Ig} \mathbb{A}$ antigen specificity in $\operatorname{Ig} \mathbb{A N}$}

IgAN has often been assumed to be an immune complex mediated disease, deposition being due either to IgA binding to an endogenous glomerular autoautigen, or to the mesangial trapping of 
preformed circulating immune complexes. Much effort has been expended in the search for the binding specificity of IgA in IgAN, but despite numerous reports implicating a wide variety of exogenous or self antigens, no convincing candidate has emerged.

\subsubsection{Cxogenous antigens}

Since $\operatorname{Ig} A$ is associated with mucosal surfaces, antigens found in such areas have received particular attention in the search for IgA specificity. Some studies have demonstrated food antigens within IgA-ICs, or within glomerular deposits, in IgAN (Russell 1986, Feehally 1987, Coppo 1992, Jackson 1992). A few reports exist of clinical improvements or reductions in the level of circulating immune complexes in response to withdrawing certain foods from the diet (Coppo 1986a, Coppo 1988, Coppo 1992), but suggestions that excess IgA-ICs containing food antigens may be due to increased mucosal permeability in IgAN have now been invalidated (Layward 1990, Bazzi 1992).

Viral antigens have also been identified within mesangial or circulating immune complexes in IgAN. Original reports of cytomegalovirus antigens in a high percentage of IgAN renal biopsies (Gregory 1988, Muller 1992) have been shown to be largely artefactual (Waldo 1989, MelegSmith 1991) or non-disease specific (Park 1992). Other viruses which have been implicated include herpes types (Nagy 1984) and Haemophilus parainfluenzae (Suzuki 1994), but these observations are sporadic and unconfirmed.

\subsubsection{Autonntigens}

Autoreactivity to a number of self-antigens has been described in IgAN, including IgA rheumatoid factors (Czerkinsky 1986, Sinico 1986, Sinico 1988, Hiki 1991), and anti-F(ab') ${ }_{2}$ activity (Jackson 1987, Schena 1989a). The finding of IgA-fibronectin aggregates in serum originally provoked considerable interest (Cederholm 1988, Jennette 1991). Autoreactivity to various mesangial components has been proposed as a mechanism of deposition, and studies have implicated laminin (Shinkai 1990), collagens (Cederholm 1986, van den Wall Bake 1992), mesangial cells (O'Donoghue 1991), and various less well characterised "glomerular components" (Tomino 1982, 
Ballardie 1988, Tomino 1990). However, many investigators have failed to confirm the diseasespecificity of these findings, proposing that slight autoreactivity may relate to the general polyclonal hyperreactivity of the IgA system (Jackson 1988, Sinico 1988, Goshen 1990, Matsiota 1990), and not pathogenic per se (O'Donoghue 1992). Indeed, some of the observed complexes of IgA with other protein may not represent true antibody-antigen associations, but be due to a non-immunological interaction (van den Wall Bake 1992, Floege 1993), and there is evidence that mesangial IgA in IgAN is polyclonal in nature and its antigen specificity is not disease specific (van den Wall Bake 1993b).

\subsection{Physical abnormalities of the IgA molecule in $\operatorname{IgAN}$}

In contrast to the wealth of data available on cellular abnormalities of the immune system in IgAN, there has been surprisingly little attention paid to the physical features of the molecule itself.

As mentioned above, mesangial IgA is of a somewhat unusual type considering its probable systemic origin, being of the IgA1 subclass, but also J-chain containing polymer (Lopez Trascasa 1980, Bene 1982, Newkirk 1983, Tomino 1984, Jones 1988, van den Wall Bake 1988a). The high expression of $\lambda$ light chain in deposited $\operatorname{IgA}$ is also an anomalous feature, since usage of the $\kappa$ light chain normally exceeds that of $\lambda$ by about 1.5:1 (Meleg-Smith 1990b, Chen 1991, Lam 1991). Both serum and mesangial IgA have been shown be rather more anionic in IgAN than that from normal serum (Monteiro 1985, 1988, 1989, Harada 1989). However, it has more recently been demonstrated that normal $\operatorname{IgA} 1 \lambda$ is more anionic than $\operatorname{IgA} \kappa \kappa$, and the altered $\kappa / \lambda$ ratio in IgAN can account for the observed differences in charge (Lai 1994).

Altered non-immunological binding of $\operatorname{IgA}$ to various proteins has been observed in $\operatorname{IgAN}$. Circulating IgA-fibronectin complexes in serum may well be due to Fc $\alpha$-fibronectin rather than antibody-antigen interactions (Cederholm 1988). Such complexes can be detected in serum from patients with $\operatorname{IgAN}$, though it is not currently clear whether they are due to a physical alteration in IgA favouring their formation, or if they merely reflect the raised serum IgA levels in these subjects (Floege 1993, van den Wall Bake 1993a). Studies on the role of food antigens in IgAN lead to investigation of IgA binding to various lectins derived from plants commonly used as 
foods, such as gluten, soya and peanut (Coppo 1988, Coppo 1992), with some differences observed in IgAN. The authors were primarily searching for antigenic targets, and though they suggested abnormal IgA carbohydrate content as an alternative mechanism for altered lectin binding in IgAN, no further examination of this was carried out in these studies. However, another study reported altered binding of $\operatorname{Ig} A$ to the lectin jacalin in $\operatorname{IgAN}$, strongly suggesting some abnormality of IgA glycosylation (Andre 1990). Further evidence for a glycosylation abnormality was subsequently provided by other groups (Hiki 1992, Coppo 1993, Mestecky 1993), using both lectin binding and gas liquid chromatography techniques.

\subsection{Tunctional abnormalities of $\operatorname{Ig} \mathbb{A}$ in $I g A \mathbb{N}$}

The functional roles of serum IgA are not well understood, and this has rather limited the scope for investigations into possible alterations of its effector activities in IgAN. However, a few observatious have been made.

One role of complement fixation by immunoglobulins is to solubilise immune complexes by interfering with lattice formation and reducing complex size. IgA-RF and IgA polymer from patients with IgAN may have reduced capacity to fulfil this function (Schena 1988a, 1988b), leading to the persistence of IgA-IC. After vaccination, patients with IgAN produce $\operatorname{IgA}$ antibodies of significantly lower affinity than controls; this functional insufficiency may also promote the formation and persistence of IgA-IC (Layward 1994a). There is also evidence that IgA from patients with IgAN interacts abnormally with various cell types. This includes increasing the activation of ueutrophils (Lai 1993), inducing the expression of an Fc $\alpha$ receptor on $T$ cells (Monteiro 1989), and some indirect evidence for reduced binding to the hepatic asialoglycoprotein receptor, which is responsible for clearance of IgA from the circulation (Roccatello 1989, Roccatello 1993). 
1.14 Pathogenesis of IgAN: mechanisms of mesangial IgA deposition and glomerular injury

Despite the well established abnormalities of the immune system in IgAN, it is expressed clinically as a disease of the kidney. The mechanisms of mesangial IgA deposition and subsequent glomerular injury remain unknown. None of of the many cellular irregularities of $\operatorname{Ig} \mathrm{A}$ production described can account for these key pathogenic events in the disease.

\subsubsection{Mechanisms of mesangial IgA deposition}

\section{Raised serum IgA}

Moderately raised serum levels of IgA are found in about half of the patients, but cannot explain mesangial deposition alone. Glomerulonephritis is not a feature of IgA myeloma, in which serum IgA can reach very high concentrations indeed, and relatives of IgAN-patients also sometimes have raised IgA-producing activity, yet do not have mesangial IgA deposits (Waldo 1990). Another condition in which high serum IgA levels occur is HIV infection. IgA-associated nephritis has been reported in HIV-positive patients (Katz 1992, Kimmel 1992), but these papers describe only a handful of cases, and in a larger series of 54 post-mortem renal biopsies from HIV-positive subjects, IgA was demonstrated in only one (Bene 1991a). Renal IgA deposition in HIV infection may be coincidental, both diseases being most frequently diagnosed in young men, or due to a different mechanism. Deposition of immune complexes containing viral antigens, IgG anti-HIV, and IgA anti-idiotypes to IgG has been proposed as one such mechanism (Kimmel 1992).

\section{Trapping of circulating IgA-ICs}

Tissue deposition of immunoglobulin is often considered to be due to the trapping of circulating immune complexes. By definition, immune complexes require antigen, but the intensive search for a consistent antigen for mesangial, or circulating complexed IgA in IgAN has failed to produce any convinciug candidates.

There is some limited evidence that the presence of circulating immune complexes may, be 
pathogenic in IgAN, though there are technical problems involved with assays of "immune complexes"; it can be difficult to know exactly what the assay is measuring, and the results need to be interpreted with caution (Feehally 1988). Correlations between the levels of IgA-ICs and clinical and histological signs of disease activity have been found (Coppo 1982), especially implicating IgA-ICs containing pIgA (Egido 1984).

There is also some evidence for various properties of the ICs found in IgAN which may promote their persistence and deposition. Immune complexes are normally solubilised by complement fixation by their immunoglobulin content. IgA is not a particularly good activator of complement (Imai 1988, Kerr 1990, Waldo 1990), and some studies have shown that IgA-ICs in IgAN are even less efficient in this respect that normal (Schena 1983a, 1988b). Size of ICs may influence their tendency to tissue deposition (Rifai 1988); excess production of polymeric as opposed to monomeric IgA would promote the formation of larger complexes. In addition, IgA antibodies in IgAN have been shown to be of low affinity (Layward 1994a), a feature which leads to failure of antigen elimination and the formation of large, possibly nephritogenic, ICs.

IgA complex formation with glomerular components

IgA deposition may also be due to in situ formation of complexes, via immunological or nonimmunological interactions with mesangial components. Early reports of mesangial autoreactivity of $\operatorname{IgA}$ in $\operatorname{IgAN}$, mostly to collagens (Cederholm 1986), have been invalidated since it has been shown that this is due to binding of IgA-fibronectin aggregates. Fibronectin has binding sites for collagens, and $\operatorname{IgA}$-complexed fibronectin provides a bridge between $\operatorname{Ig} \mathrm{A}$ and its apparent collagen antigen (Cederholm 1988, van den Wall Bake 1992, Floege 1993). The nature and specificity of the binding involved in circulating IgA-fibronectin aggregates requires further elucidation, but it is probably not specific to IgAN (Coppo 1994).

Recently, the presence of a specific receptor for IgA on cultured mesangial cells has been established (Gomez-Guerrero 1993, Allen 1994b), and this may also have a part to play in mesangial $\operatorname{Ig}$ A deposition in $\operatorname{Ig} A N$. 


\subsubsection{Fnitiation of glomerular injury}

\section{Nature of glomerular injury in $\operatorname{Ig} A N$}

The most frequently observed histological lesions seen in early IgAN are mesangial cell proliferation and expansion of extracellular matrix (d'Amico 1987, Alamartine 1990, van Es 1992). Once the disease has become progressive, these features worsen, and glomerular sclerosis, adhesions and crescent formation, and tubulointerstitial changes are seen. The later stages of the disease are indistinguishable from other forms of chronic glomerulonephritis, and presumably result from the same mechanisms of progression (Harper 1993).

The mechanisms by which glomerular injury is initiated in IgAN is still not clear. It has been suggested that $\operatorname{IgG}$ co-deposition is required, and that patients with $\operatorname{IgA}$ deposited alone have a benign course (Emancipator 1989, Emancipator 1990, Waldo 1990), but progressive disease in biopsies from patients with IgA alone are well described (Jennette 1988, van Es 1992). There is mounting evidence that the deposited IgA itself can interrupt the delicate balance of the normal mesangium and initiate inflammation, which, once in progress, becomes a self-perpetuating chronic lesion.

\section{Activation of mesangial cells}

Mesangial cells have for some time been known to express receptors for the constant region of $\operatorname{IgG}(\mathrm{Fc} \gamma \mathrm{R})$, and that their ligation activates the cell to produce pro-inflammatory substances (Baud 1983, Santiago 1989). Human mesangial cells are now known to possess Fc $\alpha$ Rs (GomezGuerrero 1993, Allen 1994b), and IgA has been shown to stimulate rat and human mesangial cells in vitro to proliferate (Fujii 1990), and to release cytokines (Chen 1994, van den Dobbelsteen 1994, Gomez-Guerrero 1994). Enhanced mesangial cell gene expression of platelet derived growth factor has been demonstrated in renal biopsies from IgAN (Nishimura 1992, Schena 1992).

\section{Activation of leucocytes}

In addition to direct effects upon mesangial cells, deposited IgA may promote inflammation by interactions with glomerular leucocytes. About $15 \%$ of cells within the normal mesangium are resident or trafficking macrophages (Vies 1993). Monocytes, macrophages and neutrophils 
possess a well characterised Fc $\alpha$ R (Albrechtsen 1988, Mazengera 1990, Monteiro 1990), ligation of which causes immune activation (Stewart 1990). Neutrophils from patients with IgA show increased expression of $F c \alpha R$, and enhanced generation of respiratory burst when exposed to IgA (Kashem 1994), while serum IgA from patients with IgAN has increased ability to activate normal human neutrophils in vitro (Lai 1993). It is conceivable that a similar effect could occur with resident mesangial macrophages, contributing to the creation of an inflammatory environment.

\subsection{Summary - unanswered questions in IgAN}

Despite years of intensive research, the basic mechanisms underlying the pathogenesis remain elusive. Two key questions remain :

Why does IgA deposit in the glomerular mesangium?

How does IgA deposition initiate glomerular injury?

The well-accepted disturbances of IgA production are numerous but modest, and none can provide adequate explanations for mesangial $\operatorname{Ig} A$ deposition and the subsequent initiation of glomerular injury. IgAN appears to be a neither an autoimmune condition, nor a purely "immunecomplex" mediated disease. There is no good evidence for any particular antigen being involved; though IgA-ICs may be detected, their presence in serum is certainly not peculiar to IgAN; and reducing serum $\operatorname{IgA}$ levels does not alter renal IgA deposition in IgAN. These considerations suggest that a qualitative abnormality of $\operatorname{IgA1}$, possibly affecting only a proportion of the molecules, may account for its anomalous behaviour and handling IgAN, in a way unrelated to its concentration or immunological activity.

This thesis describes a series of studies designed to investigate potential abnormalities of one physicochemical feature of the IgAl glycoprotein molecule: the carbohydrate component. 


\section{CHAPTER TWO}

Immunoglobulin Glycosylation 


\subsection{Introduction}

Protein glycosylation is a universal phenomenon; addition of carbohydrate components is the commonest and most diverse post-translational modification of newly synthesised proteins carried out by living organisms. In comparison to the study of protein synthesis, structure and function, the carbohydrate element of glycoproteins has until recently received little attention, and the science of glycobiology is still in its relative infancy. However, it is now clear that protein glycosylation is a precisely controlled process, and that the glycans play important roles in the structure, function and handling of glycoproteins. Moreover, alterations in protein glycosylation are characteristic of a growing list of disease states.

\subsection{Classification of protein glycosylation}

The carbohydrate components of glycoproteins consist of chains of monosaccharides covalently attached to specific amino acid residues of the protein backbone. Protein glycosylation is immensely diverse; this arises from the many different combinations of individual monosaccharides, linkages and sequences from which the glycan chains may be constructed. A particular protein may have a number of different glycosylation sites, each of which may carry different glycans, leading to an array of potential "glycoforms" of the same basic protein (Montreuil 1984, Axford 1992b, Lis 1993).

\subsubsection{Momosaccharides occurring in mammallian glycoproteins}

The vast range of different glycans seen in mammalian glycoproteins are built up from the following six-carbon monosaccharides :

$\begin{array}{ll}\text { Glucose } & \text { Gle } \\ \text { Mannose } & \text { Man } \\ \text { Galactose } & \text { Gal } \\ \text { Xylose } & \text { Xyl } \\ \text { Fucose } & \text { Fuc } \\ \text { N-acetyl glucosamine } & \text { GlcNAc } \\ \text { N-acetyl galactosamaine } & \text { GallNe }\end{array}$


In addition, various forms of the nine-carbon sialic acids are found in mammalian glycoproteins, predominately :

- N-acetyl neuraminic acid NeuNAc

- N-glycolyl neuraminic acid NeuGc

\subsubsection{Glycan linkages to the amino acid chain}

\section{N-linked glycans}

$\mathrm{N}$-glycosylation takes place as a cotranslational event in the endoplasmic reticulum, as the protein chain is assembled (Opdenakker 1993). A core glycan, consisting of two GlcNAc monosaccharides carrying branched chains of mannose and glucose, is enzymatically transferred from a dolichol carrier to asparagine (Asn) residues recognised as $\mathrm{N}$-glycosylation sites (Montreuil 1984, Lis 1993, Opdenakker 1993).

$N$-linked sugars are always attached to the protein chain by GlcNAc in $\beta 1-N$ linkage, but the rest of the core sugar undergoes extensive modificatiou after attachment, leading to a variety of branched chains, falling into three types:

- $\quad$ High mannose type, consisting of GlcNAc and mannose only;

- Complex type, which contain Gal, Fuc and sialic acid as well as the GlcNAc and Man of the original core structure;

- $\quad$ HHybrid type, in which the branches are of different types, both high mannose and complex type chains being represented.

(Montreuil 1984)

$\mathrm{N}$-linked glycosylation is common in both membrane-bound and secreted proteins, and is a feature of the majority of human serum proteins, including immunoglobulins. 


\section{O-linked glycans}

O-glycosylation occurs in the Golgi as a post-translational modification of the fully formed protein, by the sequential enzymatic addition of monosaccharides to serine (Ser) or threonine (Thr) residues. Since the protein is already folded by the time O-glycosylation occurs, the tertiary structure may prevent some potential sites being occupied due their inaccessibility to glycosyltranferases (Opendakker 1993). The core sugars of O-linked glycans are classified as follows:

- Mucin type sugars, based upon GalNAc linked to Ser or Thr in the $\alpha 1-3$ configuration (GalNAc $\alpha 1,3$ Ser/Thr);

Proteoglycan type, based on Xyl $\beta 1,3$ Ser and forming long, unbranched chains of repeating disaccharide units;

- Collagen types, based on Gal in $\beta 1,5$ linkage with hydroxy-lysine or hydroxy-proline.

(Montreuil 1982, Montreuil 1984, Hart 1992).

There are also a number of newly described types of O-linkage, including simple Ser/Thr-linked GlcNAc, which appears to be common in intracellular proteins such as components of the cytoskeleton and endoplasmic reticular membrane, and transcription factors (Hart 1992, Lis 1993).

O-linked glycans are found in many membrane-bound proteins, some of which carry them in very high densities. However, they are much less frequently seen in serum proteins. Mucin-type Oglycosylated proteins present in buman serum include $\operatorname{IgAl}, \operatorname{IgD}, \mathrm{Cl}$ inhibitor (C1inh), plasminogen, chorionic gonadotropin, and various cytokines (Hortin 1990).

\section{GPI anchors}

Many membrane proteins are attached to the phospholipid bilayer by a GPI anchor. This consists of a phosphotidylinositol-linked tetrasaccharide core (Man 2 2-Man $\alpha 6-\mathrm{Man} \alpha 4-\mathrm{GlcN} \alpha-\mathrm{PI}$ ), the terminal mannose of which is linked to the carboxy-terminal of the membrane protein (Lis 1993). The phospholipid-tetrasaccharide is assembled in the rough endoplasmic reticulum, and added to 
the protein at an early stage, but little is as yet known about the details of this process, or the role of GPI anchors in protein function (Hart 1992).

\subsubsection{Sialylation of core glycans}

The sialic or neuraminic acids differ in a number of respects from the other monosaccharides found in mammalian glycoproteins. They are a diverse group of 9-carbon carboxylated sugars which can display a wide range of substitutions at various positions, giving rise to many possible forms. The commonest type of sialic acid found in human glycoconjugates is $\mathrm{N}$-acetyl neuraminic acid (NeuNAc), which is acetylated at the 5-C position. Sialic acids are usually seen as the terminal monosaccharide component of both $\mathrm{N}$ - and $\mathrm{O}$-linked glycans, and like other sugars, are attached by specific intracellular enzymes. The number and linkage configuration of the NeuNAc units added to glycans varies, giving rise to differing degrees of sialylation. Sialic acids are biologically significant, since they are reactive, highly charged terminal constituents of sugar chains, and form the outer surface of glycoproteins. However, being reactive and labile species in comparison to the core sugars, sialic acids are readily altered or lost during the life of a protein. This is a particular problem in the study of glycoproteins, since variations in sialylation may be due to degradation in vivo, or to in vitro effects. Thus many investigations into aspects of protein glycosylation necessarily concentrate on the core sugars rather than on sialylation (Hart 1992, Varki 1992).

\subsubsection{Immunoglobulin glycosylation}

Like the majority of secreted and membrane proteins, human immunoglobulins are glycosylated. The constant regions of all five heavy chain types are glycosylated, but neither $\kappa$ nor $\lambda$ constant regions contain glycosylation sites (Wright 1993). The variable regions of both light and heavy chains may also be glycosylated if they contain an amino acid sequence defining a glycosylation site. Where this occurs, it is usually an Asn-X-Ser/Thr sequon resulting in N-glycosylation (Parekh 1988b); O-glycosylated variable regions have been described, but they are rare (Wright 1993, Rudd 1995). 


\section{IgG glycosylation}

IgG is the best studied of the immunoglobulins, and its glycosylation profile is well known. All four human IgG subclasses contain a single $\mathrm{N}$-linked glycosylation site at Asn 297 in the $\mathrm{C} \gamma 2$ domain of the constant region. Therefore, the complete $\operatorname{IgG}$ molecule has two N-linked moieties. In addition, the variable regions of some $30 \%$ of IgG molecules possess $\mathrm{N}$-linked sugars, resulting in an average of 2.5-2.8 oligosaccharides per IgG molecule (Parekh 1988b, Jefferis 1993, Wright 1993, Malhotra 1995).

The N-linked oligosaccharide of IgG is a biantennary structure of the complex type (Higure 2.1) (Parekh 1985). The core sugars of the basic peptide-linked chain Man $\beta 1,4$ GlcNAc $\beta 1,4$ GlcNAc1-N Asn are conserved, but a number of variations are found in the antennae, and the proximal GlcNAc sometimes carries $\alpha 1,6$-linked fucose. In all there are some 30 different forms of the oligosaccharide structure represented in human IgG (Parekh 1985), some of which may be favoured by certain IgG subclasses (Jefferis 1993). There are characteristic features more frequently seen in either the Fc- or the Fab-associated moieties, but the rules are not rigid.

The two antennae are built up on mannose units, one in $\alpha 1,3$ and the other in $\alpha 1,6$ linkage with the Man at the distal end of the core. There may also be a GlcNAc unit attached to the core Man, bisecting the $\alpha 1,3$ and $\alpha 1,6$ arms; this is characteristic of Fab rather than Fc sugars (Wright 1993). Both antennae are further extended with $\beta 1,2$-linked GlcNAc, which can carry Gal in the $\beta 1,4$ configuration. The occurrence of this terminal $\mathrm{Gal}$ in the carbohydrate moieties of $\mathrm{IgG}$ has received a great deal of attention. In the $\mathrm{Fc}$, one of the $\alpha 1,3$ arms always lacks Gal (Parekh 1985), and it may be absent from others also; the totally agalactosyl phenotype is recoguised and termed $\mathrm{G}_{0}$ (Parekh 1988a, Roitt 1988).

\section{IgA glycosylation}

There are two $\operatorname{IgA}$ subclasses in humans, with two allotypic variants of $\operatorname{IgA}, A 2 \mathrm{~m}(1)$ and $\mathrm{A} 2 \mathrm{~m}(2)$; each of these forms can exist as monomers ( $\mathrm{mIgA}$ ), as J chain-containing dimers or higher polymers (pIgA), and as secretory $\operatorname{IgA}(\operatorname{sIg} A$ ), consisting of pIgA with associated secretory component (SC) (Kerr 1990). All these proteins are glycosylated to varying degrees. 
IgA1, and both allotypes of $\operatorname{IgA}$, have $\mathrm{N}$-linked glycosylation sites, and carry complex-type glycans similar to those found in $\operatorname{IgG}$. IgA1 has two N-linked sites, $\operatorname{IgA} 2 \mathrm{~m}(1)$ four and $\operatorname{IgA} 2 \mathrm{~m}(2)$ five (Kerr 1990). The original work on the carbohydrate composition of IgA1, carried out using a myeloma protein, described three forms of the N-linked sugar (Baenziger 1974a). More recently, a study of IgAl obtained from normal serum found more heterogeneity, but still far fewer different forms than those displayed by IgG (Field 1994). The N-linked sugars of IgA1 are more completely galactosylated and sialylated than those of $F c \gamma$; the $\mathrm{G}_{0}$ phenotype is rare. Less work has been done on $\operatorname{IgA2}$ glycosylation, but an early study found that it has a higher carbohydrate content than IgA1, accounted for by more N-acetyl galactosamine, mannose and fucose (Tomana 1972).

In addition to the common $\mathrm{N}$-linked glycans, $\operatorname{IgA} 1$ is one of rather few serum proteins with $\mathrm{O}$ linked sugars, a feature which distinguishes it from other serum immunoglobulins, including $\operatorname{IgA} 2$. The O-linked sites lie in the hinge region of the molecule, between the $\mathrm{CH} 1$ and $\mathrm{CH} 2$ domains, in an area deleted in the $\alpha 2$ gene. This is the major difference between the IgA subclasses (Kerr 1990).

The IgA1 hinge region is a short series of amino acids with a repeating sequence of serine, threonine and proline residues. The serines each carry an O-linked glycan, resulting in five sugars lying within a stretch of just 17 amino acids. Therefore, the complete IgA1 monomer, with its two $\alpha 1$ heavy chains, has a block of ten closely adjacent O-linked moieties in the hinge region; an unusual and distinctive characteristic of the molecule (Figure 2.2) (Kerr 1990). The O-linked carbohydrates of $\operatorname{IgAl}$ are of the mucin type, that is, linked to the peptide backbone by GalNAc in $\alpha 1,3$ linkage with serine. The initial work on an IgA1 myeloma protein described one moiety simply consisting of GalNAc, and four with the further addition of Gal in $\beta 1,3$ linkage (Galß1,3GalNAc) (Baenziger 1974b). The ungalactosylated moiety was proposed to be located on the Asn at the $\mathrm{NH}_{2}$ end of the hinge region. No sialylation of the O-linked glycans was detected in this study. Subsequently, analysis of normal serum IgA1 has established that substitution with NeuNAc occurs in the galactosylated moieties, and that the distribution varies considerably between the individual glycans (Field 1989). A study of the O-linked sugars from the hinge region of secretory $\operatorname{IgA}$ indicated more heterogeneity than found in serum $\operatorname{IgA1}$. The 
core GalNAc in secretory IgA is often substituted with GlcNAc in $\beta 1,6$ linkage in addition to the usual $\beta 1,3$ linked Gal, and this GlcNAc may itself be galactosylated. $\alpha 2,3$-sialylated Galß1,3GalNAc was also found (Pierce-Cretel 1981).

The different forms of the O-linked carbohydrates of serum IgA1 are shown in Figure 2.3.

Taking into account the varying carbohydrate components of $\operatorname{Ig} A \operatorname{land} \operatorname{Ig} A 2$, and also the $J$ chain and secretory component content of polymeric and secretory forms of IgA, it becomes clear that different combinations of these units will result in proteins with distinct glycoyslation profiles; the two extremes being $\operatorname{mIgA} 1$ and $\operatorname{sIgA2}$. These types of $\operatorname{IgA}$ each predominate in different compartments, $\mathrm{mIgA} 1$ in serum and $\operatorname{sIg} \mathrm{A} 2$ in mucosal secretions.

It is important to note that the glycosylation of human IgA is fundamentally different from that of experimental animals. Murine $\mathrm{IgG}$ is similar enough to that of the human to allow extrapolation of animal data. The murine IgA molecule has two N-linked glycosylation sites, one in the $\mathrm{C} \alpha 1$ (Fab) domain, and the other at the C-terminal of the $\mathrm{C} \alpha 3$ domain; the $\mathrm{Fc}$ is not glycosylated. Both glycaus are complex type; they differ in a number of features both from each other, and from the N-linked glycans of human Igs (Young 1990). Mouse IgA does not have Olinked sugars.

Glycosylation of other immunoglobulin isotypes

IgM, IgE and IgD all carry N-glycosylation sites (Baenziger 1974b, Edge 1993). In addition, IgD has an extended hinge region, and shares with $\operatorname{IgA} 1$ the distinction of possessing a series of $\mathrm{O}-$ linked sugars in this location (Mellis 1983). 


\subsection{Functional aspects of protein glycosylation}

\subsubsection{General principles}

There are several ways in which carbohydrate moieties can influence the physicochemical characteristics of a glycoprotein. Carbohydrate chains are often large and bulky in relation to the protein backbone; the $\mathrm{N}$-linked biantennary oligosaccharide of IgG is comparable in size to the protein domain to which it is attached. This physical size, and interactions between carbohydrate moieties and peptides, can dictate and stabilise the tertiary and quaternary structure of a glycoprotein (Wright 1993). The addition of $\mathrm{N}$-glycans to the nascent peptide chain in the endoplasmic reticulum influences the folding and conformation of the protein (Lis 1993). Olinked glycosylation typically occurs in repeating protein sequences, rich in serine, threonine and proline. These amino acids do not conform readily to helix formation, but tend to form an extended structure with many $\beta$ turns. Clusters of $O$-linked sugars attached to the repeating peptide sequence series confer rigidity, allowing the formation of very long mucin domains (Jentoft 1990, Hounsell 1993, Lis 1993). Since sugar moieties are located on the outside of the glycoprotein, and may envelope it completely, their chemical properties can strongly influence those of the whole molecule. Sialic acids are particularly potent in this respect because they are highly negatively charged, reactive and labile entities (Lis 1993). Proper glycosylation of a newly synthesised protein can be essential for assembly of its constituent subunits, and for subsequent processing, transporting and surface expression or secretion (Lis 1993).

Once secreted or expressed, the role of the carbohydrate components of glycoproteins are many and varied. Some general functions include protection from proteolysis, decreasing immunogenicity, increasing solubility, and prolonging half-life (Montreuil 1982, Lis 1993). Clearance of circulating proteins may also be mediated by their sugar moieties, due to binding by the asialoglycoprotein receptor (ASGPR) or mannose receptors (Lis 1993, Opdenakker 1993). 


\subsubsection{The roles of the carbohydrate components of $\mathrm{IgG}$ and $\mathrm{IgA}$}

$\operatorname{Ig} G$

The carbohydrate moieties of IgG have been the focus of much investigation, and their functional importance is well appreciated.

The biantennary N-linked glycans at Asn 297 in the CH2 domain of the $\gamma$ heavy chain have structural and functional roles. Each IgG molecule consists of two $\gamma$ chains. The sugar moieties have been shown by $\mathrm{X}$ ray crystallography to lie between the $\mathrm{CH} 2$ domains, with the terminal antennae in multiple contact with the exposed peptides of the $\gamma$ chains (Jefferis 1993). This imposes a single three dimensional structure upon the molecule (Hounsell 1993), which is necessary for various effector functions. These include $\mathrm{Fc}$ receptor and $\mathrm{C} 1 \mathrm{q}$ binding, $\mathrm{C} 1$ activation, monocyte/macrophage activation, triggering of antibody-dependent cell-mediated cytotoxicity, and clearance from the circulation (Nose 1983, Tao 1989, Walker 1989, Jefferis 1993, Lis 1993). The loss of these effector functions is likely to be due to a major conformational change in the $\mathrm{CH} 2$ domain, since the $\mathrm{Fc} \gamma \mathrm{R}$ and $\mathrm{C} 1 \mathrm{q}$ binding sites are located in different areas of the domain, yet are both affected by the lack of glycosylation.

$\operatorname{Ig} A$

Less is known about the role of $\operatorname{IgA}$ glycosylation, but being a more heavily glycosylated molecule than IgG, it seems likely that the carbohydrates are just as important. The marked glycosylation differences between the various forms of human $\operatorname{IgA}$, which have different biological functions, suggests that the carbohydrate components may have fundamental roles to play.

The ligand of the human FcaR expressed by neutrophils and monocytes lies within the $\mathrm{CH} 2$ domain, close to an N-linked glycosylation site at Asn 263, and to the O-glycosylated IgA1 hinge region (Mazengera 1990). Studies employing site-directed mutagenesis to eliminate the glycosylation sites of human IgA molecules (Burton 1992, Woof 1994), and inhibition experiments with various monosaccharides (Keidan 1995) have indicated that the sugars are involved in this interaction. Recently, a receptor expressed by human $\mathrm{T}$ cells has been described, which binds IgA1 and IgD but not IgA2, and recognises the O-linked sugars on the hinge regions 
of the two former isotypes (Rudd 1994). The significance of this receptor is as yet unknown, but it appears to be expressed by activated CD4 and CD8 T cells.

IgA does not have a C1q binding site, and therefore fails to fix complement by the classical pathway, but it now seems established that it can activate the alternative pathway in some circumstances (Kerr 1990, Bogers 1991, Valim 1991). N-glycosylation of IgA has been shown to be important in $\mathrm{C} 3$ binding and production of terminal complement components in a study employing IgA2 produced in the presence of tunicamycin, which blocks the Asu-glycosylation pathway (Zhang 1994). The authors used IgA2 for these investigations to avoid the confounding effects of O-linked carbohydrate, and the role of this in complement interactions remains unknown.

The major route of IgA clearance from the circulation is by the hepatic ASGPR (Moldoveanu 1990), which binds to desialylated terminal Gal and GalNAc on various proteins (Baenziger 1980, Ashwell 1982, Lee 1983, Lee 1984). This receptor has a higher affinity for IgA1 than IgA2, and the O-linked sugars of the hinge region appear to be the most important ligand for the interaction (Stockert 1982).

IgA1 is susceptible to degradation by bacterial and other proteases which attack the hinge region, absent in IgA2 (Kerr 1990). The heavier hinge region glycosylation of SIgA1 than serum IgA1 (Pierce-Cretel 1981) may help to protect this vuluerable region from proteolysis. One reason for the heavier and qualitatively different glycosylation profile of $\operatorname{SIgA}$ than serum $\operatorname{IgA}$ is probably to protect its conformation and activity in the hostile environment of external secretions (Tomana 1972, Taylor 1988, Wold 1994). In addition, the extra glycosylation of SIgA over serum IgA has been shown be essential for inhibition of the adherence of pathogens such as Helicobacter pylori to the gastric mucosal surface (Borén 1993). 


\subsection{Glycosyltransferases}

Biosynthesis of the carbohydrate components of glycoproteins is carried out by a group of specific enzymes, the glycosyltransferases. As yet, few of these enzymes have been well characterised, but it is apparent that they are numerous and diverse (Roth 1985, Kleene 1993, Narimatsu 1994). Glycosyltransferases have proved difficult to purify and characterise; they are present in very small quantities, are readily degraded, and are poorly antigenic due to a high degree of interspecies homology (Kleene 1993). Despite their phylogenetic sequence conservation, most of the different glycosyltransferases cloned so far have little homology. $\beta 1,4$ galactosyltransferase $(\beta 1,4 \mathrm{GT})$ and $\alpha 1,3$ galactosyltransferase $(\alpha 1,3 \mathrm{GT})$ both transfer the same donor substrate (galactose) to their respective acceptors, but they show no homology with one another. Rat and human $\alpha 2,6$ sialyltransferase genes are highly conserved in both the coding regions and the untranslated sequences, but are entirely different from any other known glycosyltransferase (Kleene 1993). However, glycosyltransferase proteins do tend to share a common architecture; they are monomeric transmembrane proteins with a tightly folded catalytic domain in the carboxyterminal, and are located within the Golgi membrane, where the majority of protein glycosylation occurs, though they are not necessarily restricted to this site. $\beta 1,4 \mathrm{GT}$ is found in a soluble form in serum, colostrum, milk and other body fluids (McGuire 1989, Tomana 1993b, Narimatsu 1994), and also as a cell-surface receptor (Tomana 1993a).

Glycosyltransferases are primarily named and classified according to their monosaccharide substrate. They catalyse the transfer of the monosaccharide $(X)$ from a nucleotide sugar donor XDP to a protein or oligosaccharide acceptor in a specific linkage configuration, in the general reaction :

$$
\text { XDP-Gly + HO-acceptor } \rightarrow \text { Gly-O-acceptor }+ \text { XDP } \quad \text { (Joziasse 1992) }
$$

The substrate specificity of glycosyltransferases appears to be absolute; none is able to transfer more than one type of sugar (Roth 1985, Narimatsu 1994). Assembly of carbohydrate chains occurs sequentially, with the product of one transferase becoming the acceptor for the next. In addition to monosaccharide substrate specificity, the activity of glycosyltransferases is restricted 
in respect to the acceptor molecule. For example, two different $\alpha 2,3$ sialyltransferases are known; one linking NeuNAc in the $\alpha 2,3$ position to O-linked Gal $\beta 1,3 \mathrm{GalNAc}$, and the other to N-linked glycans (Kleene 1993). Both the protein being glycosylated, and the oligosaccharide core onto which the monosaccharide is added can influence the ability of a glycosyltransferase to transfer its sugar. This is illustrated by the alternative distal sugar chains built onto common core structures when they occur different proteins. The protein template dictates which glycosyltransferases can be used, and therefore which monosaccharides are added (Baenziger 1994). Specificity of the enzymes for the oligosaccharide acceptor ensures that the correct sequences are built up. In the biosynthesis of fetuin in calf liver, the initial addition of a first sialic acid unit to Gal $\beta 1,3$ GalNAc by an $\alpha 2,3$ sialyltransferase is a prerequisite for the subsequent addition of a second sialic acid unit by an $\alpha 2,6$ sialyltransferase. The latter enzyme will not sialylate GalNAc or Galß1,3GaINAc alone (Bergh 1983).

The factors regulating glycosyltransferase expression are not yet well understood. They are often highly cell and tissue specific, and occur at precise stages of development and differentiation. Protein levels usually correlate with mRNA expression, indicating that the control mechanisms work at the transcription rather than translation level (Kleene 1993). Mechanisms such as alternative splicing or usage of different promoters to produce isoenzymes with varying functions from the same gene are recognised. For example, the use of different start sites for transcription of murine $\beta 1,4 \mathrm{GT}$ results in alternative isoforms, one of which is ubiquitous and galactosylates many N-linked glycans, while another is involved in lactose synthesis and is only expressed in the lactating mammary gland (Shaper 1994, Shur 1994).

\subsection{Glycosylatiom and disease}

\subsubsection{General considerations}

Protein glycosylation changes have been described in a wide variety of disease states, and more are being added to this list all the time. Some of these alterations are physiological, reflecting altered functional activity of the protein; for example, glycosylation changes in acute phase proteins in inflammatory conditions may be part of the normal reponse to infection (van Dijk 
1994). However, there are also diseases in which aberrant protein glycosylation is a characteristic marker, or is directly involved in pathogenesis. The roles of glycosylation abnormalities in some diseases particularly relevant to the studies described in this thesis are outlined below.

\subsubsection{Autoimmune rheumatoid disease}

The best known glycosylation abnormality of immunoglobulins is that of IgG in theumatoid arthritis (RA) and other rheumatoid diseases. The abnormality affects the biantennary N-linked moieties at Asn 297 of the $\gamma$ heavy chain, which have the capacity to carry one to three terminal galactose units per IgG molecule. The proportion of IgG molecules with the agalactosyl phenotype $\left(\mathrm{G}_{0}\right)$ is significantly higher in patients with RA and primary osteoarthritis than in agematched controls (Parekh 1985, Parekh 1988a, Parekh 1988b). Similar changes have been observed in some patients with other conditions such as SLE (especially with Sjögren's syndrome), Crohn's disease and mycobacterial infections (Axford 1991).

IgG agalactosylation in RA is due to reduced activity of $\beta 1,4$ galactosyltransferase $(\beta 1,4 \mathrm{GT})$ in lymphocytes (Axford 1992a, Wilson 1993). Both B and T cells are affected, and the enzyme activities of these cell types in individual RA patients is correlated, suggesting a common control mechanism (Axford 1992a). Monocyte $\beta 1,4$ GT activity is normal or raised in RA (Axford 1987, Axford 1992a). $\% \mathrm{G}_{0}$ of serum $\mathrm{IgG}$ was found to be inversely proportional to lymphocyte $\beta 1,4 G T$ activity in RA, while in controls the reverse was true; this suggests aberrant regulation of IgG glycosylation in RA (Axford 1992a). The mechanism underlying altered $\beta 1,4 \mathrm{GT}$ activity remains unclear; there is no apparent abnormality of the gene locus (Delves 1990, Axford 1994b), and the $B$ cells can be stimulated to increase their $\beta 1,4 \mathrm{GT}$ activity by Epstein Barr virus transformation (Wilson 1993). No inhibitor of $\beta 1,4 G T$ has been detected in rheumatoid sera (Axford 1994b). N-glycosylation of $\operatorname{IgA1}$ is unchanged in RA, demonstrating that the altered enzyme activity is restricted to $\gamma$-chain producing cells (Field 1994).

$\% \mathrm{G}_{0}$ correlates with disease activity in $\mathrm{RA}$, and high $\mathrm{G}_{0}$ levels can predict poor prognosis early in the course of the disease (Bodman 1994, Isenberg 1994, van Zeben 1994), while efficacious treatment with sulphasalazine can normalise both $G_{0}$ and $\beta 1,4 G T$ activity (Axford 1992a). IgG 
galactosylation decreases during pregnancy in both normal individuals and those with RA. A high proportion of RA patients remit during pregnancy and relapse soon afterwards, and $G_{0}$ levels and $\beta 1,4$ GT activity correlate with this phenomenon (Hay 1991, Alavi 1994, Bond 1994). Together, these observations suggest that IgG galactosylation may be involved in the pathogenesis of RA. A number of mechanisms have been put forward for this. Defectively galactosylated IgG molecules tend to self-aggregate due to terminal galactose units on Fab-linked sugars inserting into the vacant terminal galactose sites of the Fc-linked moieties, and leading to the formation of complement-fixing IgG-complexes (Roitt 1988, Roitt 1990). It has been shown that IgG theumatoid factors often utilise heavy chain variable region genes of the VH3 subgroup, which contain a glycosylation sequon, thus increasing the likelihood of self-association through sugar interactions (Hay 1991). In addition, the binding affinity of IgG and IgM rheumatoid factors is influenced by IgG galactosylation, which may further enhance the formation of immune complexes (Newkirk 1993, Soltys 1994). Agalactosyl IgG is a ligand for serum mannose-binding protein (MBP), which has affinity for multiple terminal GlcNAc units, but not for galactose. MBP has considerable homology with $\mathrm{Clq}$ and can activate the classical pathway of complement; it normally aggregates and opsonsises pathogens by binding their outer sugars. IgG-MBP association is another route by which complement activation may occur in the rheumatoid synovium (Ezekowitz 1995, Mallotra 1995). Another intriguing theory suggests that agalactosyl IgG does not ligate B cell Fc receptors efficiently, and would therefore interfere with normal feedback suppression of $B$ cell activity in the absence of $T$ cell help signals. This could lead to the expansion of autoreactive B cell clomes, and the development of autoimmune disease (Rademacher 1991).

\subsubsection{Tn polyagghutinability syndrome}

The Tn polyagglutinability syndrome (TnPS) is a rare haematalogical disorder, in which erythrocytes are agglutinated by normal, $\mathrm{ABO}$ compatible serum, presenting as haemolytic anaemia. This is due to a glycosylation defect of the major erythrocyte membrane proteins, glycophorins A and B (the MN blood group determinants), resulting in the expression of a neoantigen to which normal sera contain 'natural" autoantibodies. (Lee 1981, Blumenfeld 1992, Thurnher 1992). Glycophorins are heavily glycosylated, with a single $\mathrm{N}$-linked glycan, and about 
14 sialylated Ga1ß1,3GalNAc units O-linked to Ser and Thr, in close proximity to each other at the amino terminal of the extracellular domain. In this context, asialyl Ga1 $\beta 1,3 \mathrm{GalNAc}$ is known as the Thomsen-Freidenrich $(\mathrm{T})$ antigen, and the abnormal agalactosyl form, consisting of GalNAc alone, is termed the Tu antigen. It is this latter form which is expressed by red cells in TnPS. Incomplete biosynthesis of these O-linked sugar moieties leading to expression of the truncated Tn form by erytbrocytes in TnPS is known to be a stable, acquired defect of clonal origin, affecting a variable proportion of circulating red cells which can reach 90\% (Blumenfeld 1992). In some cases, platelet and leucocyte membrane proteins are also affected, resulting in thrombocytopenia and leucopenia (Cartron 1979, Thurnher 1992). In lymphocytes, the membrane protein affected is leukosialin (CD43), an important functional receptor which displays characteristic variations in $\mathrm{O}$-glycosylation according to cell type, stage of differentiation, and activation state (Carlsson 1986, Piller 1988). The failure to galactosylate O-linked GalNAc arises from loss of activity of the key enzyme $\beta 1,3$ galactosyltransferase $(\beta 1,3 \mathrm{GT})$ by the affected cells (Cartron 1978, Cartron 1979). The mechanism behind this is unknown, but is due to repression of gene expression rather than a mutation, since $\mathrm{Tn} \mathrm{T}$ cells produce normally glycosylated membrane proteins when cultured in the presence of agents which non-selectively induce gene expression (Thurnher 1993).

TnPS occasionally represents a pre-leukaemic condition, while abnormal synthesis of the O-linked sugars of the membrane protein leukosialin has been described in T lymphocytic leukaemia (Saitoh 1991). The human T leukaemia cell line Jurkat is known to express the Tn antigen (Piller 1990), as are colonic and other cancer cells (King 1994). However, in malignancy, the underlying abnormalities leading to Tn expression are not the same as in idiopathic TnPS. Unlike TnPS T cells, Jurkat cells do not express the normal $\mathrm{T}$ antigen when cultured with gene-inducing agents (Thurnher 1993). In colonic cancer cells, Tn expression results from lack of activity of a glycosyltransferase which normally adds GlcNAc to the O-linked GalNAc of membrane proteins in epithelial cells, a different enzyme in a different biosynthetic pathway to that affected in TnPS (King 1993). 


\subsubsection{IgA nephropathy}

During the 1980's and early 1990's much intensive research was carried out into IgAN, and among the observations emerging from this was some indirect evidence for glycosylation abnormalities of serum $\operatorname{IgA}$. Studies of $\operatorname{IgA}$ interactions with food antigens first noted that the carbohydrate component of IgA may be involved in the pathogenesis of the disease. Increased circulating complexes of IgA and gluten-derived lectins were detected in the serum of patients with IgAN (Coppo 1986a), leading to a theory that lectius in such complexes may form "bridges" between IgA and glomerular components and contribute to mesangial IgA deposition (Coppo 1988, Coppo 1992, Emancipator 1992). These authors tended to the opinion that increased mucosal permeability, and raised serum IgA levels or specific IgA antibody to food antigens were responsible for high complex concentrations, and the studies did not focus upon putative $\operatorname{Ig} \mathrm{A}$ glycosylation abnormalities. The first report specifically indicating altered IgA glycosylation in IgAN showed decreased binding of the lectin jacalin to serum IgA from 27 patients with $\operatorname{IgAN}$, compared to that from 43 controls (Audre 1990). Jacalin recognises the terminal galactose unit of the O-linked Galß1,3GaINAc moieties located in the IgA1 hinge region, and the authors of this paper suggested that low jacalin binding to $\operatorname{IgA}$ in $\operatorname{IgAN}$ may be due to altered hinge region sugars, either truncation, or elongation.

Two further studies subsequently confirmed the reduced jacalin binding of IgA1 in IgAN (Coppo 1993, Mestecky 1993), and the latter of these also demonstrated reduced total galactose content of the $\operatorname{IgA} 1$ molecule by gas-liquid chromatography in 3 patient samples, as compared to 9 controls. Though the technique used could not identify whether the low galactose content was due to N- or O-linked sugar abnormalities, the parallel low jacalin binding of the same samples led the authors to conclude that their results were due to reduced galactosylation of O-linked moieties in IgAN. However, yet another study found increased jacalin binding of IgA1 in 52 IgAN patients, compared to 45 controls (Hiki 1992). These authors also used HPLC to analyse the O-liwked sugars released from IgA by hydrazinolysis, and found those from IgAN to be different from controls, but could draw no more specific conclusions.

It is difficult to resolve the conflicting evidence regarding jacalin binding from these studies. The 
latter group involved Japanese patients, whereas the former three groups were European and North American, and different genetic profiles in these populations could conceivably be responsible. Alternatively, differences in methodology or in the jacalin preparations used may account for the findings. However, all the studies found the glycosylation of IgA1 in IgAN to be markedly different from control groups. Further investigations to more precisely elucidate the nature of the abnormality and its functional and pathogenic significance were clearly warranted at this stage.

\subsection{Lectins}

Lectius are proteins derived from plants and animals, which show strong and specific affinity for certain carbolydrate moieties. They are polyvalent, with multiple sugar binding sites, and their binding to glycoconjugates can be inhibited by the appropriate free oligosaccharide, or a low molecular weight compound carrying it. Virtually all living organisms produce proteins with lectin activity, and the structural features of lectins are diverse, but their specificity is believed to be restricted to carbohydrate moieties found in animal glycoconjugates. The functions of lectins within the organisms producing them is variable, but in general, they are involved in recognition and binding events (Sharon 1989). Lectins are widely used as tools to identify particular carbohydrate moieties, and the studies described in this thesis took advantage of the sugar specificities of a range of plant and animal lectins to detect glycosylation changes in serum proteins.

\subsubsection{Lectins with specificity for components of $\mathbb{N}$-linked glycans}

Lectin-binding assays have been used to detect glycosylation changes in IgG in rheumatoid disease, and show acceptable correlation with results obtained from structural analysis of released glycans (Sumar 1990). To measure the degree of agalactosylation of the N-linked moiety of the IgG heavy chain, the relative binding of lectins with specificity for the alternative terminal sugars, GlcNAc or Gal, are used. A variety of such lectins are commercially available, and the ones used in these experiments are shown in Table 2.1. The degree of agalactosylation of IgG samples can be calculated by expressing the results as a ratio of GlcNAc:Gal terminal sugars (Griffiths 1989, 
Sumar 1990). This method has been extensively evaluated, and has been shown to be a valid and convenient way of analysing the IgG N-glycosylation, especially when a series of $\mathrm{IgG}$ samples of known $\% \mathrm{G}_{0}$ are available to construct standard curves (Sumar 1990).

The N-linked glycan of the IgG heavy chain is buried within the folded protein, and protein denaturation is required to expose the terminal sugars for lectin binding (Sumar 1990). Terminal sialic acid could possibly interfere with lectin binding in this technique, though these are not heavily sialylated moieties (Parekh 1985), and since sialic acid is such a labile species, denaturation probably removes any that is present (Dennis 1994).

\subsubsection{Lectins with specificity for O-linked glycans}

The rarity of O-glycosylation in serum proteins has been exploited in techniques using the $\mathrm{O}$ glycam specific lectin jacalin as an agent to purify IgA1 and Clinh, and consequently, the binding characteristics of jacalin are well described. There are a variety of other lectins which bind components of mucin-type O-glycans such as those found in IgA1. Some have been mainly used for staining cell surface proteins in histochemical techniques, or for blood group typing, and unlike the assays for IgG N-linked glycans mentioned above, their use in serum glycoprotein analysis has not been fully elucidated. The published specificities of the lectins used in this study are summarised in Table 2.2.

\section{Jacalin}

The use of jacalin as a tool for the purification of $\operatorname{IgA1}$ from serum is well described (RoqueBarreira 1985, Kondoh 1986, Aucouturier 1989, Biewenga 1989, Haun 1989, Loomes 1991), and it is also known to bind Clinh (Hiemstra 1987, Pilatte 1989, Hortin 1990). Both these proteins contain series of O-linked sugars of the mucin-type, predominantly Gal $\beta 1,3 \mathrm{GalNAc}$, with varying degrees of sialic acid substitution, and it is this moiety, the $T$ antigen, for which jacalin shows high affinity. The affinity of the lectin for this $\mathrm{O}$-linked disaccharide is high, a single moiety being sufficient for binding, but $\mathrm{N}$-linked sugars are not recognised at all (Hortin 1990). Jacalin binding is inhibited by free D-galactose and GalNAc, showing that both components of the disaccharide are involved in the interaction with the lectin, but the complete moiety is the strongest ligand 
(Aucouturier 1989). Sialic acid substitution does not affect the binding (Hortin 1990). Therefore, jacaliu binds all the O-linked oligosaccharides of the IgA1 hinge region (Field 1989), including protein fragments carrying agalactosyl GaINAc, though these show lower affinity than the complete moiety (Biewenga 1989). However, steric hindrance and the physical structure of the protein probably render some of them inaccessible. Some studies have found that IgA2 also bound to jacalin to some extent (Aucouturier 1989, Andre 1990), but this is not a consistent observation (Kondoh 1986, Haun 1989) and is likely to be due to impurity of the jacalin preparations.

\section{Other Galß1,3GalNAc-binding lectins}

Two other lectins which bind the $\mathrm{T}$ antigen were used in this study; the peanut agglutimin (PNA) and Amaranthus caudatus (AC). PNA requires the asialyl form of the disaccharide ligand for binding, and does not recognise ungalactosylated GalNAc (Osawa 1987); free Gal will inhibit binding, but the disaccharide is much more effective (Rinderle 1989). AC tolerates substitution of the terminal galactose with a variety of groups, including sialic acid; it appears able to bind the $T$ antigen even when it is present as an internal part of a core sugar (Rinderle 1989). AC binding is inhibited by GalNAc and not Gal, but the full disaccharide is several hundred times more potent as an inhibitor, demonstrating that though GalNAc is the primcipally recognised component, AC can be considered as a true T antigen specific lectin (Rinderle 1989, Boland 1991).

\section{Lectins which recognise terminal O-linked GalNAc}

The best described lectin to the Tn antigen, GalNAc $\alpha 1,3 \mathrm{Ser} / \mathrm{Thr}$, is that from Vicia villosa (VV), which is highly specific for this moiety (Tollefsen 1983, Osawa 1987). This lectin has often been used as a cell surface marker for "contrasuppressor" $T$ cells and in various cancers (Nishiyama 1987, Itzkowitz 1989). VV lectin requires GalNAc to be linked to peptide for optimum recognition; it is not well inhibited by free GalNAc alone (Sharon 1989).

Lectins from the suails Helix aspersa (HA) and Helix pomatia (HP) were also used in these studies. These are less well characterised than VV; both are reported to have maximum affinity for O-linked GaINAc, but also to show some binding to GlcNAc (Uhlenbruck 1966, Prokop 1968, Hammarstrom 1969, Pemberton 1969, Hammarstrom 1972, Baker 1983, Sharon 1989). 


\subsubsection{Drawbacks of using lectins to amalyse glycoproteins}

Though lectins can be very useful tools to detect certain carbohydrate moieties within glycoproteins, there are some drawbacks to their use. It can be difficult to establish exactly what the lectin is binding to, since many of them have weak affinity for ligands other than their main reported specificities. In addition, substitution of oligosaccharides with sialic acid or other entities may alter the affinity of lectin binding, as can physical or electrical interference by surrounding peptides or carbohydrates. Many lectins show somewhat different binding to free mono- or oligosaccharides than to the same sugars attached to protein. The biochemical environment must also be considered, since lectins often have $\mathrm{pH}$ or metal ion requirements for optimum binding. The degree of lectin binding to a protein is probably not directly proportional to the number of oligosaccaride ligands present; there must be a maximum number of lectin molecules that can physically bind to a closely adjacent series of sugars such as those in the $\operatorname{IgA} 1$ hinge region. In addition, the polyvalent nature of lectins means that each molecule may be binding one or more sugar ligand. Differences in the purity and affinity of lectins from various sources have been a problem in the comparison of data from different groups, particularly when "home-made" preparations were used (Sharon 1989, Turner 1992, Axford 1994a). On the other hand, lectins are inexpensive, and many are now commercially available in a purified form, ready conjugated to detection agents such as biotin. Provided these limitations are appreciated, well designed and carefully evaluated lectin binding assays can rapidly and conveniently provide useful information about protein glycosylation. 


\begin{tabular}{|c|c|c|c|}
\hline $\begin{array}{l}\text { Lecti } \\
\text { linked }\end{array}$ & $\begin{array}{l}\text { h specificity f } \\
\text { ms }\end{array}$ & r the terminal & components of $\mathrm{N}$ - \\
\hline $\begin{array}{l}\text { Lectin source } \\
\text { (common name) }\end{array}$ & Abbreviation & $\begin{array}{l}\text { Sugar } \\
\text { specificty }\end{array}$ & Reference \\
\hline $\begin{array}{l}\text { Erythrina cristagalli } \\
\text { (Andean coral tree) }\end{array}$ & EC & $\begin{array}{l}\text { D-Gal } \\
\text { (as Gal } \beta 1,4 \mathrm{GlcNAc})\end{array}$ & $\begin{array}{l}\text { Griffiths 1989; } \\
\text { Sharon } 1989\end{array}$ \\
\hline $\begin{array}{l}\text { Triticum vulgaris } \\
\text { (Wheatgerm) }\end{array}$ & TV & $\begin{array}{l}\text { GlcNAc } \\
\text { (in } \beta 1,4 \text { linkage) }\end{array}$ & $\begin{array}{l}\text { Osawa 1987; } \\
\text { Griffiths 1989; } \\
\text { Sharon } 1989\end{array}$ \\
\hline
\end{tabular}

\begin{tabular}{|c|c|c|c|}
\hline \multicolumn{4}{|c|}{$\begin{array}{l}\text { Table } 2.2 \text { Lectins with specificity for the terminal components of } \\
\text { O-linked glycans }\end{array}$} \\
\hline $\begin{array}{l}\text { Lectin source } \\
\text { (common name) }\end{array}$ & Abbreviation & Sugar specificity & Reference \\
\hline $\begin{array}{l}\text { Artocarpus integrifolia } \\
\text { (Jackfruit) }\end{array}$ & Jacalin & $\begin{array}{l}\text { D-Gal } \\
\text { (as Gal } \beta 1,3 \mathrm{GalNAc} \text {; } \\
\mathrm{T} \text { antigen; sialic acid } \\
\text { tolerated) }\end{array}$ & $\begin{array}{l}\text { Roque-Barreira 1985; } \\
\text { Aucouturier } 1989 \text {; } \\
\text { Hortin } 1990\end{array}$ \\
\hline $\begin{array}{l}\text { Arachis hypogaea } \\
\text { (Peanut agglutinin) }\end{array}$ & PNA & $\begin{array}{l}\text { D-Gal } \\
\text { (as asialyl } \\
\text { Gal } \beta 1,3 \text { GalNAc; } T \\
\text { antigen) }\end{array}$ & $\begin{array}{l}\text { Osawa 1987; } \\
\text { Sharon 1989; } \\
\text { Rinderle 1989; } \\
\text { Boland 1991; } \\
\text { Kottgen } 1992\end{array}$ \\
\hline $\begin{array}{l}\text { Amaranthus caudatus } \\
\text { (Love-lies-bleeding) }\end{array}$ & AC & $\begin{array}{l}\text { Galß1,3GalNAc } \\
\text { (T antigen; sialic acid } \\
\text { tolerated) }\end{array}$ & $\begin{array}{l}\text { Rinderle 1989; } \\
\text { Boland } 1991\end{array}$ \\
\hline $\begin{array}{l}\text { Vicia villosa } \\
\text { (Hairy vetch) }\end{array}$ & $\mathbf{V V}$ & $\begin{array}{l}\text { GalNAc } \\
\text { (as GalNAc } 1,3 \mathrm{Ser} \text {; } \\
\text { Tn antigen) }\end{array}$ & $\begin{array}{l}\text { Tollefsen 1983; } \\
\text { Nishiyama 1987; } \\
\text { Osawa 1987; } \\
\text { Itzkowitz 1989; } \\
\text { Sharon } 1989 \\
\end{array}$ \\
\hline $\begin{array}{l}\text { Helix aspersa } \\
\text { (Garden snail) }\end{array}$ & $\mathbf{H A}$ & GalNAc & Pemberton 1969 \\
\hline $\begin{array}{l}\text { Helix pomatia } \\
\text { (Roman or edible snail) }\end{array}$ & $\mathbf{H P}$ & GalNAc & $\begin{array}{l}\text { Uhlenbruck 1966; } \\
\text { Prokop 1968; } \\
\text { Hammarstrom 1969; } \\
\text { Hammarstrom 1972; } \\
\text { Baker 1983 }\end{array}$ \\
\hline
\end{tabular}




\section{Figure 2.1}

\section{$\alpha 1,6$ arm}

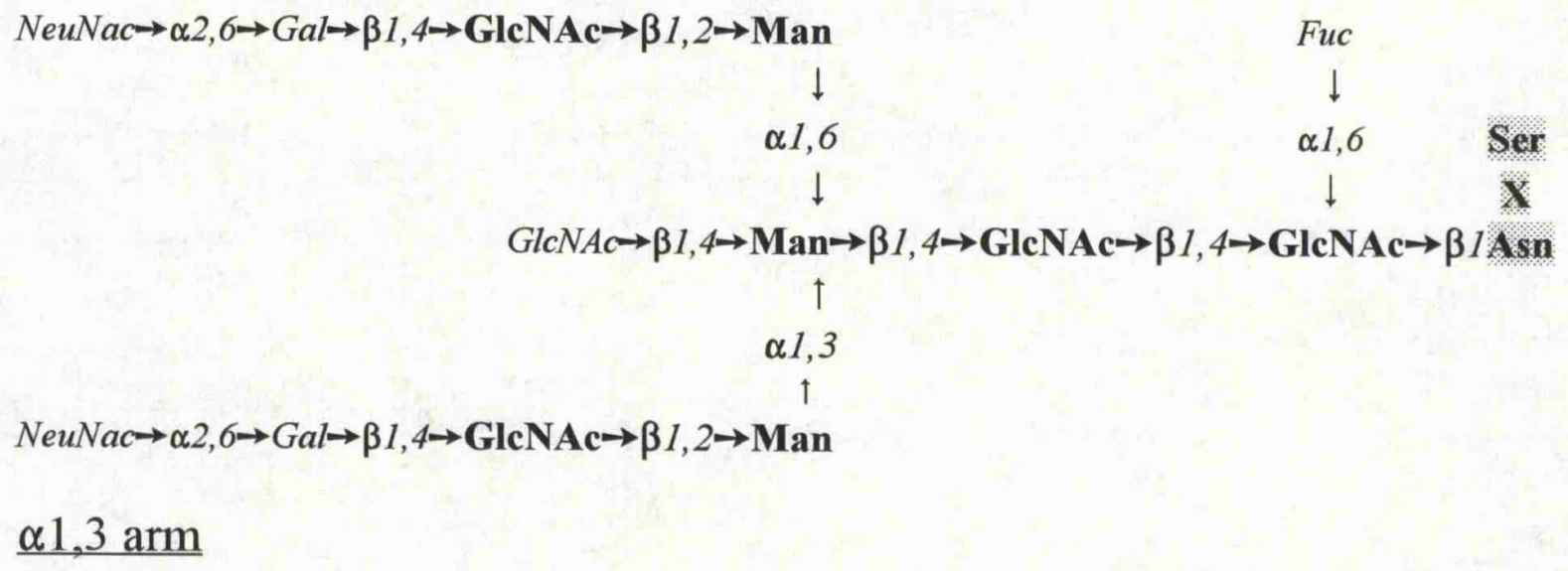

Invariable core oligosaccharide units are shown in bold

Oligosaccharide units of variable occurrence are shown in italics

Amino acid residues are shown in shaded print

(from Parekh 1985)

Figure 2.1 Complex-type N-linked carbohydrate moiety of IgG 
Figure 2.2

$\lg A 1$

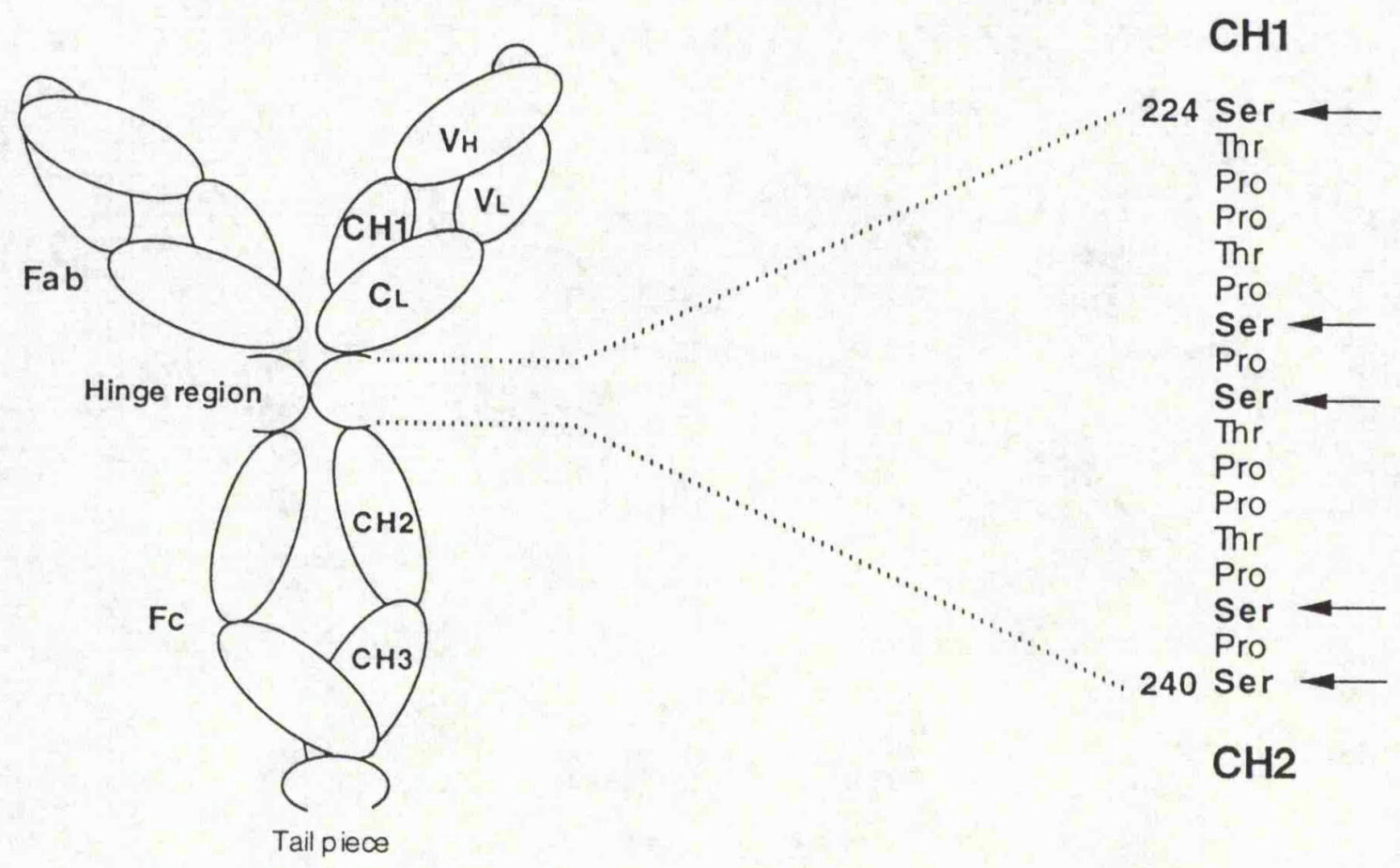

(from Kerr 1990)

Figure 2.2 IgA1 hinge region O-glycosylation sites. On the left is the $\operatorname{IgA1}$ molecule, showing the position of the hinge region between the $\mathrm{CH} 1$ and $\mathrm{CH} 2$ domains. The amino acid sequence of the hinge region is shown on the right; the positions of the five serine-linked O-glycosylation sites are marked with arrows. 
Figure 2.3

\title{
GalNAc $\rightarrow \alpha 1,3 \rightarrow$ Ser/ Th: \\ (Tn antigen)
}

\section{Gal $\rightarrow \beta 1,3 \rightarrow$ GalNAc $\rightarrow \alpha 1,3 \rightarrow$ Ser Thr}

(T antigen)

\section{NeuNAc $\rightarrow \alpha 2,3 \rightarrow$ Gal $\rightarrow \beta 1,3 \rightarrow$ GalNAc $\rightarrow \alpha 1,3 \rightarrow$ Ser $/ \mathrm{Th}$.}

\author{
NeuNAc \\ $\downarrow$ \\ $\alpha 2,6$ \\ $\downarrow$ \\ NeuNAc $\rightarrow \alpha 2,3 \rightarrow$ Gal $\rightarrow \beta 1,3 \rightarrow$ GalNAc $\rightarrow \alpha 1,3 \rightarrow$ ser $/$ Th
}

Amino acid residues are shown in shaded print

(From Field 1989)

Figure 2.3 O-linked glycans of the IgA1 hinge region 


\begin{abstract}
AIMS OF THE STUDY
The studies constituting this thesis were designed to address the following questions :

- Can an abnormality of IgA glycosylation in IgAN be confirmed and further characterised by the use of a range of lectins with various binding specificities? A range of lectins with specificities for the various sugars terminating the core $\mathrm{N}$ - and $\mathrm{O}$ linked carbohydrate moieties of $\operatorname{IgA1}$ were employed in novel assays developed for the study of this glycoprotein. These assays were used to investigate the lectin binding of IgAl samples from patients with IgAN and control subjects. The lectin binding characteristics of IgG and $\mathrm{C} 1$ inhibitor from the same subjects were also analysed to establish whether the abnormality is restricted to IgAl or shared by other serum glycoproteins with similar carbohydrate types.
\end{abstract}

- What is the biochemical basis of altered IgA1 O-glycosylation in IgAN?

A novel assay system for the quantitation of IgA1-O-galactosylating enzyme activity in cell lysates was developed and evaluated. This assay was then used to measure the activity of $\beta 1,3 G T$ in peripheral blood $B$ cells, T cells, and monocytes, and the enzyme activity was related to the lectin binding profile of serum IgAlfrom the same subjects. 


\section{CHAPTER THREE}

\section{General Materiatls and Methods}




\subsubsection{Patients}

The studies described in this thesis focussed upon patients with primary IgA nephropathy. All the patients recruited were under the care of Professor John Walls and Drs John Feehally, Kevin Harris and Graham Warwick in the Department of Nephrology, Leicester General Hospital, Leicester, UK. Ethical approval for the studies undertaken was given by the Ethical Committee of Leicestershire Health Authority (Appendix I).

A total of 36 patients with IgA nephropathy were used in these studies. IgAN was diagnosed by immunostaining of a renal biopsy specimen, and no patient had evidence of other systemic disease such as gastrointestinal or liver disease, or systemic lupus erythaematosus. Particular care was taken to exclude patients with a clinical history suggesting that their original disease may have been HSP. All patients had normal renal function, and none had macroscopic haematuria at the time of study. As is usual for patients with IgAN, the majority had microscopic haematuria by dipstick urinalysis, and some also had proteinuria, though none were nephrotic. No patient was taking immunosuppressive drugs, though several were on anti-hypertensive therapy. Details of the IgAN subjects used for each experiment are summarised in the relevant chapter.

\subsubsection{Controls}

Appropriate age and sex matched controls were selected for the patients studied in each investigation described in this study. Controls were recruited from hospital staff volunteers; all were healthy, with no known renal or systemic disease.

\subsection{Consumables}

Unless otherwise stated, all hardware consumables were purchased from Appleton Woods Ltd, and all chemicals from Sigma Chemical Company. 


\subsection{Serum samples}

The majority of the analyses described in this thesis were performed on proteins purified from serum samples.

When serum only was required from a subject, venous blood was taken into plain plastic tubes without anticoagulant, allowed to clot for 2-4 hours, centrifuged at $1000 \mathrm{~g}$ for 10 minutes, and the serum removed and stored in aliquots at $-20^{\circ} \mathrm{C}$ until required.

When peripheral blood cells were also required, venous blood was taken into preservative free heparin at $10 \mathrm{U} / \mathrm{ml}$ blood, and centrifuged at $500 \mathrm{~g}$ for 15 minutes. The plasma was aspirated in to $25 \mathrm{ml}$ plastic tubes, mixed with $250 \mu$ l of a solution of $50 \mu \mathrm{g} / \mathrm{ml}$ protamine sulphate and $50 \mathrm{U} / \mathrm{ml}$ bovine thrombin in phosphate buffered saline (PBS; Appendix II), and allowed to stand at room temperature for 2-4 hours to clot. It was then centrifuged at $1000 \mathrm{~g}$ for 15 minutes, and the serum removed and frozen as above.

\subsection{Ammonium sulpliate and polyethylene glycol precipitation of serum}

As a preliminary step in the purification of proteins from serum samples, a precipitation stage was carried out to separate serum proteins into fractions with different solubilities, which, in effect, approximates to higher and lower molecular weights. For the majority of the experiments, the proteins to be purified were all in the least soluble fraction, and ammonium sulphate was used for precipitation. Where the more soluble protein $\mathrm{C} 1$ inhibitor (C1inh) was also required, a two stage precipitation technique was employed, using polyethylene glycol (PEG) 6000 .

\subsubsection{Ammonium sulphate precipitation}

$5 \mathrm{ml}$ serum samples were diluted with an equal concentration of PBS, and $2.8 \mathrm{~g}$ ammonium sulphate added slowly, with constant stitring. When the ammonium sulphate had completely dissolved, the samples were rotated at room temperature for $1 \mathrm{~h}$ to equilibrate, and centrifuged at $5000 \mathrm{~g}$ for $15 \mathrm{~min}$. The supernatants were aspirated and discarded, and the precipitates 
redissolved in $5 \mathrm{ml}$ of a buffer appropriate to the intended next stage of protein purification.

\subsubsection{Polyethylene glycol precipitation}

Polyethylene glycol 6000 (PEG) was used to prepare from serum two crude fractions, one containing IgA and the other Clinh. Serum was first precipitated with $15 \%$ PEG, and the supernatant from this further precipitated with $40 \%$ PEG.

$5 \mathrm{ml}$ serum samples were added to $25 \mathrm{ml}$ plastic tubes containing $600 \mu 10.1 \mathrm{M}$ EDTA pH 7.6, $1 \mathrm{ml}$ Tris buffered saline (TBS; Appendix II) and 1g PEG (15\%). The tubes were rotated at room temperature for 1 h to equilibrate, and centrifuged at $5000 \mathrm{~g}$ for $15 \mathrm{~min}$. The supernatant was aspirated and added to another tube containing $600 \mu \mathrm{lEDTA}, 1 \mathrm{ml}$ TBS and $1.65 \mathrm{~g}$ PEG ( $40 \%$ final concentration), rotated and centrifuged as before, and the supernatants discarded. Both precipitates were redissolved in $5 \mathrm{ml}$ of an appropriate buffer for the next stage of purification.

\subsection{Enzyme linked immumosorbent assay (CLISA)}

Sandwich ELISAs were used to measure IgA, IgG, IgG subclasses IgG1-4, and C1inh. These ELISA systems were developed, evaluated and routinely used in the department.

\subsubsection{Primary antibodies}

Primary antibody to the required human protein was diluted to $10 \mu \mathrm{g} / \mathrm{ml}$ in coating buffer $(0.05 \mathrm{M}$ carbonate/bicarbonate buffer pH9.6; Appendix II), and 100 $\mu 1 /$ well applied to 96 well plates (Nunc Immunoplate, Life Technologies). The plates were sealed at incubated at $4^{\circ} \mathrm{C}$ for at least $24 \mathrm{~h}$ prior to use. The following primary antibodies were used :

- Rabbit anti-human IgA and IgG (A0262, A0423, Dako)

- Monoclonal anti-human IgG1-4 subclasses (clones HP-6012, HP-014, HP-6050, HP6025, Sigma)

- Sheep anti-human Clinh (PE019, The Binding Site) 


\subsubsection{Washing}

Between each stage of the assays, the ELISA plates were washed 4 times using an automated plate washer (Wellwash 4; Denley) with washing buffer (PBS/0.3M NaCl /0.1\% Tween 20; Appendix II).

\subsubsection{IBlocking}

Excess protein binding sites were blocked with $100 \mu \mathrm{l} /$ well $2 \%$ bovine serum albumin (BSA) in PBS for 1 h at RT.

\subsubsection{Standards and samples}

Standard curves were set up on each plate, using commercial immunoglobulin and complement component reference preparations (BP062, BP164, The Binding Site). Samples were used at preoptimised dilutions for each assay. All the standards and samples were diluted in PBS and $50 \mu \mathrm{l}$ aliquots applied to the plates in duplicate wells. The plates were sealed and incubated at $4{ }^{\circ} \mathrm{C}$ overnight.

\subsubsection{Secondary antibodies}

Horseradish peroxidase (HRP) conjugated second antibodies were diluted in PBS:

- Rabbit auti-human IgA-HRP (P0216, Dako) at 1:2000

- Rabbit anti-human IgG-HRP (P0214, Dako) at 1:3000

- Sheep anti-human Clinh-HRP (PP019, The Binding Site) at 1:200

All secondary antibodies were applied to the plates at $50 \mu \mathrm{l} /$ well and incubated at RT for 2 hours. 


\subsubsection{Development}

The assays were developed with 1,2-phenylenediamine dihydrochloride (OPD) substrate (Appendix II), at $50 \mu \mathrm{l} /$ well. The plates were protected from light while the colour was developing, and the reaction stopped when the colour reached an appropriate intensity with $75 \mu \mathrm{l} /$ well $1 \mathrm{M} \mathrm{H}_{2} \mathrm{SO}_{4}$.

\subsubsection{Results}

The results were read using an automated plate reader with a $492 \mathrm{~nm}$ filter (Titertek Multiscan, ICN Flow). Means of duplicate wells were calculated, and a standard curve constructed for each plate. Sample values were read from the standard curves, excluding samples which did not fall on the linear part of the curves; these were repeated at a more suitable dilution. Once the assays had been optimised with manual calculations, the results were obtained using a data analysis software package (Titersoft, ICN Flow), programmed to exclude samples where the duplicates differed by more than $5 \%$. Results were expressed in $\mathrm{mg} / \mathrm{ml}$ or $\mu \mathrm{g} / \mathrm{ml}$, as appropriate.

These assays were sensitive and reproducible, measuring their respective analytes in the following ranges:

$\begin{array}{lllrc}\circ & \text { IgA } & 10-1000 \mathrm{ng} / \mathrm{ml} & \text { IgG1 } & 5-500 \mu \mathrm{g} / \mathrm{ml} \\ \circ & \text { IgG } & 10-500 \mathrm{ng} / \mathrm{ml} & \text { IgG2 } & 20-500 \mathrm{ng} / \mathrm{ml} \\ . \quad \text { Clinh } & 10-1000 \mathrm{ng} / \mathrm{ml} & \text { IgG3 } & 1-100 \mu \mathrm{g} / \mathrm{ml} \\ & & \text { IgG4 } & 10-100 \mathrm{ng} / \mathrm{ml}\end{array}$

Intra-assay coeffiecients of variation were calculated for the ELISAs, and ranged between 1.9 and 3.8. In the majority of cases, samples to be compared to one another were run together in the same assay at the same time; inter-assay coefficients of variation were between 4.0 and 7.1. 


\subsection{Protein assay}

Total protein concentrations of protein samples and detergent-solubilised cell lysates were measured using a commercial kit (DC Protein Assay, Bio-Rad) based on the Lowry method (Lowry 1951). The assay was carried out in microtitre plates according to the manufacturer's instructions, using a series of dilutions of a standard ( $2 \mathrm{mg} / \mathrm{ml} \mathrm{BSA}$ in PBS) to construct standard curves.

Briefly, duplicate $5 \mu 1$ aliquots of the standards and samples were pipetted into the wells of a 96 well plate, followed by first $25 \mu \mathrm{l} /$ well of Reagent A (alkaline copper tartrate solution) and then $200 \mu 1 /$ well Reagent B (Folin reagent). When samples contained detergent, the standards were prepared in the same buffer, with detergent, and $20 \mu 1 / \mathrm{ml}$ Reagent S (5-10\% SDS) added to Reagent $A$ before use. The plates were tapped gently to mix, and allowed to stand at RT for 1545 minutes for the colour to develop. The ODs at $710 \mathrm{~nm}$ or $750 \mathrm{~nm}$ were then read using the automated plate reader. The Titersoft data analysis package was used to construct the standard curve and read the sample results from it. Samples with duplicates differing by more than $5 \%$ were rejected, as were those giving OD above or below the linear part of the standard curve; these were repeated at a more suitable dilution.

The assay gave linear results over protein range of approximately $0.1-1.8 \mathrm{mg} / \mathrm{ml}$. In some cases accurate protein concentrations were not required, and the assay was used to give a simple indication of relative protein concentrations in a series of samples. No standard curves were used for these and the results were expressed as OD alone.

\subsection{Sephadex columms}

Gel filtration on Sephadex columns was used for buffer exchange and removal of small molecules such as free galactose from protein preparations. Columns of various sizes were packed in syringe barrels with central hubs, using Sephadex beads with retention capacity selected to suit the application. 
Syringe barrels were plugged with filter paper. Sephadex was swollen in excess elution buffer, carefully poured into the syringe barrel, and the buffer allowed to run out to pack the colwumn. The column was washed through with at least 5 bed volumes of elution buffer. Buffer was gently drawn through the columu into another graduated syringe by means of a short length of flexible plastic tubing.

The columns were calibrated using $1 \%$ blue dextran in elution buffer. Buffer was drawn into the column until the meniscus was level with the top of the Sephadex bed. A measured volume of blue dextran equivalent to the sample volume to be exchanged was applied to the top of the column, drawn into the Sephadex until the meniscus was again level with the top of the bed, and flushed through with elution buffer. The volume of eluate collected between application of the blue dextran to the column and its first appearance in the collection syringe was noted (void volume), and discarded. The volume required for all the blue dextran to come through the column was also noted; this is the volume in which molecules too large to be retained by the Sephadex pores (ie the proteins applied) were recovered. The column was then washed through with 4 bed volumes of buffer, and the next sample applied. Once calibrated, the column characteristics were extremely reproducible, and each column was stored at $4^{\circ} \mathrm{C}$ and reused for up to a week before discarding.

\subsection{Sodium dodecyl sulphate polyacrylamide gel electrophoresis (SHD-PAGL)}

SDS-PAGE was used to evaluate the purity of the protein fractions prepared in these investigations. A Biorad Mini-Protean II vertical slab system was used, which gave satisfactory resolution of proteins between approximately $20-200 \mathrm{kD}$ molecular weight.

Discontinuous $0.75 \mathrm{~mm}$-thick polyacrylamide gels were used, the samples being loaded into wells in a $4 \%$ stacking gel to concentrate the proteins before they entered a $12-20 \%$ separating gel below. The samples were denatured with 2-mercaptoethanol (2-ME) before loading on to the gel to improve resolution, and stained with Coomassie blue after ruming, to visualise the bands. 


\subsubsection{Gel preparation}

Acrylamide and N'N'-bis-methylene-acrylamide were purchased in a pre-weighed 37.5:1 mixture (Bio-Rad), and dissolved in water to obtain a $30 \%$ solution. The gel monomers were prepared in appropriate Tris HCl buffers (stacking gel 0.125M, pH6.8; separating gel 0.375M, pH8.8, both with $0.1 \%$ SDS; Appendix $\amalg$ ). The glass plate sandwiches were assembled and gels cast according to the manufacturers' instructions, adding $0.05 \%$ ammonium persulphate and $0.05 \%$ TEMED to the monomer solution immediately before casting to initiate polymerisation.

\subsubsection{Sample preparation}

The samples were diluted to approximately $100 \mu \mathrm{g} / \mathrm{ml}$ in sample buffer (62.5mM Tris HCl pH 6.8/10\% glycero $1 / 2 \%$ SDS/0.02\% bromophenol blue, 5\% 2-ME; Appendix II), and boiled for 5 minutes in a water bath. A broad range molecular weight marker (Bio-Rad 161-0317) consisting of a mixture of proteins ranging from $6.5-200 \mathrm{kD}$ was also run on each gel. This was diluted 1:20 in sample buffer and treated the same as the samples.

\subsubsection{Electrophoresis}

The gels were removed from the casting stand, and placed in the electrophoresis tank. The inner and outer chambers were filled with running buffer (25mM Tris $/ 192 \mathrm{mM}$ glycine/0.5\% SDS, pH8.3; Appendix II), and $30 \mu \mathrm{l}$ of sample loaded per well. The gels were run at $200 \mathrm{~V}$ for approximately $30-45 \mathrm{~min}$, until the leading band stained with bromophenol blue reached the bottom of the gel.

\subsubsection{Gel staining}

The gels were stained in Coomassie blue (Appendix II) for 1-2 hours, and then destained in $40 \%$ methanol/10\% acetic acid for 24 hours with gentle mixing, changing the destain solution several times. When the backgrounds were clear, the gels were soaked in equilibration buffer $(40 \%$ methanol/10\% acetic acid/3\% glycerol) for 1 hour, and dried on a Bio-Rad Model 543 Gel Dryer. 
To confirm the identities of bands on PAGE gels, proteins were electrophoretically transferred to nitrocellulose membranes, and detected with antibodies, using a double staining method with HRP and alkaline phosphatase visualisation systems on the same membrane to distinguish different proteins. A Bio-Rad Mini Trans-Blot system was used for the transfers.

\subsubsection{Electrophoretic transfer}

After running an SDS-PAGE, the gel was soaked in electrophoretic transfer buffer (25mM Tris/192mIM glycine $/ 20 \%$ methanol; Appendix II) at $4^{\circ} \mathrm{C}$ for at least 1 hour. A $0.45 \mu \mathrm{m}$ nitrocellulose sheet, 2 pieces of thick filter paper, and 2 fibre pads per gel were cut to size, and also soaked in the transfer buffer at $4^{\circ} \mathrm{C}$. The gel was placed on top of a soaked $0.45 \mu \mathrm{m}$ nitrocellulose and placed in the gel cassette between filter paper and fibre pads. The cassette was then placed in the electrophoresis tank with the gel toward the cathode and the membrane toward the anode. The tank was filled with transfer buffer, and the system was run at $100 \mathrm{~V}, 150 \mathrm{~mA}$ for $1 \mathrm{~h}$, at $4^{\circ} \mathrm{C}$.

\subsubsection{Staining}

The nitrocellulose and gel were separated. The gel was stained with Coomassie blue as before, to check for untransferred proteins. The nitrocellulose was rinsed rapidly in PBS, and soaked in 2\% BSA in PBS for at least 1 hour to block excess protein binding sites. The membrane was then washed in three changes of washing buffer (Appendix II) and placed in a dish of HRP-conjugated antibody diluted in PBS for 2 hours. The following antibodies were used :

HRP-anti-IgG (Dako) at 1:2000, or

HRP-anti-Clinh (The Binding Site) at 1:500 
After a further three washes, the membrane was transferred to a dish of AP-conjugated anti-IgA

(Dako) at 1:1000 in PBS for 2 hours at RT, washed again, and the colours developed :

- $\quad \mathbb{A P}$ was developed first, with naphthol AS-MX phosphate/ Fast Red TR salt substrate (Appendix II). The membrane was immersed in the substrate for up to 20 minutes, until the bands had developed (red colour), then rapidly rinsed in washing buffer.

- $\quad H R \mathbb{R}$ was then developed with 3'3'-diaminobenzidine (DAB) (Sigma-Fast, Appendix II). The membrane was immersed in the solution for up to 2 min, until the bands had developed (brown colour).

The membrane was rinsed in water and air dried.

\subsection{Purification of $\operatorname{Ig} \mathbb{A}$}

The experiments described in this study required a practical method for the purification of IgA1 from a large series of serum samples, avoiding harsh treatments which may denature the protein or affect the carbohydrate profile. The best described method for this is affinity chromatography on jacalin-agarose (Roque-Barreira 1985, Biewenga 1989, Haun 1989). Purification of IgAl by virtue of its carbohydrate components is clearly not an ideal method for subsequent glycosylation studies, but was employed in these investigations for want of a satisfactory and practical alternative. The results clearly need to be interpreted with this technical limitation in mind.

Most studies describing the application of jacalin-agarose affinity chromatography to $\operatorname{IgAl}$ purification employed HPLC or FPLC systems. No such system was available at the time of this study. Instead, IgA1 was purified from ammonium sulphate or PEG precipitates of serum by immobilisation on jacalin-agarose in centrifuge tubes, followed by repeated washing to remove unbound protein before elution of the bound IgA1 with excess galactose. This rapid process allowed the satisfactory purification of IgA1 from a number of serum samples at the same time. 


\subsubsection{Affinity purification of IgA $\mathbb{1}$ on jacalin agarose}

Agarose-bound jacalin ( $4 \mathrm{mg}$ lectin/ml of gel) was purchased from Vector Laboratories. $12 \mathrm{ml}$ of jacalin-agarose was washed 3 times in 30ml 0.175M Tris HCl buffer, pH7.5 (Appendix II), in a $50 \mathrm{ml}$ centrifuge tube, each wash consisting of a $10 \mathrm{~min}$ rotation at $\mathrm{RT}$, followed by centrifugation at $5000 \mathrm{~g}$ for $15 \mathrm{~min}$, and aspiration of the supernatant buffer. $2 \mathrm{ml}$ agarose was then placed into each of $610 \mathrm{ml}$ polypropylene tubes, centrifuged, and all the supernatant discarded. $5 \mathrm{ml}$ ammonium sulphate precipitate in Tris $\mathrm{HCl}$ was applied to each tube, and the tubes were rotated at RT for 1 th to allow equilibration of IgA1- jacalin binding. The agarose was then washed three times as above, $5 \mathrm{ml}$ per tube $1 \mathrm{M}$ galactose in Tris HCl (Appendix II) applied, the tubes rotated for $1 \mathrm{~h}$ at RT, and centrifuged for $15 \mathrm{~min}$ at $5000 \mathrm{~g}$. The supernatants (galactoseeluates) from the tubes were aspirated and retained, while the jacalin agarose was washed three times in excess jacalin agarose storage buffer (Appendix II), and stored at $4{ }^{\circ} \mathrm{C}$ in this buffer.

The galactose eluates were passed through a Sepharose G25 gel filtration column to remove the free galactose and exchange the buffer to PBS. Each $5 \mathrm{ml}$ eluate was recovered from the G25 column in a final volume of $6-7 \mathrm{ml}$; these $\mathrm{IgA} 1$ samples were stored in $1 \mathrm{ml}$ aliquots at $-20^{\circ} \mathrm{C}$ until required.

\subsection{Sequential parification of $\operatorname{IgA} 1$ and $\mathbb{C l i n h}$ from serum}

The technique of $\operatorname{IgA} 1$ separation on jacalin-agarose described above was adapted to sequentially purify $\operatorname{IgA1}$ and Clinh from the same serum samples. Clinh is a smaller (104kD), more soluble protein than $\operatorname{IgA1}$, and is one of the very few other serum proteins carrying O-linked sugars which bind to jacalin (Bock 1986, Hiemstra 1987). Precipitation of serum with PEG 6000 was used to prepare two fractions, one rich in IgA1 and the other in C1inh, in an adaptation of the method of Pilatte (1989). A range of concentrations of PEG were used to precipitate less soluble proteins from serum, and the supernatant from these was further precipitated with $40 \%$ PEG. The IgA1 and $\mathrm{C}$ 1inh concentrations of the redissolved precipitates were measured, and 15\% PEG precipitation was found to give the cleanest separation of the two proteins. 
For IgA1 and Clinh purification, the $15 \%$ and $40 \%$ PEG precipitates from each serum were redissolved separately in Tris HCl buffer, applied to and eluted from jacalin-agarose, and the buffer exchanged to PBS on Sephadex G25 columns, as described above.

\subsection{Purification of $\mathrm{IgG}$}

IgG was purified from serum samples by a combination of gel filtration and ion exchange chromatography, performed consecutively on a single column (method adapted from Sumar 1990). This method has been shown to be more suitable for the preparation of IgG samples for glycosylation analysis than affinity chromatography on Protein G (Axford 1994a).

\subsubsection{Preparation of composite column}

$6 \mathrm{~g}$ DE52 ion exchanger (Whatman) and $5 \mathrm{~g}$ Sephadex $\mathrm{G} 25$ were each stirred in 50ml 0.2M phosphate buffer, pH7.2 (Appendix II), to swell them. A $60 \mathrm{ml}$ syringe barrel with centre outlet was plugged with No1 filter paper (Whatman) and the DE52 poured onto it. The buffer was allowed to run out of the column and the Sephadex was then layered on top. The composite column was washed through with $100 \mathrm{ml} 0.02 \mathrm{M}$ phosphate buffer/1M KCl, followed by $100 \mathrm{ml}$ 0.02M phosphate buffer (Appendix II).

\subsubsection{Evaluation of composite column}

Buffer was drawn through the column with another syringe, until the meniscus was level with the top of the Sephadex. $1 \mathrm{ml}$ ammonium sulphate precipitate in $0.02 \mathrm{M}$ phosphate buffer was applied to the column, drawn into the Sephadex, and then washed through with $37 \mathrm{ml} \mathrm{0.02M} \mathrm{phosphate}$ buffer. $20 \mathrm{ml} 0.02 \mathrm{M}$ phosphate buffer $/ 1 \mathrm{M} \mathrm{KCl}$ was then drawn through the column to dislodge the remaining bound proteins from the anion exchanger. 
Starting when the sample was applied to the column, the following fractions were collected :

\begin{tabular}{lll}
\multicolumn{3}{l}{ Iml sample applied } \\
- & Fraction A & $5 \mathrm{ml}$ \\
- & Fractions 1-12 & $12 \times 1 \mathrm{ml}$ \\
- & Fractions B-E & $4 \times 5 \mathrm{ml}$ \\
& $20 \mathrm{ml} 1 \mathrm{M} \mathrm{KCl}$ applied
\end{tabular}

- Fractions F-I $4 \times 5 \mathrm{ml}$

Total protein and IgG concentrations were measured in the fractions (Figures 3.1 and $\mathbf{b}$ ).

\subsubsection{IgG purification}

$1 \mathrm{ml}$ ammonium sulphate precipitate samples in 0.02M phosphate buffer were applied to the column, and washed through with the same buffer. The first $10 \mathrm{ml}$ eluate was discarded, and the second $10 \mathrm{ml}$ containing $\mathrm{IgG}$ was collected and stored in aliquots at $-20^{\circ} \mathrm{C}$. The column was washed with $30 \mathrm{ml} 0.02 \mathrm{M}$ phosphate buffer/1M KCl, followed by $60 \mathrm{ml} 0.02 \mathrm{M}$ phosphate buffer, and was then ready for the next sample.

\subsection{Purity of protein preparations}

The performance of the protein purification methods was assessed in the following ways :

- Yields were estimated from the mean levels of the proteins in their respective purified preparations, measured by ELISA (Table 3.1). Similar amounts of these proteins were obtained from control and patient sera.

- Contaminants: IgA1, IgG and Clinh levels in the preparations of each of these proteins were measured by ELISA (Table 3.2).

- Efficiency of elution of IgA1 from the jacalin agarose was estimated for five samples, by repeating the galactose elution step three times in succession, and measuring the concentration of IgA obtained in each sequential eluate by ELISA (Table 3.3). The 
majority of the IgA was eluted in the first eluate, with declining levels in the next two. Lectin binding of these eluates was also investigated (Chapter 4 , Section 4.2 .3 ) to ensure their glycosylation profiles did not differ.

- $\quad \lg G$ subclass levels in sera and correspouding IgG preparations were measured by ELISA, to demonstrate that the separation method did not alter the relative proportions obtained (Table 3.4).

- Purity was assessed by SDS-PAGE of the protein preparations on $12 \%$ separating gels, confirming the identity of the bands by Western blotting (Figure 3.2).

Despite these measures, the protein preparations were not completely pure, and the contributions of the contaminants to the lectin binding results obtained in the subsequent assays must be considered. IgA1 and $\mathrm{Clinh}$ are the only two proteins carrying $\mathrm{O}$-linked glycans present in appreciable concentrations in serum. Ensuring miminal contamination of each of these in the preparations of the other means that the majority of lectin binding to O-linked sugars can be attributed to the appropriate protein in assays of O-linked glycosylation. N-linked glycosylation is a much more common feature of serum proteins, and the assays of $\mathrm{N}$-glycans will be subject to more error introduced by the presence of contaminants. Western blotting for particularly likely candidates such as transferrin would help to indicate how much of the lectin binding to N-linked glycans is due to the presence of contaminants in the $\operatorname{IgA1}$ and $\operatorname{IgG}$ preparations.

\subsection{Preparation of detergent-solubilised cell lysates}

Intracellular enzyme activity was measured in lysates of peripheral blood monouuclear cells (PBMCs), and of populations of $\mathrm{T}$ and $\mathrm{B}$ cells and monocytes fractionated from PBMC preparations.

\subsubsection{Density gradient centrifugation of peripheral blood mononuclear cells}

PBMCs were prepared from whole blood by centrifugation on Ficoll 400, density 1.077 (Histopaque, Sigma). Venous blood was taken into preservative free heparin (10U/ml blood) and used within an hour. For whole PBMC preparations, $40 \mathrm{ml}$ of blood was obtained from each 
subject; for separated cell populations, $120 \mathrm{ml}$ was taken. The samples were centrifuged at $500 \mathrm{~g}$ for $15 \mathrm{~min}$, and the plasma aspirated and clotted with protamine sulphate and thrombin as described in Section $\mathbf{3 . 3}$.

The cells were gently resuspended to twice the original volume in Hank's balanced salt solution buffered with 10mM HEPES (HBSS/HEPES; Appendix II). $3 \mathrm{ml}$ aliquots of Histopaque were placed in 10ml centrifuge tubes, and $5 \mathrm{ml}$ cell suspension layered on to each. The tubes were centrifuged at $400 \mathrm{~g}$ for $30 \mathrm{~min}$ at room temperature, and the PBMC band carefully aspirated from between the Histopaque and HBSS layers. PBNICs from each subject were collected together in 25ml universal containers, and washed twice in HBSS/HEPES, centrifuging at $500 \mathrm{~g}$ for $10 \mathrm{~min}$. For whole PBMC preparations, the cells were lysed at this point. For fractionation into $\mathrm{T}$ and $\mathrm{B}$ cell and monocyte populations, the PBMCs were resuspended in 10ml HBSS/HEPES with 1\% fetal calf serum (HBSS/HEPES/FCS; Appendix II).

Typical yields of PBMCs prepared by this method were $1-3 \times 10^{6}$ cells $/ \mathrm{ml}$ blood (counted in a haemocytometer). Examination of haematoxylin-stained cytocentrifuge preparations of the PIMBCs showed that they consisted of $>90 \%$ lymphocytes and monocytes.

\subsubsection{Separation of cell populations with magnetic beads}

The PBMCs were separated into $\mathrm{T}$ and $\mathrm{B}$ cell and monocyte populations by positive selection on magnetic beads conjugated with the following specific monoclonal antibodies (M-450 Dynabeads, Dynal):

$\begin{array}{llll}\circ & \mathbb{T} \text { cells } & \text { Anti-CD2 } & \text { (Dynabead 111.01) } \\ \circ & \mathbb{B} \text { cells } & \text { Anti-CD19 } & \text { (Dynabead 111.03) } \\ \circ & \mathbb{M} \text { Monocytes } & \text { Anti-CD14 } & \text { (Dynabead 111.11) }\end{array}$

The three cell populations were separated sequentially from one cell suspension for each subject.

A measured volume of each Dynabead suspension (supplied at $4 \times 10^{8} / \mathrm{ml}$ ) was taken and washed 
three times in excess HBSS/HEPES/FCS, using a magnetic particle concentrator (Dynal MPC-6) to immobilise the beads against a test tube wall while the medium was changed. The beads were resuspended in a known volume.

Monocytes were selected by adding $25 \times 10^{6} \mathrm{CD} 14$ beads to $10 \mathrm{ml}$ PBMC suspension in HBSS/HEPES/FCS, and mixing gently at RT for lh on a Dynal Sample Mixer. The tubes were then placed in the concentrator for $5 \mathrm{~min}$ to immobilise the beads and cells bound to them, and the unbound cell suspension aspirated into another tube for $\mathrm{T}$ cell separation.

For $\mathrm{T}$ cell separation the above process was repeated with $10 \times 10^{6} \mathrm{CD} 2$ beads, transferring the unbound cells to a final tube for B cell separation with $40 \times 10^{6} \mathrm{CD} 19$ beads.

The separated cell/Dynabead preparations were washed twice in HBSS/HEPES (no FCS) with rapid centrifugation at $500 \mathrm{~g}$ to pellet the cells.

\subsubsection{Purity of separated cell populations}

The purity of the cell populations was assessed by a combination of immunohistochemistry and morphological examination. Antibodies to the pan-T cell marker CD3 and the MHC Class II antigen HLA-DR, expressed by $B$ cells and monocytes but not $T$ cells, were chosen to avoid using the same cell markers as the Dynabeads (CD2, CD14, CD19). The immunohistochemically stained cells were counterstained with haematoxylin to distinguish between B cells and monocytes.

Aliquots of the Dynabead-selected cells were incubated at $37^{\circ} \mathrm{C}$ overnight for some bead detachment to occur due to receptor recycling, and vortexed vigorously to detach the beads further. Cytospin preparations were made using a cytocentrifuge (Shandon Cytospin 2, Life Sciences Ltd), air dried, and fixed in acetone/methanol (Appendix II) for 90s. The slides were washed three times in TBS (Appendix II), and placed in a moist box. 50 $\mu$ l aliquots of mouse monoclonal antibodies to CD3 (clone UCHT1, Dako) and HLA-DR (clone DK22, Dako) at 1:50 in TBS were applied to duplicate slides, and incubated at RT for 2 hours. After further washing, 
alkaline phosphatase-conjugated anti-mouse immunoglobulin antibody (Dako D0314) at 1:20 in TBS was applied to the slides, incubated for a further 2 hours at RT, and washed again. The colour was developed with $50 \mu \mathrm{l} /$ slide of the naphthol AS-MX phosphate/Fast Red substrate (Appendix II), incubating the slides in the moist box for 20 min at RT, and then washing again. The cells were counterstained for $2 \mathrm{~min}$ in haematoxylin solution (Appendix II), and blued under running tap water. The slides were mounted in aqueous mounting medium (Gurr Aquamount, BDH Ltd), and examined by light microscopy using a 40x objective lens.

The percentage of positive (red-staining) cells on each slide were counted, and the percentage of monocytes and lymphocytes assessed by their distinct morphological appearance. From this, the percentages of $\mathrm{T}$ cells, $\mathrm{B}$ cells and monocytes in the cell preparations were estimated (Table 3.5, Figures 3.3, 3.4 and 3.5).

\subsubsection{Lysate preparation}

Cell lysates were prepared by detergent solubilisation, sonication, and freezing. All cell suspensions were washed in serum-free HBSS before lysis, so that all the protein content was derived from the cells.

PMBC or separated cell pellets were resuspended in $0.5-1 \mathrm{ml} 0.5 \%$ Nonidet P40 nonionic detergent in PBS, drawing vigorously in and out of a plastic Pasteur pipette, and left to stand for 15 minutes. The samples were then sonicated three times with an ultrasonic processor (Jencons Scientific Ltd), pelleting the insoluble material at $10000 \mathrm{~g}$ for $1 \mathrm{~min}$ in a microfuge between sonications, and frozen at $-85^{\circ} \mathrm{C}$ in 3 aliquots per sample. A further $60 \mu l$ aliquot was stored separately for protein assay. The lysing procedure was carried out as rapidly as possible to minimise decay of enzyme activity once the cells were no longer viable.

\subsection{Statistical analysis}

Parametric data was analysed by unpaired Student' $t$-test, and non-parametric data by WilcoxonMann-Whituey test. Correlations were analysed by linear regression. 


\begin{tabular}{|l|l|l|l|}
\hline \multicolumn{3}{|l|}{ Table 3.1 - Yields of proteins purified from sera } \\
\hline Protein & $\begin{array}{l}\text { Volume of } \\
\text { serum used } \\
(\mathrm{ml})\end{array}$ & $\begin{array}{l}\text { Amount of } \\
\text { protein } \\
\text { obtained } \\
(\mu \mathrm{g})\end{array}$ & $\begin{array}{l}\text { Yield } \\
(\mu \mathrm{g} / \mathrm{ml} \\
\text { serum })\end{array}$ \\
\hline $\operatorname{lgAl}$ (mean of 42 separations) & 5 & 2370 & 474 \\
\hline IgG (mean of 53 separations) & 1 (approx) & 2380 & 2380 \\
\hline Clinh (mean of 24 separations) & 5 & 434 & 87 \\
\hline
\end{tabular}

\begin{tabular}{|c|c|c|c|c|}
\hline \multicolumn{5}{|c|}{$\begin{array}{l}\text { Table } 3.2 \text { - Levels of contaminants in purified } \\
\text { protein preparations }\end{array}$} \\
\hline \multirow[b]{2}{*}{$\begin{array}{l}\text { Purified } \\
\text { protein }\end{array}$} & \multirow[b]{2}{*}{ Sample } & \multicolumn{3}{|c|}{$\begin{array}{l}\text { Protein } \\
\text { conc }^{\mathrm{n}} \\
(\mu \mathrm{g} / \mathrm{ml})\end{array}$} \\
\hline & & $\operatorname{Ig} A$ & $\operatorname{Ig} G$ & Clinh \\
\hline IgAI & $\begin{array}{l}1 \\
2 \\
3 \\
4 \\
5\end{array}$ & $\begin{array}{c}90 \\
120 \\
130 \\
100 \\
200\end{array}$ & $\begin{array}{l}0.5 \\
0.5 \\
0.6 \\
0.3 \\
0.7\end{array}$ & $\begin{array}{l}- \\
5.0 \\
3.6 \\
3.4 \\
5.6\end{array}$ \\
\hline $\lg G$ & $\begin{array}{l}1 \\
2 \\
3 \\
4 \\
5\end{array}$ & $\begin{array}{l}1.5 \\
- \\
1.5 \\
0.5 \\
5.0\end{array}$ & $\begin{array}{l}600 \\
660 \\
340 \\
120 \\
465\end{array}$ & $\begin{array}{l}27 \\
- \\
- \\
- \\
-\end{array}$ \\
\hline Clinh & $\begin{array}{l}1 \\
2 \\
3 \\
4 \\
5\end{array}$ & $\begin{array}{l}- \\
0.3 \\
- \\
3.9 \\
1.6\end{array}$ & $\begin{array}{l}0.02 \\
0.01 \\
0.03 \\
- \\
-\end{array}$ & $\begin{array}{l}72 \\
40 \\
81 \\
120 \\
100\end{array}$ \\
\hline
\end{tabular}




\begin{tabular}{|c|c|c|}
\hline \multirow{2}{*}{$\begin{array}{l}\text { Table } 3.3 \\
\text { Sample }\end{array}$} & \multicolumn{2}{|c|}{$\begin{array}{l}\text { IgA levels in sequential } \\
\text { eluates from jacalin agarose }\end{array}$} \\
\hline & Eluate & $\operatorname{IgA}(\mu \mathrm{g} / \mathrm{ml})$ \\
\hline \multirow[t]{3}{*}{ A } & 1 & 540 \\
\hline & 2 & 268 \\
\hline & 3 & 127 \\
\hline \multirow[t]{3}{*}{ B } & 1 & 329 \\
\hline & 2 & 237 \\
\hline & 3 & 51 \\
\hline \multirow[t]{3}{*}{ C } & 1 & 668 \\
\hline & 2 & 159 \\
\hline & 3 & 56 \\
\hline \multirow[t]{3}{*}{ D } & 1 & 501 \\
\hline & 2 & 185 \\
\hline & 3 & 74 \\
\hline \multirow[t]{3}{*}{ E } & 1 & 191 \\
\hline & 2 & 134 \\
\hline & 3 & 58 \\
\hline
\end{tabular}




\begin{tabular}{|c|c|c|c|}
\hline \multirow[t]{2}{*}{ Sample } & \multirow[t]{2}{*}{ IgG subclass } & \multicolumn{2}{|l|}{$\%$ total } \\
\hline & & Pre-purification & Post-purification \\
\hline \multirow[t]{4}{*}{1} & IgG1 & 16 & 81 \\
\hline & IgG2 & 63 & 10 \\
\hline & IgG3 & 12 & 3 \\
\hline & IgG4 & 9 & 5 \\
\hline \multirow[t]{4}{*}{2} & IgG1 & 60 & 76 \\
\hline & IgG2 & 33 & 17 \\
\hline & IgG3 & 6 & 5 \\
\hline & IgG4 & 2 & 2 \\
\hline \multirow[t]{4}{*}{3} & IgG1 & 77 & 74 \\
\hline & IgG2 & 9 & 12 \\
\hline & IgG3 & 8 & 11 \\
\hline & IgG4 & 6 & 3 \\
\hline
\end{tabular}

For each sample, the IgG subclass percentages were calculated from :

$\%$ subclass $=\frac{[\text { IgG subclass }]}{[\operatorname{IgG} 1+2+3+4]} \quad x \quad 100 \%$ 


\begin{tabular}{|c|c|c|c|c|c|c|}
\hline \multirow{3}{*}{$\begin{array}{l}\text { Cell } \\
\text { population }\end{array}$} & \multicolumn{2}{|c|}{$\begin{array}{l}\text { Cell marker } \\
\%+\text { +ve cells }\end{array}$} & \multicolumn{2}{|l|}{ Morphology } & \multirow{2}{*}{\multicolumn{2}{|c|}{$\begin{array}{l}\text { Overall } \\
\% \\
\text { cell type } \\
\end{array}$}} \\
\hline & CD3 & HLA-DR & $\begin{array}{l}\% \\
\text { lymphocytes }\end{array}$ & $\begin{array}{l}\% \\
\text { monocytes }\end{array}$ & & \\
\hline & 96 & 2 & 98 & 2 & $\begin{array}{l}\mathrm{T} \\
\mathrm{B} \\
\mathbf{M}\end{array}$ & $\begin{array}{c}96 \\
2 \\
2\end{array}$ \\
\hline$B$ cells & 4 & 95 & 94 & 6 & $\begin{array}{l}\text { T } \\
\text { B } \\
\text { M }\end{array}$ & $\begin{array}{c}4 \\
90 \\
6\end{array}$ \\
\hline Monocytes & 13 & 91 & 19 & 81 & $\begin{array}{l}\text { T } \\
\text { B } \\
\text { M }\end{array}$ & $\begin{array}{c}13 \\
6 \\
81\end{array}$ \\
\hline
\end{tabular}




\section{Figure $3.1 \mathrm{a}$}

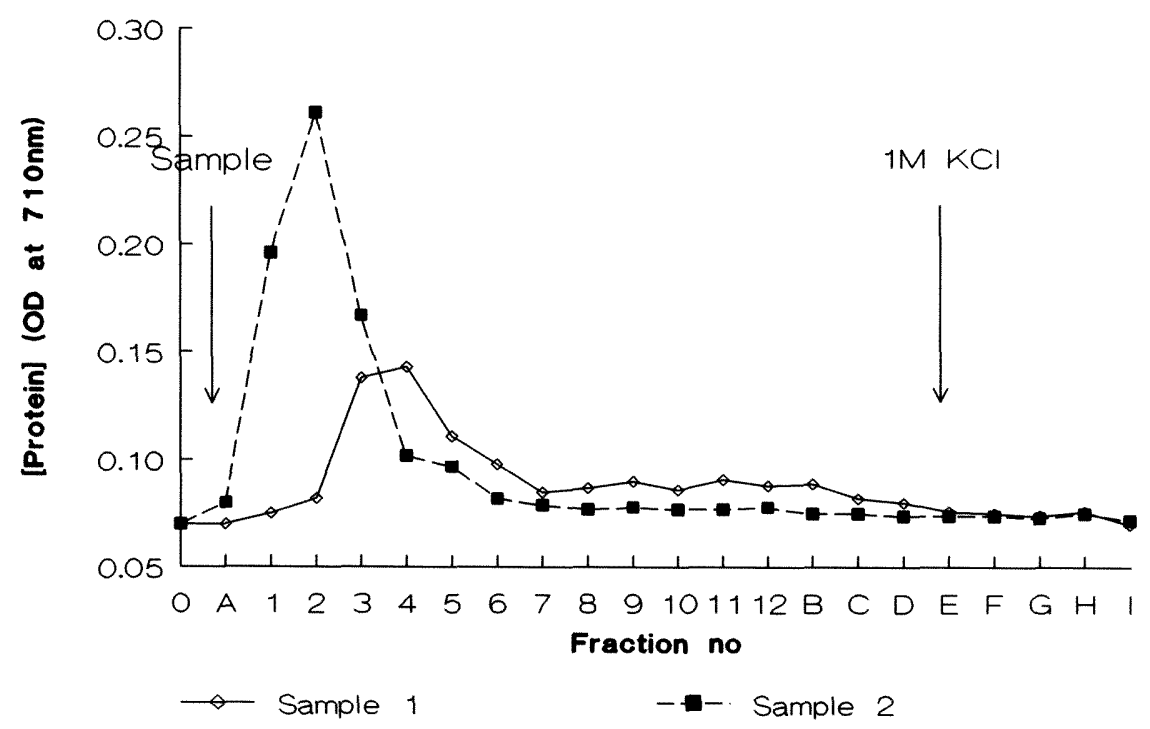

Figure 3.1 Elution from composite gel filtration/anion exchange column. $1 \mathrm{ml}$ ammonium sulphate precipitate sample was applied to the column and washed through with $0.02 \mathrm{M}$ phosphate buffer, collecting $1 \times 5 \mathrm{ml}$ (Fraction A), $12 \times 1 \mathrm{ml}$ (Fractions 112) and $4 \times 5 \mathrm{ml}$ (Fractions B-E). The column was then washed with $0.02 \mathrm{M}$ phosphate buffer containing $1 \mathrm{M} \mathrm{KCl}$, and a further $4 \times 5 \mathrm{ml}$ were collected (Fractions F-I). Figure 3.1a Total protein in eluate fractions. 


\section{Figure $3.1 \mathrm{~b}$}

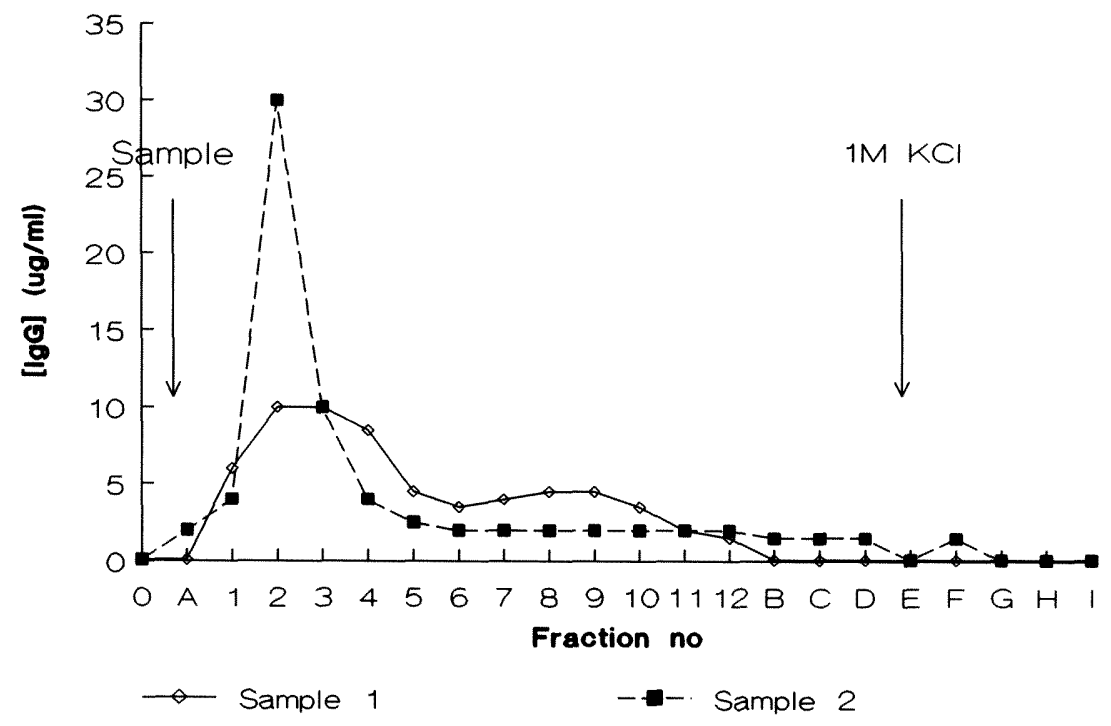

Figure 3.1 Elution from composite gel filtration/anion exchange column. $1 \mathrm{ml}$ ammonium sulphate precipitate sample was applied to the column and washed through with $0.02 \mathrm{M}$ phosphate buffer, collecting $1 \times 5 \mathrm{ml}$ (Fraction A), $12 \times 1 \mathrm{ml}$ (Fractions 112) and $4 \times 5 \mathrm{ml}$ (Fractions B-E). The column was then washed with $0.02 \mathrm{M}$ phosphate buffer containing $1 \mathrm{M} \mathrm{KCl}$, and a further $4 \times 5 \mathrm{ml}$ were collected (Fractions F-I). Figure 3.1b IgG in eluate fractions. IgG was recovered in Fractions 1-10. 
Figure 3.2a

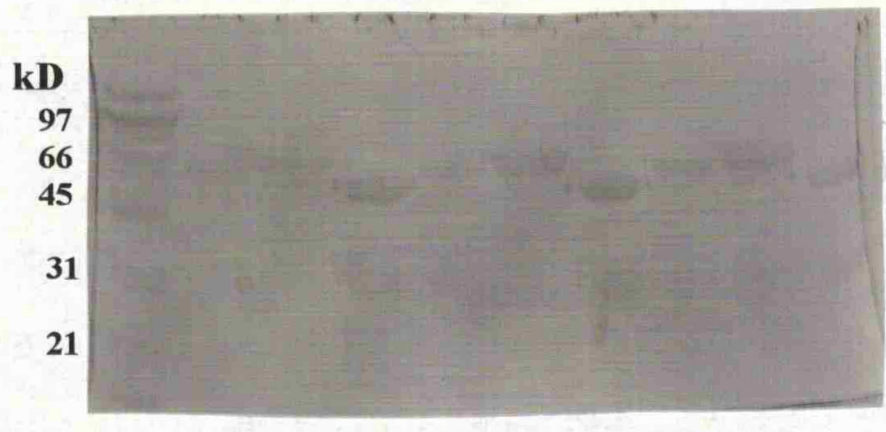

$\begin{array}{lllllllllll}\text { Lane } & 1 & 2 & 3 & 4 & 5 & 6 & 7 & 8 & 9 & 10\end{array}$

Figure $3.2 b$

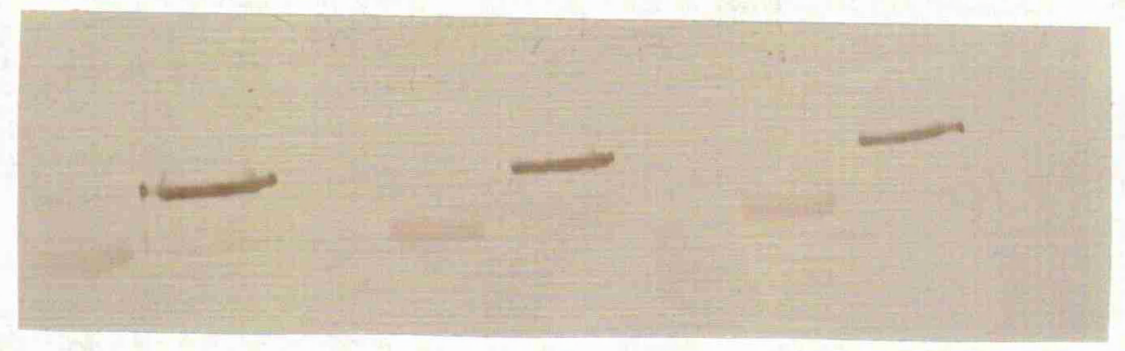

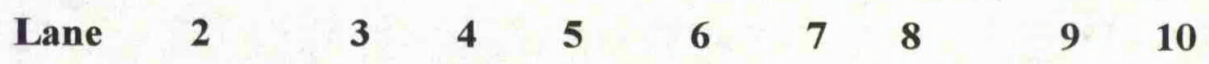

Figure 3.2c

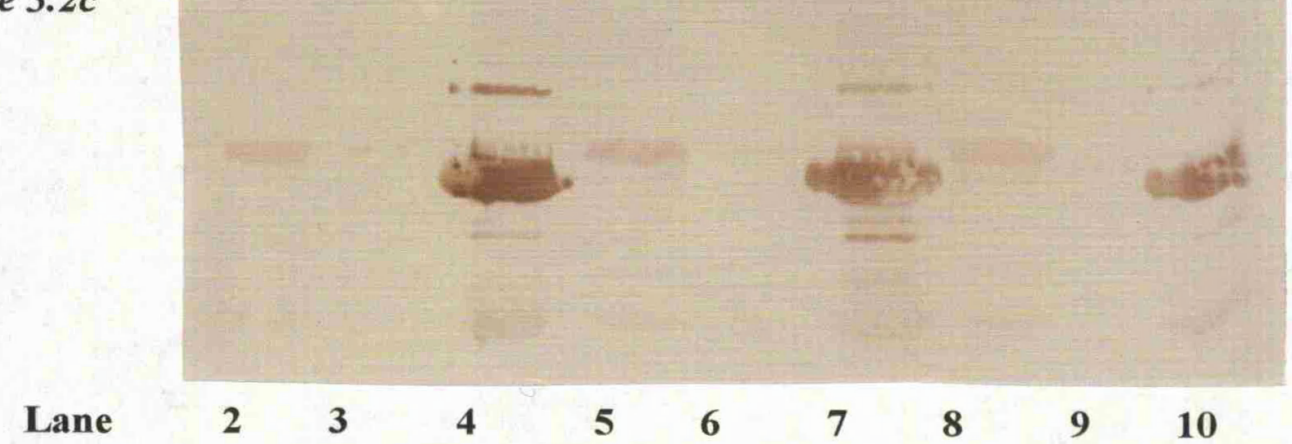

Figure 3.2 Purity of IgA1, IgG and C1inh samples separated from serum.

3.2a SDS-PAGE. Lane 1 is a molecular weight marker. Lanes 2, 5 and 8 are IgA1 samples; Lanes 3, 6 and 9 are Clinh samples and Lanes 4, 7 and 10 are IgG samples.

3.2b Western blot of the above gel, stained with AP-conjugated anti-IgA (pink bands; Lanes 2, 5 and 8 positive) and HRP-conjugated anti-Clinh (brown bands; Lanes 3, 6 and 9 positive).

3.2c Western blot of the above gel, stained with AP-conjugated anti-IgA (pink bands; Lanes 2, 5 and 8 positive) and HRP-conjugated anti-IgG (brown bands; Lanes 4,7 and 10 positive). 
Figure 3.3a

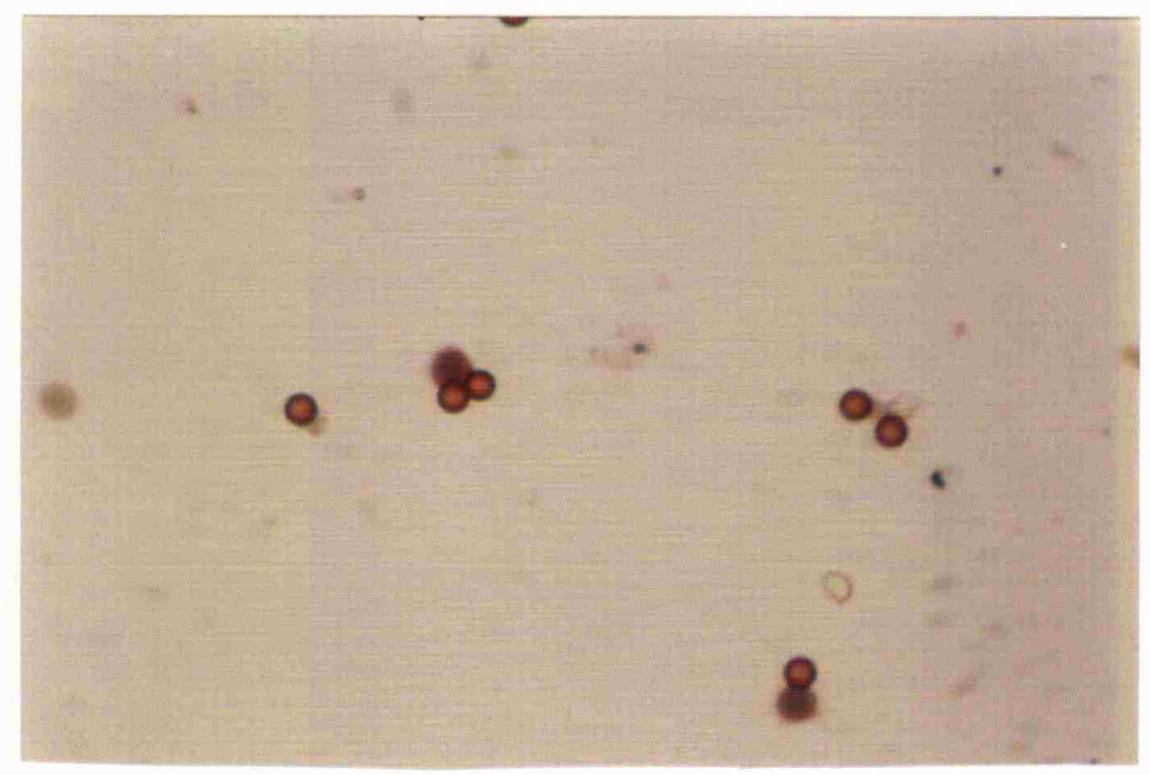

Figure 3.3b

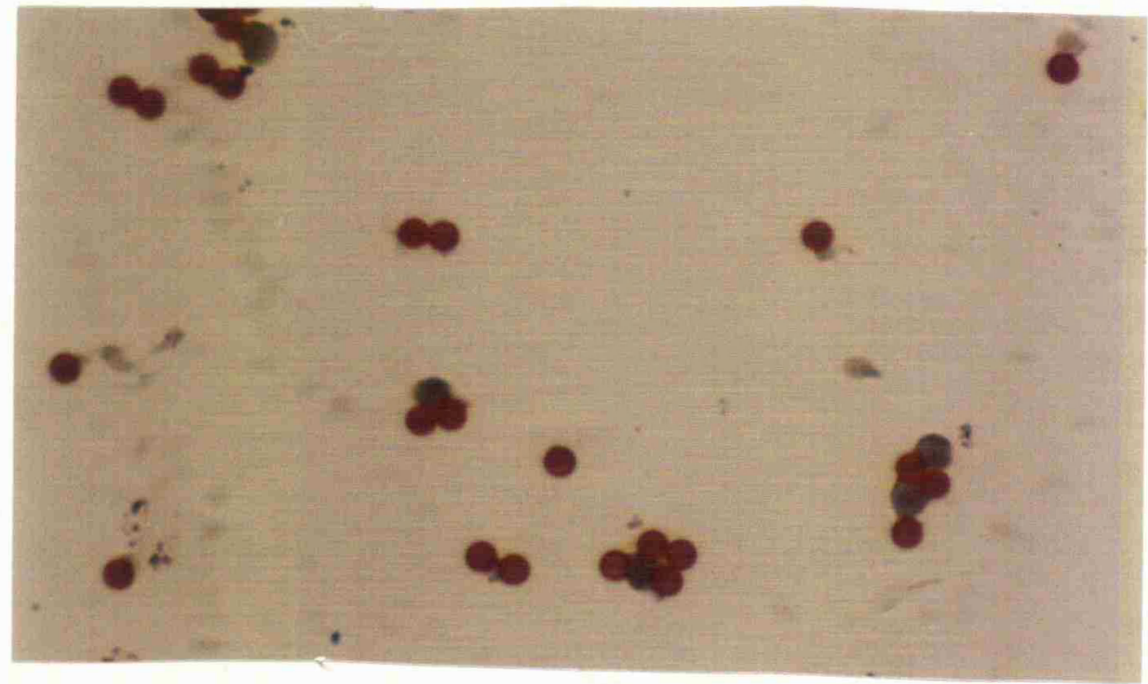

Figure 3.3 B cells separated from peripheral blood by density gradient centrifugation and antibody-conjugated magnetic beads. Figure 3.3a Cells stained for HLADR. Figure 3.3b Cells stained for CD3. 
Figure $3.4 a$

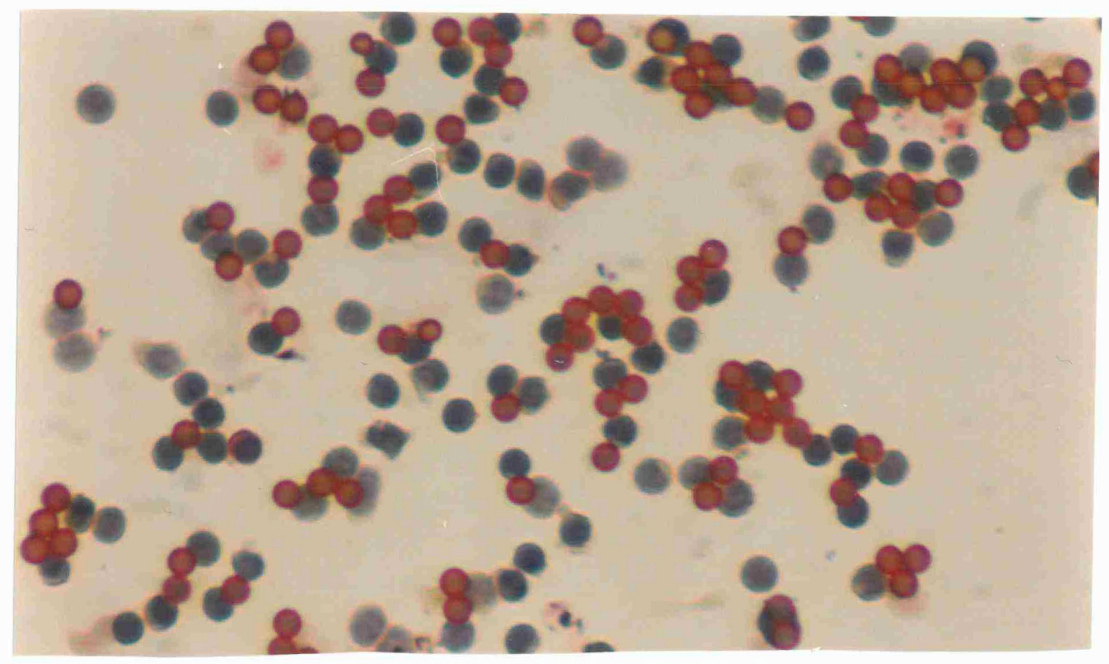

Figure $3.4 b$

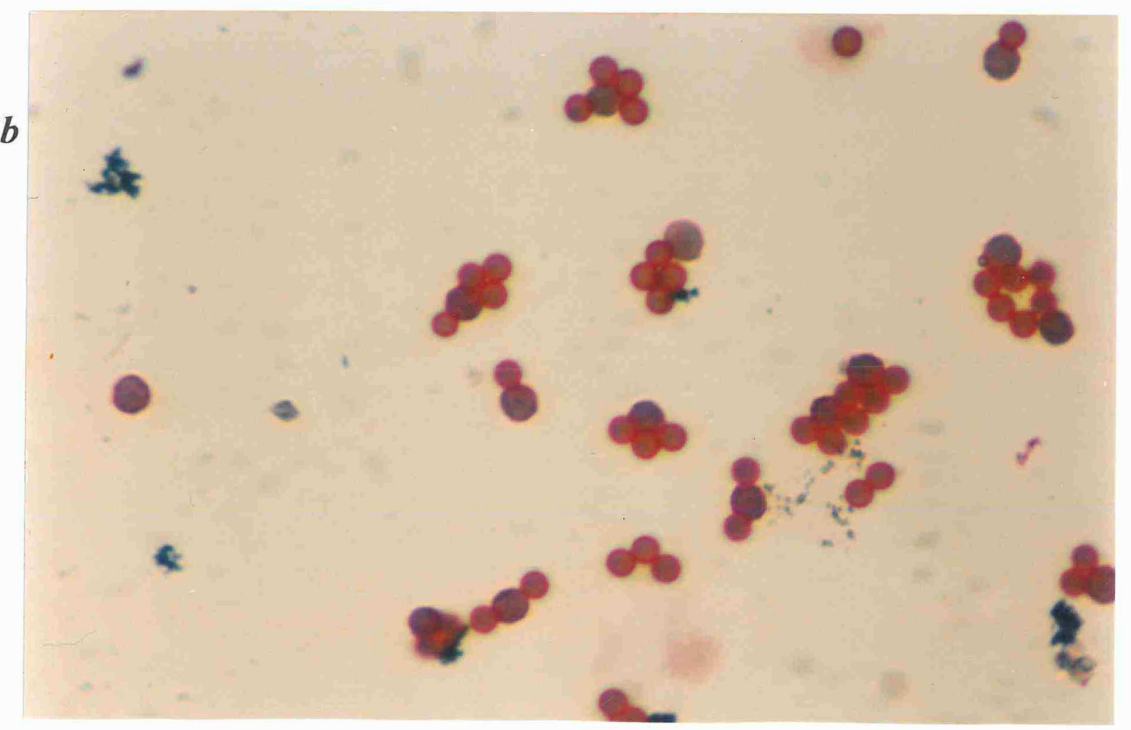

Figure 3.4 T cells separated from peripheral blood by density gradient centrifugation and antibody-conjugated magnetic beads. Figure 3.4a Stained for HLA-DR. Figure 3.4b Stained for CD3. 
Figure 3.5a

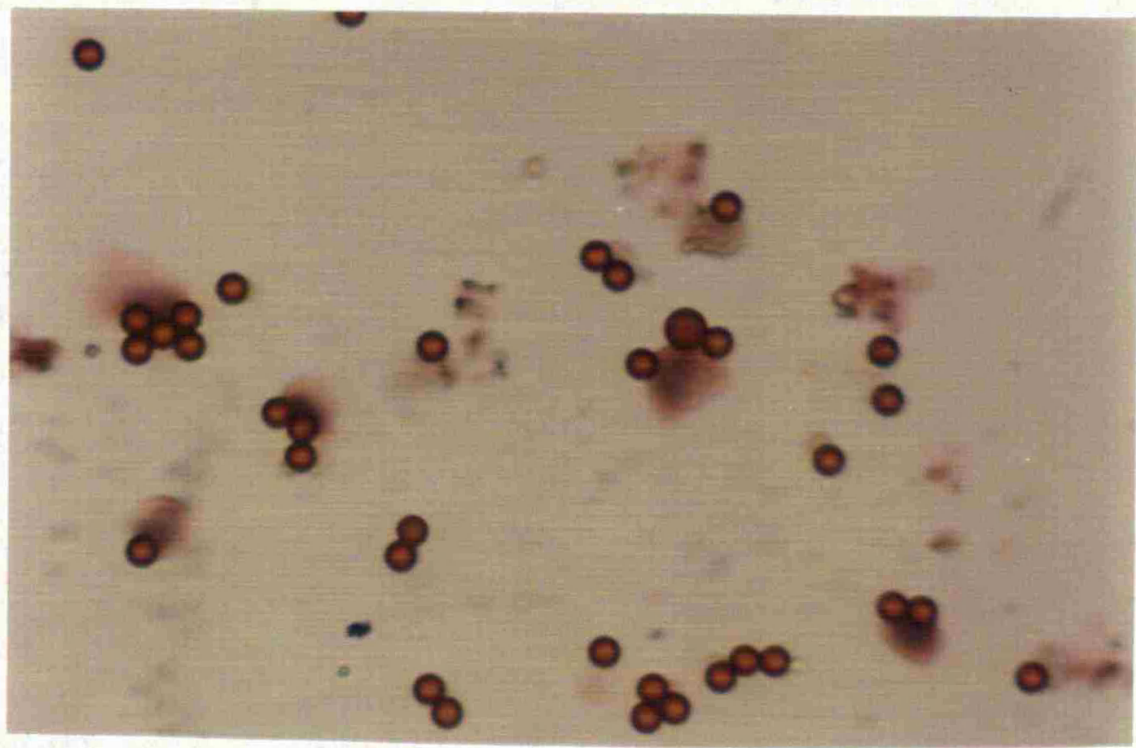

Figure 3.5b

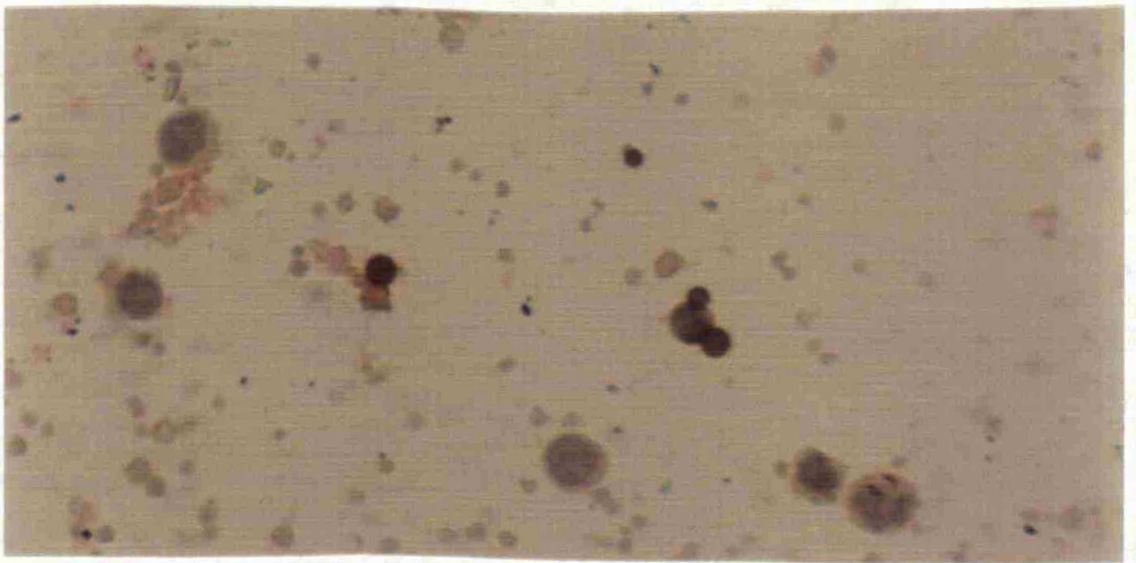

Figure 3.5 Monocytes separated from peripheral blood by density gradient centrifugation and antibody-conjugated magnetic beads. Figure 3.5 $a$ Stained for HLA-DR. Figure 3.5b Stained for CD3. 


\section{CHAPTER FOUR}

Development of Enzyme-linked Lectin Binding Assays 


\subsection{Introduction}

The experiments described in this chapter were designed to develop a method of measuring the binding of various lectins to serum $\operatorname{IgA}$ and $\operatorname{IgG}$ in large series of samples from patients and controls, in order to identify and characterise glycosylation abnormalities. A technique based on the "ELISA" principle was chosen for these assays, which can be summarised as follows :

- Samples immobilised on 96-well immunoplates

- Biotinylated lectins applied, to detect carbohydrate moieties

- HRP-conjugated avidin D applied to detect biotin

- Colour developed by action of HRP on OPD- $\mathrm{H}_{2} \mathrm{O}_{2}$ substrate solution

- Results expressed as OD at $492 \mathrm{~nm}$

These assays were adapted from the method of Dr Helen Griffiths in the Department of Molecular Toxicity, Leicester University, who used Triticum vulgaris and Erythrina crystagalli lectins to measure $\% \mathrm{G}_{0}$ of purified IgG samples applied directly to immunoplates (Griffiths 1989, Griffiths 1991). IgG is easily purified from serum using the dual gel filtration/ion exchange chromatography method described in Chapter 3. Unfortunately, no method as satisfactory as this one is available for serum IgA purification. Jacalin-purified $\operatorname{IgA1}$ is not ideal for glycosylation analysis, since it depends upon the carbohydrate moieties for its binding affinity, but is the only practical method available. Dissociation of $\operatorname{IgA}$ from anti-IgA affinity columns requires harsh treatment which may affect the glycans, particularly the sialic acid content. In an attempt to avoid these problems, the use of anti-IgA antibodies coated onto immunoplates to capture $\operatorname{IgA}$ from serum for lectin-binding experiments was also evaluated.

A criticism of the use of lectins is the uncertainty of their exact specificities. Little work has been done on the binding of IgA to lectins other than jacalin. The specificity of each lectin used in this study was evaluated by inhibition of its binding with various monosaccharides. 


\subsection{Lectin-binding assays using purified $\operatorname{Ig}_{\mathbb{1}} \mathbb{1}$ and $\mathrm{Hg} \mathbb{G}$ samples}

Purified IgAl and IgG samples were applied directly to immunoplates, and the binding of the various lectins to these immobilised glycoproteins studied.

\subsubsection{Basic Method}

Samples

IgA1 was purified from serum by affinity chromatography on jacalin agarose, and IgG by gel filtration and ion exchange chromatography, as described in Chapter 3, and the buffers exchanged to PBS. All the samples to be run in a single assay were adjusted to approximately equal concentrations in PBS; these concentrations varied between assays, but were at least $25 \mu \mathrm{g} / \mathrm{ml}$.

The samples were applied to new immunoplates, in duplicate $30 \mu 1 /$ well volumes. The plates were tapped gently to ensure the base of the wells were completely coated, sealed, and incubated at $4^{\circ} \mathrm{C}$ overnight. Blank wells, coated with PBS alone, were set up on each plate.

\section{Washing}

The plates were washed four times in washing buffer (Appendix II) between each stage, using an automated Denley Wellwash 4 plate washer.

\section{Denaturation}

For lectin binding to N-linked carbohydrates, the samples were denatured with $50 \mu 1 /$ well $0.5 \%$ SDS in PBS for 30 minutes at $37^{\circ} \mathrm{C}$. For assays of lectin binding to O-linked sugars, IgA1 samples were not denatured, since preliminary experiments to investigate the effect of this indicated that it was not necessary (described in 4.2 .2 ).

\section{Blocking}

Excess protein binding sites were blocked with $50 \mu 1 /$ well oxidised glutathione (GSSG) at $2 \mathrm{mg} / \mathrm{ml}$ in PBS, for $1 \mathrm{~h}$ at RT. 
Lectins

$30 \mu \mathrm{l} /$ well biotinylated lectins diluted in PBS were applied and incubated at RT for $2 \mathrm{~h}$. Optimum concentrations for each lectin were chosen from preliminary experiments using plates coated with pooled IgAl or IgG samples and a series of dilutions of the lectins. The concentrations used throughout the project are shown in Table 4.1.

Avidin HRP

Biotinylated lectins were detected with $30 \mu \mathrm{l} /$ well peroxidase conjugated Avidin D (Vector) at $2.5 \mu \mathrm{g} / \mathrm{ml}$ in PBS, incubated for $2 \mathrm{~h}$ at RT. This concentration was found to be optimum in preliminary experiments using a variety of dilutions.

\section{Substrate and Results}

The colour was developed with $30 \mu 1 /$ well OPD/ $\mathrm{H}_{2} \mathrm{O}_{2}$ substrate (Appendix II), and the reaction stopped with $45 \mu \mathrm{l} /$ well $\mathrm{H}_{2} \mathrm{SO}_{4}$, as previously described for ELISA (Chapter 3, Section 3.5). When more than one plate was required for a single assay, the plates were developed and stopped in strict rotation, to ensure that the colour reaction continued for the same amount of time. The ODs were read at $492 \mathrm{~nm}$ on a Titertek Multiscan automated plate reader, and the results expressed as the mean of duplicate wells, with background values for each individual plate subtracted.

\subsubsection{Sample denaturation}

IgG is known to require denaturation to expose the $\mathrm{N}$-linked carbohydrate moieties in the $\mathrm{CH} 2$ domain to lectins. The binding of lectins to native and denatured IgG and IgA1 was investigated to evaluate two methods of denaturation, and to find out whether this is necessary to expose the sugars of IgAl

Method

Immunoplates were coated with $30 \mu \mathrm{l} /$ well of $\operatorname{IgG}$ or $\operatorname{IgAl}$ purified from pooled normal serum, and incubated at $4{ }^{\circ} \mathrm{C}$ overnight. Replicate wells were treated with either $0.5 \%$ SDS in PBS, 5M

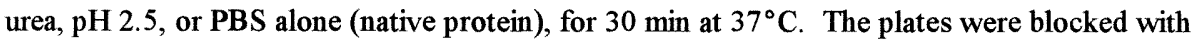


GSSG, and each lectin applied to duplicate wells of each denaturation treatment, as described above. Lectin binding was detected with avidin-HRP and OPD substrate, and the results expressed as mean OD at $492 \mathrm{~nm}$ of duplicate wells.

Results

The effects of denaturation on lectin binding to the N-linked sugars of IgG and to the $\mathrm{N}$ - and $\mathrm{O}$ linked sugars of $\operatorname{IgA} 1$ are shown in Table 4.2 .

Both SDS and urea treatment increased the binding of lectins to IgG approximately threefold. Binding of the lectins TV and EC to the N-linked sugars of IgA1 was also increased by denaturation, but this was not as marked as with IgG (less than twofold). Lectin bindiug to the O-linked sugars of IgA1 was unaffected by denaturation.

\section{Conclusions}

As expected, $\operatorname{IgG}$ requires denaturation to expose the $\mathrm{N}$-linked sugars for lectin binding. IgA1 $\mathrm{N}$-linked sugars appear to be more accessible in the native protein; lectin biuding was only slightly increased by denaturation. This is probably partly accounted for by the second N-linked moiety of IgA1 which lies in the $\mathrm{CH} 3$ domain and may be more external to the protein structure than that of the $\mathrm{CH} 2$ domain. However, this result may indicate that the $\mathrm{CH} 2$ moiety of $\operatorname{IgA} 1$ is less obscured by the protein structure than that of IgG.

Exposure of the O-linked sugars of IgAl does not need protein denaturation; the binding of three lectins recognising $\mathrm{O}$-linked GalNAc (HA, HP, VV), and one recognising O-linked Galp1,3GalNAc (AC) were all unaffected by denaturation, despite the close physical proximity of the short $\mathrm{O}$-linked sugars to the peptide backbone. Repeating sequences of O-linked glycans such as that of the IgA1 hinge region are believed to confer an extended structure upon the protein domain (Jentoft 1990), and this may well account for the accessibility of these carbohydrate ligands to lectin binding.

Following this evaluation, IgA1 and IgG were denatured with $0.5 \%$ SDS in lectin binding assays for $\mathrm{N}$-linked sugars, but no IgA1 denaturation was carried out in the assays for O-linked sugars. 


\subsubsection{Lectin binding of sequential jacalin eluates}

One of the major disadvantages of this method for the measurement of the O-linked glycosylation profile of $\operatorname{IgAl}$ is the use of jacalin to purify it from serum. Immobilisation of IgA1 on jacalin is likely to result in the loss of those molecules with lowest affinity for this lectin, while galactoseelution of the molecules may fail to dislodge those molecules with the highest binding affinity. To address the latter issue, the lectin binding of the sequential jacalin eluates prepared in Chapter 3, Section 3.13 was investigated.

\section{Methods}

Three $\operatorname{Ig} A 1$ samples were eluted sequentially from jacalin with galactose, from five different serum samples (Chapter 3 , Section 3.13). The samples were diluted to equal concentration $(50 \mu \mathrm{g} / \mathrm{ml})$ in PBS and $50 \mu \mathrm{l}$ aliquots applied to immunoplates in duplicate. The plates were incubated at $4^{\circ} \mathrm{C}$ overnight, and the binding of $\mathrm{HA}, \mathrm{VV}$ and $\mathrm{AC}$ lectins measured as described above (Section 4.2.1).

Results

The results are shown in Table 4.3 .

\section{Conclusions}

IgAl obtained from each serum sample showed a different level of binding to the lectins, but this did not differ appreciably between the sequential eluates from jacalin. These results suggest that serum IgA1 from individuals has a characteristic lectin binding profile, and that jacalin does not preferentially retain IgA1 molecules with high affinity for this lectin. 


\subsection{Inhibition of lectin binding with monosaccharides}

To elucidate which carbohydrate moieties of IgG and IgAl the various lectins used in these assays were actually binding to, inhibition experiments with monosaccharides were carried out.

\subsubsection{Method}

Samples

Immunoplates were coated with $\operatorname{IgG}$ or $\operatorname{IgAl}$ samples purified from pooled normal serum. The samples for lectin binding to $\mathrm{N}$-linked sugars were denatured with $0.5 \% \mathrm{SDS}$, and the plates blocked with GSSG, exactly as detailed above (Section 4.2.1).

\section{Lectins and monosaccharides}

The monosaccharides D-galactose (Gal), D-glucose (Glc), N-acetyl glucosamine (GlcNAc) and $\mathrm{N}$-acetyl galactosamine (GaINAc) were dissolved PBS to concentrations of $0.8 \mathrm{mM}, 8 \mathrm{mM}$ and $80 \mathrm{mM}$. $10 \mu \mathrm{l}$ aliquots were applied to duplicate wells of the immunoplates, and $30 \mu \mathrm{l}$ of the various lectins at $4 / 3$ their usual concentrations in PBS added, to make a final volume of $40 \mu 1 /$ well, with the lectins at the concentrations detailed in Table 4.1, and the sugars at 0.2, 2 and 20mM. Wells with PBS instead of the monosaccharides were also set up. The plates were incubated at RT for $2 \mathrm{~h}$.

\section{Completion of the assay and calculation of the results}

The assays were completed by detection of bound lectins with HRP-avidin, colour development with OPD substrate, and reading of the ODs at $492 \mathrm{~nm}$, exactly as before. $\%$ inhibition of lectin binding by each sugar at all three concentrations was calculated from :

$$
\left.\% \text { inhibition }=100 \%-\frac{\text { OD with sugar }}{\text { OD without sugar }} \times 100 \%\right)
$$




\subsubsection{Results}

The inhibition of lectin binding to IgG by the various monosaccharides is shown in Table 4.4 , and to $\operatorname{IgA} 1$ in Tables $4.5 \mathrm{a}-\mathrm{c}$.

Where significant effects were seen, inhibition curves for the various sugar/lectin combinations were constructed to find the concentrations of each sugar which resulted in $50 \%$ inhibition of lectin binding. Examples of these are shown in Figure 4.1 (TV binding to IgA1) and Figure 4.2 (HA binding to $\operatorname{IgA} 1$ ).

\subsubsection{Conclusions}

These experiments demonstrated that although the lectins did indeed have major specificities in agreement with the literature, they all displayed some affinity for other carbohydrate ligands to a greater or lesser extent. The conclusions drawn about the binding of the various lectins to IgG and IgA1 in this assay system are summarised in Table 4.6.

Of the lectins used to identify N-linked sugars, Triticum vulgaris showed good specificity for GlcNAc, but Erythrina cristagalli was inhibited by GalNAc and GlcNAc as well as its reported optimum ligand, galactose.

Vicia villosa proved to be the most specific lectin for O-linked GalNAc detection, and since it is reported have a higher affinity for peptide-linked GalNAc than the free monosaccharide (Sharon 1989), it may be a better detector of this ligand than indicated by these studies. The two Helix lectins also showed highest affinity for GalNAc, though they were also inhibited by GlcNAc and Gal. VV is therefore best lectin for the detection of GaINAc in IgA1.

The disaccharide Gal $\beta 1,3$ GalNAc was not available for these inhibition studies. Two lectins with reported maximum specificity for this ligand were investigated. Arachis hypogaea lectin (PNA) was most inhibited by Gal, but also by GalNAc and GlcNAc, while Amaranthus caudatus lectin was inhibited only by high concentrations of GalNAc. This is consistent with other studies on the 
monosaccharide specificities of these lectins, but it is not known how much higher the affinity for the full disaccharide ligand would be. The multiple specificity of PNA suggests that it is probably not a very good lectin for use with $\operatorname{IgA}$.

\subsection{IgA lectin binding assays on antibodly-coated immunoplates}

\subsubsection{Lvaluation of plate saturation and nom-specific binding}

Anti-IgA coated immunoplates were used to capture and immobilise IgA from serum samples for subsequent lectin binding studies. The first step in the development of these assays was to find suitable dilution of serum which saturates the binding capacity of the wells regardless of differences in $\operatorname{IgA}$ concentration of the sera, but minimises non-specific binding.

\section{Method}

Immunoplates were coated with $100 \mu 1 /$ well rabbit anti-human IgA (Dako A0262) at $10 \mu \mathrm{g} / \mathrm{ml}$ in coating buffer (Appendix II), overnight at $4^{\circ} \mathrm{C}$. The plates were washed four times in washing buffer (Appendix II) and blocked with $100 \mu 1 /$ well $2 \mathrm{mg} / \mathrm{ml}$ GSSG in PBS for 1 hour at RT.

Three normal sera and an $\operatorname{IgA}$ deficient serum were used for these experiments. $50 \mu \mathrm{l}$ aliquots of serial dilutions of the samples ranging from 1:50 to 1:51200 were applied to the plates in duplicate wells, and incubated overnight at $4^{\circ} \mathrm{C}$.

Peroxidase conjugated anti human IgA, IgG and IgM (Dako) were applied to the wells, incubated for 2 hours at $\mathrm{RT}$, and the colour developed with $\mathrm{OPD} / \mathrm{H}_{2} \mathrm{O}_{2}$ (Appendix $\mathrm{I}$ ) as previously described.

\section{Results}

The results were expressed as OD only, since in most cases, the analytes were present in concentrations above the range of ELISA. The wells were saturated with $\operatorname{IgA}$ at serum dilutions up to 1:2000, as shown in Figure 4.3. Binding of IgG and IgM at the maximum serum dilutions required for reliable saturation (1:2000) are shown in Table 4.7 . 


\section{Conclusions}

A serum dilution of 1:1000 was chosen as optimal for use in the subsequent lectin binding experiments, to ensure that all the wells were saturated with a consistent amount of $\operatorname{IgA}$ regardless of the serum concentration. The relative amounts of IgA1 and IgA2 captured will depend upon their ratio in the serum. There was some degree of non-specific binding at this serum dilution, illustrated by the presence of detectable IgG and IgM.

\subsubsection{BBasic method for lectin binding assays on anti-IgA coated plates}

Lectins from Triticum vulgaris (TV; GlcNAc detection) and Erythrina cristagalli (EC; Gal detection) were used to examine the terminal components of the $\mathrm{N}$-linked sugars of $\operatorname{Ig} \mathrm{A}$ as above. Helix aspersa (HA) and Arachis hypogaea (PNA) lectins were used to analyse the O-linked glycans.

\section{Capture antibody}

Immunoplates were coated with $100 \mu 1 /$ well rabbit anti-human IgA (Dako A0262) at $10 \mu \mathrm{g} / \mathrm{ml}$ in coating buffer, sealed, and incubated overnight at $4^{\circ} \mathrm{C}$.

\section{Washing}

The plates were washed four times in washing buffer between each stage of the assay procedure, using an automated plate washer (Denley Wellwash 4).

\section{Blocking}

Excess protein binding sites were blocked with $100 \mu \mathrm{l} /$ well $2 \mathrm{mg} / \mathrm{ml} \mathrm{GSSG}$, incubating at RT for $1 \mathrm{~h}$.

\section{Samples}

Lectin binding to $\mathrm{N}$ - and $\mathrm{O}$-linked sugars was investigated using a normal serum, serum from a patient with $\operatorname{IgA}$ deficiency, and commercially purified $\operatorname{IgA} 1$ and $\operatorname{IgA} 2$ myeloma proteins (The Binding Site). The "IgA deficient" serum was not completely IgA free, but was found to contain $80 \mu \mathrm{g} / \mathrm{ml}$ IgA by ELISA. $50 \mu \mathrm{l} /$ well of the samples were applied to sets of duplicate wells, with 
the sera at 1:1000 and the myeloma proteins at $1 \mu \mathrm{g} / \mathrm{ml}$, all in PBS. Blank wells, containing $50 \mu 1$ PBS, were also set up. The plates sealed and incubated overnight at $4^{\circ} \mathrm{C}$.

\section{Denaturation}

In the assays for N-linked sugars, IgA was denatured with $50 \mu 1 /$ well $0.5 \%$ SDS in PBS, incubating at RT for $30 \mathrm{~min}$. A pair of duplicate wells were left undenatured, incubating in PBS alone at this stage, to ensure that denaturation did not affect the immobilisation of the $\operatorname{IgA}$.

\section{Lectins}

Biotinylated lectins were applied to the plates at $50 \mu \mathrm{l} / \mathrm{well}$, and incubated at RT for $2 \mathrm{~h}$.

\section{Substrate}

Lectin binding was detected with $50 \mu 1 /$ well $\mathrm{OPD} / \mathrm{H}_{2} \mathrm{O}_{2}$ substrate.

\section{Calculation of the results}

The results were read at $492 \mathrm{~nm}$ by automated plate scanner, and the mean ODs of duplicate wells calculated. In addition, the ratio of TV:EC (GlcNAc:Gal) binding was calculated for each sample.

\subsubsection{Results of lectin binding assay on anti-HgA coated plates}

The results of lectin binding to N-linked sugars, and the effect of denaturation, are summarised in Table 4.8 , and the results of lectin binding to O-linked sugars in Table 4.9 . Table 4.10 shows the results of lectin binding to normal and IgA deficient sera.

\section{N-linked sugars}

Both TV and EC lectius showed detectable binding to all the samples, while the blank wells gave background OD. Denaturation with $0.5 \%$ SDS did not significantly alter the lectin binding of any of the samples, and the TV:EC ratio calculated for each sample remained consistent. The IgA2 myeloma protein had a strikingly different lectin binding profile to the $\operatorname{IgA1}$ myeloma protein, and to the serum IgA, which would be predominantly IgA1. EC binding of IgA2 was much higher, and TV binding correspondingly lower than the other two samples, and this was reflected in the 
lower TV:EC ratio of $\operatorname{IgA2}$. With both lectins, the IgA deficient serum showed lower binding than normal serum, but somewhat higher than background.

\section{O-linked sugars}

As expected, the $\operatorname{IgA} 2$ myeloma protein failed to bind either PNA or HA, since IgA2 lacks Olinked sugars. The IgA deficient serum also gave very low results, demonstrating that both lectins were predominantly binding to IgA1in these assays.

\subsubsection{Conclusions on lectin binding assays on anti-IgA coated plates}

The results of these small pilot studies indicated that the use of anti-IgA coated plates to immobilise serum IgA for lectin binding studies is a practical approach. The rabbit anti-IgA used to coat the plates did not appear to bind the lectins itself, and denaturation with $0.5 \%$ SDS did not displace the $\operatorname{Ig} A$ from the antibody.

The IgA1 and IgA2 myeloma proteins gave strikingly different lectin binding results. The EC binding of $\operatorname{IgA} 2$ was much higher than $\operatorname{IgA1}$, both in absolute terms, and in relation to the TV binding. $\operatorname{IgA} 2$ is known to carry more carbohydrate moieties than $\operatorname{IgA} 1$, but these have been reported to be less galactosylated (Wold 1994). The high EC binding of this myeloma IgA2 may simply be due to the higher density of its sugars, though the low TV:EC ratio suggests that they are also more galactosylated. This may be artefactual, as though the myeloma proteins were applied to the plate at the same concentrations, the results do not provide information about the actual amount captured; in addition, myeloma proteins may not necessarily be representative of normal immunoglobulins. The IgA2 myeloma protein did not bind PNA or HA, confirming that it lacks O-linked sugars.

The serum sample applied to the wells gave lectin binding results very similar to those of the IgA1 myeloma protein, which would be expected, as serum $\operatorname{IgA}$ is mostly of the $\operatorname{IgA1}$ subclass. The only lectin which showed a marked difference in its binding to myeloma $\operatorname{IgA1}$ and serum $\operatorname{IgA}$ was PNA; this lectin is sensitive to the presence of terminal sialic acid, and its lower binding to serum IgA may be due to higher sialylation of O-linked moieties. Sialylation is the major difference 
between normal and myeloma IgA1 (Field 1989).

The possibility of non-specific binding by proteins other than IgA remains a problem with this method. The IgA deficient serum gave virtually background results with the lectins for O-linked sugars, suggesting that the anti-IgA coated plates do not capture appreciable amounts of other proteins with O-linked sugars. However, its binding to TV and EC was slightly above background; this could have been due to the capture of the trace amounts of IgA present in this serum, or to non-specific capture of other serum proteins. The most likely contaminants would be albumin and other immunoglobulin isotypes.

Anti-IgA coated plates will capture both $\operatorname{IgA} 1$ and $\operatorname{IgA2}$, and this is a drawback when comparing lectin binding between individuals, as the ratio of serum $\operatorname{IgA1}$ to $\operatorname{IgA} 2$ varies, and is raised in IgAN. The study of O-linked sugars requires isolation of $\operatorname{IgA1}$, which carries them, from $\operatorname{IgA} 2$, which does not. Experiments using anti-IgA1 coated plates indicated that there was very high non-specific binding with $\operatorname{IgG}$ and $\operatorname{IgA} 2$ at serum dilutions required to reliably saturate the plates (data not shown), rendering this approach to IgA1 isolation impractical. In addition, the $\mathrm{O}$ glycosylated IgA1 hinge region represents the major difference between the subclasses, and antiIgA1 specific antibodies are very likely to recognise an epitope in this area of the molecule. Therefore, lectin binding to $\mathrm{O}$-linked sugars could well be disrupted or prevented by anti-IgA1 antibodies immobilising the molecule.

\subsection{Discussion}

Lectin binding assays using purified $\operatorname{IgG}$ and $\operatorname{IgA} 1$ samples provide a rapid and simple way of comparing the glycosylation profiles of a large number of samples. The major drawbacks are twofold.

Firstly, a method of protein purification is required which does not affect the carbohydrate component of the immunoglobulin and gives a representative selection of molecules, not unduly favouring or omitting certain glycoforms. This is available for IgG, but the jacalin-agarose affinity technique employed for IgA1 separation is less than ideal in the latter respect. The observation 
that IgA1 samples obtained by repeated elutions from the jacalin do not vary in their lectin binding profile argues against the loss of those molecules with the highest affinity for this lectin being a significant occurrence in this method. However, it remains a possibility that the IgA1 molecules with the lowest affinity for jacalin may not be harvested from the serum at all during the separation process. Jacalin purified IgAl was used for analysis of $\mathrm{N}$ - and $\mathrm{O}$-linked sugar moieties in this thesis. Where differences in O-glycosylation were observed between patient and control groups, the findings were confirmed using immobilisation of $\operatorname{IgA}$ from serum by anti-IgA coated immunoplates, as described in Section 4.4 .

The second major drawback of any lectin-binding method is the uncertainty of the precise binding specificities of the lectins. The monosaccharide inhibition experiments carried out the this chapter demonstrate that most of the lectins have multiple specificities, and these need to be taken into account when interpreting the data. The results are strengthened by the use of more than one lectin for each carbohydrate ligand.

Published methods for the estimation of agalactosylation of IgG samples by lectin binding assay employ a set of standard IgG samples with known $\% \mathrm{G}_{0}$ to construct a standard curve of lectin binding ratios in order to express the results as $\% \mathrm{G}_{0}$. No such standards are currently available for IgA, and it is not known how well the TV:EC ratio of IgA compares to its glycosylation profile, particularly since the N-linked moieties of $\operatorname{IgA}$ are not identical to those of $\operatorname{IgG}$. A further complication is added by the different numbers of $\mathrm{N}$-linked moieties possessed by $\operatorname{IgA} 1$ and $\operatorname{IgA} 2$. This is the first study employing a range of lectins to analyse the $\mathrm{O}$-linked glycans of $\operatorname{IgA1}$, and no standards are avaliable for this purpose. It is therefore necessary to express the results of the lectin binding assays as OD at $492 \mathrm{~nm}$ only. 


\begin{tabular}{|l|l|l|}
\hline Table 4.1 $\begin{array}{l}\text { Working concentrations of biotinylated } \\
\text { lectins }\end{array}$ & Abbreviation & $\begin{array}{l}\text { Concentration } \\
(\mu \mathrm{g} / \mathrm{ml})\end{array}$ \\
\hline Lectin & EC & 2.0 \\
\hline Erythrina cristagalli & TV & 1.0 \\
\hline Triticum vulgaris & HA & 2.0 \\
\hline Helix aspersa & HP & 5.0 \\
\hline Helix pomatia & VV & 1.0 \\
\hline Vicia villosa & PNA & 2.5 \\
\hline $\begin{array}{l}\text { Arachis hypogaea } \\
\text { (peanut agghtinin) }\end{array}$ & AC & 0.5 \\
\hline Amaranthus caudatus & & \\
\hline
\end{tabular}




\begin{tabular}{|c|c|c|c|c|}
\hline Table 4 & Denatu & on of $\operatorname{lgG}$ and & & \\
\hline \multirow[b]{3}{*}{ Protein } & \multirow[b]{3}{*}{ Lectin } & \multirow[b]{2}{*}{ Native protein } & \multicolumn{2}{|c|}{$\begin{array}{l}\text { Denaturation } \\
\text { treatment }\end{array}$} \\
\hline & & & SDS & Urea \\
\hline & & \multicolumn{3}{|c|}{ OD at $492 \mathrm{~nm}$} \\
\hline \multicolumn{5}{|l|}{ IgG } \\
\hline & EC & 0.505 & 1.595 & 1.622 \\
\hline & TV & 0.539 & 1.370 & 1.491 \\
\hline & no lectin & 0.106 & 0.110 & 0.116 \\
\hline \multicolumn{5}{|l|}{$\operatorname{IgA1}$} \\
\hline & $\mathrm{EC}$ & 0.403 & 0.524 & 0.553 \\
\hline & TV & 2.660 & 2.739 & 2.884 \\
\hline & HA & 0.519 & 0.530 & 0.500 \\
\hline & HP & 0.625 & 0.660 & 0.644 \\
\hline & VV & 0.528 & 0.489 & 0.601 \\
\hline & $\mathrm{AC}$ & 3.338 & 3.266 & 3.240 \\
\hline & no lectin & 0.128 & 0.102 & 0.140 \\
\hline
\end{tabular}




\begin{tabular}{|c|c|c|c|c|}
\hline \multirow{2}{*}{ Table 4.3} & \multirow[b]{3}{*}{ Eluate } & \multicolumn{3}{|c|}{ Lectin } \\
\hline & & HA & $\mathbf{V V}$ & $\mathbf{A C}$ \\
\hline Sample & & \multicolumn{3}{|c|}{ OD at $492 \mathrm{~nm}$} \\
\hline \multirow[t]{3}{*}{ A } & 1 & 2.19 & 1.46 & 2.46 \\
\hline & 2 & 2.17 & 1.33 & 2.42 \\
\hline & 3 & 2.05 & 1.43 & 2.50 \\
\hline \multirow[t]{3}{*}{ B } & 1 & 1.74 & 0.97 & 2.54 \\
\hline & 2 & 1.74 & 0.91 & 2.74 \\
\hline & 3 & 1.83 & 0.93 & 2.74 \\
\hline \multirow[t]{3}{*}{$\mathrm{C}$} & 1 & 2.04 & 1.16 & 2.61 \\
\hline & 2 & 1.88 & 1.14 & 2.41 \\
\hline & 3 & 2.07 & 1.06 & 2.51 \\
\hline \multirow[t]{3}{*}{ D } & 1 & 2.43 & 1.29 & 2.30 \\
\hline & 2 & 2.44 & 1.23 & 2.38 \\
\hline & 3 & 2.40 & 1.40 & 2.38 \\
\hline \multirow[t]{3}{*}{ E } & 1 & 1.95 & 1.20 & 2.72 \\
\hline & 2 & 1.87 & 1.19 & 2.62 \\
\hline & 3 & 2.00 & 1.31 & 2.65 \\
\hline
\end{tabular}




\begin{tabular}{|c|c|c|c|c|c|}
\hline \multirow[t]{4}{*}{ Table 4.4} & \multicolumn{5}{|c|}{ Monosaccharide inhibition of lectin binding to IgG } \\
\hline & & \multicolumn{4}{|c|}{ Lectin } \\
\hline & & \multicolumn{2}{|l|}{ TV } & \multicolumn{2}{|l|}{$\mathbf{E C}$} \\
\hline & & $\begin{array}{l}\text { OD at } \\
492 \mathrm{~nm}\end{array}$ & $\begin{array}{l}\% \\
\text { inhibition }\end{array}$ & $\begin{array}{l}\text { OD at } \\
492 \mathrm{~nm}\end{array}$ & $\begin{array}{l}\% \\
\text { inhibition }\end{array}$ \\
\hline Sugar & $\begin{array}{l}\text { Concentration } \\
(\mathbf{m M})\end{array}$ & & & & \\
\hline PBS & & 0.79 & & 2.45 & \\
\hline \multirow[t]{3}{*}{ Gal } & 0.2 & 0.70 & 13 & 1.77 & 28 \\
\hline & 2 & 0.71 & 11 & 1.76 & 28 \\
\hline & 20 & 0.71 & 11 & 1.49 & 31 \\
\hline \multirow[t]{3}{*}{ Glc } & 0.2 & 0.86 & - & 2.18 & 11 \\
\hline & 2 & 0.76 & 4 & 2.05 & 16 \\
\hline & 20 & 0.71 & 11 & 2.71 & - \\
\hline \multirow[t]{3}{*}{ GalNAc } & 0.2 & 0.75 & 5 & 1.94 & 21 \\
\hline & 2 & 0.75 & 5 & 1.66 & 32 \\
\hline & 20 & 0.83 & - & 1.33 & 46 \\
\hline \multirow[t]{3}{*}{ GlcNAc } & 0.2 & 0.66 & 16 & 2.18 & 11 \\
\hline & 2 & 0.65 & 18 & 1.93 & 21 \\
\hline & 20 & 0.43 & 46 & 1.88 & 23 \\
\hline
\end{tabular}

The $\%$ inhibition of the binding of each lectin by each sugar was calculated from :

$\%$ inhibition $=100 \%-($ OD with sugar $\quad \times 100 \%)$

OD without sugar 


\begin{tabular}{|c|c|c|c|c|c|}
\hline \multicolumn{6}{|c|}{$\begin{array}{l}\text { Table 4.5a Monosaccharide inhibition of lectin binding to N-linked } \\
\text { glycans of } \operatorname{IgA1}\end{array}$} \\
\hline & & \multicolumn{4}{|c|}{ Lectin } \\
\hline & & \multicolumn{2}{|l|}{ TV } & \multicolumn{2}{|l|}{ EC } \\
\hline & & $\begin{array}{l}\text { OD at } \\
492 \mathrm{~nm}\end{array}$ & $\begin{array}{l}\% \\
\text { inhibition }\end{array}$ & $\begin{array}{l}\text { OD at } \\
492 \mathrm{~nm}\end{array}$ & $\begin{array}{l}\% \\
\text { inhibition }\end{array}$ \\
\hline Sugar & $\begin{array}{l}\text { Concentration } \\
(\mathbf{m} \mathbf{M})\end{array}$ & & & & \\
\hline$P B S$ & & 1.07 & & 0.55 & \\
\hline \multirow[t]{3}{*}{ Gal } & 0.2 & 1.12 & - & 0.36 & 35 \\
\hline & 2 & 1.14 & - & 0.37 & 33 \\
\hline & 20 & 1.13 & - & 0.36 & 35 \\
\hline \multirow[t]{3}{*}{ Glc } & 0.2 & 1.12 & - & 0.51 & 7 \\
\hline & 2 & 0.99 & 7 & 0.44 & 20 \\
\hline & 20 & 1.16 & - & 0.51 & 7 \\
\hline \multirow[t]{3}{*}{ GalNAc } & 0.2 & 1.10 & - & 0.38 & 31 \\
\hline & 2 & 1.12 & - & 0.32 & 42 \\
\hline & 20 & 0.98 & 8 & 0.33 & 40 \\
\hline \multirow[t]{3}{*}{ GlcNAc } & 0.2 & 1.02 & 5 & 0.49 & 11 \\
\hline & 2 & 0.87 & 19 & 0.36 & 35 \\
\hline & 20 & 0.33 & 69 & 0.44 & 20 \\
\hline
\end{tabular}

The \% inhibition of the binding of each lectin by each sugar was calculated from :

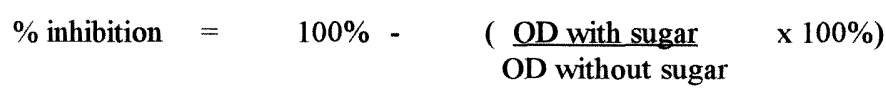




\begin{tabular}{|c|c|c|c|c|c|c|c|}
\hline & \multicolumn{6}{|l|}{ Lectin } \\
\hline & & \multicolumn{2}{|l|}{ HA } & \multicolumn{2}{|l|}{ HP } & \multicolumn{2}{|l|}{ VV } \\
\hline & & $\begin{array}{l}\text { OD at } \\
492 \mathrm{~nm}\end{array}$ & $\begin{array}{l}\% \\
\text { inhibition }\end{array}$ & $\begin{array}{l}\text { OD at } \\
492 \mathrm{~nm}\end{array}$ & $\begin{array}{l}\% \\
\text { inhibition }\end{array}$ & $\begin{array}{l}\text { OD at } \\
492 \mathrm{~nm}\end{array}$ & $\begin{array}{l}\% \\
\text { inhibition }\end{array}$ \\
\hline Sugar & $\begin{array}{l}\text { Concen- } \\
\text { tration } \\
(\mathbf{m M})\end{array}$ & & & & & & \\
\hline PBS & & 2.11 & & 1.41 & & 0.65 & \\
\hline \multirow[t]{3}{*}{ Gal } & 0.2 & 2.06 & 2 & 1.12 & 21 & 0.62 & 5 \\
\hline & 2 & 2.12 & - & 0.92 & 35 & 0.47 & 28 \\
\hline & 20 & 1.38 & 35 & 0.68 & 52 & 0.43 & 34 \\
\hline \multirow[t]{3}{*}{ Glc } & 0.2 & 2.11 & - & 1.07 & 24 & 0.77 & - \\
\hline & 2 & 2.16 & - & 0.92 & 35 & 0.64 & 2 \\
\hline & 20 & 1.91 & 9 & 0.89 & 37 & 0.50 & 23 \\
\hline \multirow[t]{3}{*}{ GalNAc } & 0.2 & 1.11 & 47 & 0.46 & 67 & 0.31 & 52 \\
\hline & 2 & 0.21 & 90 & 0.13 & 91 & 0.38 & 42 \\
\hline & 20 & 0.17 & 91 & 0.13 & 91 & 0.29 & 55 \\
\hline \multirow[t]{3}{*}{ GlcNAc } & 0.2 & 1.68 & 20 & 0.79 & 44 & 0.60 & 8 \\
\hline & 2 & 0.47 & 78 & 0.22 & 84 & 0.58 & 11 \\
\hline & 20 & 0.16 & 92 & 0.12 & 91 & 0.51 & 22 \\
\hline
\end{tabular}

The \% inhibition of the binding of each lectin by each sugar was calculated from :

$\%$ inhibition $=100 \%-\quad($ OD with sugar $\quad \times 100 \%)$

OD without sugar 


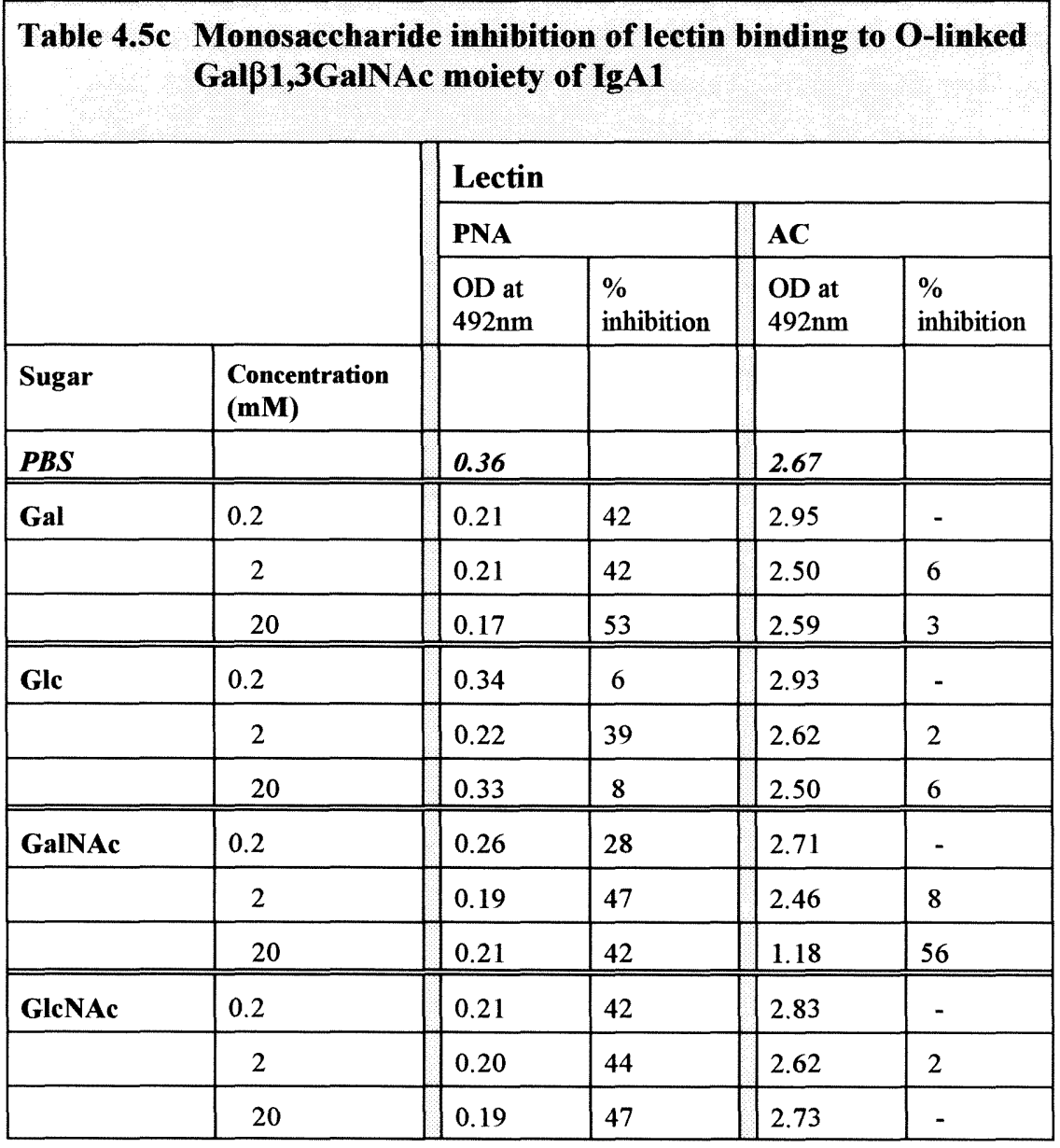

The \% inhibition of the binding of each lectin by each sugar was calculated from :

$\%$ inhibition $=100 \%-\quad($ OD with sugar $\quad \times 100 \%)$ OD without sugar 


\begin{tabular}{|c|c|c|c|c|c|}
\hline \multicolumn{6}{|c|}{$\begin{array}{l}\text { Table 4.6 Monosaccharide inhibition of lectin binding } \\
\text { Summary }\end{array}$} \\
\hline & & \multicolumn{4}{|l|}{ Sugars } \\
\hline & & $\begin{array}{l}\text { Best } \\
\text { inhibitor }\end{array}$ & $\begin{array}{l}\text { Conc" } \\
\text { required for } \\
50 \% \\
\text { inhibition } \\
(\mathrm{mM}) \\
\end{array}$ & $\begin{array}{l}\text { Other } \\
\text { significant } \\
\text { inhibitors }\end{array}$ & $\begin{array}{l}\text { Apparent } \\
\text { specificity } \\
\text { of lectin }\end{array}$ \\
\hline Protein & Lectin & & & & \\
\hline \multirow[t]{2}{*}{ IgG } & TV & GlcNAc & 20 & Gal (slight) & GlcNAc \\
\hline & EC & GalNAc & 20 & Gal;GlcNAc & $\begin{array}{l}\text { GalNAc }> \\
\text { Gal=GlcNAc }\end{array}$ \\
\hline \multirow[t]{7}{*}{ IgAI } & TV & GlcNAc & 8 & - & GlcNAc \\
\hline & EC & $\begin{array}{l}\text { GalNAc } \\
\text { Gal }\end{array}$ & $\begin{array}{l}>20 \\
>20\end{array}$ & GlcNAc & $\begin{array}{l}\text { GalNAc }=\text { Gal }> \\
\text { GlcNAc }\end{array}$ \\
\hline & HA & $\begin{array}{l}\text { GalNAc } \\
\text { GlcNAc }\end{array}$ & $\begin{array}{l}0.22 \\
0.69\end{array}$ & Gal & $\begin{array}{l}\text { GalNAc }> \\
\text { GlcNAc }>>\text { Gal }\end{array}$ \\
\hline & HP & $\begin{array}{l}\text { GalNAc } \\
\text { GlcNAc } \\
\text { Gal }\end{array}$ & $\begin{array}{l}<0.2 \\
0.29 \\
10.5\end{array}$ & Glc & $\begin{array}{l}\text { GalNAc }> \\
\text { GlcNAc }> \\
\text { Gal }>\text { Glc }\end{array}$ \\
\hline & VV & GalNAc & 0.2 & Gal;GlcNAc & $\begin{array}{l}\text { GalNAc }>> \\
\text { Gal }>\text { GlcNAc }\end{array}$ \\
\hline & PNA & Gal & 20 & $\begin{array}{l}\text { GalNAc; } \\
\text { GlcNac }\end{array}$ & $\begin{array}{l}\text { Gal }>\text { GalNAc }= \\
\text { GlcNAc }\end{array}$ \\
\hline & $\mathrm{AC}$ & GalNAc & 20 & - & GalNAc \\
\hline
\end{tabular}




\begin{tabular}{|c|c|c|c|c|c|}
\hline \multirow[t]{3}{*}{ Table 4.7} & \multicolumn{5}{|c|}{$\begin{array}{l}\text { Estimation of non-specific binding of serum } \\
\text { proteins to polyclonal anti-IgA coated } \\
\text { immunoplates }\end{array}$} \\
\hline & \multicolumn{5}{|c|}{$\begin{array}{l}\text { OD at } \\
492 \mathrm{~nm}\end{array}$} \\
\hline & \multicolumn{5}{|c|}{$\begin{array}{c}\text { Sera } \\
1: 2000\end{array}$} \\
\hline Antibody & 1 & 2 & 3 & $\begin{array}{l}\operatorname{Ig} A \\
\text { deficient }\end{array}$ & Blank \\
\hline anti-IgA & 3.58 & 3.69 & 3.62 & 0.11 & 0.07 \\
\hline anti-IgG & 1.46 & 1.28 & 1.06 & 0.96 & 0.86 \\
\hline anti-IgM & 0.23 & 0.46 & 0.26 & 0.59 & 0.05 \\
\hline
\end{tabular}

\begin{tabular}{|c|c|c|c|c|}
\hline Table 4.8 & \multicolumn{4}{|c|}{$\begin{array}{l}\text { Lectin binding to N-linked sugars of } \\
\text { IgA on anti-lgA coated immunoplates } \\
\text { Effect of denaturation }\end{array}$} \\
\hline \multirow[b]{2}{*}{ Lectin } & \multicolumn{2}{|c|}{$\begin{array}{l}\text { No } \\
\text { denature }\end{array}$} & \multicolumn{2}{|l|}{$\begin{array}{l}0.5 \% \\
\text { SDS } \\
\end{array}$} \\
\hline & $O D$ & $T V: E C$ & $O D$ & $T V: E C$ \\
\hline $\begin{array}{l}\text { IgA1 } \\
\text { TV } \\
\text { EC }\end{array}$ & $\begin{array}{l}0.158 \\
0.377\end{array}$ & 0.42 & $\begin{array}{l}0.160 \\
0.343\end{array}$ & 0.47 \\
\hline TV & $\begin{array}{l}0.078 \\
0.936\end{array}$ & 0.08 & $\begin{array}{l}0.088 \\
0.988\end{array}$ & 0.09 \\
\hline $\begin{array}{r}\text { Serum } \\
\text { TV } \\
\text { EC }\end{array}$ & $\begin{array}{l}0.151 \\
0.443\end{array}$ & 0.34 & $\begin{array}{l}0.163 \\
0.418\end{array}$ & 0.39 \\
\hline $\begin{array}{r}\text { Blank }(P B S) \\
\text { TV } \\
\text { EC }\end{array}$ & $\begin{array}{l}0.03 \\
0.03\end{array}$ & & $\begin{array}{l}0.03 \\
0.03\end{array}$ & \\
\hline
\end{tabular}




\begin{tabular}{|l|l|l|}
\hline \multicolumn{3}{|l|}{ Table 4.9 $\begin{array}{l}\text { Lectin binding to O-linked sugars of IgA } \\
\text { on anti-IgA coated immunoplates }\end{array}$} \\
\hline & OD at 492nm \\
\hline Sample & PNA & HA \\
\hline IgAI & 0.865 & 0.466 \\
\hline IgA2 & 0.076 & 0.100 \\
\hline Serum & 0.410 & 0.312 \\
\hline Blank (PBS) & 0.095 & 0.082 \\
\hline
\end{tabular}

Table 4.10 Lectin-binding of normal and IgA deficient serum on antiIgA coated immunoplates

\begin{tabular}{|c|c|c|c|c|}
\hline \multirow[b]{2}{*}{ Sample } & \multicolumn{4}{|c|}{ OD (492nm) } \\
\hline & $T V$ & $E C$ & $P N A$ & $\boldsymbol{H A}$ \\
\hline Normal serum & 0.550 & 0.450 & 0.410 & 0.312 \\
\hline IgA deficient serum & 0.244 & 0.203 & 0.137 & 0.106 \\
\hline Blank (PBS) & 0.133 & 0.183 & 0.095 & 0.082 \\
\hline
\end{tabular}


Figure 4.1

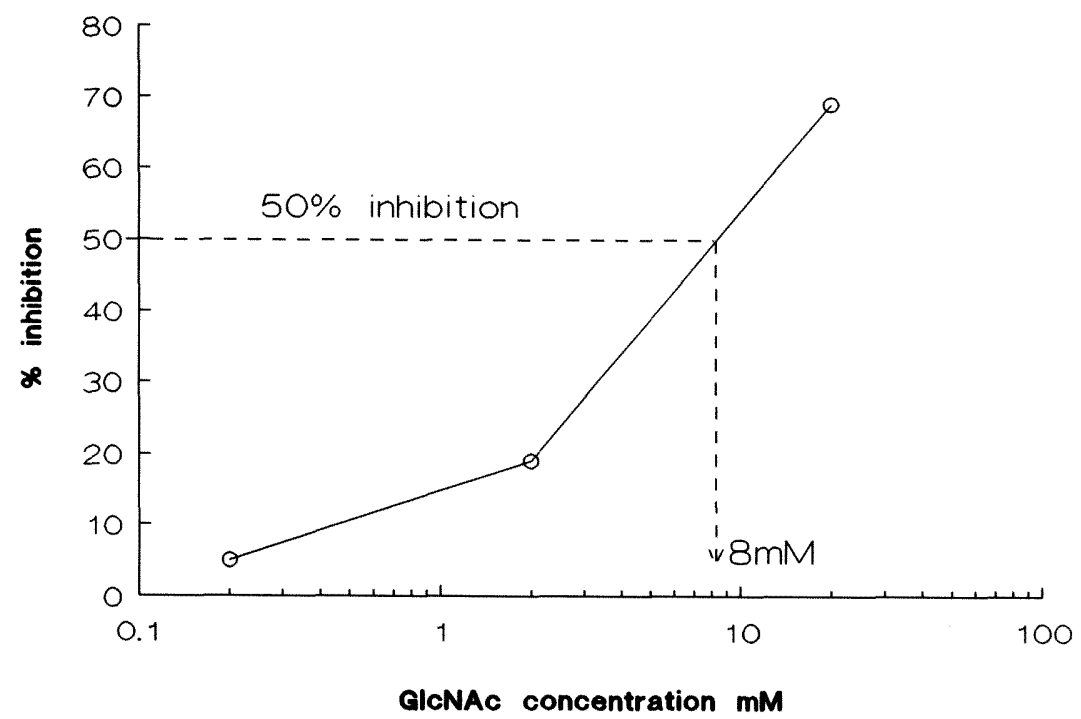

Figure 4.1 Inhibition of TV lectin binding to IgA1 by GlcNAc. The inhibition is dose dependent with regard to the monosaccharide concentration. $50 \%$ inhibition of lectin binding is seen with $8 \mathrm{mM}$ GlcNAc. 
Figure 4.2

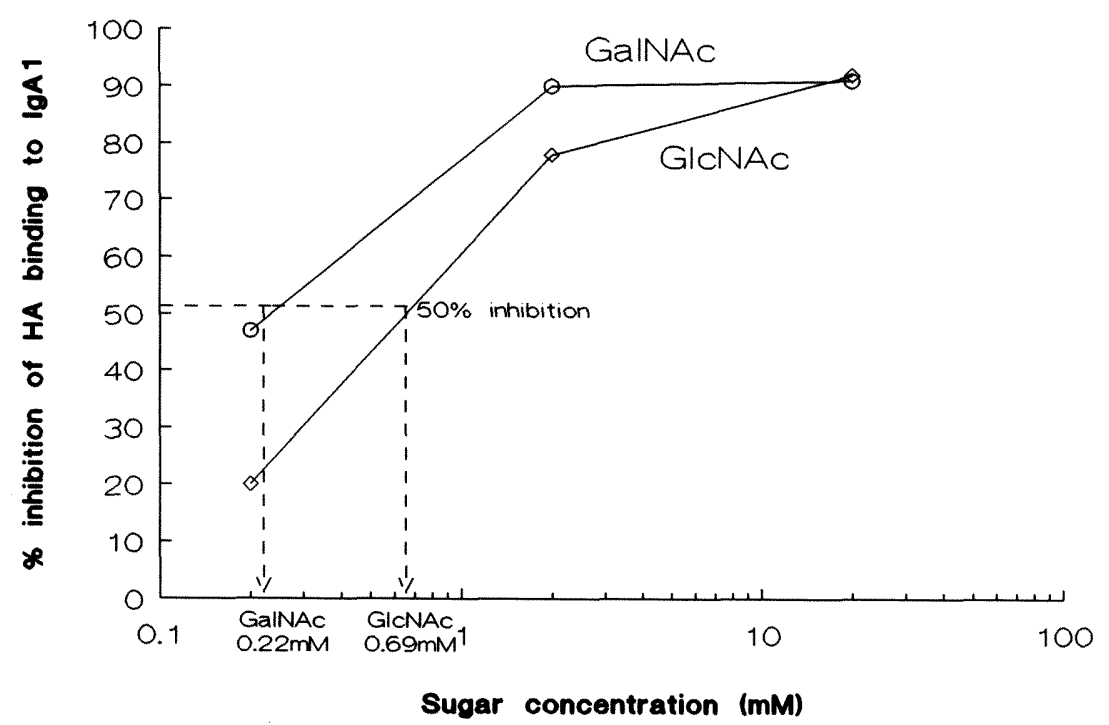

Figure 4.2 Inhibition of HA lectin binding to IgA1 by GalNAc and GlcNAc. Both monosaccharides inhibit lectin binding in a dose dependent manner. GalNAc $(0)$ is the more potent inhibitor $(50 \%$ inhibition at $0.22 \mathrm{mM})$, but GlcNAc $(\diamond)$ also shows significant inhibiting activity $(50 \%$ inhibition at $0.69 \mathrm{mM})$. 
Figure $\mathbf{4 . 3}$

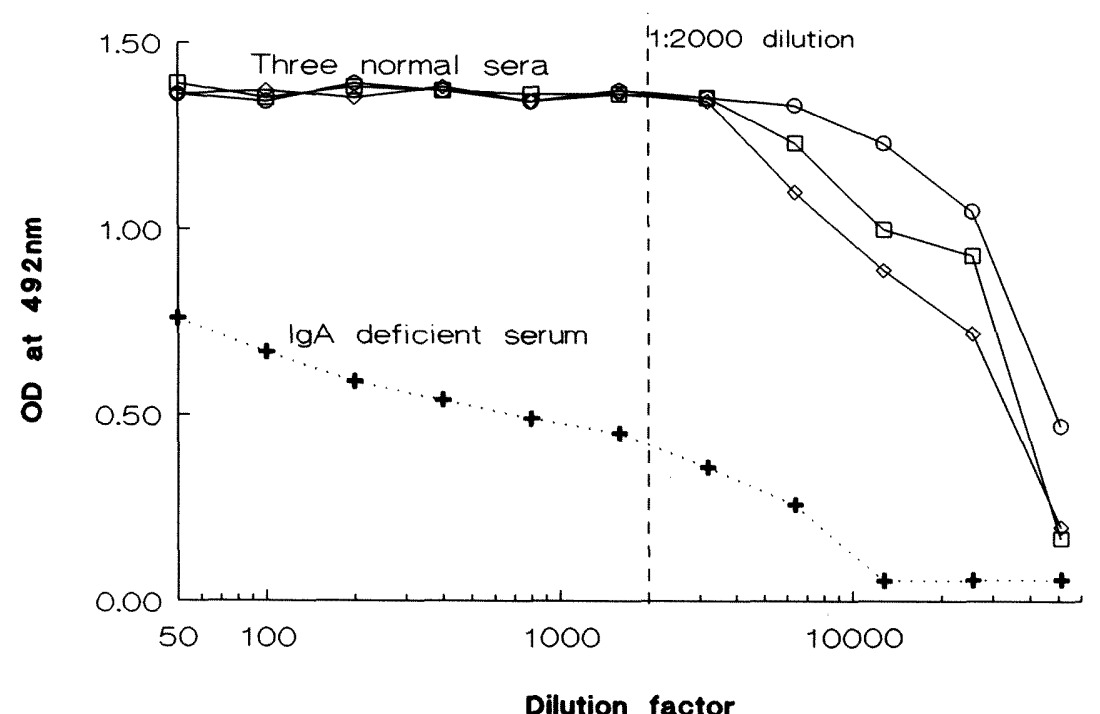

Figure 4.3 Saturation of anti-IgA coated immunoplates by serum $\operatorname{IgA}$. Three normal sera $(\diamond, \circ, \square)$ saturate the binding capacity of the wells at dilutions up to 1:2000. Detectable IgA is captured from an "IgA deficient" serum (+) (containing $80 \mu \mathrm{g} / \mathrm{ml}$ $\operatorname{IgA}$ ) at dilutions above 1:10 000, but the wells are not saturated even at a 1:10 dilution. 


\section{CHAPTER FIVE}

N-linked glycosylation of IgA1 and IgG in IgA nephropathy 


\subsection{Introduction}

A few preliminary studies of IgA glycosylation in IgAN suggest an abnormality, but this is not well characterised, and warrants further study (Andre 1989, Hiki 1992, Coppo 1993, Mestecky 1993). IgA1 is an unusual serum protein in its possession of both $\mathrm{N}$ - and O-linked sugars. The synthetic pathways leading to $\mathrm{N}$ - and $\mathrm{O}$-linked glycosylation of proteins are separate from one another, occurring in different intracellular compartments, and involving different enzymes (Lis 1993). Therefore, it is possible, and indeed quite likely, that an error of IgA1 glycosylation would affect oligosaccharides in one or other of these linkages only. This chapter, and the next, describe studies which aimed to investigate each of these carbohydrate types separately in order to elucidate where the putative glycosylation abnormality of IgA1 lies. In each case, another serum protein carrying similar glycans to those under study was also analysed to establish whether abnormal IgA glycosylation arises from a defect restricted to the synthesis of this molecule, or is more widespread.

The best described glycosylation defect of a serum glycoprotein in disease is that of the N-linked sugars of IgG in rheumatoid arthritis (Parekh 1985, Parekh 1988a, Parekh 1988b). There have been some reports of IgA rheumatoid factor in IgAN (Czerkinsky 1986, Sinico 1986, Sinico 1988, Hiki 1991), and circulating IgA complexes with a variety of other proteins have also been described (Coppo 1993). The proposed role of altered IgG glycosylation in promoting selfaggregation of this molecule (Roitt 1988) suggests the intriguing possibility of a similar phenomenon occurring due to altered $\operatorname{IgA}$ glycosylation in $\operatorname{IgAN}$.

In this study, the terminal galactosylation of the N-linked carbohydrate moieties of IgAl and IgG was investigated in IgAN and matched controls, to look for an abnormality akin to that of IgG in RA. The relative binding of lectins with affinity for terminal galactose or $\mathrm{N}$-acetyl glucosamine was measured in an assay system validated for the study of IgG in RA (Griffiths 1989, Sumar 1990). The IgG glycosylation of a small group of patients with RA and matched controls was also measured in this study, in order to demonstrate that the assay system was effective in identifying the recognised agalactosylation abnormality. 


\subsection{Materials and Methods}

\subsubsection{Subjects}

Serum was obtained from 20 patients with IgAN (14 male; mean age 40 years, range 20-63 years), and 20 controls ( 14 male; mean age 39 years, range 21-62 years). Since IgG glycosylation is known to vary with age, the subjects were carefully matched for this study; the details of the individuals are shown in Table 5.1.

Serum was also obtained from five patients with rheumatoid arthritis, and matched controls (detailed in Table 5.2). The RA patients were recruited from the outpatient clinic of Dr A Samanta at Leicester Royal Infirmary, and gave their informed consent.

\subsubsection{IgA1 and IgG sample preparation}

IgAl and IgG were purified from the sera as detailed in Chapter 3. The purified proteins were exchanged to PBS buffer on Sephadex G25 columns. The purity of each was checked by SDSPAGE, and the concentrations measured by ELISA. Most of the IgAl and IgG samples fell within a concentration range of $200-500 \mu \mathrm{g} / \mathrm{ml}$; the few which were above this level were diluted in PBS, so that all the samples were at approximately the same concentration.

\subsubsection{Lectin binding assay}

The binding of Triticum vulgaris and Erythrina cristagalli lectins to each $\operatorname{IgAl}$ and IgG sample was measured in the method detailed in Chapter 4, Section 4.2.1, applying the purified samples directly to the wells, and denaturing the samples with $0.5 \%$ SDS. The results were expressed as OD at $492 \mathrm{~nm}$. 


\subsubsection{Calculation of the results}

The means of the duplicate wells were calculated, and the background value of each lectin subtracted from the sample ODs. The ratio of TV:EC binding was calculated for each sample to give an indication of the relative occurrence of terminal GlcNAc to Gal. The results of TV, EC and TV:EC for IgA1 and IgG, and of these isotypes in patients with IgAN and matched controls were compared by unpaired $t$-test. Regression analysis was carried out on lectin binding results and the ages of the subjects.

\subsection{Results}

All the IgG and IgA1 samples bound both TV and EC lectins, while background binding was very low in both cases (OD at $492 \mathrm{~nm}$ : $\mathrm{TV}=0.102 ; \mathrm{EC}=0.096$ ). The $\mathrm{TV}$ and $\mathrm{EC}$ OD values depend on the binding dynamics and extent of biotinylation of the individual lectins. These factors will be different for the two lectins, and the OD results cannot be compared directly to one another to indicate actual amounts of terminal GlcNAc or Gal on a single sample. In other words, a higher TV than EC value for a sample does not mean that more moieties terminate in GlcNAc than Gal. However, comparisons of the binding of each individual lectin to a series samples in a single assay run are meaningful; protein samples with high TV binding carrying more terminal GlcNAc units than samples with lower TV binding. Ratios of TV:EC binding have been used by other authors to indicate the relative amounts of terminal GlcNAc to Gal, and have been shown to correlate with $\% \mathrm{G}_{0}$ in IgG (Griffiths 1989, Griffiths 1991). This parameter was also calculated for the IgG and $\operatorname{IgAl}$ samples in the experiments presented here.

\subsubsection{IgG glycosylation in rheumatoid arthritis}

The lectin binding results of $\operatorname{IgG}$ from the five patients with RA and their matched controls are shown in Table 5.3. IgG from subjects with RA showed a slightly higher binding to TV lectin and lower binding to EC lectin than controls, and the TV:EC ratio was correspondingly higher in the RA group. None of these differences reached statistical significance in this small group. When the TV:EC ratio for each subject was plotted against age (Tigure 5.1), the RA subjects did 
appear to have higher ratios than controls, lending support to the usefulness of this method in detecting galactosylation changes in IgG.

The results of TV and EC binding, and the TV:EC ratios for IgA1 and IgG from patients with IgAN and matched controls are shown in Table 5.4

\subsubsection{Comparison of the lectin binding patterns of IgA1 and IgG}

IgAl and IgG showed strikingly and consistently different patterns of binding to TV and EC lectins. In both IgAN and control, IgG had lower TV and higher EC binding than IgAl, and the TV:EC ratios were correspondingly lower for IgG ( $p<0.001$ in all cases). Figure 5.2 shows the TV, EC and TV:EC results for IgA1 and IgG. Lectin binding of IgG and IgA1 from the same subjects showed no correlation (data not shown).

\subsubsection{Variation of lectin binding by $\operatorname{IgA1}$ and $\operatorname{IgG}$ with age}

The lectin binding of IgG did not obviously vary with age in this group of subjects. Figure 5.3 shows subject age plotted against TV:EC ratio for IgAN and control groups together. However, the EC binding of IgA1 showed a significant positive linear correlation with age in both IgAN and controls, and the TV:EC ratio showed a correspondingly negative age correlation, shown in Figure 5.4.

\subsubsection{Comparison of $\mathrm{N}$-linked glycosylation of $\operatorname{IgA1}$ and $\operatorname{IgG}$ in $\operatorname{IgAN}$ and controls}

Figure 5.5 shows the TV, EC and TV:EC results of IgA1 and Figure 5.6 those of $\mathrm{IgG}$ from patients with IgAN and matched controls. Only TV binding of IgA1 differed, with the patients showing slightly but significantly lower binding to this lectin than the controls. IgG lectin binding was normal in IgAN. 


\subsection{Conclusions}

Though both IgA1 and IgG showed strong affinity for both the lectins used in this study, the isotypes differed in their lectin binding profiles. IgA1 bound more GlcNAc-specific TV lectin than IgG, with correspondingly lower binding to EC lectin, and the higher TV:EC ratio of $\operatorname{IgAl}$ reflected this. There was no evidence for a relationship between $\operatorname{IgA1}$ and $\operatorname{IgG}$ glycosylation in either IgAN or control populations; the lectin binding pattern of each isotype was distinctive and unrelated to that of the other. N-linked galactosylation of IgA1 as judged by EC binding increased with the age of the both $\operatorname{IgAN}$ and control subjects. No abnormality of IgG glycosylation was detected in IgAN, and though IgA1 showed lower binding to TV in IgAN, EC binding, and the TV:EC ratio were not different.

\subsection{Biscussion}

The results of this study strongly suggest that the $\mathrm{N}$-linked moieties of $\operatorname{IgA} 1$ have more terminal GlcNAc and less terminal Gal than those of IgG. This is somewhat hard to explain, since IgA1 has been reported to be more N-galactosylated than IgG (Field 1994), though the same authors demonstrated a much higher occurrence of bisecting GlcNAc in IgA1 as compared to IgG $(40 \%$ vs $13 \%$ respectively). The lectin binding profiles of the isotypes were quite distinct from one another, with the TV:EC ratios showing no overlap in either patient or control groups, as shown in Figure 5.2. This cannot be explained by different amounts of protein coating the plates, since one lectin binding was high while the other was low. IgA1 has two N-linked glycosylation sites per heavy chain, while IgG has only one, but again, the difference in total numbers of carbohydrate moieties cannot explain the striking different lectin binding patterns, particularly the TV:EC ratio, which corrects for the number of moieties present. The different N-glycosylation of IgA1 and IgG is also reflected in the lack of correlation between the binding of either lectin, or the TV:EC ratio, of IgAl and IgG samples from the same individuals. The glycosylation of these isotypes appear to result from different control mechanisms, which presumably accompany isotype switching in B cells. 
It is established that IgG galactosylation has a characteristic parabolic relationship with age (Parekh 1988c). This was not apparent in the present study, but the numbers were relatively small, and the age range probably not wide enough to demonstrate it. Interestingly, however, galactosylation of $\operatorname{IgA1}$ did vary with age in these subjects. EC binding showed a significant positive linear correlation with age in both IgAN and control subjects, and the TV:EC ratio correspondingly decreased with age. This contrasts with IgG galactosylation, which is lower later in life. No very young subjects were available for this study, but a full investigation into age variations in IgA glycosylation is warranted by these findings. In the meantime, they underline the necessity for careful matching of patient and control populations in glycosylation studies.

One uncertainty in the interpretation of the data obtained in these studies is the possibility that impurities in the IgG and IgA1 preparations may contribute to the lectin binding results obtained. Though SDS-PAGE and Western blotting of the protein preparations demoustrated that no major contaminants were present (Chapter 3 , Section 3.13), some of the impurities may be heavily Nglycosylated, and therefore make a significant contribution. Western blotting using antibodies to particularly likely candidate proteins, such as transferrin, would help to clarify how much of a problem this is. Similarly, staining Western blots with the lectins themselves would identify contaminating bands likely to interfere in the lectin binding assays.

No striking abnormality of $\mathrm{N}$-linked galactosylation in IgAN was seen in this study. No difference was found in IgG lectin binding. The TV binding of IgA1 was slightly lower in the patient group than in the controls, but this difference was not borne out in the TV:EC ratio. The TV binding of the IgA1 samples in each of the IgAN and control groups showed very little variation, as reflected by the very small errors of the means (Table 5.4), and though the means of the groups were only slightly different, statistically, this was highly significant. It is difficult to know how much biological significance this small discrepancy in TV binding may have. It is possible that it truly reflects an increase in terminal galactosylation of the N-linked sugars, and that the EC lectin fails to corroborate this due to the less specific binding of the latter lectin, which was shown in Chapter 4 , Section 4.3 to be inhibited by GalNAc and GlcNAc as well as Gal. One recent study suggested the converse to this finding; reduced galactosylation of the N-linked glycans of IgAl in IgAN (Dueymes 1994). In this chapter, the binding characteristics of IgG and IgAl to 
TV and EC lectins were inverted, with IgG showing low TV and high EC binding, and IgA1 displaying the opposite. This provides indirect evidence that the two lectins are predominantly recognising different and alternative terminal components of $\mathrm{N}$-linked moieties, rather than $\mathrm{EC}$ binding to both Gal and GlcNAc with equal affinity. The lower EC binding of IgAl than IgG also argues against the extreme non-specificity of EC binding, since IgA1 has GalNAc sugars, whereas IgG does not. For IgG, the TV:EC ratio has been shown to be an adequate measure of $\% \mathrm{G}_{0}$ (Griffiths 1989).

The findings do not indicate a striking abnormality of IgA1 N-galactosylation in IgAN, but the low TV binding warrants further investigation. Analysis of the terminal galactosylation of the Nlinked moieties using other galactose-binding lectins, or antibodies to GlcNAc, as employed for IgG in the method of Sumar (1990) would provide useful information. More precise characterisation of these moieties by high performance liquid chromatography, mâss spectrometry or carbohydrate electrophoresis after release from the protein by exoglycosidases or hydrazinolysis is also indicated. Such investigations are beyond the scope of this thesis. 
Table 5.1 Subjects. IgAN and controls.

\begin{tabular}{|l|l|l|l|l|l|l|}
\hline \multicolumn{5}{|l}{} & \multicolumn{3}{l|}{ Control } \\
\hline IgAN & $\begin{array}{l}\text { Age } \\
\text { (years) }\end{array}$ & $\begin{array}{l}\text { Sex } \\
\text { (M/F) }\end{array}$ & Initial & $\begin{array}{l}\text { Age } \\
\text { years })\end{array}$ & $\begin{array}{l}\text { Sex } \\
\text { (M/F) }\end{array}$ \\
\hline RF & 63 & M & KR & 62 & M \\
\hline JWi & 58 & M & BH & 55 & M \\
\hline AS & 59 & M & RS & 61 & M \\
\hline SA & 41 & M & JFe & 40 & M \\
\hline AM & 21 & M & SD & 21 & M \\
\hline LN & 51 & M & JWa & 51 & M \\
\hline KT & 34 & M & PA & 34 & M \\
\hline DG & 28 & M & MBu & 27 & M \\
\hline VB & 31 & M & SB & 33 & M \\
\hline MBr & 38 & M & SLP & 38 & M \\
\hline YS & 25 & M & SMu & 26 & M \\
\hline CBr & 31 & M & DT & 31 & M \\
\hline TA & 36 & M & AB & 36 & M \\
\hline GS & 38 & M & PS & 37 & M \\
\hline LJ & 44 & F & CBa & 46 & F \\
\hline SMo & 29 & F & AA & 30 & F \\
\hline JFr & 20 & F & CA & 21 & F \\
\hline RT & 39 & F & CL & 39 & F \\
\hline HL & 47 & F & CBe & 46 & F \\
\hline AT & 36 & F & MC & 37 & F \\
\hline
\end{tabular}




\section{Table 5.2 Subjects. Rheumatoid arthritis and controls.}

\begin{tabular}{|l|l|l|l|l|l|l|l|}
\hline RA & \multicolumn{2}{|l|}{} & \multicolumn{2}{|l|}{ Control } \\
\hline Initial & $\begin{array}{l}\text { Age } \\
(\text { years })\end{array}$ & $\begin{array}{l}\text { Sex } \\
(M / F)\end{array}$ & Drug Rx & Initial & $\begin{array}{l}\text { Age } \\
\text { (years) }\end{array}$ & $\begin{array}{l}\text { Sex } \\
(M / F)\end{array}$ \\
\hline JC & 61 & F & $\begin{array}{l}\text { Penicillamine, } \\
\text { prednisolone, } \\
\text { naproxen, } \\
\text { cocodamol }\end{array}$ & E & 62 & F \\
\hline BT & 66 & F & $\begin{array}{l}\text { Azathioprine, } \\
\text { diclofenac }\end{array}$ & M & 62 & F \\
\hline EW & 77 & F & Sulphasalazine & F & 78 & F \\
\hline PG & 47 & M & Methotrexate & MG & 43 & M \\
\hline RH & 73 & M & Sulphasalazine & TW-S & 66 & M \\
\hline
\end{tabular}




\begin{tabular}{|c|c|c|c|c|}
\hline \multirow[t]{3}{*}{ Table 5.3} & \multicolumn{4}{|c|}{$\begin{array}{l}\text { IgG lectin binding in rheumatoid arthritis and } \\
\text { controls }\end{array}$} \\
\hline & & TV & EC & TV:EC \\
\hline & & \multicolumn{2}{|c|}{ OD at $492 \mathrm{~nm}$} & Ratio \\
\hline Mean & $\begin{array}{l}\text { JC } \\
\text { BT } \\
\text { EW } \\
\text { PG } \\
\text { RH }\end{array}$ & $\begin{array}{l}0.85 \\
1.09 \\
1.52 \\
0.85 \\
1.00 \\
\\
1.06\end{array}$ & $\begin{array}{l}2.52 \\
2.38 \\
2.48 \\
2.43 \\
2.51 \\
\\
2.46\end{array}$ & $\begin{array}{l}0.34 \\
0.46 \\
0.61 \\
0.35 \\
0.40 \\
\\
0.43\end{array}$ \\
\hline Controls & $\begin{array}{l}\text { E } \\
\text { M } \\
\text { F } \\
\text { MG } \\
\text { TW-S }\end{array}$ & $\begin{array}{l}0.76 \\
0.82 \\
0.86 \\
0.74 \\
0.93\end{array}$ & $\begin{array}{l}2.42 \\
2.39 \\
2.47 \\
2.66 \\
2.66\end{array}$ & $\begin{array}{l}0.31 \\
0.35 \\
0.34 \\
0.28 \\
0.35\end{array}$ \\
\hline Mean & & 0.82 & 2.52 & 0.33 \\
\hline
\end{tabular}

\begin{tabular}{|c|c|c|c|c|}
\hline Table 5.4 & $\begin{array}{l}\text { ectin bir } \\
\text { d Cont }\end{array}$ & N-linked sug & rs of IgA1 an & IgG in IgAN \\
\hline \multirow[b]{2}{*}{ Sample } & \multirow[b]{2}{*}{ Lectin } & IgAN & Control & \multirow[b]{2}{*}{$p$} \\
\hline & & OD at $492 \mathrm{~nm}$ & Mean $( \pm S E M)$ & \\
\hline \multirow[t]{3}{*}{ IgA1 } & TV & $2.627 \quad(0.021)$ & $2.736(0.015)$ & $<0.001$ \\
\hline & EC & $0.969(0.031)$ & $0.982 \quad(0.029)$ & NS \\
\hline & TV:EC & $2.764(0.093)$ & $2.838(0.095)$ & NS \\
\hline \multirow[t]{3}{*}{ IgG } & $\mathrm{TV}$ & $1.656(0.084)$ & $1.630(0.085)$ & NS \\
\hline & EC & $1.498 \quad(0.038)$ & $1.507 \quad(0.032)$ & NS \\
\hline & TV:EC & $1.131(0.075)$ & $1.093(0.065)$ & NS \\
\hline
\end{tabular}


Figure 5.1

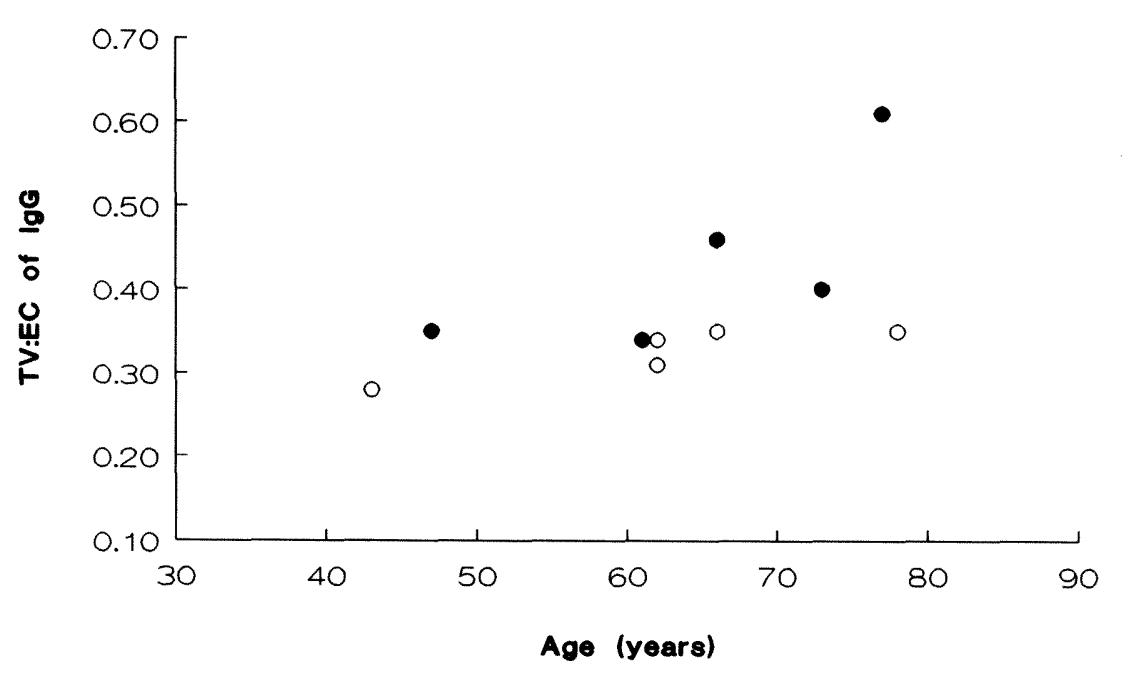

- ra o Controls

Figure 5.1 Variation in IgG galactosylation (TV:EC) with age in subjects with RA and controls. - RA $\circ$ Control. IgG agalactosylation as detected by TV:EC ratio is slightly higher in RA than controls, especially in older patients. This did not reach statistical significance in this small group of subjects. 
Figure $\mathbf{5 . 2}$

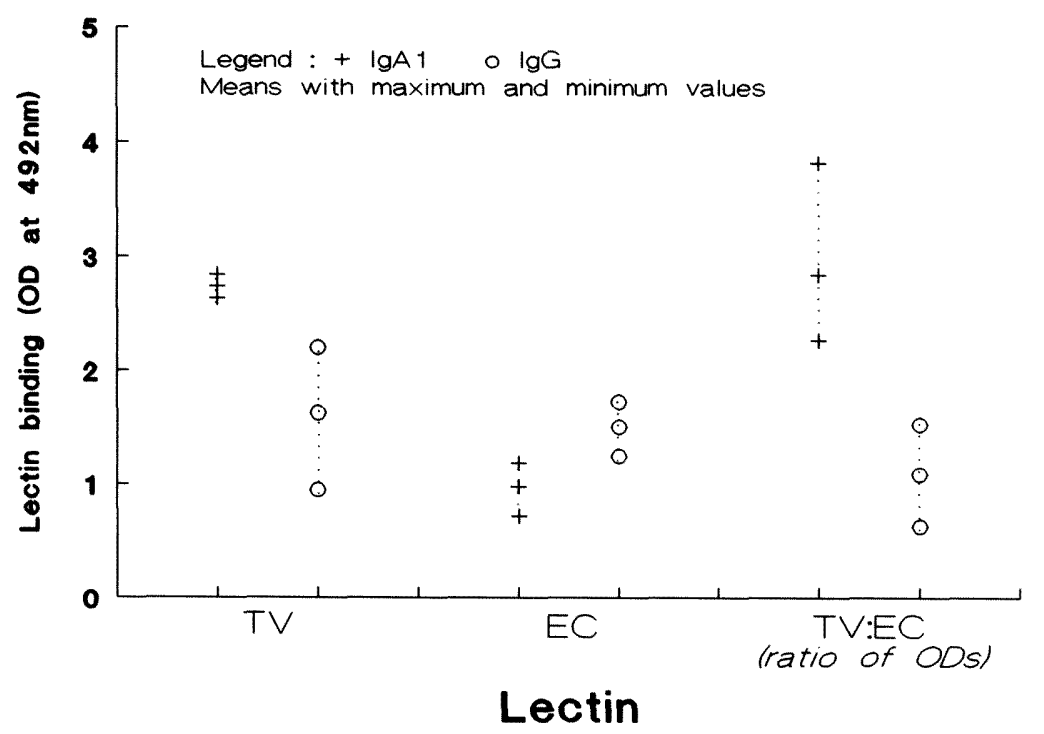

Figure 5.2 Lectin binding to $\mathrm{N}$-linked glycans of IgA1 and IgG. $+\operatorname{IgAl} \circ \operatorname{IgG}$. All subjects included; means with maximum and minimum values. IgAl showed strikingly and consistently higher binding to TV and lower binding to EC than IgG, and the TV:EC ratio of $\operatorname{IgA} 1$ was correspondingly higher in IgAl. 
Figure $\mathbf{5 . 3}$

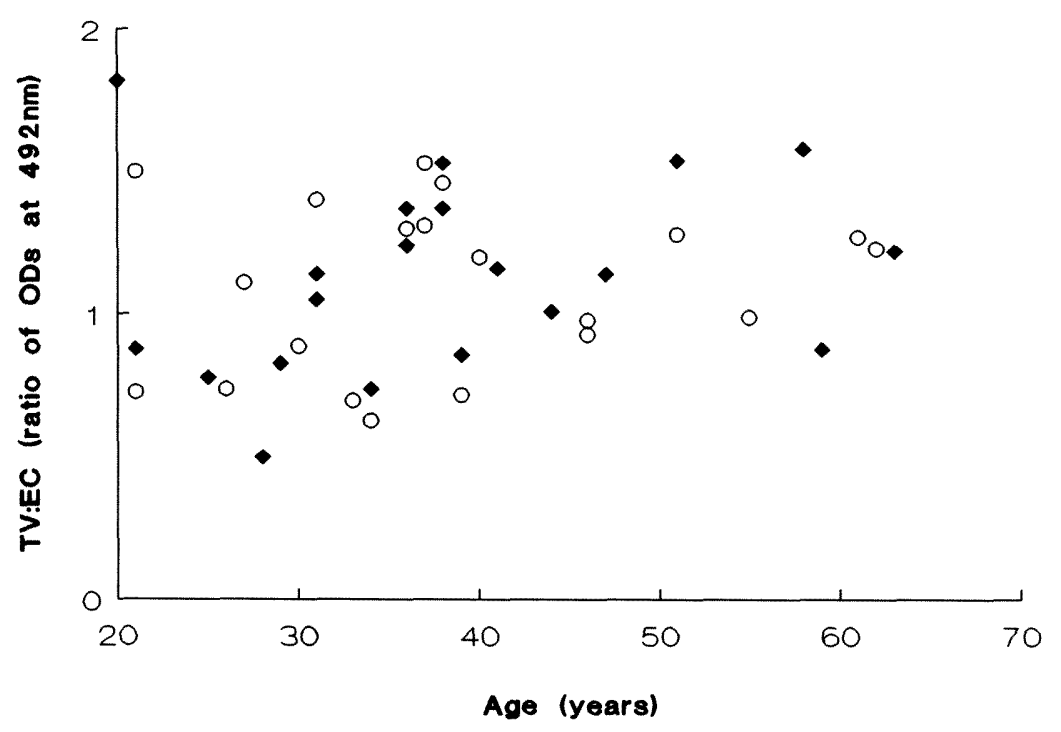

Figure 5.3 Variation in IgG galactosylation (TV:EC) with age in IgAN and controls.

- IgAN, O Control. No obvious age distribution was apparent in either group. 


\section{Figure 5.4}

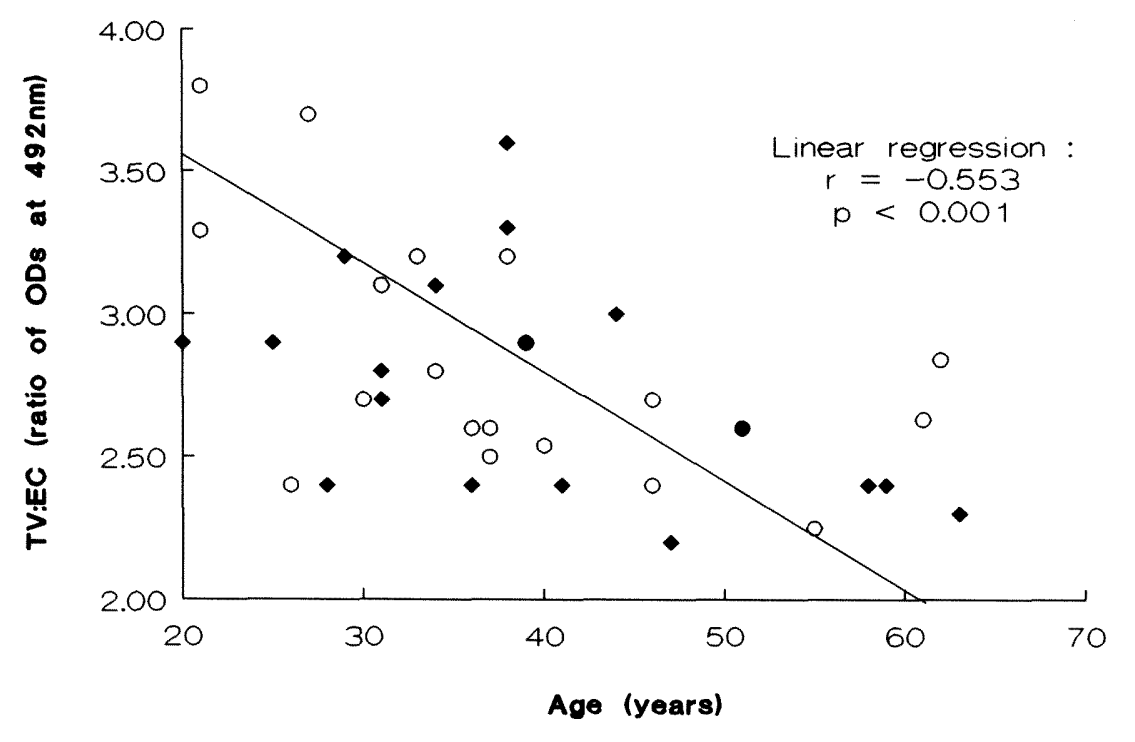

Figure 5.4 Variation in IgA1 galactosylation (TV:EC) with age in IgAN and controls. - IgAN, O Control. Both groups showed a significant linear increase in IgAl galactosylation with age. 


\section{Figure $\mathbf{5 . 5}$}

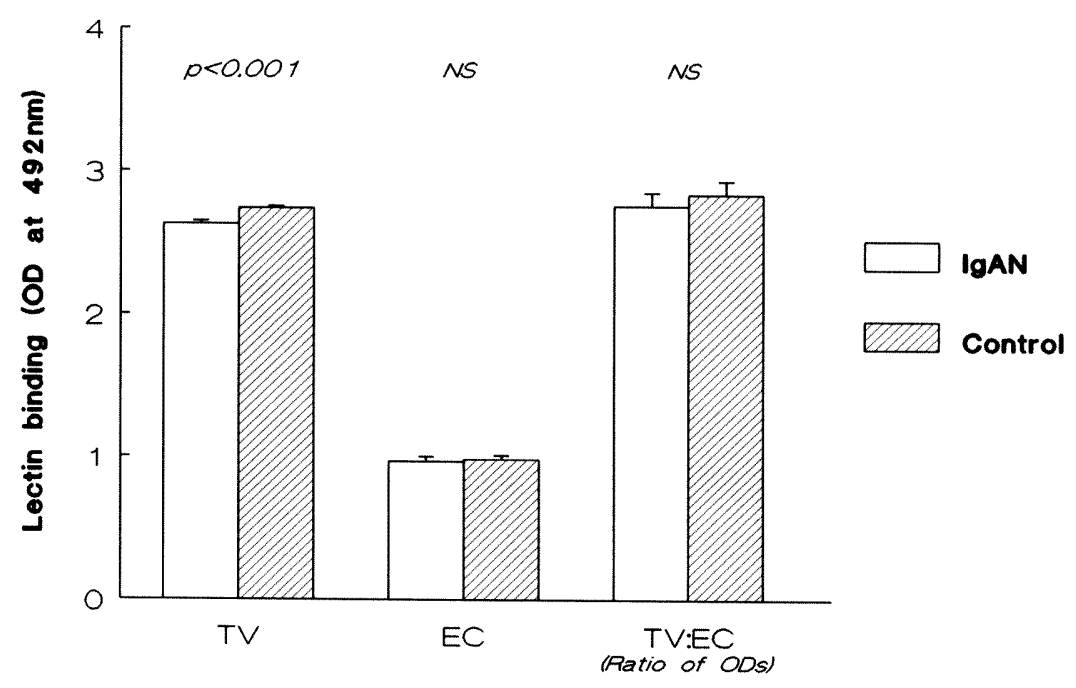

Lectin

Figure 5.5 Lectin binding to N-linked glycans of IgA1 in IgAN and Controls. $\square \operatorname{IgAN}$, II/ Control. IgA1 from patients with IgAN showed a significantly higher binding to TV lectin than IgA1 from controls $(p<0.001)$, but there was no difference between the groups in EC lectin binding or TV:EC ratio. 
Figure 5.6

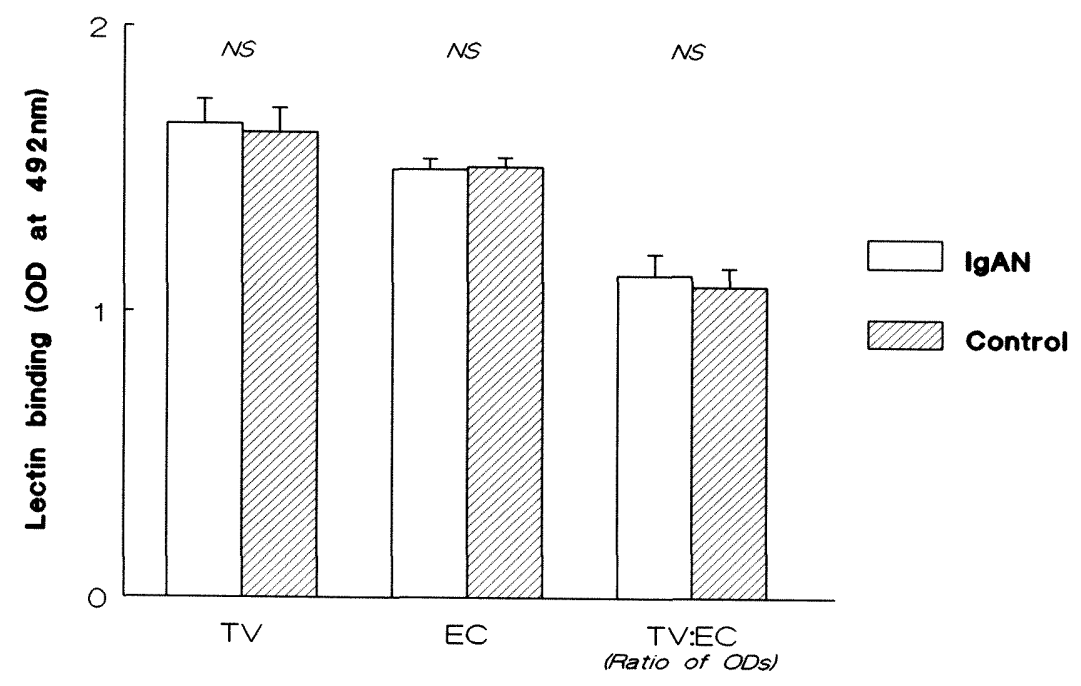

Lectin

Figure 5.6 Lectin binding to $\mathbf{N}$-linked glycans of IgG in IgAN and Controls. $\square \operatorname{IgAN}$, III Control. There was no difference in lectin binding or TV:EC ratio between IgG from patients with IgAN and controls. 


\section{CHAPTER SIX}

O-linked glycosylation of IgA1 and C1 inhibitor in IgA nephropathy 


\section{1 $\quad$ Tntroduction}

O-linked glycans are highly expressed by some cell surface proteins, and characteristic abnormalities of these are well recognised in a range of disease states, most frequently taking the form of agalactosylation of the "T antigen" (Gal $\beta 1,3 \mathrm{GalNAc}$ ). The quintessential example of this is the Tn polyagglutinability syndrome, in which the expression of the agalactosyl neoantigen Tn by erythrocytes, and sometimes platelets and $T$ cells, leads to agglutination and depletion of the affected cells (Lee 1981). The glycosylation defect is directly pathogenic in this rare condition, and arises from lack of activity of the galactosylating enzyme $\beta 1,3 \mathrm{GT}$ (Thurnher 1993). The Tn antigen is also expressed by some types of cancer cells and may arise from the failure of other glycosylation routes, or represent an immature phenotype (King 1994).

There are as yet no well-described abnormalities of O-linked glycosylation affecting serum proteins. Few serum proteins display O-glycosylation; those that do include IgA1, Clinh, plasminogen, human chorionic gonadotropin (HCG) and some cytokines (Hortin 1990). The reports of unusual binding affinity of $\operatorname{IgA}$ for the lectin jacalin in IgAN (Andre 1990, Hiki 1992, Coppo 1993, Mestecky 1993) strongly suggest that the putative glycosylation abnormality in this condition lies in the O-linked glycans. The experiments described in this chapter aimed to confirm and further characterise this by the use of other lectins with affinity for O-linked sugars. The experiments were carried out using both jacalin-purified $\operatorname{Ig} A 1$ samples, and serum samples applied to anti-IgA coated immunoplates, since these two methods have different drawbacks. The lectin binding of Clinh purified from the same sera as the $\operatorname{IgA1}$ was also investigated, to indicate whether defective O-glycosylation is an abnormality restricted to $\operatorname{IgA} 1$ in $\operatorname{IgAN}$, or if other serum proteins are also affected. 


\subsection{Materials and Methods}

\subsubsection{Subjects}

To investigate the lectin binding of the $\mathrm{O}$-linked glycans of IgA1, serum was obtained from 20 patients with IgAN (14 male; mean age 40 years, range 20-63 years), and 20 matched controls (14 male; mean age 39 years, range 21-62 years). These were the same samples as were used to study N-linked glycosylation (Chapter 5); details of the subjects are given in Table 5.1.

To compare the O-glycosylation of IgA1 and Clinh, serum was obtained from a further 12 patients with IgAN (10 male; mean age 46 years [median age 49 years], range 28-62 years) and 12 controls ( 9 male; mean age 33 years [median 33], range 25-42 years). Details of these subjects are shown in Table 6.1. These subjects were not as well matched for age as the other groups used in this study. However, the larger cohort used to examine IgA1 O-linked glycosylation initially (Table 5.1) did not show any variation with subject age (Section 6.3.1).

\subsection{2 $\lg \mathbb{A} 1$ and $\mathbb{C} 1$ imh sample preparation}

For investigation of $\operatorname{Ig} A 1$ lectin binding, $\operatorname{IgA} 1$ was purified from sera as described (Chapter $\mathbf{3}$, Section 3.10). For comparison of paired IgA1 and Clinh samples, these two glycoproteins were purified sequentially from the same serum samples as described in Chapter 3 , Section 3.11. The concentrations of the samples were measured by ELISA, and adjusted to equality in PBS (IgA1 samples to $50 \mu \mathrm{g} / \mathrm{ml}$; Clinh samples to $20 \mu \mathrm{g} / \mathrm{ml}$ ).

\subsubsection{Lectin binding assays}

The O-glycosylation of serum IgA1 from the 20 matched IgAN and control subjects was analysed in two ways :

- The binding of Helix aspersa, Helix pomatia, Vicia villosa, Amaranthus caudatus and Arachis hypogaea lectins to the purified IgAl samples applied directly to uncoated 
immunoplates was measured as described in Chapter 4 , Section 4.2 .1 , without sample denaturation.

- The binding of lectins from Helix aspersa and Arachis hypogaea to serum applied to antiIgA coated plates was measured using the method described in Chapter 4 , Section 4.4.2. The sera were diluted to 1:1000 in PBS, and were not denatured prior to application of the lectins.

In addition, the binding of Helix aspersa, Vicia villosa, and Amaranthus caudatus lectins to paired IgAl and Clinh samples was measured, applying the purified proteins directly to the wells as described in Chapter 4 , Section 4.2.1.

\subsubsection{Calculation of the results}

The results were expressed as OD at 492nm. Mean ODs of duplicate wells were calculated, and the appropriate background values subtracted. Lectin binding of IgAN and control groups were compared by unpaired $t$-test. Regression analysis was used to analyse the relationships between the binding of the different lectins to purified $\operatorname{IgA} 1$ and serum applied to anti-IgA coated plates, $\operatorname{IgA} 1$ and $\mathrm{Clinh}$, and to look for variations in lectin binding with age of the subjects.

\subsection{Results}

All the lectins showed detectable binding to all the $\operatorname{IgAl}$ and Clinh samples used in this study; background (no sample) ODs ranged between 0.150 and 0.620 and were subtracted from sample values for each lectin.

The results of lectin binding to purified $\operatorname{IgA} 1$ samples and serum $\operatorname{IgA}$ immobilised on anti-IgA coated plates are shown in Table 6.2. The binding results of paired IgA1 and Clinh samples to each lectin in the IgAN and control groups are shown in Table 6.3. 


\subsubsection{General observations on lectin binding to O-linked moieties}

\section{Lectin binding to GalNAc}

The lectins from Helix aspersa (HA), Helix pomatia (HP) and Vicia villosa (VV) bind to ungalactosylated O-linked GalNAc, VV lectin having the strongest specificity. The binding of all these three lectins to purified IgA1 from both the $\operatorname{IgAN}$ and control groups showed strong positive correlations to one another ( $p \leq 0.001$ in all cases). Taking all $40 \operatorname{IgA} 1$ samples from both IgAN and controls as a single group to compare the binding characteristics of the lectins, HA and HP showed extremely close correlation $(\mathrm{r}=0.955, \mathrm{p}<0.001)$, while VV lectin showed a less strong, but still highly significant correlation with HA $(x=0.78, p<0.001)$ and $\mathrm{HP}(x=0.798, p<0.001)$.

This information is summarised in Table 6.4 .

Though all the Clinh samples bound both HA and VV lectins, no correlation between the binding of these lectins was apparent in the IgAN or control groups, or when all $24 \mathrm{C} 1 \mathrm{inh}$ samples were grouped together. Similarly, no correlation between the $\operatorname{IgA1}$ and Cliwh binding of either lectin was observed.

\section{Lectin binding to Gal $\beta 1,3$ GalNAc}

Arachis hypogaea (PNA) and Amaranthus caudatus (AC) lectins both have preferential affinity for the galactosylated form of O-linked glycans. AC lectin had very high affinity for all the purified IgA1 samples, while PNA binding was much more variable, with some samples giving results only marginally above background, while others showed strikingly high binding to this lectin. There was no correlation between AC and PNA binding in either IgAN or control groups, or when all the samples were grouped together (Table 6.4).

$\mathrm{Clinh}$ also showed high affinity for $\mathrm{AC}$ lectin, again with little variation between samples. There was no correlation between AC binding of the paired IgA1 and Clinh samples. 
Comparison of lectin binding results of $\operatorname{IgAI}$ obtained by different methods of $\operatorname{IgAI}$ isolation

Binding to HA and PNA lectins to IgA immobilised from serum by application to anti-IgA coated immunoplates was compared to that of IgA1 purified from the same samples on jacalin agarose. In IgAN, the HA and PNA binding of the samples measured by the two different methods showed significant correlation by linear regression analysis (HA $1=0.642, p=0.002$; PNA $r=0.582$, $\mathrm{p}=0.007$ ), but this was not seen in controls $(\mathrm{HA} r=0.374, \mathrm{p}=\mathrm{NS}$; PNA $1=-0.16, p=N S$ ).

Age variation of O-galactosylation

No clear relationship could be seen between subject age and $\operatorname{IgA} 1$ binding to any of the lectins with affinity for $\mathrm{O}$-linked glycans in either the IgAN or control groups.

\subsubsection{O-linked glycosylation of $\operatorname{Ig} \mathbb{A} 1$ in $\operatorname{Ig} \mathbb{A N}$ and controls}

Figure 6.1 compares the lectin binding of purified IgA1 in IgAN and control groups. IgA1 from patients with IgAN showed significantly higher binding to all three GalNAc-specific lectins than did IgA1 from matched controls ( $p<0.001$ in all cases). There was no difference in the IgA1 binding to PNA or AC lectins between the patient and control groups.

HA and PNA binding of IgA immobilised on IgA-coated plates rather than jacalin purified was also measured using the same serum samples. The results are shown in Table 6.2. Again, HA binding was significantly higher in IgAN than control. In this case the IgAN samples also showed significanly higher binding to PNA than did control samples.

\subsubsection{O-linked glycosylation of $\operatorname{Ig} \mathbb{A}$ and $\mathbb{C}$ linh in $\operatorname{Ig} \mathbb{A}$ and controls}

Tigure 6.2 compares the lectin binding of Clinh in IgAN and controls groups, and Figure 6.3 shows the lectin binding of $\operatorname{IgAl}$ purified from the same sera as the Clinh. These data are also presented in Table 6.3. In IgAN, IgAl again showed significantly higher binding to the GalNAc specific lectins HA and VV, while AC binding did not differ from control. Clinh from IgAN had similar HA and AC binding as control, while VV binding was lower in IgAN. 


\subsection{Conclusions}

All the IgA1 and $\mathrm{Clinh}$ samples bound all the lectins, demonstrating that both Gal $\beta 1,3 \mathrm{GaINAc}$ and GalNAc are carried by these molecules, in a structural formation which renders them accessible to the extemal environment without denaturation of the protein molecule. Comparison of the binding profiles of the lectins to the series of samples demonstrated that the lectins with affinity for GalNAc (HA, HP and VV) all recognise a similar target on IgA1. However, they bound to $\mathrm{Clinh}$ in a different pattern to one another, suggesting that the O-linked glycans in this glycoprotein are not present in exactly the same arrangement as those of IgA1. The Gal $\beta 1,3$ GalNAc specific lectins (PNA and AC) showed very different binding patterns from one another with both $\operatorname{IgAl}$ and $\mathrm{Clinh}$; they have maximum affinity for different parts of this more complex moiety, and the degree of sialylation also affects their binding. In addition, PNA was shown in Chapter 4, Section 4.3 to be rather non-specific in its binding affinity.

Lectin binding patterns by IgAl and Clinh purified from the same sera showed no relationship, suggesting that their glycosylation is effected under different control mechanisms. In this relatively small study, no clear age variation in $\mathbf{O}$-linked glycosylation was apparent

The expression of terminal GalNAc by IgAl from patients with IgAN was strikingly and consistently higher than that of controls, with all the GalNAc specific lectins showing significantly higher binding in IgAN. The increased HA binding in IgAN was also seen when measured by a different method, immobilising $\operatorname{IgA}$ from serum on anti-IgA coated plates rather than purifying it first.

No difference in Gal $\beta 1,3 \mathrm{GalNAc}$ expression was observed in jacalin-purified IgA1, as judged by PNA and AC binding, but the PNA binding of anti-IgA immobilised IgA was raised in IgAN

The increase in GalNAc expression was not shared by Clinh in IgAN; indeed, this molecule actually had reduced affinity for one of the GalNAc-specific lectins (VV) in the patients. 


\subsection{Discussion}

The O-linked moieties of the IgA1 hinge region are short and simple in comparison to $\mathrm{N}$-linked glycans, but nonetheless, at least five different forms occur in serum $\operatorname{IgAl}$ :

- asialo GalNAc

- monosialo GalNAc

- $\quad$ asialo Galß1,3GalNAc

- monosialo Galß1,3GalNAc

- disialo Gal $\beta 1,3$ GalNAc

(Field 1989)

Since each $\operatorname{IgAl}$ monomer has ten potential O-glycosylation sites in the hinge region, a bewildering array of different glycoforms are possible.

These studies used of a range of lectins with affinity for different $\mathrm{O}$-linked oligosaccharides in an attempt to provide information about the relative predominance of these various possible glycoforms in IgAl purified from serum. For comparison, the lectin binding of $\mathrm{Cl}$ inh was also investigated, since it is one of the few other serum proteins with $\mathrm{O}$-linked glycosylation.

Various observations were made about the binding characteristics of the lectins to $\operatorname{IgA1}$ and Clinh. Three GalNAc-binding lectins were used: HA, HP and VV. HA and HP come from closely related Helix snail species, while $\mathrm{VV}$ is derived from a vetch plant, and was shown in Chapter 4, Section 4.3 to be the most specific of the GalNAc-binding lectins. The binding patterns of these lectins to $\operatorname{IgAl}$ were closely correlated to one another, though with VV the relationship was less strong than for the other two lectins. HA and VV showed completely different binding patterns to $\mathrm{Clinh}$. This reflects the slightly different binding characteristics of the lectins from the phylogenetically unrelated snail and vetch, and the somewhat different specificities. The affinity of VV lectin is reportedly partly dependent upon the amino acid sequence in the vicinity of the O-linked GalNAc (Sharon 1989), while the Helix lectins are almost as strongly inhibited by GlcNAc as GalNAc. The lectins from the two Helix species unsurprisingly have very similar binding characteristics, and the molecules probably have a high 
degree of homology. The different amino acid sequences and tertiary and quaternary structures of the O-glycosylated domains of IgA1 and Clinh, and differences in their GlcNAc content, probably account for the lack of correlation between HA and VV binding of these two proteins. The degree of O-glycosylation is approximately the same, with $\operatorname{IgA1}$ having ten sites per monomer, and Clinh eleven (Hortin 1990).

The two Gal $\beta 1,3$ GalNAc binding lectins used, PNA and AC, are known to have very different binding characteristics, and this was borne out by these experiments. PNA binding varied immensely between the IgA1 samples, with some hardly binding it at all, and others having high affinity for it. PNA is very sensitive to sialylation of the moiety (Osawa 1987) and is inhibited by a variety of monosaccharides (Chapter 4 , Section 4.3 ), making it very difficult to interpret data obtained from its binding. AC binding is not affected by substitution with sialic acid or other groups, and is inhibited by high concentrations of GalNAc only. All the samples showed approximately the same degree of $\mathrm{AC}$ binding.

IgA1 from patients with IgAN bound all three GalNAc specific lectins to a significantly higher degree than that from controls. The fact that this was consistently demonstrated by both Helix derived lectins and Vicia villosa lectin suggests that the difference can be attributed to an increase in the expression of O-linked GaINAc by IgA1 in IgAN. Furthermore, IgA immobilised from serum on anti-IgA coated plates showed the same increase in HA binding in IgAN. The main criticism of this latter method is that $\operatorname{IgA} 2$ is also captured by the anti-IgA, and the increased binding of lectins to O-linked sugars in IgAN may be due to the well recognised increase in IgA1 levels and $\operatorname{IgA1}: \operatorname{Ig} A 2$ ratio in these patients. On the other hand, the main criticism of jacalinpurification of $\operatorname{IgA} 1$ is that it may not provide a representative selection of IgA1 molecules. The finding that lectin binding to O-linked GalNAc is increased by both these methods strongly suggests that it is a real phenomenon and not a technical artefact. The finding of increased PNA binding to the anti-IgA immobilised samples from patients with $\operatorname{IgAN}$ is more difficult to understand. It may indicate that serum $\operatorname{IgA} 1$ has increased expression of both GalNAc and Gal 1 1,3GalNAc in IgAN. However, it may be due to the non-specificity of PNA, which was shown in Chapter 4 , Section $\mathbf{4 . 3}$ to be inhibited by galactose, GalNAc and GlcNAc; it may therefore simply be demonstrating the same increased GalNAc expression as suggested by HA. 
Analyses of the O-linked sugars of normal serum and myeloma IgA1 indicate that ungalactosylated GalNac usually accounts for one in five of the glycans (Baenziger 1974b, Field 1989). The reason for the increase in ungalactosylated GalNAc expression in IgAN is not clear from these studies, but can be speculated upon. Possible mechanisms include :

- altered conformation of the molecule in the hinge region, leading to increased accessibility of the usual ungalactosylated moieties

- a difference in the amino acid sequence in the area resulting in more O-glycosylation sites, some being agalactosyl a normal number of O-glycosylation sites, with more than usual lacking terminal galactose

- a normal number of O-glycosylation sites, with further GalNAc units substituting some of the Gal $\beta 1,3 \mathrm{GalNAc}$ moieties

The first two of these possiblities require some alteration in the protein component of the $\operatorname{IgA} 1$ molecule. There is no evidence for a gross abnormality of the protein sequence or tertiary or quaternary structure of $\operatorname{IgA} 1 \mathrm{in} \operatorname{IgAN}$, though a subtle mutation in the hinge region cannot be discounted.

The latter two possibilities implicate an abnormality in the carbohydrate component, which is intriguing in the light of recent descriptions of other diseases associated with aberrant protein glycosylation, such as IgG agalactosylation in rheumatoid disease (Parekh 1985), and Tn expression in the Tn polyagglutinability syndrome (Lee 1981). The glycosylation defect in both these well-described examples takes the form of a failure of terminal galactosylation of $\mathrm{N}$ - and $\mathrm{O}$ linked moieties respectively. It is possible that the increased GalNAc expression of IgA1 in IgAN arises from a similar defect, particularly since the affected moiety in TnPS is identical to that of the IgA1 hinge region, albeit in a different, cell surface protein. Failure of terminal Ogalactosylation of GalNAc in a normal IgA1 hinge region would be expected to result in increased expression of GalNAc, in parallel with reduced expression of Gal $\beta 1,3$ GalNAc. No such decrease 
in Gal $\beta 1,3$ GalNAc expression could be detected in this study. On the contrary, increased PNA binding was seen in IgAN when IgA was immobilised on anti-IgA, though this data is difficult to interpret due to the non-specificity of the lectin. Jacalin separation may be responsible for the lack of detectable changes in Gal $\beta 1,3$ GalNAc expression in the experiments with purified IgA1. Indeed, this method of purification may be expected to "normalise" the IgAl glycosylation profile of the purified sample, since the molecules with the least terminal galactosylation may be lost. Despite this, the IgA1 samples in IgAN showed increased binding to GalNAc specific lectins, and it may be that the full range of serum IgA1 in these patients is in fact still more abnormal in this respect, a speculation partly supported by the experiments ou anti-IgA coated plates. Other studies have demonstrated reduced binding of serum IgA1 to jacalin in IgAN (Andre 1990, Coppo 1993, Mestecky 1993), and also reported a reduction in total galactose content of the IgA1 (Mestecky 1993), providing further evidence that simple GalNAc is expressed instead of Gal $\beta 1,3$ GalNAc. The lectin binding results may be explained by the presence of an extra GaINAc substituting the Galß1,3GalNAc moiety, forming a branched trisaccharide which presents GalNAc to the external environment or prevents jacalin binding to the Gal $\beta 1,3$ GalNAc moiety. Such a possibility cannot be discounted, though this trisaccharide is not a moiety that has been found in IgA1. On the other hand, agalactosyl GalNAc is a minority constituent of normal serum IgA1, and protein agalactosylation is recognised as a disease-associated phenomenon, suggesting that truncation of some of the usually galactosylated moieties is perhaps the most plausible explanation of the data.

Raised expression of terminal GalNAc in IgAl may arise from two basic mechanisms :

- a synthetic defect, either a failure of galactosylation or inappropriate addition of further GalNAc

- a degradative process, such as the enzymatic removal of terminal galactose by circulating galactosidases

A precedent for a synthetic defect is set by RA and the TnPS, in both of which agalactosylation of the affected proteins is due to reduced activity of galactosyltransferases, in B cells and 
erythrocytes respectively (Axford 1992a, Thuraher 1993). To address the possibility that the increased GalNAc expression in IgAN is a widespread phenomenon affecting different $\mathrm{O}$ glycosylation pathways, the lectin binding of serum Clinh was also investigated. Though it is unrelated to IgA1, Clinh is one of the very few other serum proteins with O-linked glycosylation. It has eleven O-linked moieties per molecule, equating well with $\operatorname{IgA1}$, which has ten, and the high affinity of Clinh for jacalin indicates that the moieties are similar to those of $\operatorname{IgAl}$. Though Clinh expresses both Gal $1,3 \mathrm{GaINAc}$ and terminal GalNAc, the lectin binding patterns differed from IgA1. Cliwh from patients with IgAN did not share the increased GalNAc expression of IgA1; on the contrary, VV lectin showed lower binding to Clinh in $\operatorname{IgAN}$. The significance of this is not clear, but it is apparent that the putative defect in the glycosylation mechanism which affects IgA1 in IgAN is not common to all $\mathrm{O}$-glycosylation pathways. Most O-glycosylation activity is involved in the production of cell surface proteins, including IgD, which would be an interesting and relevant molecule to investigate in this context.

The finding that Clinh does not appear to be agalactosyl in IgAN argues against a degradative mechanism for the increased GalNAc expression of IgA1, since any circulating galactosidase activity would probably be expected to affect the O-linked sugars of Clinh as well as IgA1. However, it remains possible that the sugars of $\lg \mathrm{A} 1$ are perhaps more accessible to galactosidase than those of Clinh due to differing sialylation or the influence of their molecular location, or that the degradation occurs within the plasma cell or its immediate environment. 


\begin{tabular}{|c|c|c|c|c|c|}
\hline \multicolumn{6}{|c|}{ Table 6.1 } \\
\hline \multicolumn{3}{|c|}{ IgAN } & \multicolumn{3}{|c|}{ Control } \\
\hline Initial & $\begin{array}{l}\text { Age } \\
\text { (years) }\end{array}$ & $\begin{array}{l}\text { Sex } \\
(M / F)\end{array}$ & Initial & $\begin{array}{l}\text { Age } \\
\text { (years) }\end{array}$ & $\begin{array}{l}\text { Sex } \\
(M / F)\end{array}$ \\
\hline SA & 41 & $\mathbf{M}$ & AS & 32 & $\mathbf{M}$ \\
\hline TW & 62 & $\mathbf{M}$ & $\mathrm{AB}$ & 38 & $\mathbf{M}$ \\
\hline $\mathbf{R R}$ & 57 & $\mathbf{M}$ & PD & 25 & $\mathbf{M}$ \\
\hline MM & 37 & $\mathbf{M}$ & SH & 33 & $\mathbf{M}$ \\
\hline $\mathrm{MC}$ & 44 & $\mathbf{M}$ & $\mathrm{JF}$ & 42 & $\mathbf{M}$ \\
\hline $\mathrm{BB}$ & 52 & $\mathbf{M}$ & DT & 31 & $\mathbf{M}$ \\
\hline DG & 28 & $\mathbf{M}$ & $\mathrm{CB}$ & 31 & $\mathbf{M}$ \\
\hline JWi & 58 & $\mathbf{M}$ & $\mathrm{CT}$ & 35 & $\mathbf{M}$ \\
\hline PI & 50 & $\mathbf{M}$ & $\mathrm{CC}$ & 34 & $\mathbf{M}$ \\
\hline WB & 50 & $\mathbf{M}$ & SC & 34 & F \\
\hline SM & 31 & F & IZ & 31 & F \\
\hline $\mathrm{JWr}$ & 48 & $\mathrm{~F}$ & AA & 32 & $\mathrm{~F}$ \\
\hline
\end{tabular}




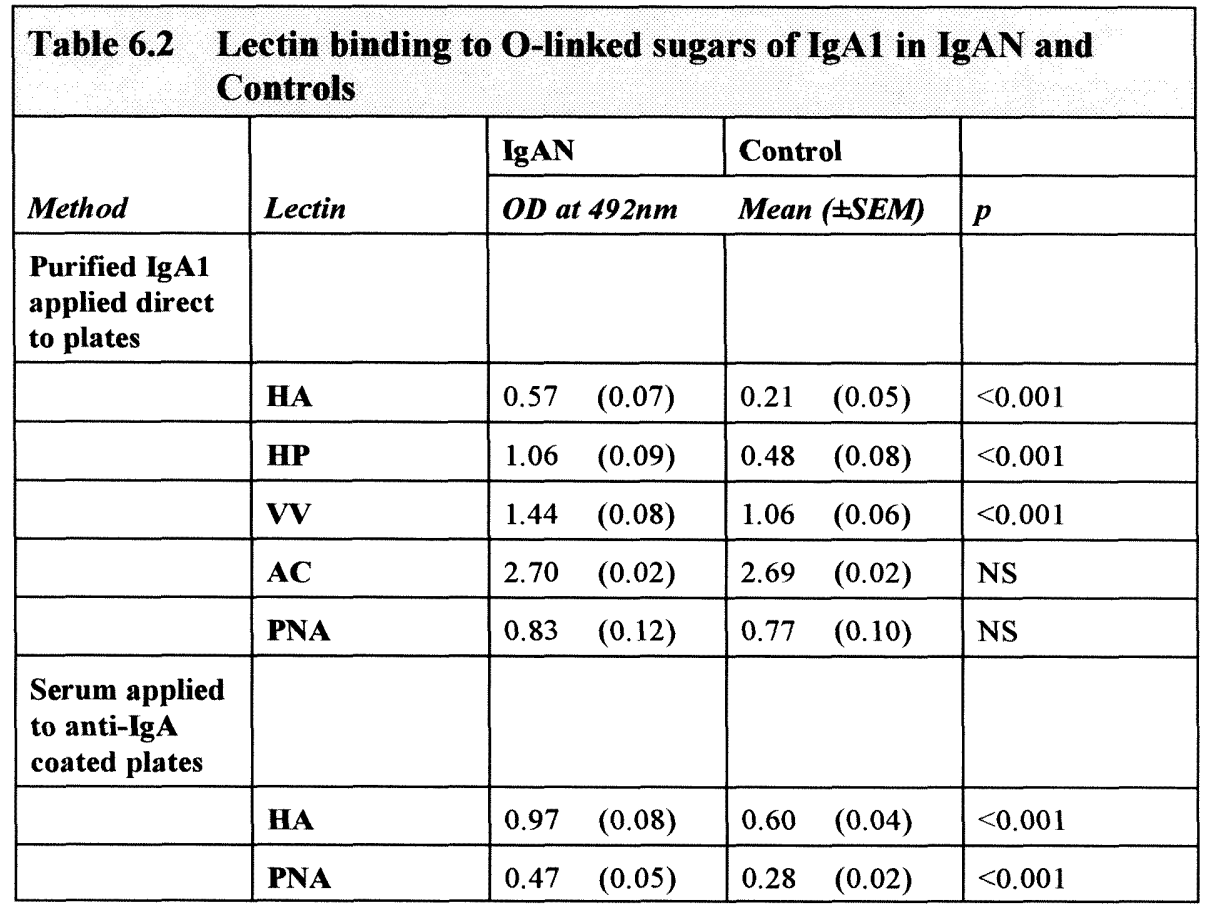




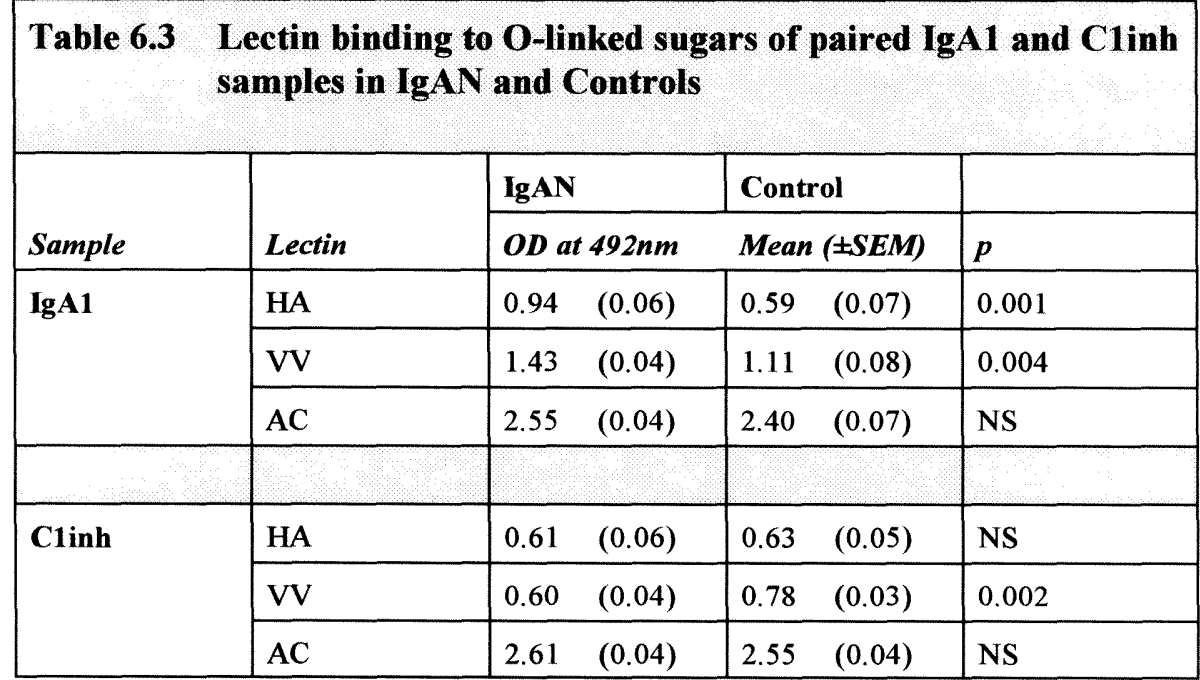




\begin{tabular}{|c|c|c|c|c|}
\hline \multirow[t]{2}{*}{ Tabl } & \multicolumn{4}{|c|}{$\begin{array}{l}\text { Linear regression analysis of the relationships between the } \\
\text { binding of different lectins to IgA1 and Clinh samples } \\
\text { All subjects grouped together }\end{array}$} \\
\hline & & & $\mathbf{r}$ & $\mathbf{p}$ \\
\hline \multicolumn{5}{|c|}{$\operatorname{IgA1}(n=40)$} \\
\hline \multirow[t]{2}{*}{ HA } & vs & HP & 0.955 & $<0.001$ \\
\hline & & $\mathbf{V V}$ & 0.780 & $<0.001$ \\
\hline $\mathrm{VV}$ & vs & HP & 0.798 & $<0.001$ \\
\hline \multirow[t]{2}{*}{ HA } & $v s$ & PNA & 0.01 & 0.940 \\
\hline & & AC & 0.190 & 0.230 \\
\hline \multirow[t]{2}{*}{ PNA } & vs & AC & 0.066 & 0.686 \\
\hline & & & . & \\
\hline \multicolumn{5}{|c|}{ C1inh $(n=24)$} \\
\hline \multirow[t]{2}{*}{ HA } & vs & VV & 0.300 & 0.150 \\
\hline & & $\mathbf{A C}$ & 0.174 & 0.417 \\
\hline
\end{tabular}


Figure 6.1

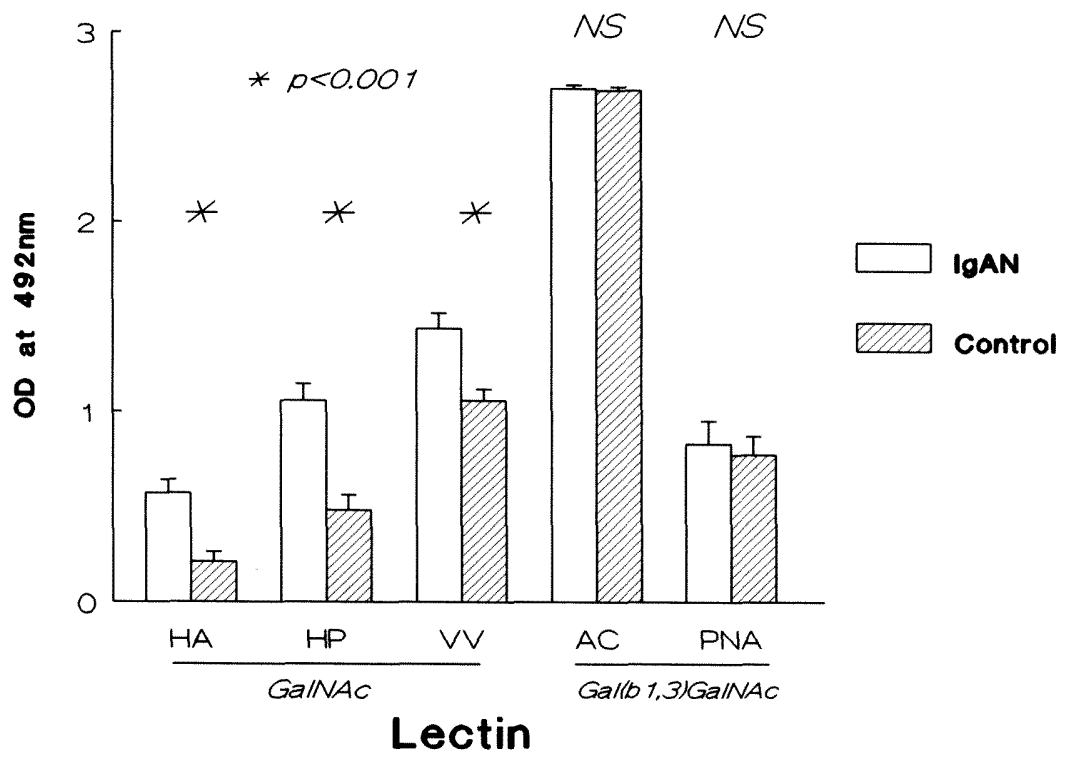

Figure 6.1 Lectin binding to O-linked glycans of purified IgA1 samples in IgAN and controls. $\square$ IgAN, I/I Controls. Lectins with affinity for GalNAc (HA, HP and VV) showed significantly higher binding to IgA1 from patients with IgAN than controls $(p<0.001)$. There was no difference in the binding of lectins with affinity for Gal 1,3 GalNAc (AC and PNA) between the groups. 


\section{Figure 6.2}

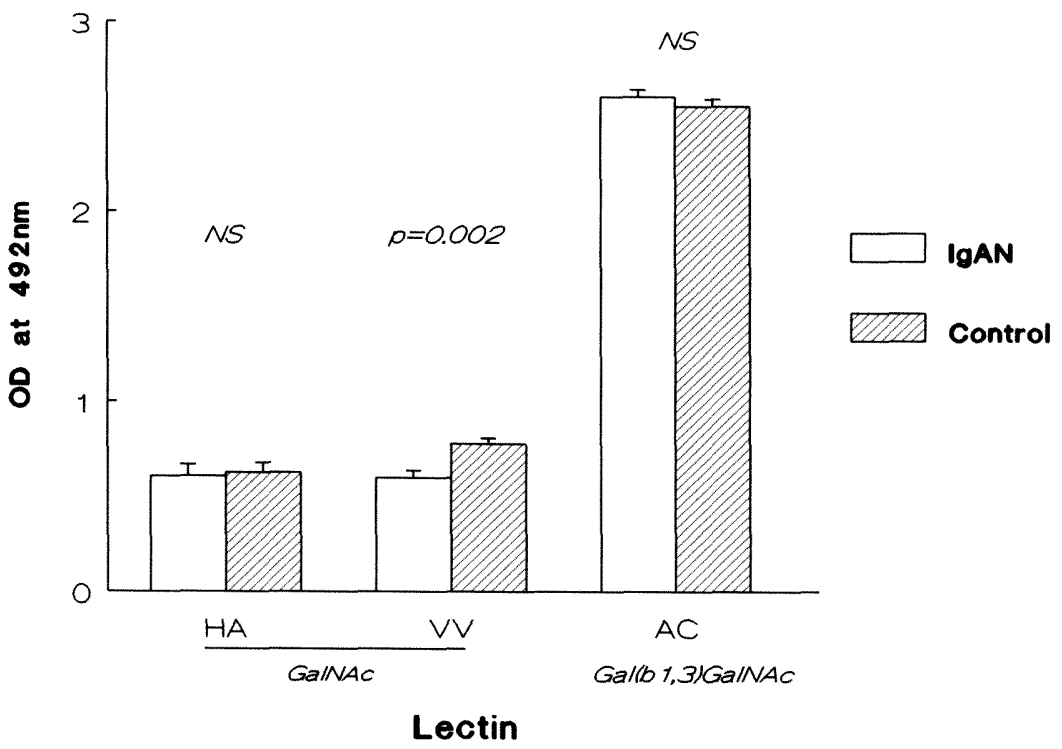

Figure 6.2 Lectin binding to O-linked glycans of purified C1inh samples in IgAN and controls. $\square$ IgAN, I// Controls. There was no difference between $\mathrm{Clinh}$ from IgAN and control in binding to HA or AC lectins, but Clinh from IgAN showed reduced binding to VV lectin in comparison to $\mathrm{Clinh}$ from controls $(p=0.002)$. 
Figure 6.3

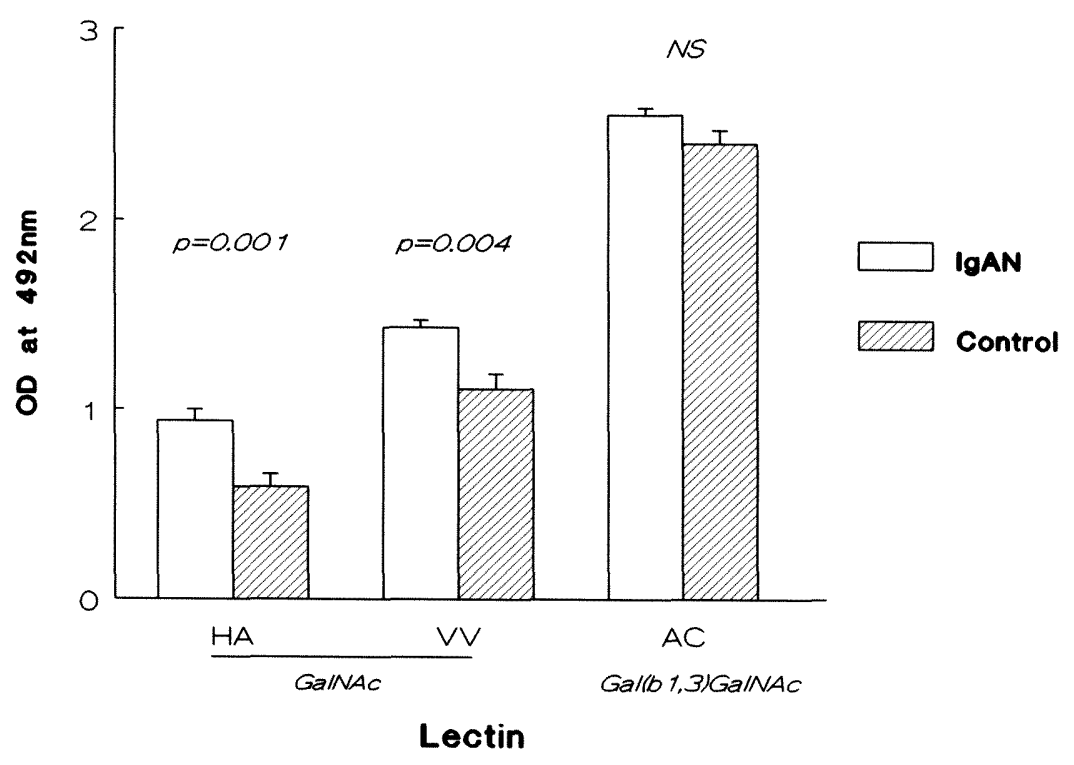

Figure 6.3 Lectin binding to O-linked glycans of purified IgA1 samples in IgAN and controls. IgAl purified from the same sera as the Clinh samples in Figure 6.2. $\square$ IgAN, III Controls. IgA1 from IgAN showed higher binding to HA and VV lectins than IgAl from controls $(p<0.005)$. There was no difference between the groups in IgAl binding of AC lectin. 


\section{CHAPTER SEVEN}

Development of a novel assay system for $\beta 1,3$ galactosyl transferase activity in cell lysates 
The studies described in this thesis so far have demonstrated an abnormality of the O-linked carbohydrate moieties of serum $\operatorname{IgA} 1$ in IgAN. There appears to be unusually high expression of terminal GalNAc, as detected by lectin binding, but the precise nature of the oligosaccharide structure resulting in this aberrant glycosylation profile is unknown. One possibililty is truncation of the usual Galß1,3GaINAc moiety. Terminal agalactosylation of normally galactosylated moieties is a recognised feature of glycoproteins in some diseases such as RA (Parekh 1985) and TnPS (Lee 1981), while reduced total galactose content of $\operatorname{IgA1}$ in $\operatorname{IgAN}$ was reported by Mestecky and colleagues (Mestecky 1993).

Substitution of O-linked GalNAc with galactose in the $\beta 1,3$ configuration is effected by the intracellular enzyme $\beta 1,3$ galactosyltransferase. This protein has not been isolated or cloned, but its activity has been measured in functional assays, and a lack of enzyme activity has been shown to be responsible for the glycosylation defect of an erythrocyte membrane glycoprotein in TnPS (Thurnher 1993). Reduced N-galactosylation of IgG in RA is also due to reduced activity of a galactosyltransferase, in this case B cell $\beta 1,4$ GT (Axford 1987, Axford 1992a).

In the light of these considerations, it was proposed that reduced $B$ cell $\beta 1,3 \mathrm{GT}$ activity may be responsible for the abnormal O-glycosylation of IgA1 in IgAN. In order to test this hypothesis, a suitable method for measuring the activity of the enzyme in B cells purified from the peripheral blood of patients with IgAN and control subjects was required. The experiments in this chapter describe the development of a novel technique designed to achieve this aim. 
Measurement of the functional activity of an enzyme requires a substrate for the enzyme to act upon, and a method of quantifying the effect of this action. $\beta 1,3 \mathrm{GT}$ catalyses the transfer of galactose from the nucleotide donor UDP-galactose (UDP-Gal) to GalNAc in $\alpha 1,4$ O-linkage with serine or threonine in a peptide chain (the acceptor) :

\section{GalNAc- $\alpha-$ Ser/Thr $\quad+$ UDP-Gal $\Rightarrow$ Gal $\beta 1,3 G a l N A c-\alpha-S e r / T h r$ Acceptor $\quad+\quad$ Sugar $\stackrel{\text { enzyme }}{\Rightarrow}$ Reaction product}

Published methods of $\beta 1,3$ GT measurement have used as acceptors the richly $O$-glycosylated protein asialo-submaxillary mucin (ovine or bovine), or p-nitrophenyl-2-acetamido-2-deoxy- $\alpha$-Dgalactopyranoside (GalNAc- $\alpha$-Nph) (Berger 1978, Cartron 1978, Cartron 1979, Piller 1990, Thurnher 1993, King 1994). In all these methods, UDP-Gal radiolabelled with ${ }^{14} \mathrm{C}$ or ${ }^{3} \mathrm{H}$ was used the monosaccharide donor, and the reaction product detected by scintillation counting.

The methods referred to above were all used to detect $\beta 1,3 \mathrm{GT}$ activity in cells with abnormalities of O-glycosylated membrane proteins, namely glycophorins and leucosialin. No study has previously attempted to measure this activity on a secreted protein such as IgA1. Glycosyltransferases show exquisite substrate specificity with respect to both the donor sugar and the acceptor (Roth 1985, Narimatsu 1994, Palcic 1994), and a submaxillary mucin may not be a suitable acceptor for use in an assay of $\operatorname{IgA1}-\beta 1,3 \mathrm{GT}$ activity. An acceptor derived from IgA1 itself would be more appropriate to this application. Tailoring the assay to $\operatorname{IgA} 1$ as much as possible may also result in increased sensitivity, since subtle changes in IgA1 galactosylating activity may easily be "swamped" by membrane protein O-galactosylating activity in the same cells, and thus be difficult to detect.

Lectins with specificity for O-linked GalNAc were successfully used to detect and semi-quantify the glycosylation defect of $\operatorname{IgA} 1$ in IgAN in the experiments previously described in this thesis (Chapters 4 and 6). The same approach was used in this functional assay for $\beta 1,3 G T$, employing Vicia villosa lectin as a tool to detect changes in the degree of terminal galactosylation of $\mathrm{O}$ - 
linked GalNAc moieites resulting from the action of the enzyme. This allowed the use of an ELISA-type assay system, which is practical, simple and convenient, and avoids the necessity of using radioactivity as a detection step.

Glycosyltransferases frequently display a requirement for a metal ion as a co-factor in their catalytic activity (Kleene 1993). In the case of galactosyltransferases ( $\beta 1,4 \mathrm{GT}$ and $\beta 1,3 \mathrm{GT}$ ), this is usually $\mathrm{Mn}^{2+}$ (Palcic 1994); all the functional assays for $\beta 1,3 \mathrm{GT}$ cited above include $\mathrm{MnCl}_{2}$ in the reaction mixture. The effect of various divalent cations on the efficiency of cell-lysate derived IgA1 $\beta 1,3$ GT activity in this assay system was evaluated as part of the assay development procedure.

The assay was based on an ELISA-type system :

- The degalactosylated acceptor was coated on to immunoplates

- The enzyme (as cell lysate samples) and the monosaccharide donor (galactose) were incubated with the acceptor in the wells, to allow galactosylation of the acceptor to proceed

- The degree of galactosylation of the acceptor was measured by Vicia villosa lectin binding

- The enzyme activity of each lysate sample was estimated by comparison of the VV binding of the acceptor with and without incubation with the lysates 


\subsubsection{Preparation of the acceptor}

Enzymatically degalactosylated hinge region fragments of $\operatorname{IgAl}$ from a pool of normal sera were used to provide a suitable acceptor substrate for the activity of the enzyme which galactosylates O-linked GalNAc in the hinge region of IgA1.

\section{Sera}

$50 \mathrm{ml}$ venous blood was obtained from each of 6 normal subjects, allowed to clot and the serum separated as described in Chapter 3, Section 3.3.

\section{Fractionation of serum protein}

A crude immunoglobulin fraction was precipitated from each serum sample with $20 \%$ PEG, as described in Chapter 3, Section 3.4.2. The precipitates were redissolved in $25 \mathrm{ml} 0.2 \mathrm{M}$ $\mathrm{NH}_{4} \mathrm{HCO}_{3}, \mathrm{pH} 8.3$, pooled together, and the protein concentration $(43 \mathrm{mg} / \mathrm{ml})$ measured using the Bio-Rad DC Protein Assay system (Chapter 3, Section 3.6), with standards in the same buffer.

\section{Digestion of crude immunoglobulin fraction}

The pooled PEG precipitate was digested with trypsin and pepsin as described for the preparation of 30-amino acid IgA1 hinge region fragments (Frangione 1972).

$50 \mathrm{ml}$ of the precipitate in $0.2 \mathrm{M} \mathrm{NH}_{4} \mathrm{HCO}_{3}$ (containing $2150 \mathrm{mg}$ protein) was taken, and $\mathrm{L}-1$ Tosylamide-2-phenylethylchloromethyl ketone (TPCK)-treated trypsin added at a concentration of $1: 50 \mathrm{w} / \mathrm{w}(43 \mathrm{mg})$. After overnight incubation at $37^{\circ} \mathrm{C}$ with slow stirring, the trypsin digest was dispensed into plastic containers to a depth of $1 \mathrm{~cm}$, frozen at $-70^{\circ} \mathrm{C}$, and freeze dried at $-40^{\circ} \mathrm{C}$ for 24 hours.

The freeze dried protein digest was redissolved in $30 \mathrm{ml} 5 \%$ formic acid, $43 \mathrm{mg}(1: 50 \mathrm{w} / \mathrm{w})$ pepsin added, and again incubated overnight at $37^{\circ} \mathrm{C}$ with slow stirring. The $\mathrm{pH}$ was adjusted to neutral 
with $2 \mathrm{M} \mathrm{NaOH}$, and the trypsin-pepsin digest passed through a Sephadex $\mathrm{G} 10$ column (Chapter 3, Section 3.7) to exchange the buffer to Tris $\mathrm{HCl}$ (Appendix II).

\section{Isolation of O-glycosylated peptides}

The trypsin-pepsin digest was applied to jacalin agarose, as described in Chapter 3, Section 3.10, and the O-glycosylated peptides eluted with galactose were passed through a Sephadex G10 column to exchange the buffer to PBS. The protein concentration was measured and found to be $254 \mu \mathrm{g} / \mathrm{ml}$.

\section{Enzymatic degalactosylation of the carbohydrate moieties}

Acrylic bead-conjugated $\beta$-galactosidase from Escherichia coli (Sigma) was added to the acceptor preparation in PBS at approximately $2 U$ enzyme/mg acceptor protein, and incubated at $37^{\circ} \mathrm{C}$ ovenuight, with stirriug. The acceptor was transferred to microfuge tubes and spun down hard at $10000 \mathrm{~g}$ for $10 \mathrm{~min}$ in a microfuge to pellet the acrylic beads. The supernatant was decanted and passed through a Sephadex G10 column to remove free galactose.

The degalactosylated acceptor preparation was divided into $5 \mathrm{ml}$ aliquots and stored at $-70^{\circ} \mathrm{C}$

The $\beta$-galactosidase conjugated acrylic beads were stored in $2 \mathrm{M}\left(\mathrm{NH}_{4}\right)_{2} \mathrm{SO}_{4} / 1 \mathrm{mMM} \mathrm{MgCl} \mathrm{Ma}_{2}$ at ${ }^{\circ} \mathrm{C}$ for reuse.

\section{Evaluation of the acceptor preparation}

An attempt was made to determine the molecular weight range of the peptide fragments constituting the acceptor preparation by SDS-PAGE, using $12 \%, 15 \%$ and $20 \%$ separating gels. The protein concentration was measured and found to be $235 \mu \mathrm{g} / \mathrm{ml}$

$50 \mu 1$ aliquots of the acceptor preparation before and after degalactosylation were coated onto wells of an immunoplate and incubated at $4^{\circ} \mathrm{C}$ overnight. The binding of biotinylated Helix aspersa, Vicia villosa, Amaranthus caudatus and jacalin lectins was measured in the assays described and evaluated in Chapter 4 , Section 4.2. The OD values of the binding of the lectins were compared, and indicated that some degalactosylation had taken place. 


\subsubsection{Preparation of a standard cell lysate}

In order to assign arbitrary units to the $\beta 1,3 \mathrm{GT}$ activity of a range of peripheral blood monounclear cell (PBMC) lysates from different subjects, a standard lysate sample was required.

$100 \mathrm{ml}$ venous blood from each of four normal subjects was taken in preservative free heparin and the PBMCs separated by density gradient centrifugation as described in Chapter 3 , Section 3.14.1. Cell lysates were prepared by detergent solubilisation with $0.5 \%$ Nonidet $\mathrm{P} 40$ and sonication as described in Chapter 3, Section 3.14.4. The lysates were pooled and frozen in $50 \mu 1$ aliquots at $-70^{\circ} \mathrm{C}$.

\subsection{3 $\quad \beta 1,3 G T$ assay}

\section{Cell lysates}

Lysate samples for the development and evaluation of this assay were prepared from PBMCs of normal subjects, as described in Chapter 3, Section 3.14. The total protein content of the individual lysate samples was measured by the Bio-Rad DC Protein Assay, as described in Chapter 3, Section 3.6.

Acceptor

Immunoplates were coated with the degalactosylated acceptor in PBS, at $50 \mu 1 /$ well, sealed, and incubated at $4^{\circ} \mathrm{C}$ overnight.

The plates were washed four times in washing buffer (Appendix II) by automated plate washer.

\section{Reaction mixture}

The assay was cartied out in $40 \mu \mathrm{l}$ volumes. The basic reaction mixture consisted of $75 \%(30 \mu \mathrm{l})$ cell lysate sample in $0.5 \%$ Nonidet P40/PBS and 25\% (10 $\mathrm{l}) 4 \mathrm{x}$ reaction buffer (1mM. UDP$\mathrm{Gal} / 80 \mathrm{mM} \mathrm{CaCl} \mathrm{Cl}_{2}$ in PBS, Appendix II). Each lysate sample was run in duplicate wells, and where possible, at more than one protein concentration within the range appropriate for the assay. In addition to the individual lysate samples, blank wells, containing $30 \mu 10.5 \%$ Nonidet P40/PBS 
and $10 \mu 14 \mathrm{x}$ reaction buffer only, and a standard curve were set up on each plate. Doubling dilutions of the lysate standard from 1:2 to 1:4096 were prepared in PBS to construct the standard curve.

The plates were sealed and incubated overnight $(18 \mathrm{~h})$ at $37^{\circ} \mathrm{C}$, then washed again as above.

\section{Detection of $\beta 1,3 G T$ activity by binding of Vicia villosa lectin}

$40 \mu \mathrm{l} /$ well biotinylated VV lectin at $1 \mu \mathrm{g} / \mathrm{ml}$ in PBS was applied to the plates for $90 \mathrm{~min}$ at RT, followed by $40 \mu \mathrm{l} /$ well HRP-conjugated avidin D at $2.5 \mu \mathrm{g} / \mathrm{ml}$ in PBS, again for $90 \mathrm{~min}$ at RT. The colour was developed with $40 \mu \mathrm{l} /$ well $\mathrm{OPD} / \mathrm{H}_{2} \mathrm{O}_{2}$ substrate (Appendix II), and the reaction stopped with $60 \mu \mathrm{l} /$ well $1 \mathrm{M} \mathrm{H}_{2} \mathrm{SO}_{4}$, exactly as described for the lectin binding assays in Chapter 4, Section 4.2. The ODs of the wells were read by automated plate scanner using a $492 \mathrm{~nm}$ filter.

\section{Calculation of $\beta 1,3 G$ T activity in the cell lysate samples}

The means of duplicate wells were calculated. Since $\beta 1,3 \mathrm{GT}$ activity has the effect of lowering VV binding to the acceptor, the mean ODs of the standard dilutions and the samples were subtracted from the OD of the blank (no lysate) wells for the appropriate plate.

The undiluted standard lysate was assigned an enzyme activity of $10^{5}$ arbitrary units (AU). The standard curve was constructed by plotting the subtracted OD of each standard dilution against AU. The cell lysate enzyme activities were then read from the standard curve, and expressed as $\mathrm{AU} / \mu \mathrm{g}$ total lysate protein.

\subsubsection{Tvaluation of the $\beta 1,3$ GT assay}

\section{Demonstration that cell lysates can alter the VV lectin binding of the acceptor}

A series of doubling dilutions of the standard lysate protein was used in the assay procedure outlined above in order to :

- demonstrate that the cell extract contained enzyme activity with the ability to produce a change in the terminal galactosylation of the acceptor that was detectable by VV lectin binding 
- demonstrate that this activity was dose dependent with respect to the protein concentration of the lysate

- find a suitable range of dilutions of this lysate preparation for the construction of a standard curve in subsequent assays

- find a suitable protein concentration at which to measure the enzyme activity of lysate samples in subsequent assays

In the light of these experiments, the remainder of the assay evaluations were carried out using series of doubling dilutions of the standard lysate consisting of eleven dilutions ranging from 1:2 to $1: 2048$, and other lysate samples were used at concentration between 100 and $500 \mu \mathrm{g} / \mathrm{ml}$.

\section{Effect of cell lysates on an irrelevant protein}

To demonstrate that the activity displayed by the cell lysates was specific to O-linked glycans, a lysate standard curve was set up a plate coated with $2 \mathrm{mg} / \mathrm{ml} \mathrm{BSA}$, which does not carry O-linked sugars, instead of the acceptor.

\section{Effect of irrelevant proteins and inactive cell lysates on $\mathrm{VV}$ binding of the acceptor}

To demonstrate that the change in VV binding of the acceptor is brought about by enzyme activity in the cell lysates, series of doubling dilutions of BSA and GSSG over the same protein concentration range ( $20 \mathrm{mg} / \mathrm{ml}$ to $4 \mu \mathrm{g} / \mathrm{ml}$ ) as the standard lysate were used in the assay.

This assay was designed to test the enzyme activity of magnetic bead-containing cell lysate preparations. Therefore, the effect on the acceptor of the magnetic beads alone was tested. The beads were applied to the plate in $0.5 \%$ Nonidet P40 in PBS, at approximately the same concentration as they were present in the lysates. During the cell-isolation procedure, the cells were suspended in Hank's buffered salt solution with $1 \%$ fetal calf serum (HBSS/FCS, Appendix II). Though the cells were washed in serum-free HBSS before lysing, the effect of the HBSS/FCS on the acceptor was also tested, in case traces of FCS remained in the cell lysate preparations.

A further control was provided by some normal PBMCs which had been cultured for 10 days under standard lymphocyte culture conditions (RPMI 1640 medium/ 1\% L-glutamine/24mM 
$\mathrm{NaHCO}_{3}$ [all Life Technologies] $50 \mathrm{mM}$ HEPES/10\% FCS with $2.5 \mu \mathrm{g} / \mathrm{ml}$ pokeweed mitogen for stimulation). These cells had been cultured for use in a different study; the culture conditions were still under evaluation, and the cultures used in this experiment had not responded well to stimulation. Though the cells were not dead, they were not producing the large amounts of immunoglobulin expected, and were probably senescent. Lysates were prepared from these cells, without separation into their constituent cell types, and applied to the plates in the $\beta 1,3 \mathrm{GT}$ assay at the same protein concentrations as for the rest of the cell lysates (250 and $500 \mu \mathrm{g} / \mathrm{ml}$ ).

\section{Reversal of acceptor galactosylation with $\beta$-galactosidase}

To demonstrate that the enzyme activity in the cell lysates was indeed regalactosylating the acceptor, unconjugated $\beta$-galactosidase from $E$ coli was added to the reaction mixture of six lysate samples at a final concentration of $1 \mathrm{U} / \mathrm{ml}$, and run in parallel with the same lysates without $\beta$-galactosidase. The lysates were used at $200 \mu \mathrm{g} / \mathrm{ml}$ final protein concentration.

\section{Requirements for UDP-Gal and divalent cations}

The optimum constituents of the reaction buffer used in the assay were evaluated by investigating the effect of three divalent cations, $\mathrm{Mn}^{2+}, \mathrm{Mg}^{2+}$, and $\mathrm{Ca}^{2+}$. Published assay methods for $\beta 1,3 \mathrm{GT}$ all include $\mathrm{MnCl}_{2}$ at concentrations ranging between 10-25mM (Berger 1978, Cartron 1978, Cartron 1979, Piller 1990, Thurnher 1993, King 1994). In this experiment, $\mathrm{MnCl}_{2}, \mathrm{MgCl}_{2}$ and $\mathrm{CaCl}_{2}$ were each included in the reaction buffer at a final concentration of $20 \mathrm{mM}$.

The methods cited all used radiolabelled UDP-Gal to detect the galactosylated product. This was included in the reaction buffer at concentrations varying from $4 \mu \mathrm{M}-4 \mathrm{mM}$. Since UDP-Gal was not used as the detection agent in this assay, the requirement for its inclusion in the reaction buffer was evaluated. Reaction buffers containing each of the divalent cations above were prepared with and without UDP-Gal at a final concentration of $0.25 \mathrm{mM}$.

To evaluate the effects of the divalent cations and UDP-Gal, replicate series of doubling dilutions of the standard lysate (1:20-1:2048) were set up on acceptor-coated plates, applying 30 $\mu 1 / \mathrm{well}$. Reaction buffers containing $4 \mathrm{x}$ concentrations of each divalent cation $(80 \mathrm{mM})$ were prepared with and without 1mM UDP-Gal, all in PBS. In addition, PBS alone and with 1mM UDP-Gal only 
was prepared. $10 \mu 1$ of each of these $4 \mathrm{x}$ reaction buffers was added to replicate series of standard lysate dilutions in duplicate, and the assay completed as outlined above.

\section{Effects of incubation temperature and time}

Replicate series of doubling dilutions of the standard lysate (1:2-1:2048) were set up on three acceptor-coated plates, using reaction buffer containing a final concentration of $20 \mathrm{mM} \mathrm{CaCl}$ and $0.25 \mathrm{mM}$ UDP-Gal. The plates were incubated under the following conditions :

$\begin{array}{lc}\text { Temperature } & \text { Duration } \\ 37^{\circ} \mathrm{C} & 18 \text { hours } \\ 37^{\circ} \mathrm{C} & 4 \text { hours } \\ 4^{\circ} \mathrm{C} & 4 \text { hours }\end{array}$

The assays were completed as for the standard procedure outlined above.

\section{Reproducibility of the $\beta 1,3 G T$ assay}

Intra-assay and inter-assay coefficients of variation (CVs) were calculated for the assay system, using a cell lysate prepared from unfractionated, normal PBMCs. For the intra-assay CV, ten sets of duplicate wells were set up on a plate with a standard curve, and the assay carried out as described (Section 7.2.3). For the inter-assay CV, the activity of separate aliquots of this same lysate was measured on three separate occasions during a two week period.

Additionally, a set of lysates prepared from unfractionated PBMCs were tested in this assay system on three separate occasions over a longer time period to assess the stability of the enzyme activity in stored samples, and to give an indication of how long the samples could satisfactorily be stored. The lysates were stored at $-20^{\circ} \mathrm{C}$ between these assays, and the same aliquots used for each assay; in other words, these sample were subjected to freeze-thaw cycles. Six weeks elapsed between the first and second assay run, and the third assay was run six months later. 


\subsubsection{Evaluation of the acceptor}

The degalactosylated acceptor preparation had a protein concentration of $235 \mu \mathrm{g} / \mathrm{ml}$. SDS-PAGE did not demonstrate a single clear band, and it is likely that the acceptor contains peptide fragments over a wide molecular weight range. A faint band could be detected between $50-60 \mathrm{kD}$, probably consisting of undigested $\alpha 1$ heavy chains complete with the hinge region (Figure 7.1), but this band was not strong enough to account for the total protein content of the acceptor. The acceptor probably did not consist of complete IgA1 molecules, since no light chain band was detectable at $25 \mathrm{kD}$.

The binding of Helix aspersa, Vicia villosa, Amaranthus caudatus and jacalin lectins to the acceptor preparation before and after degalactosylation are shown in Table 7.1. Vicia villosa lectin was chosen as the most suitable to detect changes in galactosylation of the acceptor in the $\beta 1,3 \mathrm{GT}$ assay.

\subsubsection{Evaluation of $\beta \mathbb{1}, 3 \mathrm{GT}$ assay}

Demonstration that cell lysates can alter the VV lectin binding of the acceptor The results of VV binding to the acceptor after incubation with a series of dilutions of the standard lysate are shown in Table 7.2. The neat acceptor was assigned an enzyme activity of $10^{5} \mathrm{AU}$, and the $\mathrm{OD}$ values of the lysate dilutions subtracted from the blank (no lysate) value. Figure 7.2 shows a typical standard curve constructed by plotting the enzyme activity of the lysate dilutions in AU against subtracted OD.

The activity of the lysates showed an exponential dose response pattern, which was linear over the range of lysate dilutions between 1:8 to $1: 128$, equating to a protein concentration range of 78 to $1250 \mu \mathrm{g} / \mathrm{ml}$.

The optimum range for a standard curve for use in the subsequent assays was chosen as $1: 2$ to 
1:2048 (10mg/ml to $4 \mu \mathrm{g} / \mathrm{ml})$, and other cell lysate samples were used at a protein concentration between 100 and $500 \mu \mathrm{g} / \mathrm{ml}$.

\section{Irrelevant protein as acceptor}

The VV binding results of a plate coated with bovine serum albumin were all at background levels; the BSA did not bind VV, and the cell lysate did not affect this (data not shown).

\section{Effect of irrelevant proteins and inactive cell lysates on VW binding of the acceptor}

The VV binding of the acceptor was unaffected by incubation with a series of dilutions of BSA or GSSG over the same protein concentration range as the standard lysate, as shown in Tigure 7.3 .

Table 7.3 shows the results of VV binding of the acceptor after incubation with fresh PBMC lysates, cultured PBMC lysates, a cell free magnetic bead suspension and HBSS/FCS. The cultured PBMCs failed to alter the VV binding of the lysate, indicating that the effect of fresh cell lysates on the acceptor is due to intrinsic enzyme activity. It was also noted that previously "active" lysates lost their activity over time when stored at $-20^{\circ} \mathrm{C}$ (data shown in Table 7.7). Neither magnetic beads nor $1 \%$ FCS had any effect on the VV binding of the acceptor.

\section{Reversal of acceptor galactosylation with $\beta$-galactosidase}

Table 7.4 shows the VV lectin binding of the acceptor after incubation with six cell lysates with and without the addition of $\beta$-galactosidase to the reaction mixture. The galactosylating activity of the lysates was ablated by the galactose-removing activity of the added enzyme.

\section{Requirements for UDP-Gal and divalent cations}

The effects of including $20 \mathrm{mMM} \mathrm{MnCl}, \mathrm{MgCl}_{2}$ or $\mathrm{CaCl}_{2}$ to the reaction buffer are shown in Figure 7.4a (with UDP-Gal) (raw data shown in Table 7.5) and Figure 7.4b (without UDP-Gal).

The assay system worked well using PBS alone as reaction buffer. The addition of UDP-Gal improved the standard curve to some degree, but was not an absolute requirement. Addition of $\mathrm{Mg}^{2+}$ ions to the reaction buffer had little effect. $\mathrm{Min}^{2+}$ caused a modest increase in the subsequent 
binding of VV to the acceptor in the blank wells, but almost completely ablated the change in VV binding of the acceptor in the wells containing lysate. $\mathrm{Ca}^{2+}$ ions dramatically increased the subsequent VV binding of the acceptor, particularly in the blank (no lysate) wells, and those with the lower lysate concentrations. The dynamics of the enzyme activity itself was unchanged by $\mathrm{Ca}^{2+}$, since the standard curve remained the same shape, and the effect appeared be on the binding affinity of the lectin to the acceptor. However, the sensitivity of the assay was improved by the addition of $\mathrm{CaCl}_{2}$ to the reaction buffer, since it produced a larger difference in the OD values of the acceptor incubated with different concentrations of lysate.

These results lead to a choice of a reaction buffer containing final concentrations of $0.25 \mathrm{mM}$ UDP-Gal and $20 \mathrm{mM} \mathrm{CaCl}_{2}$ for use in subsequent assays. Though UDP-Gal did not appear to be a necessary constituent, presumably because the cell lysate itself contained a sufficient quantity, it was added to ensure that the sugar donor was not a limiting factor in the enzyme activity.

\section{Effect of incubation time and temperature}

Figure 7.5 shows the effect of incubating the reaction mixture at 37 and $4{ }^{\circ} \mathrm{C}$ for different periods of time. Galactosylation of the acceptor was much more efficient at $37^{\circ} \mathrm{C}$ than at $4^{\circ} \mathrm{C}$, and a longer incubation time also improved the results.

Reproducibility of the assay

Intra-assay and inter-assay CVs were calculated from :

$$
\mathrm{CV}=\frac{\mathrm{sd}}{\text { mean }} \times 100 \%
$$

The intra-assay CV calculated from ten sets of duplicate wells of the same lysate sample was $10.2 \%$, while the intra-assay $\mathrm{CV}$, calculated from the results of this lysate measured on three separate occasions within a two week period was $16.2 \%$. This data is shown in Table 7.6.

Table 7.7 shows the enzyme activities of a set of PBMC lysates tested on three occasions, separated by six weeks and six months respectively. The lysates are arranged in rank order with 
respect to their $\beta 1,3 \mathrm{GT}$ activity as measured on the first occasion. Though the actual $\mathrm{AU} / \mu \mathrm{g}$ decayed with time, the rank order did not change, with the same lysates always having the highest and the lowest activities. The lysates were stored at $-20^{\circ} \mathrm{C}$ between assays, and were subjected to repeated freeze-thaw cycles. The standard lysate was also stored at $-20^{\circ} \mathrm{C}$, but multiple aliquots were available, and a fresh one used each time. The decreasing AU/ $\mu \mathrm{g}$ values of the test lysates is therefore attributable a more rapid rate of decay of enzyme activity than the standard lysate.

\subsection{Conclusions}

The set of experiments described in this chapter concerned the development and evaluation of an assay system to detect and quantify $\beta 1,3$-galactosylating activity in PBMC lysates.

An acceptor was prepared from $O$-galactosylated protein fragments of a crude immunoglobulin fraction from pooled normal sera, which were then partially degalactosylated with $\beta$ galactosidase. This acceptor displayed a high binding affinity for the GalNAc-specific lectin VV, and this affinity could be reduced by incubation of the acceptor with fresh cell lysates. The degree of reduction was shown to be proportional to the protein concentration of the lysate over a range of approximately $80-1200 \mu \mathrm{g} / \mathrm{ml}$ for the standard lysate sample prepared. Similar activity could be demonstrated in other fresh PBMC lysate samples within the same concentration range.

To show that the apparent alteration in terminal GalNAc exposure of the acceptor was indeed due to an O-galactosylating enzyme contained in the cell lysates, a number of control experiments were carried out. The lysates did not change the lectin binding of BSA, which lacks O-linked sugars, and conversely, no reduction in VV binding to the acceptor could be brought about by irrelevant proteins. Cell lysates prepared from aging cultured cells were ineffective, and the activity of lysates from fresh cells decayed with time if not stored at $-70^{\circ} \mathrm{C}$. The change in VV binding was reversed by co-incubation of the cell lysates with $\beta$-galactosidase, and as would be expected for an enzyme, the galactosylating activity of the lysates was time and temperature dependent. 
The assay did not appear to require the addition of exogenous nucleotide donor (UDP-Gal), though this was used as a precaution against its availability becoming a limiting factor. The sensitivity of the assay was improved by the presence of $20 \mathrm{mM} \mathrm{CaCl} \mathrm{C}_{2}$ in the reaction mixture. This was probably due to an effect upon the lectin binding to the acceptor, rather than to a requirement for this cation by the enzyme. Unlike other assay systems for $\beta 1,3 \mathrm{GT}$, no requirement for $\mathrm{Mn}^{2+}$ was seen, and indeed, the addition of $\mathrm{MnCl}_{2}$ at $20 \mathrm{mM}$ apparently interfered with the enzyme activity in this assay.

\subsection{Discussion}

The functional $\beta 1,3 \mathrm{GT}$ assay developed in this chapter was designed to specifically assess IgA1 O-galactosylating activity as specifically as possible, since galactosyltransferases are known to be highly substrate-specific (Roth 1985, Narimatsu 1994, Palcic 1994). To this end, IgAl fragments were used as an acceptor for the enzyme activity. This is a novel approach, as is the use of a lectin to detect and quantify the glycosylation change in the acceptor brought about by the action of the enzyme.

The acceptor peptides were shown to be carrying O-linked carbohydrate moieties by their binding affinity for the lectins Helix aspersa, Vicia villosa, Amaranthus caudatus and jacalin. Enzymatic degalactosylation of the acceptor resulted in the anticipated increase in affinity for the former two lectins, which bind terminal GalNAc moieties. A corresponding decrease in binding to the Gal $\beta 1,3 \mathrm{GalNAc}$ lectins $A$ caudatus and jacalin would be expected, but was not observed. The reason for this is not clear, but indicates that the degalactosylation was incomplete. A caudatus lectin has been extensively used in the assays described in this thesis, and always shows extremely high binding to glycoproteins with $\mathrm{O}$-linked sugars. Little variation in its binding is detectable in series of IgAl and Clinh samples which show widely different affinities for GalNAc-specific lectins (Chapter 6), so this is perhaps not an unexpected observation. Jacalin has not previously been used in lectin assays in this thesis, since it is used for protein purification. It is known to have partial affinity for GalNAc (Biewenga 1989), which may explain the findings. Vicia villosa lectin was considered to be the most sensitive in detecting changes in terminal O-galactosylation of the acceptor, and was used successfully in the assay system. 
Evidence that the reduction in GalNAc-specific Vicia villosa lectin binding of the acceptor was indeed due to the activity of an enzyme in the cell lysates was provided by a number of observations made during evaluation of the assay.

The linear variation of activity over a tenfold range in lysate protein concentration, the observation that this activity decays over time in stored lysates, and the effects of incubation time and temperature are typical features of enzyme activity which were exhibited in this system. Since the lectin binding decreases with increasing lysate concentration, the change cannot be attributed to some $V$ villosa-binding factor within the lysates which may adhere to the acceptor and remain after the fluid phase lysate has been washed off. Reduced VV binding may be due to such a factor blocking the acceptor binding sites, but lysates from PWM-cultured cells and aged lysates had no effect, which argues against non-specific blocking being responsible. Similarly, high concentrations of irrelevant proteins failed to alter the lectin binding of the acceptor.

The exact identity of the enzyme acting upon the acceptor substrate in this assay has not been conclusively proven. The reduced lectin binding was reversed by inclusion of $\beta$-galactosidase in the reaction mixture, suggesting that addition of terminal galactose to GalNAc is indeed the activity detected in this system. However, this is not necessarily in $\beta 1,3$ linkage, and some of the reduction in VV lectin binding may be due to the addition of sugar units other than galactose. Investigating the effect of $\beta 1,4 \mathrm{GT}$, which is available commercially, on the VV binding of the acceptor would help to clarify the specificity of the assay system. Analysis of the carbohydrate moieties of the acceptor before and after action of the lysates by a more precise method such as HPLC would be necessary to be absolutely sure of the enzyme activity measured.

Mauy intracellular enzymes, including glycosyltransferases, require a divalent cation as a cofactor in their catalytic activity (Kleene 1993), and previous assays for $\beta 1,3 \mathrm{GT}$ have included $\mathrm{Mn}^{2+}$ in the reaction mixture (Berger 1978, Cartron 1978, Cartron 1979, Piller 1990, Thurnher 1993, King 1994). However, the addition of $20 \mathrm{mM} \mathrm{MnCl}_{2}$ to the reaction buffer in this system had a marked inhibitory effect on the enzyme activity. This is difficult to explain, but may indicate that a different $\beta 1,3 \mathrm{GT}$ enzyme is acting on this acceptor. The effect is peculiar to $\mathrm{Mn}^{2+}$, since another divalent cation, $\mathrm{Mg}^{2+}$, at the same concentration, had no particular effect on the enzyme activity. 
The addition of $\mathrm{CaCl}_{2}$ to the reaction buffer also had a dramatic effect upon the assay system, but in this case it apparently affected the subsequent affinity of the acceptor for VV lectin rather than the actual enzyme activity, even though the plates were thoroughly washed before the lectin was applied. The binding of legume lectins to their ligands are often strongly influenced by specific divalent cations, notably $\mathrm{Mn}^{2+}$ and $\mathrm{Ca}^{2+}$ (Sharon 1989), and it has to be assumed that residual $\mathrm{Ca}^{2+-}$ ions are sufficient to promote the VV binding. The sensitivity of the assay was markedly improved by the use of $\mathrm{CaCl}_{2}$, and it was included in the standard reaction mixture. It may be more appropriately included in the VV lectin buffer, in both this assay and in the lectin binding assay developed in Chapter 4 . Further evaluation is required to elucidate this.

Addition of the mucleotide sugar donor UDP-Gal to the reaction mixture did not appear to be a strict requirement in the assay; presumably the cell lysates themselves contained sufficient of this substrate for the enzyme to function. However, it was included in the buffer at a concentration of $0.25 \mathrm{mM}$ to ensure that its availability did not become a limiting factor in the rate of catalysis of acceptor galactosylation, since such reactions will proceed until the free substrates reach equilibrium with the product.

The observed decay in enzyme activity over time in stored lysates make the reproducibility of the assay suspect, since the standard lysate is also subject to such decay. However, valid comparisons between the activities of lysates measured in a single assay run are possible. In order to minimise the error incurred by variable lysate enzyme decay, storage should be at $-70^{\circ} \mathrm{C}$, and aliquots of lysate should be thawed once only. Lysate samples to be compared to one another should be collected within a short period, and stored for the minimum possible time. The standard lysate can be used to construct a standard curve for conversion of $\mathrm{OD}$ values to $\mathrm{AU}$ values, but the results obtained from one assay cannot be reliably compared to those from another assay carried out at a different time. With these provisos, the assay may be used to look for variations in enzyme activity in PBMC lysates from different subjects.

This assay is a convenient, practical and effective method of measuring the $\beta 1,3$ galactosylating activity of PBMC lysates, though the absolute specificity of the enzyme activity has yet to be proven. IgA1 fragments are used as acceptor in an attempt to isolate the activity of the enzyme 
which galactosylates IgA1, rather than membrane proteins. Since unfractionated PBMCs contain only some $10 \% \mathrm{~B}$ cells, and of these only a few will be making IgA1, it does not seem likely that the considerable activity detected is actually IgA1-specific. There may or may not be a $\beta 1,3 \mathrm{GT}$ specific to $\operatorname{IgA} 1$, but at least the use of this acceptor should include the activity of the required enzyme in the assay, even if it cannot isolate it. A less tailored acceptor, such as an asialosubmaxillary mucin, may not detect IgAl-galactosylating activity at all. 


\begin{tabular}{|c|c|c|}
\hline \multicolumn{3}{|c|}{$\begin{array}{l}\text { Table } 7.1 \text { Lectin binding of acceptor before and after } \\
\text { degalactosylation }\end{array}$} \\
\hline & OD at $492 \mathrm{~nm}$ & \\
\hline Lectin & Pre- $\beta$-galactosidase & Post- $\beta$-galactosidase \\
\hline Helix aspersa & 1.435 & 2.523 \\
\hline Vicia villosa & 0.392 & 2.100 \\
\hline Amaranthus caudatus & 2.988 & 3.055 \\
\hline Jacalin & 3.371 & 3.134 \\
\hline
\end{tabular}

\begin{tabular}{|c|c|c|c|c|c|}
\hline \multirow{2}{*}{$\begin{array}{l}\text { Table } 7.2 \\
\begin{array}{l}\text { Lysate } \\
\text { dilution }\end{array}\end{array}$} & \multicolumn{5}{|c|}{$\begin{array}{l}\text { Construction of standard curve for } \boldsymbol{\beta} 1,3 \mathrm{GT} \text { assay } \\
\text { Standard lysate preparation }\end{array}$} \\
\hline & $\begin{array}{l}\text { [Protein] } \\
(\mu \mathrm{g} / \mathbf{m l})\end{array}$ & $\begin{array}{l}\beta 1,3 G T \\
\text { activity } \\
(\mathbf{A U})\end{array}$ & $\mathbf{A U} / \mu \mathrm{g}$ & $\begin{array}{l}\text { OD at } \\
492 \mathrm{~nm}\end{array}$ & Blank-OD \\
\hline $\begin{array}{l}\text { Blank } \\
\text { (no lysate) }\end{array}$ & 0 & 0 & 0 & 2.857 & - \\
\hline neat & 20000 & 10000 & 2 & 0.447 & 2.410 \\
\hline $1: 2$ & 10000 & 5000 & 2 & 0.514 & 2.343 \\
\hline $1: 4$ & 5000 & 2500 & 2 & 0.487 & 2.370 \\
\hline $1: 8$ & 2500 & 1250 & 2 & 0.529 & 2.328 \\
\hline $1: 16$ & 1250 & 625 & 2 & 0.597 & 2.260 \\
\hline $1: 32$ & 625 & 312 & 2 & 0.732 & 2.125 \\
\hline $1: 64$ & 312 & 156 & 2 & 0.753 & 2.104 \\
\hline $1: 128$ & 156 & 78 & 2 & 1.054 & 1.803 \\
\hline $1: 256$ & 78 & 39 & 2 & 1.663 & 1.194 \\
\hline $1: 512$ & 39 & 20 & 2 & 1.894 & 0.963 \\
\hline $1: 1024$ & 20 & 10 & 2 & 2.456 & 0.401 \\
\hline $1: 2048$ & 10 & 5 & 2 & 2.829 & 0.028 \\
\hline 1:4096 & 5 & 2.5 & 2 & 2.753 & 0.104 \\
\hline
\end{tabular}



\begin{tabular}{|l} 
Table 7.3 $\begin{array}{l}\beta 1,3 G T \text { activity of fresh and cultured PBMC } \\
\text { lysates, magnetic beads and } 1 \% \text { FCS }\end{array}$
\end{tabular}

\begin{tabular}{|c|c|c|c|}
\hline Sample & & OD at $492 \mathrm{~nm}$ & Blank-OD \\
\hline Blank (no lysate) & & 2.344 & - \\
\hline $\begin{array}{l}\text { Fresh PBMC } \\
\text { lysates at } 500 \mu \mathbf{g} / \mathbf{m l}\end{array}$ & 1 & 1.180 & 1.164 \\
\hline & 2 & 1.022 & 1.322 \\
\hline & 3 & 1.054 & 1.290 \\
\hline & 4 & 1.186 & 1.158 \\
\hline & 5 & 1.227 & 1.117 \\
\hline & 6 & 1.522 & 0.822 \\
\hline $\begin{array}{l}\text { Cultured PBMC } \\
\text { lysates at } 500 \mu \mathrm{g} / \mathrm{ml}\end{array}$ & 1 & 2.359 & - \\
\hline & 2 & 2.384 & - \\
\hline & 3 & 2.171 & 0.173 \\
\hline & 4 & 2.238 & 0.106 \\
\hline & 5 & 2.084 & 0.260 \\
\hline & 6 & 2.198 & 0.146 \\
\hline Blank (no lysate) & & 1.210 & - \\
\hline $\begin{array}{l}\text { Magnetic bead } \\
\text { suspension }\end{array}$ & & 1.152 & 0.058 \\
\hline $1 \%$ FCS in HBSS & & 1.169 & 0.041 \\
\hline
\end{tabular}




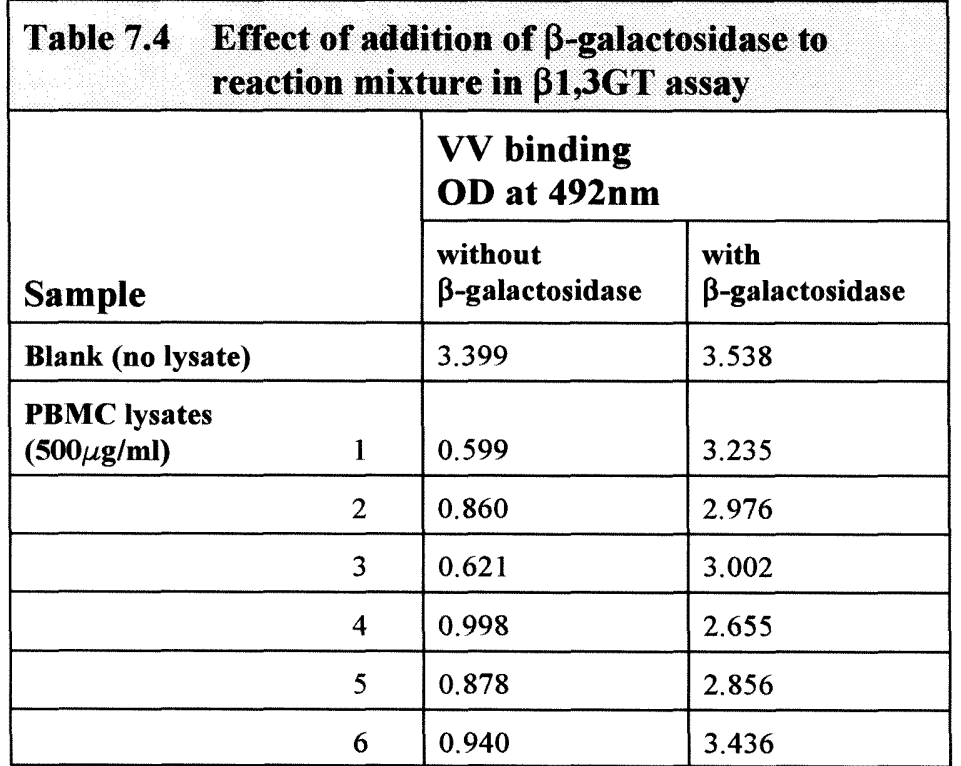




\begin{tabular}{|c|c|c|c|c|c|c|c|c|}
\hline Table 7.5 & $\begin{array}{l}\beta 1,30 \\
\text { Effec } \\
\text { buffe }\end{array}$ & $\begin{array}{l}\text { T assa } \\
\text { of ad } \\
\text { r. Wit }\end{array}$ & $\begin{array}{l}\text { tion o } \\
0.25 \mathrm{~m}\end{array}$ & $\begin{array}{l}\text { divale } \\
\text { Y UD }\end{array}$ & $\begin{array}{l}\text { t catio } \\
\text { Gal. }\end{array}$ & as to r & etion & \\
\hline & & & & Cation & $20 \mathrm{mM}$ & & & \\
\hline & $\begin{array}{l}\text { PBS } \\
\text { only }\end{array}$ & & $\mathbf{M n}^{2+}$ & & $\mathbf{M g}^{2+}$ & & $\mathrm{Ca}^{2+}$ & \\
\hline $\begin{array}{l}\text { Standard } \\
\text { lysate } \\
\text { dilution }\end{array}$ & $\begin{array}{l}\text { OD at } \\
492 \mathrm{~nm}\end{array}$ & $\begin{array}{l}\text { Blank- } \\
\text { OD }\end{array}$ & $\begin{array}{l}\text { OD at } \\
492 \mathrm{~nm}\end{array}$ & $\begin{array}{l}\text { Blank- } \\
\text { OD }\end{array}$ & $\begin{array}{l}\text { OD at } \\
492 \mathrm{~nm}\end{array}$ & $\begin{array}{l}\text { Blank- } \\
\text { OD }\end{array}$ & $\begin{array}{l}\text { OD at } \\
492 \mathrm{~nm}\end{array}$ & $\begin{array}{l}\text { Blank- } \\
\text { OD }\end{array}$ \\
\hline $\begin{array}{l}\text { Blank } \\
\text { (no } \\
\text { lysate) }\end{array}$ & 1.33 & - & 1.67 & - & 1.24 & - & 2.61 & - \\
\hline $1: 2$ & 0.60 & 0.77 & 1.36 & 0.31 & 0.48 & 0.76 & 0.70 & 1.91 \\
\hline $1: 4$ & 0.58 & 0.75 & 1.33 & 0.34 & 0.45 & 0.80 & 0.74 & 1.87 \\
\hline $1: 8$ & 0.67 & 0.66 & 1.60 & 0.07 & 0.53 & 0.72 & 1.04 & 1.57 \\
\hline $1: 16$ & 0.83 & 0.50 & 1.70 & - & 0.65 & 0.59 & 1.25 & 1.36 \\
\hline $1: 32$ & 0.86 & 0.47 & 1.74 & - & 0.81 & 0.44 & 1.48 & 1.13 \\
\hline $1: 64$ & 0.91 & 0.42 & 1.79 & - & 0.92 & 0.32 & 1.75 & 0.86 \\
\hline $1: 128$ & 1.05 & 0.28 & 1.91 & - & 1.09 & 0.16 & 2.06 & 0.55 \\
\hline $1: 256$ & 1.30 & 0.03 & 1.84 & - & 1.42 & - & 2.47 & 0.14 \\
\hline $1: 512$ & 1.56 & - & 1.85 & - & 1.50 & - & 2.47 & 0.41 \\
\hline $1: 1024$ & 1.66 & - & 2.03 & - & 1.73 & - & 2.50 & 0.11 \\
\hline $1: 2048$ & 1.83 & - & 2.07 & - & 1.91 & - & 2.71 & - \\
\hline
\end{tabular}




\begin{tabular}{|c|c|c|c|}
\hline \multicolumn{4}{|c|}{ Table 7.6 Coefficients of variation of $\beta 1,3 G T$ assay } \\
\hline \multicolumn{2}{|r|}{ Intra-assay } & \multicolumn{2}{|r|}{ Inter-assay } \\
\hline $\begin{array}{l}\text { Replicates } \\
\text { (assayed on } \\
\text { a single } \\
\text { occasion) }\end{array}$ & $\begin{array}{c}\beta 1,3 G T \text { activity } \\
\mathbf{A U} / \mu \mathrm{g} \\
\text { (Mean of } 2 \text { duplicate } \\
\text { wells) }\end{array}$ & $\begin{array}{l}\text { Replicates } \\
\text { (assayed } \\
\text { on } \\
3 \\
\text { occasions } \\
\text { within } \\
\text { two } \\
\text { weeks) }\end{array}$ & $\begin{array}{c}\beta 1,3 G T \text { activity } \\
\text { AU } / \mu \mathrm{g} \\
\text { (Mean of } 2 \\
\text { duplicate wells) }\end{array}$ \\
\hline 1 & 2.4 & 1 & 2.6 \\
\hline 2 & 2.8 & 2 & 3.2 \\
\hline 3 & 2.4 & 3 & 2.4 \\
\hline 4 & 2.8 & Mean & 2.78 \\
\hline 5 & 2.4 & SD & 0.45 \\
\hline 6 & 2.4 & $\mathrm{CV} \%$ & 16.2 \\
\hline 7 & 2.8 & & \\
\hline 8 & 2.4 & & \\
\hline 9 & 2.0 & & \\
\hline 10 & 2.4 & & \\
\hline Mean & 2.44 & & \\
\hline SD & 0.25 & & \\
\hline $\mathrm{CV} \%$ & 10.2 & & \\
\hline
\end{tabular}




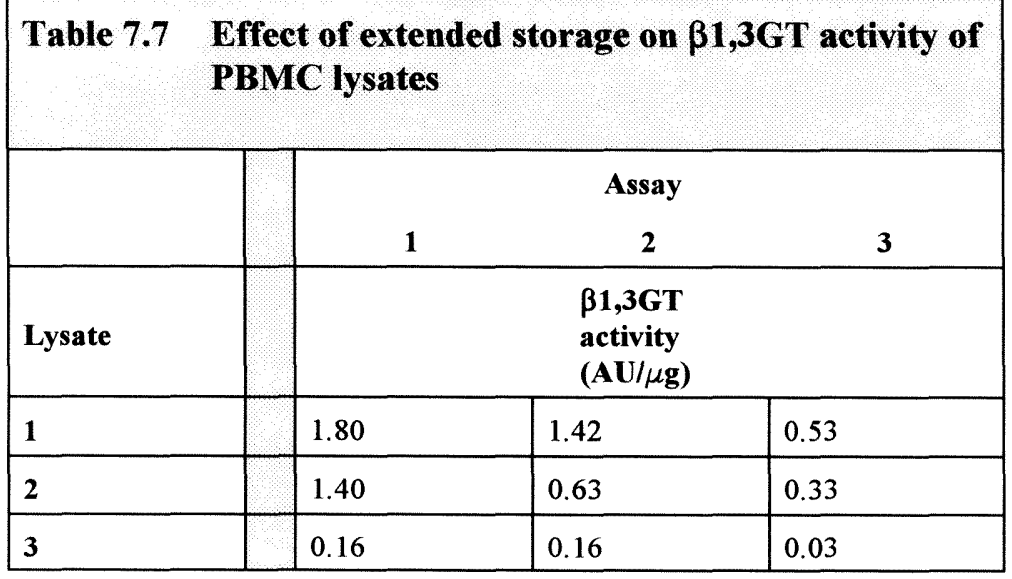

Six weeks elapsed between Assays 1 and 2, and six months between assays 2 and 3 .

Enzyme activity of all three lysates decayed in storage, but their rank order remained the same;

Lysate 1 always had the highest activity, and Lysate 3 the lowest. 


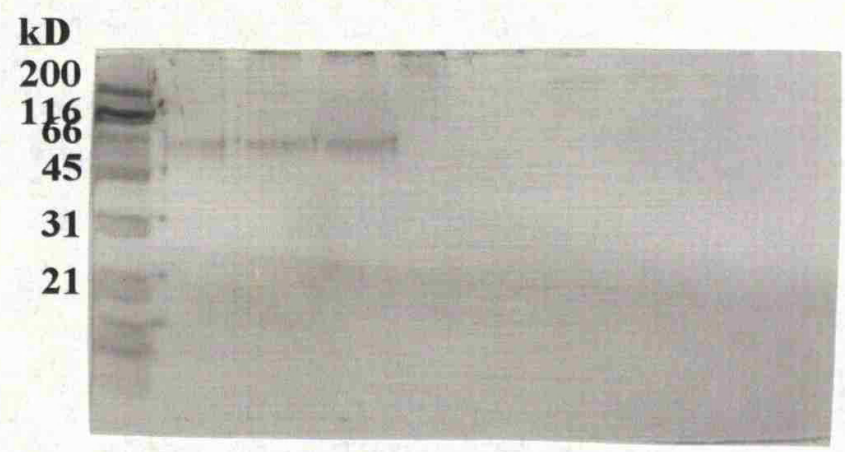

Lane $\quad \begin{array}{llll}1 & 2 & 3 & 4\end{array}$

Figure 7.1 SDS-PAGE gel of acceptor preparation. $15 \%$ polyacrylamide gel. Lane 1 is a molecular weight marker; Lanes 2-4 are the acceptor preparation. 
Figure 7.2

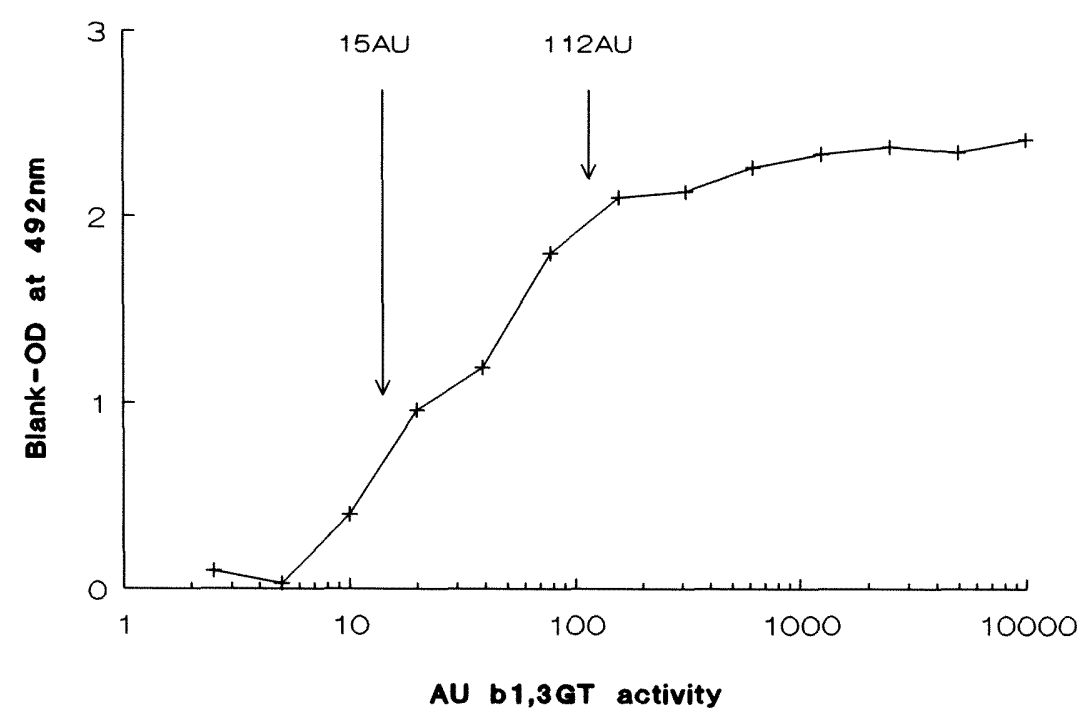

Figure 7.2 $\quad \beta 1,3 G T$ activity of PBMC lysate preparation. Typical standard curve. Arrows mark the positions of the lowest (15AU) and highest (112AU) values obtained by $\mathrm{B}$ cell lysates applied to the wells in $30 \mu \mathrm{l}$ aliquots at $250 \mu \mathrm{g} / \mathrm{ml}$ (ie $7.5 \mu \mathrm{g} / \mathrm{well}$ ), as an example to indicate the part of the standard curve from which $A U$ values were read. Absolute AU values for each lysate were then corrected for protein concentration (as $\mu \mathrm{g}$ applied to well) to express the results as $\mathrm{AU} / \mu \mathrm{g}$. 


\section{Figure 7.3}

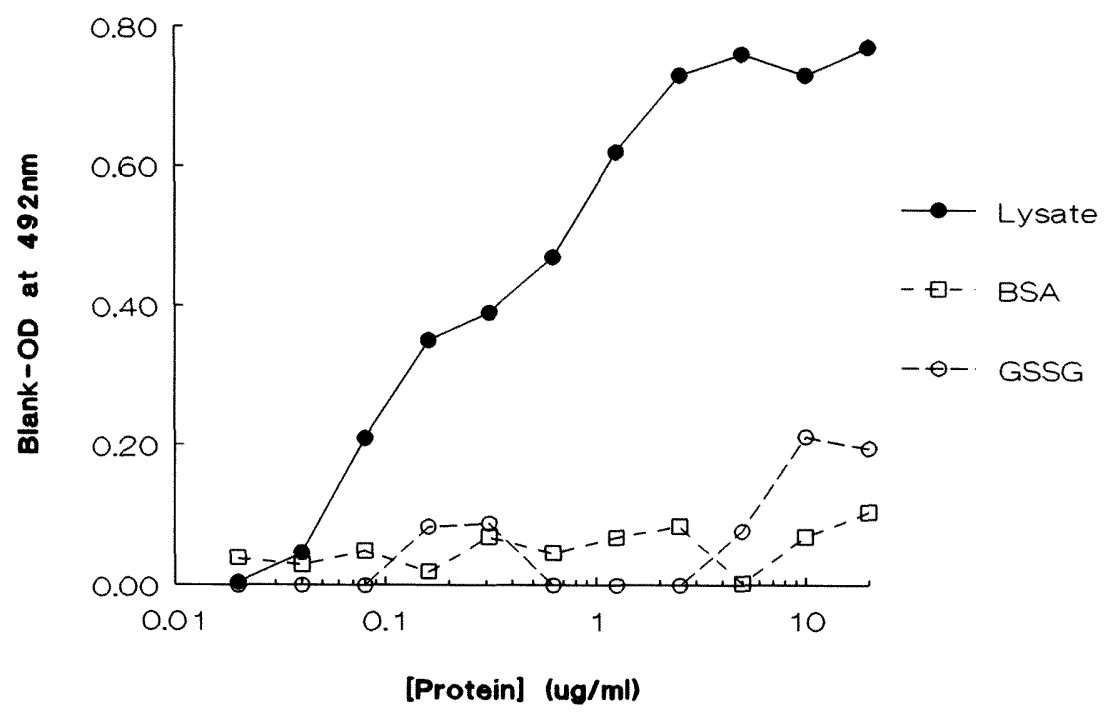

Figure 7.3 Effects of irrelevant proteins in $\beta 1,3 \mathrm{GT}$ assay. - Standard cell lysate, $\square$ BSA, $\circ$ GSSG. Irrelevant proteins do not alter the VV lectin binding of the acceptor over the same protein concentration range as the cell lysate. 
Figure $7.4 \mathrm{a}$

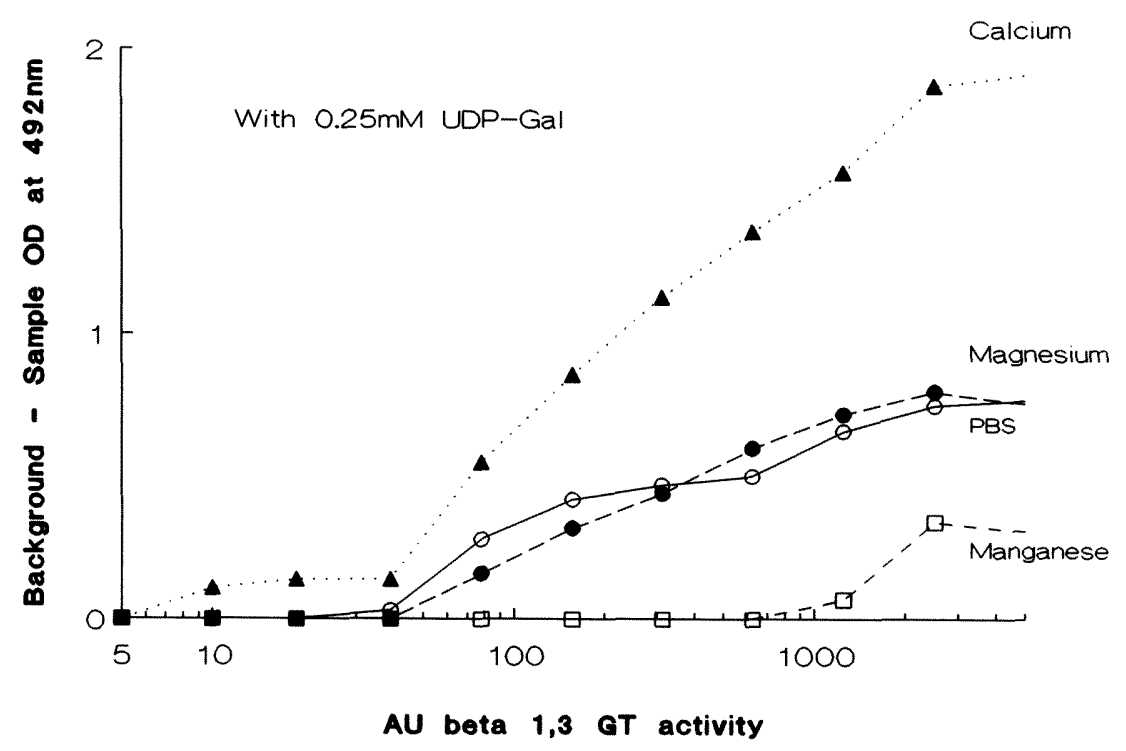

Figure 7.4 Effect of addition of divalent cations to the reaction mixture in $\beta 1,3 \mathrm{GT}$ assay. Compared to PBS $(0)$ alone as reaction buffer. $\mathrm{Ca}^{2+}(\Delta)$ promotes VV binding to the acceptor, while $\mathrm{Mn}^{2+}(\square)$ appears to inhibit the enzyme activity. $\mathrm{Mg}^{2+}(\bullet)$ has no effect. Figure 7.4a With UDP-Gal. 
Figure $7.4 \mathrm{~b}$

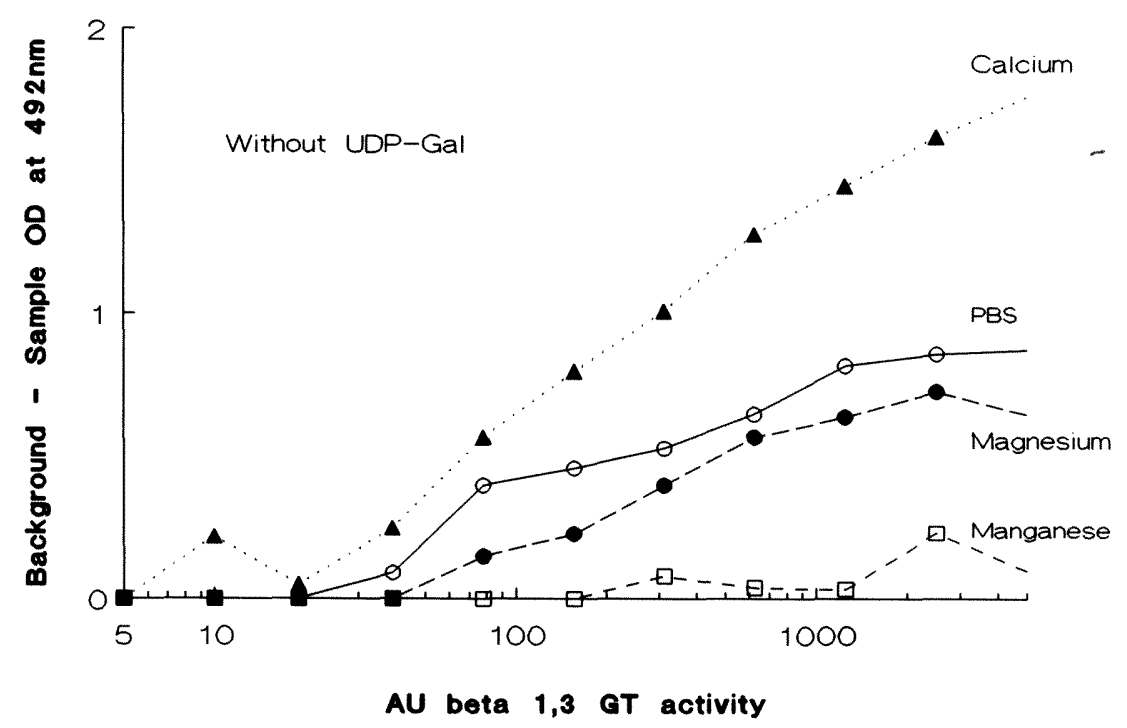

Figure 7.4 Effect of addition of divalent cations to the reaction mixture in $\beta 1,3 \mathrm{GT}$ assay. Compared to PBS (O) alone as reaction buffer. $\mathrm{Ca}^{2+}(\boldsymbol{\Delta})$ promotes VV binding to the acceptor, while $\mathrm{Mn}^{2+}(\square)$ appears to inhibit the enzyme activity. $\mathrm{Mg}^{2+}(\bullet)$ has no effect. Figure 7.4b Without UDP-Gal. Addition of UDP-Gal to the reaction mixture was not an absolute requirement of the assay system. 
Figure 7.5

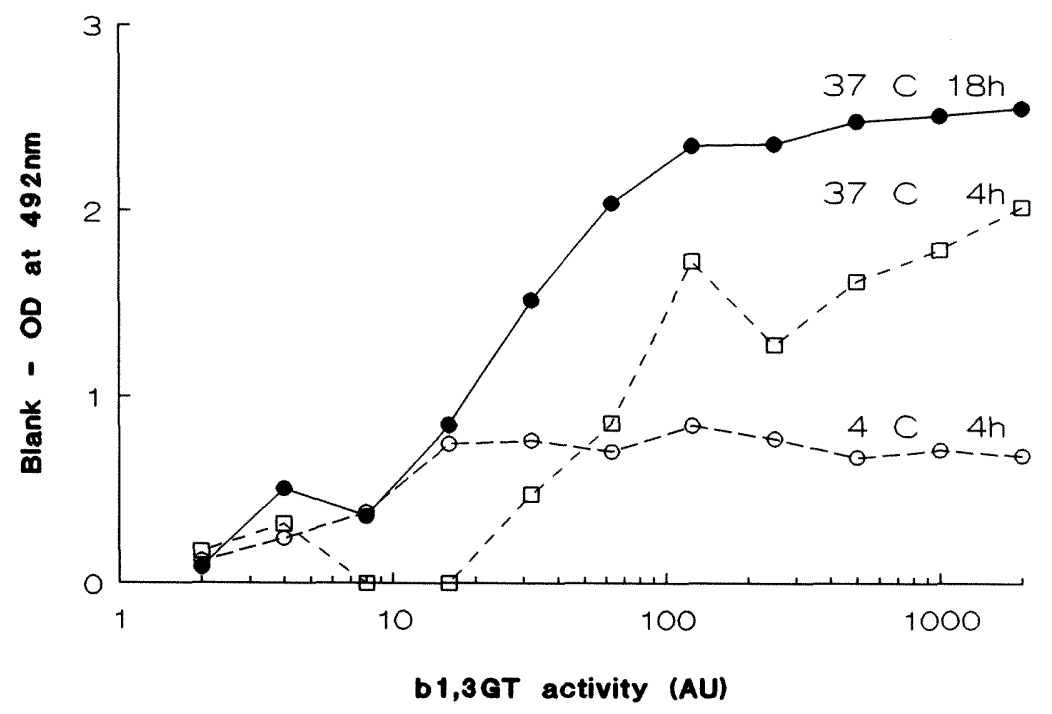

Figure 7.5 Effect of incubation time and temperature on $\boldsymbol{\beta 1 , 3 G T}$ assay. Acceptor incubated with standard lysate for $\bullet 18 \mathrm{~h}$ at $37^{\circ} \mathrm{C} \square 4 \mathrm{~h}$ at $37^{\circ} \mathrm{C} \quad \circ 4 \mathrm{~h}$ at $4^{\circ} \mathrm{C}$. The enzyme is more active at $37^{\circ} \mathrm{C}$ than $4^{\circ} \mathrm{C}$, and a greater change in the acceptor is detected with a longer incubation time. 


\section{CHAPTER EIGHT}

Leucocyte $\beta 1,3$ galactosyl transferase activity in $\operatorname{IgA}$ nephropathy 
The studies described in Chapter 6 showed that serum IgA1 from patients with IgAN has an increased binding affinity for lectins which recognise terminal O-linked GalNAc. One attractive interpretation of this finding is reduced galactosylation of the series of serine-linked carbohydrate moieties in the IgA1 hinge region, most of which usually take the form of Ga1 $\beta 1,3 \mathrm{GaINAc}$ with varying degrees of sialylation. Reduced galactosylation of IgG in RA and of glycophorins in the TnPS are associated with low or absent activity of the key galactosylating enzymes in affected cells (Berger 1978, Cartron 1978, Cartron 1979, Axford 1992a, Thurwher 1993). The experiments described in this chapter were designed to investigate the possibility that a similar phenomenon is responsible for the aberrant IgAl glycosylation observed in IgAN. To this end, the $\beta 1,3$ GT activity of lysed cells from patients with IgAN and matched controls was measured using the assay system developed in Chapter 7.

Abnormalities of both the mucosal and systemic arms of the $\operatorname{IgA}$ system have been reported in IgAN, but it seems most likely that the IgA1 deposited in the glomerular mesangium is derived from the systemic IgA system (Harper 1994a, Harper 1994b, Harper 1995b). Therefore, the search for cells expressing the putative galactosyltransferase deficiency would ideally be focussed on the bone marrow. However, obtaining samples from this site is an extremely invasive procedure, and the investigations were carried out using peripheral blood cells as a necessary compromise. A large proportion of circulating $\operatorname{IgA} B$ cells are probably in the process of trafficking to the mucosae, and may not be those responsible for the production of serum IgA1. The glycosylation status of secreted $\operatorname{Ig} \mathrm{A}$ in $\operatorname{IgAN}$ is unknown.

$\beta 1,3 \mathrm{GT}$ activity was first measured in unfractionated peripheral blood monounclear cells. However, the proportion of $B$ cells in such preparations is variable, and the majority of the cells are $T$ cells and monocytes, which do not produce $\operatorname{IgA}$. Most of the $\beta 1,3 \mathrm{GT}$ activity detected in PBMICs will be involved in the production of membrane proteins, and there is no evidence for any abnormality of such glycoproteins in IgAN. Indeed, the reduced O-galactosylation seems to be restricted to IgAl, siuce Clinh is normal or even over-galactosylated (Chapter 6). To attempt to focus the study onto IgA1-producing cells, the constituent cell populations were isolated from 
PBMCs, and their $\beta 1,3 \mathrm{GT}$ activities measured separately.

In order to relate the $\beta 1,3 \mathrm{GT}$ activity of the $\mathrm{B}$ cells to the $\mathrm{O}$-glycosylation of $\operatorname{IgA1}$, serum was obtained from the subjects at the same time as the cells. $\operatorname{IgAl} 1$ lectin binding was measured by two methods in this study. Firstly, IgAl was purified on jacalin agarose as before. In addition, ammonium sulphate precipitates were prepared from each serum sample to partially purify the immunoglobulin fraction and to remove as much Clinh as possible, since this is the other major serum protein with O-linked glycosylation. IgA was immobilised from these samples on anti-IgA coated plates and the lectins applied to these, as described in Chapter 4 , Section 4.4. This method is subject to error due to non-specific binding of other proteins to the plates at sample dilutions required to ensure saturation with $\operatorname{Ig} A$, and the complications of differing $\operatorname{Ig} A 1: \operatorname{Ig} A 2$ ratios in the samples. However, it avoids the drawbacks of the use of jacalin to purify $\operatorname{IgA1}$, thus possibly selecting only the most "normally" O-glycosylated IgA1 molecules. The lectin binding results by these two methods were considered together, bearing in mind the disadvantages of each. 


\subsubsection{Subjects}

For the measurement of $\beta 1,3 \mathrm{GT}$ activity in unfractionated PBMCs, $40 \mathrm{ml}$ venous blood was obtained from 12 patients with IgAN (9 male, mean age 45 years, range 17-63 years) and 11 controls ( 8 male, mean age 46 years, range 22-64 years). Details of these subjects are shown in Table 8.1.

Subsequently, the study was extended to measure $\beta 1,3 \mathrm{GT}$ activity in $\mathrm{B}$ cells, $\mathrm{T}$ cells and monocytes separately. For these experiments, $120 \mathrm{ml}$ venous blood was obtained from 9 patients with IgAN ( 2 male, mean age 33 years, range 23-51 years) and 12 controls (6 male, mean age 38 years, range 20-64 years). Details of this cohort of subjects are shown in Table 8.2 .

\subsubsection{Samples}

PBMCs were prepared from the blood samples by density gradient centrifugation as described in Chapter 3, Section 3.14.1, and, in the second part of the study, these were separated into B cell, $T$ cell and monocyte populations as described in Chapter 3, Section 3.14.2. The cells were lysed as outlined in Chapter 3, Section 3.14.4, and stored at $-70^{\circ} \mathrm{C}$ until required. All lysate samples to be compared to one another were collected, prepared and assayed within as short a period of time as possible (no more than 3 weeks), to minimise decay of enzyme activity during storage. Patient and control samples were collected together, not as patient group followed by control group, and differences in enzyme activities cannot be attributed to different lengths of storage time between these two subject groups.

The protein concentration of each lysate sample was measured with the Bio-Rad DC Protein Assay kit (Chapter 3, Section 3.6), using a separate aliquot frozen for this purpose.

Serum IgA1 was purified from the same samples as the fractionated PBMC populations, using the methods described in Chapter 3, Section 3.10. In addition, a $1 \mathrm{ml}$ aliquot of the ammonium 
sulphate precipitate prepared from each serum sample was passed twice through a Sephadex G25 column to exchange the buffer to PBS.

\subsection{3 $\quad \beta 1,3 G T$ assay}

The $\beta 1,3$ GT activity of the lysate samples was measured by the assay developed in Chapter 7 , using the protocol described in Section 7.2.3. All the lysate samples to be compared to one another were assayed in a single run to avoid interassay error.

\section{Acceptor}

Sufficient immunoplates for all the samples to be assayed were coated with the acceptor preparation at $50 \mu 1 /$ well, sealed, and incubated overnight at $4^{\circ} \mathrm{C}$.

\section{Lysate standard and samples}

Blank wells (no lysate), and a lysate standard curve consisting of eleven doubling dilutions ranging from 1:2 to 1:2048 were set up on each plate.

The lysate samples were thawed and diluted in PBS immediately before the assay. The samples were diluted to the same protein concentration as one another, and where possible, each sample was assayed at more than one protein concentration. For the whole PBMC preparations, the lysate samples were used at 200 , and when sufficient protein was available, $500 \mu \mathrm{g} / \mathrm{ml}$. The T cell, B cell and monocyte preparations were used at $250 \mu \mathrm{g} / \mathrm{ml}$, and when enough protein was available, at $660 \mu \mathrm{g} / \mathrm{ml}$.

$30 \mu \mathrm{l}$ aliquots of the lysate dilutions were applied to the wells in duplicate, and $10 \mu \mathrm{l} / \mathrm{well} 4 \mathrm{x}$ reaction buffer (Appendix II) added. The plates were then sealed and incubated overnight (18h) at $37^{\circ} \mathrm{C}$.

The actual protein concentration of each lysate dilution was measured, and the amount of protein in the $30 \mu \mathrm{l}$ aliquot applied to the wells calculated. 


\section{Completion of the assay}

The VV binding of the acceptor after incubation with the lysate samples was measured as described in the assay protocol (Chapter 7, Section 7.2.3).

\section{Calculation of the results}

The means of duplicate well were calculated, and the mean OD value for each sample subtracted from the blank value of the plate. The standard curve for each plate was constructed by plotting the subtracted $O D$ values against the assigned AU enzyme activity, and the AU results of the lysate samples read from the curve. The results were expressed in AU/ $\mu \mathrm{g}$, using the measured value of the protein applied per well. Where more than one lysate protein concentration had been used for an individual, the mean values obtained from the different dilutions were calculated.

\subsubsection{Lectin binding of serum IgA1}

The VV and AC lectin binding of IgA1 purified from the same blood samples as the fractionated $B$ cell, $T$ cell and monocyte populations was measured as described in Chapter 4 , Section 4.2 , and the results expressed as OD at 492nm.

The VV and AC lectin binding of the samples of ammonium sulphate precipitate prepared from these sera was also measured, using anti-IgA coated immunoplates to immobilise $\operatorname{IgA}$ from the samples, in the method described in Chapter 4 , Section 4.4 . The samples were applied to the wells at a dilution of 1:100, providing approximately the same IgA concentration as serum at 1:1000, which was found to be suitable for this method in the initial evaluations.

\subsubsection{Statistics}

$\beta 1,3 \mathrm{GT}$ activity in IgAN and control cell lysate samples assayed together were compared by unpaired $t$-tests, as were the lectin binding results of the $\operatorname{IgA} 1$ and ammonium sulphate precipitate samples prepared from patient and control sera. The relationship between lectin binding of purified $\operatorname{IgAl}$ and ammonium sulphate precipitates from the same serum samples, and the relationship between lectin binding of serum $\operatorname{IgA} 1$ and $\beta 1,3 \mathrm{GT}$ activity of $\mathrm{B}$ cell lysates from the 
same subjects was investigated by linear regression analysis.

\subsection{Results}

\subsubsection{B1,3GT activity in unfractionated PBMC lysates}

$\beta 1,3 \mathrm{GT}$ activity was measured in lysates of unfractionated peripheral blood mononuclear cells from 12 patients with IgAN and 11 controls. All the lysates were assayed at $200 \mu \mathrm{g} / \mathrm{ml}$. In addition, 19 lysates ( $9 \mathrm{IgAN}, 10$ control) were assayed at $500 \mu \mathrm{g} / \mathrm{ml}$. Different dilutions of the same lysate sample gave comparable results over this protein range (data shown in Table 8.3).

The $\beta 1,3 G T$ activity of PBMCs from patients with $\operatorname{IgAN}$ was significantly higher than that of matched controls, as shown in Figure 8.1.

\subsection{2 $\beta 1,3 G T$ activity in peripheral blood $B$ cell, $T$ cell and monocyte populations in IgAN and controls}

PBMCs from 9 patients with IgAN and 12 controls were fractionated into their constituent cell populations. Two monocyte lysates ( $1 \mathrm{IgAN}$ and 1 control) contained insufficient protein for the assay. $\beta 1,3 \mathrm{GT}$ activity of the rest of the lysates was measured at $250 \mu \mathrm{g} / \mathrm{ml}$ (approximately $12 \mu \mathrm{g}$ protein per well), and in addition, the T cell lysates were used at $660 \mu \mathrm{g} / \mathrm{ml}$ (approximately $20 \mu \mathrm{g}$ protein per well). The actual protein concentrations of the lysate dilutions were measured and used to calculate the $\beta 1,3 \mathrm{GT}$ activity in $\mathrm{AU} / \mu \mathrm{g}$. The mean values of the measurements made at two protein concentrations were calculated for the $T$ cell lysates.

Table 8.4 shows the B cell, T cell and monocyte $\beta 1,3 G T$ activities of lysates from patients with IgAN and controls. No difference was found between the T cell or monocyte enzyme activities of patients with IgAN and controls (Figure 8.2). However, the $B$ cell lysates from patients with IgAN had significantly lower $\beta 1,3 \mathrm{GT}$ activity than those of the controls (Figure 8.3). 
Linear regression analysis was carried out to look for any relationship between the enzyme activites of the different cell types in individuals, but no correlation was seen in this small number of subjects (data not shown).

\subsubsection{Lectin binding of $\operatorname{IgA1}$ and ammonium sulphate precipitate samples}

The lectin binding results of purified $\operatorname{IgA1}$ samples and $\operatorname{IgA}$ immobilised from ammonium sulphate precipitates on anti-IgA coated plates are shown in Table 8.5.

As before, purified IgA1 from patients with IgAN showed significantly higher binding to VV lectin than control, while AC binding did not differ between the groups. This was also seen in the ammonium sulphate precipitate samples. The VV binding of both patient and control groups showed a significant positive correlation between the purified $\operatorname{IgAl}$ and ammonium sulphate precipitate samples (all subjects grouped together, $r=0.734, p<0.001$; Figure 8.4), but no such relationship was seen with $\mathrm{AC}$ lectin binding $(\mathrm{r}=0.342, \mathrm{p}=0.129)$.

\subsubsection{Relationship between $B$ cell $\beta 1,3 G T$ activity and lectin binding of serum $\operatorname{IgA1}$}

The results of the regression analyses between $\mathrm{B}$ cell $\beta 1,3 \mathrm{GT}$ activity and lectin binding of $\operatorname{IgAl}$ from the corresponding sera are shown in Table 8.6. No correlation was seen between B cell $\beta 1,3 \mathrm{GT}$ activity and $\mathrm{IgA1}$ lectin binding by either method in controls. In IgAN, a strong negative correlation was found between B cell $\beta 1,3 \mathrm{GT}$ activity and Vicia villosa binding of $\operatorname{IgA}$ in the ammonium sulphate precipitates $(r=-0.87, p=0.002)$, as shown in Figure 8.5. No such relationship was seen with $\mathrm{AC}$ binding, or with lectin binding to the purified $\operatorname{IgAl}$ samples.

There was no correlation between IgAl lectin binding and T cell or monocyte $\beta 1,3 \mathrm{GT}$ activities in either IgAN or control subjects (data not shown). 


\subsection{Conclusions}

The initial experiments in this chapter demonstrated an increase in $\beta 1,3 G T$ activity in unfractionated PBMCs from patients with IgAN as compared to control subjects. The study was then extended to study the activity of this enzyme in separated $B$ cells, $T$ cells and monocytes from peripheral blood. No difference was found in the $\mathrm{T}$ cell or monocyte $\beta 1,3 \mathrm{GT}$ activity, but B cell enzyme activity was significantly lower in IgAN than controls.

The binding of lectins to the O-linked glycans of serum $\operatorname{IgA1}$ from the same subjects was also measured, and as expected, the IgAN subjects displayed a raised expression of terminal O-linked GalNAc. This was apparent by lectin binding assays carried out on jacalin-purified $\operatorname{IgA1}$, and $\operatorname{Ig} A$ immobilised from ammonium sulphate precipitates of serum on anti-IgA coated immunoplates, and the VV binding results obtained by these two methods correlated with one another, demonstrating that increased VV binding is not an artefact of jacalin-purification. AC binding did not differ between patients and controls by either method, and nor was there any correlation between the data obtained from the two methods with this lectin.

The VV lectin binding of the ammonium sulphate precipitate samples showed a significant negative correlation with $\beta 1,3 \mathrm{GT}$ activity of the corresponding $B$ cells in patients with $\operatorname{IgAN}$, but not in controls. No relationship between $\mathrm{B}$ cell $\beta 1,3 \mathrm{GT}$ activity and $\mathrm{AC}$ binding was apparent, and nor was there any relationship between $T$ cell or monocyte enzyme activity and any lectin binding to $\operatorname{IgAl}$.

\section{5 $\mathbb{D}$ iscussion}

The O-glycosylation defect of IgAl in IgAN has not been fully characterised, but the increased binding of lectins with affinity for terminal GaINAc indicate that it may take the form of a lack of terminal galactosylation of $\mathrm{O}$-linked moieties. The experiments described in this chapter attempted to investigate the activity of the enzyme responsible for this galactosylation in peripheral blood cells from patients with $\operatorname{IgAN}$. The use of an acceptor made from IgA1 itself, and of VV lectin to detect galactosylation changes tailor the assay system to identify changes 
specifically in the putative enzyme activity involved in this defect. The finding that B cell $\beta 1,3 \mathrm{GT}$ activity appears to be reduced in IgAN strongly supports the hypothesis that increased GaINAc expression by $\operatorname{IgA} 1$ is indeed due to the failure to fully galactosylate the moieties to produce the usual Gal $\beta 1,3 \mathrm{GalNAc}$ form. Furthermore, the activity of this galactosylating enzyme in B cells showed a significant negative correlation with terminal GalNAc expression of serum IgA1 as judged by VV lectin binding in patients with IgAN, intriguingly suggesting a causal relationship. No such relationship was seen in controls; presumably the control IgA1 is fully galactosylated in all the available sites, and its lectin binding is not therefore related to the limiting factor of enzyme activity. In normal serum $\operatorname{IgA1}$, one in five of the O-linked glycans are ungalactosylated (Baenziger 1974b, Field 1989), though the reason for this is not known. This study cannot indicate whether the IgA1-producing B cells are partially or completely lacking in IgAl Ogalactosylating activity. A partial reduction seems more likely, since there is no evidence for abnormalities of $\mathrm{O}$-glycosylation of membrane proteins in IgAN, and the serum IgAN, though consistently abnormal in its lectin binding characteriatics, is not grossly so. IgA1-producing B cells constitute only a proportion of circulating B cells. In addition, most of these will probably be trafficking to the mucosae, and are not those responsible for the production of serum $\operatorname{IgA} 1$. It may be that there is a subpopulation of B cells which is completely lacking in $\beta 1,3 \mathrm{GT}$ activity, such as in the TnPS, but where these may reside remains a mystery. Little is known about the factors controlling $\beta 1,3 \mathrm{GT}$ gene expression and activity, though since other major Ig isotypes are not O-glycosylated, the enzyme may be linked to the IgA1 switch event. Failure to correctly activate O-galactosylation of $\operatorname{IgA1}$ in IgAN may be another manifestation of the numerous modest dysregulations of $\operatorname{Ig} A$ biology seen in this condition.

The assay employed in this study cannot indicate whether the apparent functional deficiency reflects low absolute levels of enzyme, lack of availability at the appropriate intracellular site, or some abnormality which compromises its activity. The factors controlling the expression of galactosyltransferase genes are not well understood, and a lack of the enzyme within the cell could arise from some mutation within the gene itself, or to an abnormality of control proteins or mechanisms. The enzyme may be transcribed and translated normally, with the apparent functional deficiency arising from a structural abnormality rendering it inefficient in its catalysing role. Lack of activity in vivo may be due toenzyme localisation at an intracellular site removed 
from the nascent $\operatorname{IgA} 1$ protein, or to inaccessibilty of the acceptor glycans due to some conformational anomaly in the $\operatorname{IgA} 1$ molecule, though these mechanisms would not show up in an in vitro assay utilising whole cell extracts and a manufactured substrate such as the one used here. Targetting of glycosyltransferases to different subcellular compartments under various situations is a concept which is currently generating interest as a mechanism of control of protein glycosylation. The apparently low enzyme activity could also be due to the presence of an inhibitor, or to a competing substrate. An inhibitor could be detected by the failure of additional purified enzyme to correct the apparent deficiency. $\beta 1,3 \mathrm{GT}$ has not been isolated, rendering such experiments impossible at this time, though in theory, mixing normal and deficient lysates would give the same information. Further elucidation of this conundrum awaits isolation of the enzyme and cloning of the gene.

No abnormality of $\beta 1,3 \mathrm{GT}$ activity could be detected in separated $\mathrm{T}$ cell or monocyte populations in IgAN, though in the initial part of the study, the enzyme activity of unfractionated PBMCs in a different cohort of patients was raised when compared to controls. The reason for this inconsistency is not clear. In Chapter 6, serum Clinh showed low binding to VV lectin in IgAN, though this apparent decrease in GalNAc expression, which could be due to increased galactosylation, was not confirmed by a parallel decrease in HA binding. It is interesting to note in this context that in one report of low $B$ cell $\beta 1,4 \mathrm{GT}$ activity in RA, monocyte enzyme activity was found to be raised (Axford 1987), though this was not confiumed by subsequent investigations (Axford 1992a). It may be that a failure of galactosylation in one arm of the immune system can result in a slight compensatory increase elsewhere, though there is no direct evidence for such a speculation. 


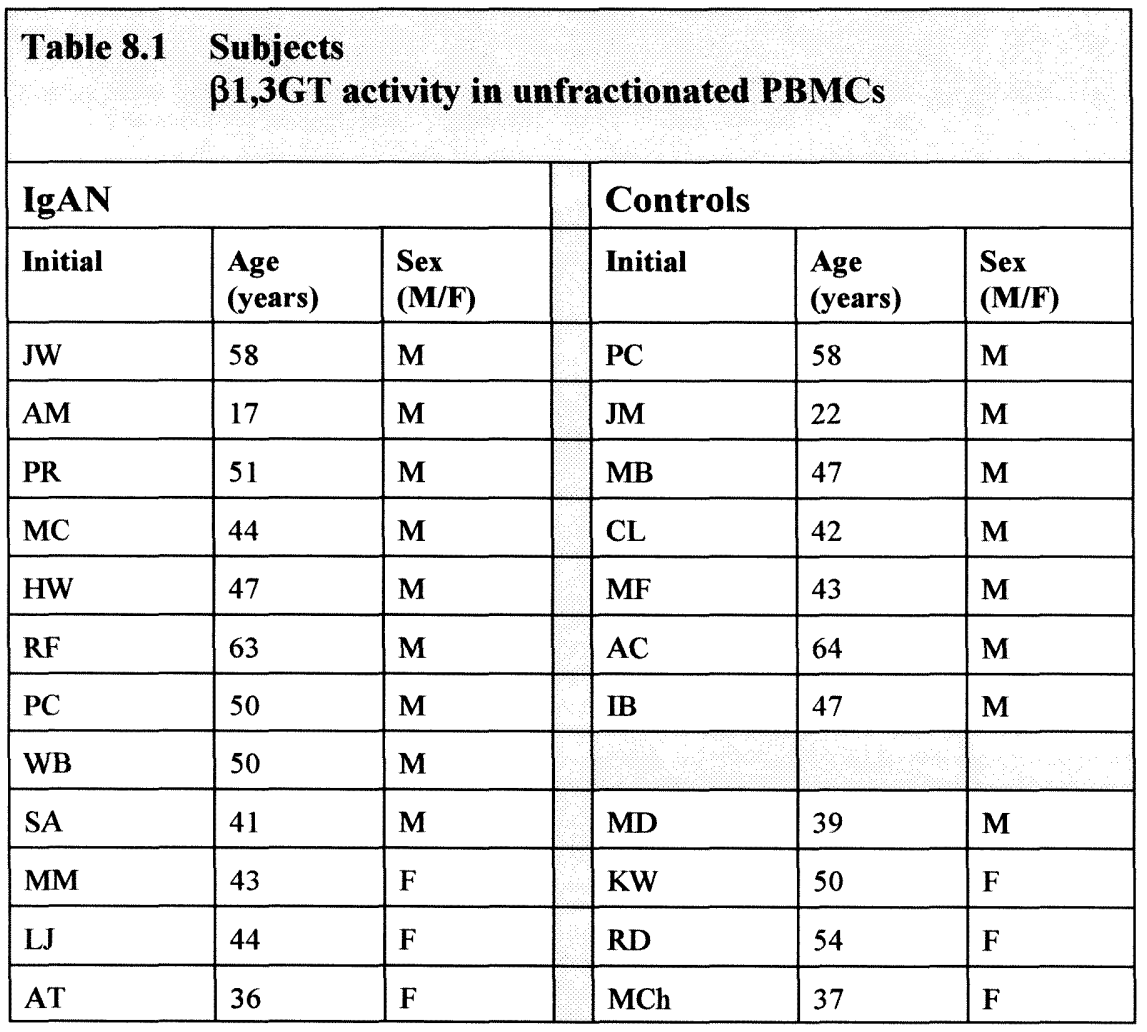




\begin{tabular}{|l|l|l|l|l|l|l|}
\hline Table 8.2 & $\begin{array}{l}\text { Subjects } \\
\beta 1,3 G T \text { activity in peripheral blood B cells, T cells and } \\
\text { monocytes }\end{array}$ \\
\hline IgAN & $\begin{array}{l}\text { Age } \\
\text { (years) }\end{array}$ & $\begin{array}{l}\text { Sex } \\
\text { (M/F) }\end{array}$ & Initial & $\begin{array}{l}\text { Age } \\
\text { (years) }\end{array}$ & $\begin{array}{l}\text { Sex } \\
\text { (M/F) }\end{array}$ \\
\hline Initial & 32 & M & AL & 28 & M \\
\hline JL & 26 & M & PT & 28 & M \\
\hline MB & 45 & F & AC & 64 & M \\
\hline MM & 23 & F & TS & 65 & M \\
\hline NC & 23 & F & AS & 33 & M \\
\hline JF & 32 & F & AA & 32 & F \\
\hline SM & 46 & F & MS & 43 & F \\
\hline LJ & 51 & F & EB & 51 & F \\
\hline JW & 23 & F & SC & 23 & F \\
\hline NM & & & AN & 20 & F \\
\hline & & & DD & 26 & F \\
\hline & & & & 44 & M \\
\hline
\end{tabular}




\begin{tabular}{|c|c|c|c|c|c|}
\hline Table 8.3 & \multicolumn{5}{|c|}{$\begin{array}{l}\beta 1,3 G T \text { activity in unfractionated PBMCs } \\
\text { IgAN and Controls }\end{array}$} \\
\hline \multicolumn{3}{|l|}{$\operatorname{Ig} \mathbf{A N}$} & \multicolumn{3}{|l|}{ Controls } \\
\hline$\beta 1, \mathbf{3 G T}$ & & $\mathbf{A} \mathbf{U} / \mu \mathbf{g}$ & $\beta 1, \mathbf{3 G} \mathbf{T}$ & & $\mathbf{A U} / \mu \mathbf{g}$ \\
\hline \multirow{2}{*}{$\begin{array}{l}\text { [Protein] } \\
200\end{array}$} & \multirow{2}{*}{$\begin{array}{l}(\mu \mathrm{g} / \mathbf{m l}) \\
\mathbf{5 0 0}\end{array}$} & & \multirow{2}{*}{\multicolumn{2}{|c|}{$\begin{array}{ll}{[\text { Protein] }} & (\mu \mathrm{g} / \mathrm{ml}) \\
200 & 500\end{array}$}} & \\
\hline & & Mean & & & Mean \\
\hline 3.0 & 3.6 & 3.3 & 2.9 & 2.4 & 2.7 \\
\hline 2.3 & 4.6 & 3.5 & 6.5 & - & 6.5 \\
\hline 6.5 & 9.8 & 8.2 & 6.5 & 5.2 & 5.9 \\
\hline 11.0 & - & 11.0 & 2.1 & 4.0 & 3.0 \\
\hline 9.5 & 17.6 & 13.6 & 1.4 & 1.8 & 1.6 \\
\hline 14.0 & 15.6 & 14.8 & 2.3 & 1.4 & 1.9 \\
\hline 6.5 & - & 6.5 & 2.0 & 2.3 & 2.2 \\
\hline 6.5 & 9.6 & 8.1 & 4.5 & 4.2 & 4.4 \\
\hline 6.0 & - & 6.0 & 6.0 & 4.6 & 5.3 \\
\hline 8.5 & 8.4 & 8.5 & 1.8 & 1.4 & 1.6 \\
\hline 1.9 & 2.7 & 5.6 & 4.4 & 3.8 & 4.1 \\
\hline 6.3 & 5.4 & 5.9 & & & \\
\hline $\operatorname{Ig} A N$ & $\begin{array}{l}\text { Mean } \\
( \pm \text { SEM })\end{array}$ & $\begin{array}{l}7.9 \\
(1.1)\end{array}$ & Control & $\begin{array}{l}\text { Mean } \\
( \pm \text { SEM })\end{array}$ & $\begin{array}{l}3.3 \\
(0.6)\end{array}$ \\
\hline
\end{tabular}




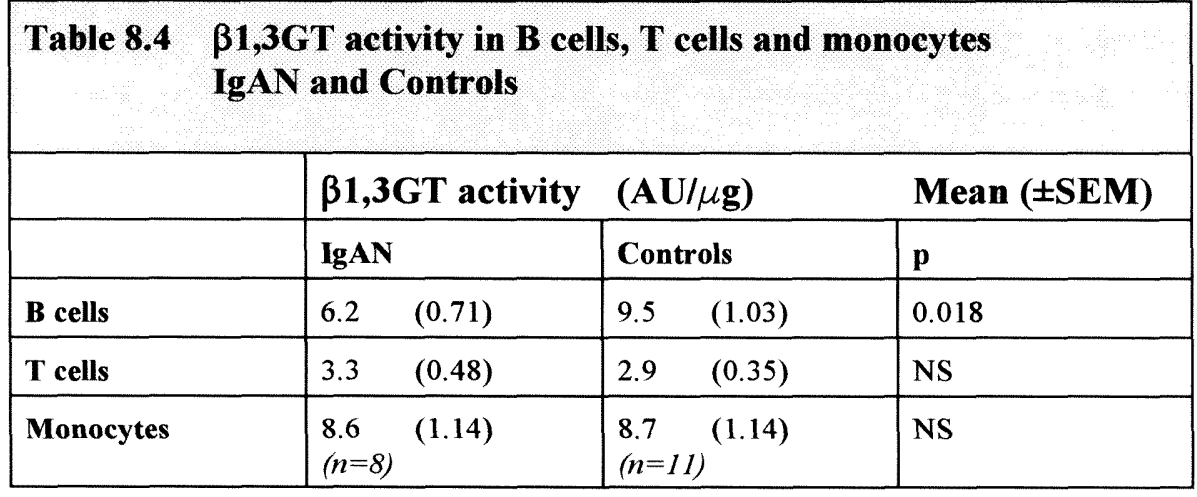

\begin{tabular}{|c|c|c|c|c|}
\hline \multirow[t]{2}{*}{ Table 8.5} & \multicolumn{4}{|c|}{$\begin{array}{l}\text { Lectin binding of serum IgA } \\
\text { Purified IgA1 samples and ammonium sulphate } \\
\text { precipitates }\end{array}$} \\
\hline & & IgAN & Control & $\mathbf{p}$ \\
\hline Lectin & Sample type & OD at $492 \mathrm{~nm}$ & Mean $( \pm$ SEM) & \\
\hline \multirow[t]{2}{*}{$V V$} & Purified IgAI & $0.91 \quad(0.05)$ & $0.70 \quad(0.07)$ & 0.021 \\
\hline & $\begin{array}{l}\text { Ammonium } \\
\text { sulphate ppt }\end{array}$ & $0.20 \quad(0.02)$ & $0.10 \quad(0.02)$ & 0.007 \\
\hline \multirow[t]{2}{*}{$A C$} & Purified IgAI & $2.33 \quad(0.03)$ & $2.42 \quad(0.06)$ & NS \\
\hline & $\begin{array}{l}\text { Ammonium } \\
\text { sulphate ppt }\end{array}$ & $1.36 \quad(0.04)$ & $1.27 \quad(0.08)$ & NS, \\
\hline
\end{tabular}




\begin{tabular}{|c|c|c|c|c|c|}
\hline Table 8.6 & \multicolumn{5}{|c|}{$\begin{array}{l}\text { Relationship of B cell } \beta 1,3 G T \text { activity to } \lg A 1 \text { lectin } \\
\text { binding }\end{array}$} \\
\hline \multicolumn{2}{|l|}{$\begin{array}{l}\text { B cell } \\
\beta 1,3 G T \\
\text { activity } \\
v s:\end{array}$} & \multicolumn{2}{|l|}{ IgAN } & \multicolumn{2}{|c|}{ Control } \\
\hline Lectin & Sample type & $\mathbf{r}$ & $\mathbf{p}$ & $\mathbf{r}$ & p \\
\hline \multirow[t]{2}{*}{$V V$} & $\begin{array}{l}\text { Purified } \\
\text { IgAI }\end{array}$ & -0.456 & NS & 0.520 & NS \\
\hline & $\begin{array}{l}\text { Ammonium } \\
\text { sulphate ppt }\end{array}$ & -0.872 & 0.002 & 0.200 & NS \\
\hline \multirow[t]{2}{*}{$A C$} & $\begin{array}{l}\text { Purified } \\
\text { IgAI }\end{array}$ & 0.224 & NS & 0.049 & NS \\
\hline & $\begin{array}{l}\text { Ammonium } \\
\text { sulphate ppt }\end{array}$ & -0.330 & NS & -0.150 & NS \\
\hline
\end{tabular}


Figure 8.1

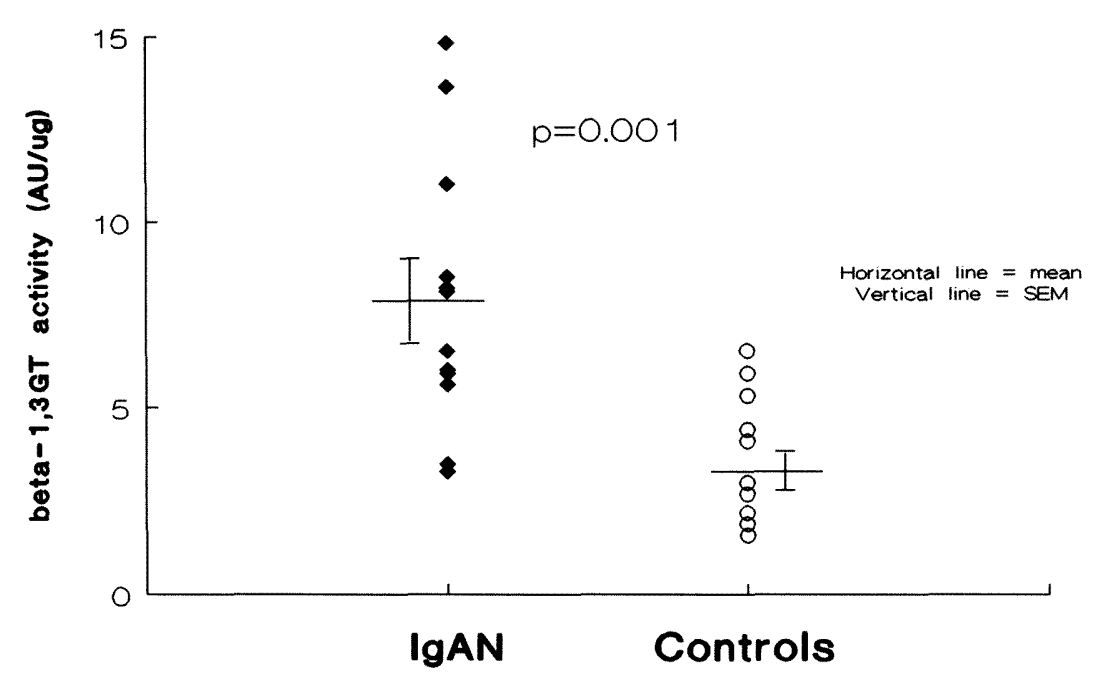

Figure 8.1 Whole PBMC $\beta 1,3 \mathrm{GT}$ activity in IgAN and controls. $\beta 1,3 \mathrm{GT}$ activity was significantly higher in lysates of unfractionated PBMCs from patients with IgAN $(\diamond)$ than controls $(\circ)(p=0.001)$. 


\section{Figure $\mathbf{8 . 2}$}

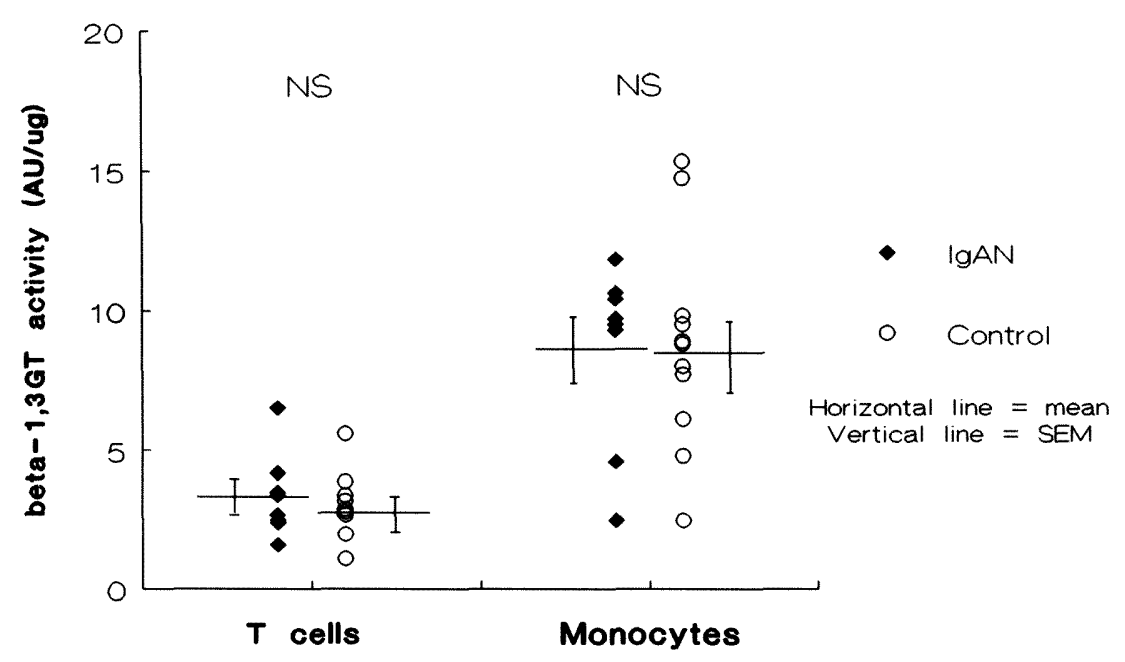

Figure 8.2 T cell and monocyte $\beta 1,3 \mathrm{GT}$ activity in IgAN and controls. There was no difference in $\beta 1,3 \mathrm{GT}$ activity in T cell or monocyte lysates from patients with $\operatorname{IgAN}(\bullet)$ and controls $(0)$. 
Figure 8.3

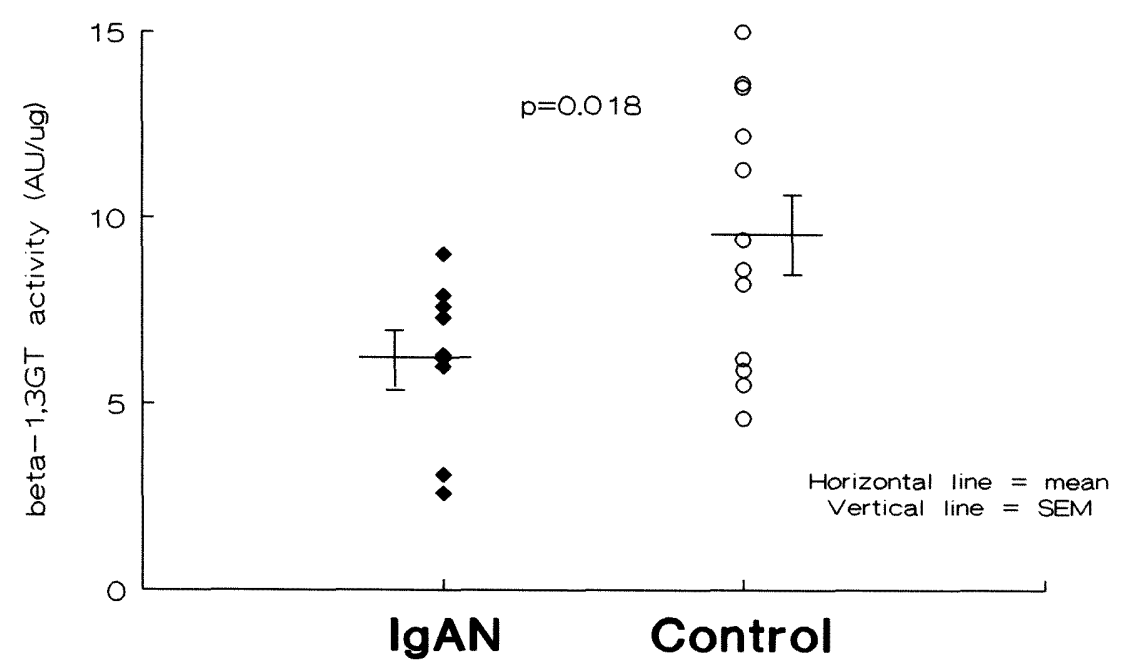

Figure 8.3 B cell $\beta 1,3 G T$ activity in IgAN and controls. B cells from patients with IgAN $(\diamond)$ showed significantly lower $\beta 1,3 \mathrm{GT}$ activity than controls $(O)(p=0.018)$. 


\section{Figure 8.4}

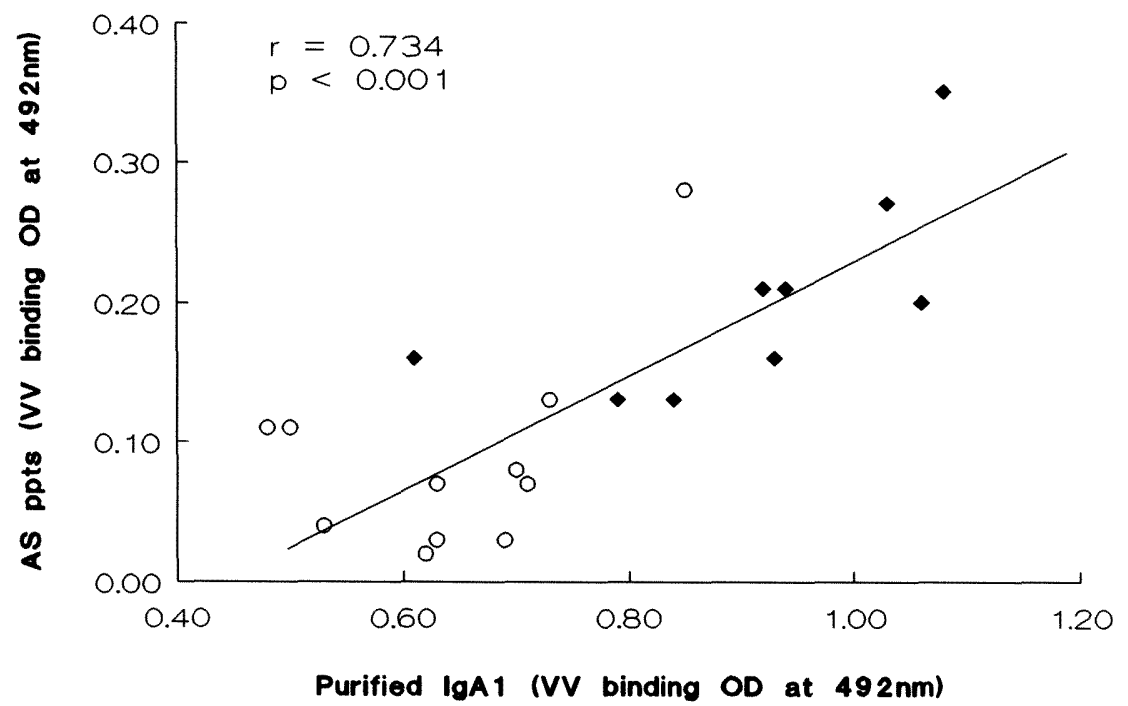

Figure 8.4 Correlation of VV lectin binding by jacalin-purified $\operatorname{IgA1}$ samples and IgA immobilised on anti-IgA coated immunoplates. All samples shown; $\bullet \operatorname{IgAN}$, o Control. $\operatorname{IgAl}$ isolated from the same sera by two methods showed the same VV lectin binding pattern $(r=0.734, p<0.001)$. 
Figure $\mathbf{8 . 5}$

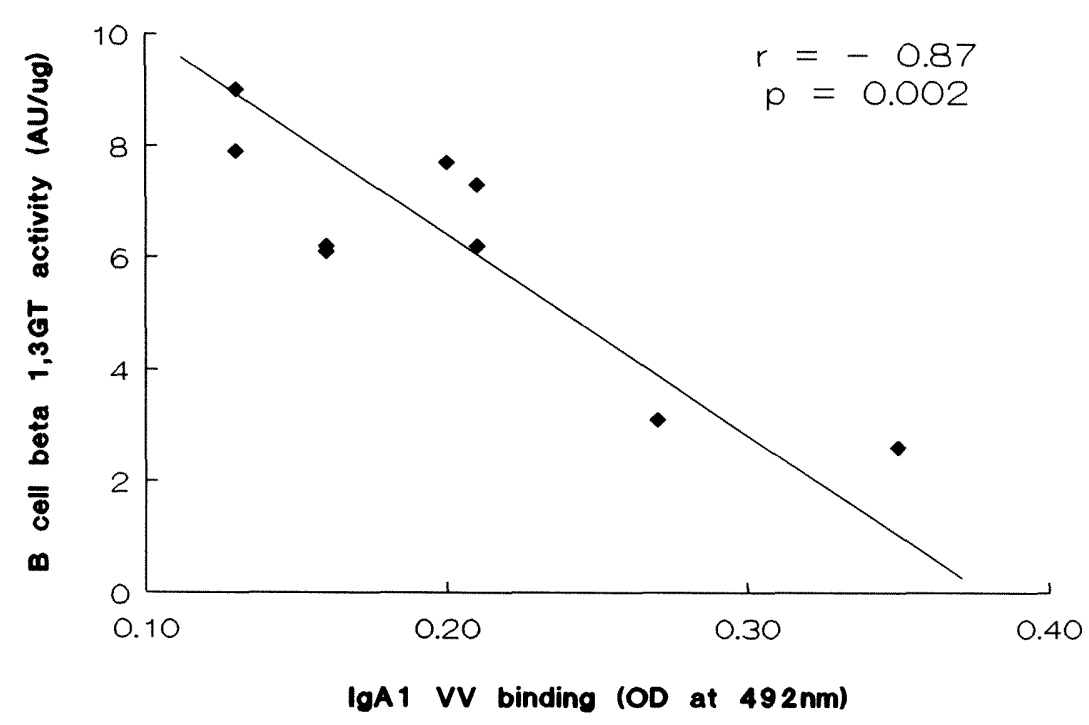

Figure 8.5 Correlation of B cell $\beta 1,3 G T$ activity and serum IgA1 VV binding in IgAN. VV binding of $\operatorname{IgA}$ immobilised on anti- $\operatorname{IgA}$ coated immunoplates showed an inverse relationship with $B$ cell $\beta 1,3 \mathrm{GT}$ activity from the same blood sample in patients with $\operatorname{IgAN}(r=-0.87, \mathrm{p}=0.002)$. 


\section{CHAPTER NINE}

Discussion 


\subsection{Summary of the thesis}

As the most prevalent cause of glomerulonephritis in developed countries, and accounting for some $10 \%$ of the world's dialysis population, IgA nephropathy is an important disease (d'Amico 1987). Despite the numerous moderate irregularities of IgA biology described in patients affected by IgAN, the fundamental pathogenic process is still a mystery. Its elucidation is a priority, since the means of identifying subjects with a poor prognosis, and development of effective and specific treatment strategies for them, awaits our further understanding.

As outlined in chapter 1, two key questions remain :

- Why does IgA1 deposit in the glomerular mesangium?

- How does this lead to glomerular injury?

Much of the research effort applied to the study of $\operatorname{IgAN}$ has focussed upon $\operatorname{IgA}$ as an antibody and the IgA immune system, and though many modest abnormalities have been reported, none can provide satisfactory answers to the above questions. The work described in this thesis aimed to approach the problem from a different angle, and was based upon the possibility that a physicochemical rather than immunological feature of $\operatorname{IgAl}$ may be responsible for mesangial deposition and subsequent glomerular damage. A handful of preliminary observations had implied that the carbohydrate component of IgAl may be unusual in IgAN (Andre 1990, Hiki 1992, Coppo 1993, Mestecky 1993). The studies comprising this thesis further explore the nature, biochemical basis and possible pathogenic implications of the putative glycosylation abnormality.

The experiments forming this study were all based upon the use of lectins to detect glycosylation changes. Though this approach has been used before, these studies extended the application of lectin-binding assays and employed lectins not previously evaluated for IgA1 binding. Therefore, much of the methodology was novel. Chapter 4 describes the development and evaluation of lectin-binding assays for $\operatorname{Ig} \mathrm{Al}$, and Chapter 7 that of a new assay system for the functional activity of the $O$-galactosylating enzyme $\beta 1,3$ galactosyltransferase in cell lysates. 
IgAl is an unusual serum protein in its possession of both $\mathrm{N}$ - and $\mathrm{O}$-linked glycans. Taking the results of the early studies of IgA1 glycosylation in IgAN together, the evidence suggested that the apparent abnormality lies within the O-linked moieties. The first set of experiments in the present study (Chapter 5) attempted to investigate $\mathrm{N}$-linked glycosylation using a lectin-binding method verified for the simpler situation of IgG (Griffiths 1989, Sumar 1990). The results were somewhat conflicting and difficult to interpret, and definitive evidence for an abnormality of IgAl $\mathrm{N}$-linked glycosylation in IgAN awaits the application of more advanced methodology.

The remainder of the thesis concentrates on the O-linked moieties of $\operatorname{IgAl}$ in IgAN. Chapter 6 employed a range of lectins in ELISA-type binding assays, and strongly suggested that IgA1 in IgAN has some physical or biochemical abnormality which results in increased availability of terminal O-linked GalNAc. Though lectin-binding assays alone cannot be used to define precisely the composition and structure of carbohydrate moieties, one explanation of the data is reduced terminal galactosylation of the $\mathrm{O}$-linked glycans.

The studies in Chapter 8 showed that B cell lysates from patients with IgAN have reduced ability to alter lectin binding to a degalactosylated IgA1-derived acceptor preparation. This reduction was inversely proportional to the lectin-binding of $\operatorname{IgA} 1$ from the same subject. These findings may indicate low levels of $B$ cell $\beta 1,3 G T$ activity in IgAN, and add weight to the supposition that the raised affinity of GalNAc-binding lectins for $\operatorname{IgA} 1$ in $\operatorname{IgAN}$ is due to a lack of terminal galactose.

\subsection{Technical limitations of the studies}

The interpretation of the data obtained from these studies is limited by some technical considerations.

\subsection{1 $\operatorname{IgA1}$ isolation}

The lack of a practical and satisfactory method of isolating IgA1 from other serum proteins is a persistent problem. Jacalin purification is subject to a number of criticisms: the selection of 
molecules by the very determinants under investigation can never be an ideal method, and the yield is only some $25 \%$ of total serum $\operatorname{IgAl}$. The characteristics of the unbound molecules are not known, and it is to be expected that those molecules with gross abnormalities of O-linked glycosylation would fail to bind jacalin. However, the following observations made during the course of this work suggest that jacalin purification may be an acceptable compromise in the absence of any better method :

- The increased GalNAc lectin binding of jacalin-purified IgA1 in IgA1 is shared by antibody-immobilised $\operatorname{Ig} \mathrm{A}$

- $\quad \operatorname{IgA1}$ samples sequentially purified from jacalin have the same lectin binding profiles as one another, suggesting that retention of molecules with high jacalin-binding affinity is not a major problem.

Immobilisation of $\operatorname{IgA1}$ on antibody-coated immunoplates provided an alternative method for lectin binding assays, but suffered from a lack of specificity at serum dilutions required for reliable saturation. This was less of a problem if an antibody to both IgA subclasses was used, but introduced the factor of variation in $\operatorname{Ig} A 1: \operatorname{IgA} 2$ ratios.

Both methods of IgA isolation demonstrated the same abnormality of lectin binding to O-linked glycans in patients with IgAN. In the light of this finding, the simpler method of anti-IgA immobilsation may be used to isolate $\operatorname{IgA1}$ from serum samples. The small amount of $\operatorname{IgA} 2$ copurified by this method does not appear to mask the results of lectin binding to O-linked sugars, which are exclusively present on IgA1. Furthermore, it may be possible to desigu experiments using a property such as charge to identify and quantify the glycosylation abnormality in the patients, though the higher degree of $\mathrm{N}$-glycosylation of $\operatorname{IgA} 2$ than $\operatorname{IgA} 1$ may diminish differences contributed by the $\mathrm{O}-$ linked glycans of $\operatorname{IgA} 1$ in this approach. 


\subsubsection{Lectin binding assays}

Studies of lectin binding can indicate abnormalities of protein glycosylation, but cannot define them precisely when used alone. In IgG, lectin binding has been related to N-galactosylation defined by mass spectrometry of released glycans (Griffiths 1989, Sumar 1990), but no such work has been carried out on IgA. Lectins are readily available, economical, and convenient to use, but many are poorly characterised and may be non-specific in their binding characteristics. Factors other than variations in monosaccharide chains may well play a part in dictating the binding of lectins to glycoproteins. The accessibility of the moieties to the lectin binding sites, particularly in the case of short, closely located series of glycans such as those of the IgA1 hinge region, is a relevant example. Raised affinity of $\operatorname{IgA} 1$ for GalNAc-binding lectins in $\operatorname{IgAN}$ may be due to altered tertiary or quateruary structure of the protein domain or to differences in carbohydrate composition. The use of a range of different lectins with similar specificities goes some way towards reducing the uncertainties of the data.

\subsubsection{Sialylation}

One major issue which was not addressed in these studies is that of sialylation. Sialic acid is among the most biologically siguificant elements of a glycoprotein, since it is a highly negatively charged, reactive entity, and constitutes the labile terminal component of carbohydrate chains. Sialylation is variable and easily affected by the in vitro handling of the protein, and changes in this aspect of protein glycosylation are therefore difficult to assess and to interpret. Changes in sialylation alone may account for the altered lectin binding observed in these and other studies, or may be the functionally relevent consequence of alterations in core sugars. This is one avenue of the investigation of the apparent abnormalities of IgA1 glycosylation in IgAN which needs to be explored.

\subsection{Interpretation of the findings}

The lectin-binding studies described here suggest that $\mathrm{O}$-linked GalNAc expression by $\operatorname{IgAl}$ is increased in IgAN, but cannot supply a precise definition of the abnormality. The finding of a 
reduction in the IgA1 O-galactosylation activity of B cells in IgAN indicates that the high GalNAc expression may well be due to truncation of Gal $\beta 1,3$ GalNAc moieties, but this is indirect evidence. Elongation of the moieties with additional GalNAc could also be accompanied by reduced $\beta 1,3 G T$ activity, with a GalNAc-transferase active instead. Full characterisation of the defect awaits mass spectrometric or HPLC analysis of O-glycans released by exoglycosidases or hydrazinolysis.

\subsubsection{Tunctional consequences of abnormal $\mathrm{Ig} \mathbb{A} 1$ O-glycosylation}

Despite the undefined basis of its altered lectin-binding profile, it seems established that $\operatorname{IgAl}$ in IgAN interacts abnormally with certain other proteins via its O-linked carbohydrate moieties, displaying increased binding affinity for GalNAc-binding lectins in this study, and reduced affinity for jacalin in other reports (Coppo 1993, Mestecky 1993). This leads to speculation as to whether the in vivo, functional interactions of IgAl may be similarly deranged, and whether this may contribute to the pathogenesis of $\operatorname{IgAN}$.

The O-linked carbohydrate moieties of the IgA1 hinge region constititute the preferred recognition motif of the hepatic ASGPR, and therefore are crucial to its handling in vivo, since this is the major catabolic pathway of $\operatorname{IgA1}$ (Stockert 1982, Tomana 1988, Moldoveanu 1990). Altered IgA1 hinge region glycosylation may therefore have important implications. Increased serum levels of $\operatorname{IgA1}$ in IgAN may not be entirely attributable to increased production, but also to decreased clearance. Furthermore, impairment of the usual catabolic route may lead to deposition of $\operatorname{Ig} A 1$ in less usual sites such as the renal mesangium. This is particularly likely to happen with the larger molecular weight forms of $\operatorname{IgA1}$, such as polymers, or IgA1-containing immune complexes.

The other biological roles of the carbohydrate components of IgA1 are not well understood. In other proteins, O-linked glycans are known to influence the structural aspects of the domain in which they occur, conferring an extended, rod-like formation (Jentoft 1990), and this may well apply to the IgA1 hinge region. What effect alterations in the O-linked glycans may have in this regard can only be speculated upon, but it may be that truncated moieties are less efficient in 
maintaining an extended structure than galactosylated and sialylated forms, thus reducing the physical distance between the Fab and Fc domains of the molecule.

The $\mathrm{CH} 2$ domain of the Fc region of antibody molecules is important in effector functions, since the Fc receptor and complement binding sites are located here (Jefferis 1993). The O-linked carbohydrates of $\operatorname{IgAl}$ are adjacent to this region, and appear to be involved in the interaction with leucocyte Fc $\alpha$ receptors. IgA1 molecules lacking O-glycosylation sites have been produced by site directed mutagenesis, and fail to effectively ligate the Fc $\alpha \mathrm{R}$ (Burton 1992, Woof 1994). This may be because the glycans are actually part of the recognition motif, or because their presence is required to confer a molecular structure which renders the ligand accessible and recognisable to the receptor. Whichever of these mechanisms are responsible, alterations in the O-linked moieties may affect the binding of FcaRs.

The relevance of these considerations to the pathogenesis of $\operatorname{IgAN}$ is unproven, but intriguing. Human mesangial cells have recently been shown to express an Fc $\alpha$ R (Gomez-Guerrero 1993, Allen 1994), and though this is as yet uncharacterised, and its ligand undefined, it seems reasonable to speculate that $O$-linked glycans may be involved, as they are with the leucocyte Fc $\alpha$ R. One of the many roles of mesangial cells is clearance of mesangial debris by receptor mediated endocytosis (Mene 1989, Baker 1994). Altered O-linked glycosylation of deposited IgA1 may result in a failure of this pathway due to impaired ligation of mesangial cell FcaR

Though a complete lack of O-glycosylation prevents $\operatorname{IgA} 1$ from binding to the leucocyte Fc $\alpha R$, it is possible that alterations in the glycans could result in increased affinity for the receptor. This may provide a pathway by which deposited IgA1 results in glomerular injury, since ligation of both leucocyte and mesangial FcaRs leads to cell activation and initiation of inflammatory events.

The complement binding site of $\operatorname{IgA}$ is also located in the $\mathrm{CH} 2$ domain. It is not known whether the hinge region $\mathrm{O}$-linked sugars of $\operatorname{IgA} 1$ are involved in the interaction with complement, but it is certainly a possibility, and N-linked glycosylation has indeed been shown to be required for complement activation by IgA (Zhang 1994). One of the immunological abnormalities reported in IgAN is an apparent increase in circulating IgA-containing complexes with a variety of other 
components which may or may not be antigens (Chapter 1 , Sections 1.9, 1.15). This may be a consequence of the impairment of hepatic clearance alluded to above. However, altered IgA1 glycosylation also has the potential to affect persistence of immune complexes by compromising complement binding, since complement fixation interferes with lattice formation and solubilises large immune complexes which may otherwise be liable to inappropriate deposition.

The abnormality of IgA1 O-linked glycosylation in IgAN is inferred from altered lectin binding potential. The same mechanism could influence binding to other proteins in vivo, promoting nonimmunological complex formation, and accounting for the increased levels of IgA complexes described in the serum of the patients (Chapter 1, Section 1.9). It is also not inconceivable that binding to mesangial matrix components may also be enhanced by lectin-like interactions. The size of true immune complexes is known to be affected by antibody affinity, a qualitative property of an immune response. If altered O-glycosylation affects the structure of the IgAl hinge region, possibly shortening it, the antibody-antigen binding may be affected by steric hindrance resulting from the proximity of the rest of the $\operatorname{IgA} 1$ molecule. Low $\operatorname{IgA}$ affinity has indeed been described in IgAN, and implicated in the formation of large, nephritogenic immune complexes (Layward 1994a).

\subsubsection{Mechanism of abnormal $\operatorname{Ig} \mathbb{A} 10$-glycosylation}

The underlying reason for production of abnormally glycosylated $\operatorname{IgA} 1$ in $\operatorname{Ig} A N$ camnot be fully elucidated until the precise nature of the abnormality is described, but the experiments described in Chapter 8 suggest that a functional deficiency of $\beta 1,3 \mathrm{GT}$ in $\mathrm{B}$ cells could be at least partly responsible. This enzyme is yet to be isolated and cloned and therefore it is impossible to say whether the defect is quantitative or qualitative, whether it lies at the protein or gene level, or whether some intracellular inhibitory factor may be involved. Intracellular control of glycosyltransferase activity is not well understood, and the apparent deficiency could be due to its localisation within some subcellular compartment distant from that of the mascent protein, to appropriate or inapproapriate inhibitors of enzyme activity, or to the presence of another competing substrate. Similarly, the factors controlling the expression of glycosyltransferase genes are shrouded in mystery. In the TnPS, $\beta 1,3$ GT deficiency has been attributed to the repression 
of a functional gene in a clone of affected cells (Thurnher 1993), and a comparable mechanism may be responsible in IgAN. Since IgM, IgG, IgE and IgA2 all lack O-linked glycans, expression of the enzymes required for their assembly may be linked to the IgA1 switch signal. Failure of enzyme expression could be attributed either to aberrant $T$ cell control, or to lack of a proper $\mathrm{B}$ cell response. Abnormalities of both $\mathrm{T}$ and $\mathrm{B}$ cell function in other respects have been reported in IgAN (reviewed in Chapter 1, Section 1.9).

Alternatively, the apparently altered glycosylation of serum $\operatorname{IgAl}$ in IgAN may reflect the disproportionate representation of a normal glycoform in the "wrong" place or at the "wrong" time. For example, in IgAN, there is evidence of increased production of $J$ chain-containing IgA polymer in the bone marrow, with decreased mucosal production, suggesting a shift of "mucosaltype" IgA1 production to a systemic location (van den wall Bake 1988b, Harper 1994a, Harper 1994b, Harper 1995b). IgA1 secreted into milk is slightly differently glycosylated to systemic IgAl, the O-linked glycans being extended with GlcNAc (Pierce-Cretel 1981). It may be that the high GalNAc expression detected in serum IgA1 in IgAN is a feature normally displayed by $\operatorname{IgA1}$ from some other mucosal compartment.

Another possibility is that glycoforms may undergo subtle changes during the development of an immune response, and the altered lectin binding profile of serum $\operatorname{IgA} 1$ in $\operatorname{IgAN}$ could be a manifestation of the general upregulation of the IgA system often described in this condition (Chapter 1 , Section 1.9). Equally, it may be a sign of immunological immaturity, since there is also evidence of a failure of normal affinity maturation of $\operatorname{IgA}$ immune responses in $\operatorname{IgAN}$ (Layward 1994a). 


\subsection{Final conclusions}

In summary, abnormal O-linked glycosylation of serum IgA seems established in IgAN, but its biological basis and pathogenic implications are as yet only speculative. This abnormality does, however, have the potential to provide some answers to the key questions posed at the start of this chapter.

\section{Why does $\operatorname{Ig} A$ deposit in the glomerular mesangium?}

Altered O-linked glycosylation may :

- promote formation of nephritogenic IgA complexes

- reduce clearance of the various forms of $\operatorname{IgA1}$ firom the circulation via the ASGPR

- $\quad$ promote $\operatorname{IgA} 1$ deposition by interaction with mesangial components

- prevent clearance of $\operatorname{IgA1}$ from the mesangium by impairment of ligation of the mesangial cell Fc $\alpha$ R.

\section{How does deposition of Ig A lead to glomerular injury?}

Altered O-linked glycosylation may :

- increase binding of deposited IgAl to leucocyte Fc $\alpha \mathrm{R}$ and trigger leucocyte activation

- activate mesangial cells via increased Fc $\alpha \mathbf{R}$ ligation, raising extracellular matrix production and initiating inflammatory cascades.

Clearly, research into aberrant IgA1 glycosylation in IgAN is in its early stages, and many of the complexities outlined above await further understanding of basic mechanisms in protein glycosylation. However, this is the first physical abnormality of the $\operatorname{IgA} 1$ molecule described in nearly 30 years of intense investigation, and may eventually explain several of the pathogenic features of this often perplexing disease. 
APPENDIX I

Ethical Committee Approval 


\section{LEICESTERSHIRE HEALTH AUTHORITY}

Director of Public Health

and District Medical Officer

Dr. G. M. Morgan MB, BS. MRCP, MFPHM, DRCOG

Your Ref:

My Ref:
Department of Public Health Medicine 20.28 Princess Road West

LEI 6TY

\section{Telephone}

eicester 10533) 559777

Extn.

Dear Dr. Feehally,

\section{$\frac{\text { Longitudinal Study of IGA Immune System Parameters in }}{\text { IGA Nephropathy }}$}

Firther to your application dated 4th April, 1991, you will be pleased to know that the Ethical Committee at its meeting held on the 3rd May, 1991 approved your request to undertake the above-mentioned research.

I would remind you, however, that your research project has been given approval only in relation to its acceptability from an ethical point of view. If, subsequently, departure from the methodology outlined in your protocol is contemplated, the Ethical Committee must be advised in order that the proposed changes may be approved. Also a report should be made to the Ethical Committee if any significant adverse reactions are noted during the course of the study.

In addition, any NHS resource implications of your project must be discussed with the appropriate Unit General Manager. Similarly, it may be that the research project has implications for other disciplines and, if so, you are advised to discuss them with the appropriate departmental manager. Researchers should also be able to assure the Ethical Committee that satisfactory arrangements have been made for the labelling, safe storage and dispensation of drugs and the District Pharmaceutical Officer and his staff are always willing to provide advice on this.

Researchers' attention is also drawn to correspondence from the Regional Director of Public Health dated 28th January, 1991 relating to Clinical Trials which sets out revision of the procedures to be followed, and the Clinical Trials Indemnity Letter and Deed of Guarantee. Researchers should ensure that these indemnity arrangements have been complied with.

Researchers intending to study selective groups of patients in the community are reminded that their first approach should be to the individual patient's general prectiticicior patient was suitable for inclusion in the study. Equally, when the researcher contacts the patient it should be emphasised that the approach is made with the knowledge of the General Practitioner, with whom the patient may discuss this research, if the patient so wished.

Yours sincerely,

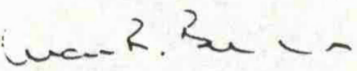

Director of Public Health and

i District Medical Officer.

Dr. J. F eehally,

Consultant Nephrologist,

Leicester General Hospital. 
APPENDIX II

Buffers and Solutions 
All chemicals and reagents were purchased from Sigma except where stated otherwise.

\section{GENERAL REAGENTS}

Phosphate buffered saline (PBS)

To 11 in $\mathrm{DI} \mathrm{H}_{2} \mathrm{O}$ :

$\begin{array}{ll} & \mathrm{g} \\ \mathrm{NaCl} & 8 \\ \mathrm{KCl} & 0.2 \\ \mathrm{Na}_{2} \mathrm{HPO}_{4} & 1.15 \\ \mathrm{KH}_{2} \mathrm{PO}_{4} & 0.2\end{array}$

Acids

IM solutions

To 11 in DI H ${ }_{2}$ O :

$\mathrm{HCl} \quad \mathrm{ml}$

$\mathrm{H}_{2} \mathrm{SO}_{4} \quad 28$

(The concentrated acids were always added slowly to excess water) 


\section{ELISA AND LECTIN BINDING ASSAYS}

\section{Coating buffer}

$0.05 \mathrm{M} \mathrm{NaHCO}_{3}, \mathrm{pH} 9.6$

Approximately 9 parts $1 \mathrm{M} \mathrm{NaHCO}\left(8.4 \mathrm{~g} / 100 \mathrm{ml} \mathrm{DI} \mathrm{H}_{2} 0\right)$ and approximately 1 part $1 \mathrm{M}$ $\mathrm{Na}_{2} \mathrm{CO}_{3}\left(10.6 \mathrm{~g} / 100 \mathrm{ml} \mathrm{DI} \mathrm{H}_{2} 0\right)$ mixed to adjust $\mathrm{pH}$ to 9.6 .

Diluted 1:20 in DI $\mathrm{H}_{2} 0$ for use.

Washing buffer

PBS/O.3M NaCl/0.1\% Tween 20

In 11 PBS :

$\mathrm{NaCl} 20.75 \mathrm{~g}$

Tween $20 \quad 1 \mathrm{ml}$

BSA blocking solution

$$
\begin{aligned}
& 2 \% \text { BSA in PBS } \\
& \text { In } 100 \mathrm{ml} \mathrm{PBS} \mathrm{:}
\end{aligned}
$$

Fraction $\mathrm{V}$ bovine serum albumin

\section{GSSG blocking solution}

$2 \mathrm{mg} / \mathrm{ml}$ oxidised glutathione in PBS

In 100ml PBS :

Oxidised gluathione

$200 \mathrm{mg}$

Substrate buffer

$0.1 M$ citric acid/phosphate, $p H 5$

To $100 \mathrm{ml}$ in $\mathrm{DI} \mathrm{H}_{2} \mathrm{O}$ :

Citric acid. $\mathrm{H}_{2} \mathrm{O}$

$\mathrm{Na}_{2} \mathrm{HPO}_{4} 12 \mathrm{H}_{2} \mathrm{O}-2.39$

Made up freshly each day 


\section{$\mathrm{OPD} / \mathrm{H}_{2} \mathrm{O}_{2}$ substrate}

To $12 \mathrm{ml}$ substrate buffer :

$\begin{array}{ll}\text { OPD } & 8 \mathrm{mg}(4 \times 2 \mathrm{mg} \text { tablets, Dako }) \\ 30 \% \mathrm{H}_{2} \mathrm{O}_{2} & 5 \mu \mathrm{l}\end{array}$

Made up immediately before use, and protected from light

\section{SDS-PAGE}

\section{Gel buffers}

1.5M Tris $\mathrm{HCl}, \mathrm{pH} 8.8$

To 11 in $\mathrm{DI} \mathrm{H}_{2} \mathrm{O}$ :

Tris base $\quad 182 \mathrm{~g}$

$1 \mathrm{M} \mathrm{HCl} \quad 256 \mathrm{ml}$
$0.5 \mathrm{M}$ Tris $\mathrm{HCl}, \mathrm{pH} 6.8$

$\begin{array}{ll}\text { Tris base } & 60.6 \mathrm{~g} \\ \mathrm{lM} \mathrm{HCl} & 440 \mathrm{ml}\end{array}$

\section{Polyacrylamide gels}

$30 \%$ acrylamide/N'N-

Stacking gel Separating gels

$\begin{array}{lll}4 \% & 12 \% \quad 15 \% \quad 20 \%\end{array}$

bis-methylene-acrylamide

(BioRad) in DI $\mathrm{H}_{2} \mathrm{O}$

$\begin{array}{lcccc}\mathrm{ml} & 1.25 & 3.35 & 5.0 & 6.7 \\ \mathrm{ml} & - & 2.5 & 2.5 & 2.5 \\ \mathrm{ml} & 2.5 & - & - & - \\ \mathrm{ml} & 6.1 & 4.0 & 2.35 & 0.65\end{array}$

1.5M Tris $\mathrm{HCl}, \mathrm{pH} 8.8$

DI $\mathrm{H}_{2} \mathrm{O}$

$\mathrm{ml} \quad 6.1$

$\begin{array}{lll}4.0 & 2.35 & 0.65\end{array}$

Degassed for $15 \mathrm{~min}$, then immediately before casting :

$\begin{array}{lrcrrr}10 \% \text { w/v SDS in DI } \mathrm{H}_{2} \mathrm{O} & \mu \mathrm{l} & 100 & 100 & 100 & 100 \\ 0.05 \% \text { APS in DI } \mathrm{H}_{2} \mathrm{O} & \mu 1 & 50 & 50 & 50 & 50 \\ \text { TEMED } & \mu \mathrm{l} & 10 & 5 & 5 & 5\end{array}$

Sample buffer

$\mathrm{ml}$

$0.5 \mathrm{M}$ Tris $\mathrm{HCl}, \mathrm{pH} 6.8$

Glycerol $\quad 1.6$

$10 \%$ SDS $w / v$ in DI $\mathrm{H}_{2} \mathrm{O} \quad 3.2$

2-ME 0.8

$1 \% \mathrm{w} / \mathrm{v}$ bromophenol blue $\quad 0.1$ 


\section{Running buffer}

\section{To 11 in $\mathrm{DI} \mathrm{H}_{2} \mathrm{O}$ :}

$\begin{array}{lr} & \mathrm{g} \\ \text { Tris base } & 3.0 \\ \text { Glycine } & 14.4 \\ \text { SDS } & 1.0\end{array}$

\section{Coomassie blue stain}

$0.25 \%$ Brilliant Blue R/40\% methanol/7\% acetic acid

Concentrate purchased from Sigma and diluted to 11 in $\mathrm{DI} \mathrm{H}_{2} \mathrm{O}$ according to manufacturer's instructions.

\section{Destain}

$40 \%$ methanol $10 \%$ acetic acid

To 11 in DI $\mathrm{H}_{2} \mathrm{O}$ :

Methanol

Glacial acetic acid $\quad 100$

Equilibration buffer for soaking gels prior to drying

$40 \%$ methanol $/ 10 \%$ acetic acid $3 \%$ glycerol

To 11 in DI $\mathrm{H}_{2} \mathrm{O}$ :

Methanol

Glacial acetic acid 100

Glycerol $\quad 30$

\section{WESTERN BLOTTING}

Electrophoretic transfer buffer

25mM Tris/192mM glycine/20\% methanol

To 11 in $\mathrm{DI} \mathrm{H}_{2} \mathrm{O}$ :

Tris base

Glycine

g $\quad 3.03$

Methanol

g $\quad 14.4$

ml 200 


\section{DAB substrate}

SigmaFast DAB tablet sets (to make $15 \mathrm{ml}$ ) purchased from Sigma, and used according to manufacturer's instructions :

To $15 \mathrm{ml} \mathrm{DI} \mathrm{H} \mathrm{H}_{2} \mathrm{O}$, immediately before use :

DAB tablets

Urea $\mathrm{H}_{2} \mathrm{O}_{2}$ tablets

1

\section{IgA1 PURIFICATION ON JACALIN AGAROSE}

Tris HCl

$0.175 \mathrm{M}$ Tris $\mathrm{HCl}, \mathrm{pH} 7.5$

To 1.41 in DI $\mathrm{H}_{2} \mathrm{O}$ :

Tris base $\quad \mathrm{g} \quad 30$

$1 \mathrm{M} \mathrm{HCl} \quad \mathrm{ml} \quad 200$

$1 \mathrm{M}$ galactose for elution

IM galactose in Tris $\mathrm{HCl}$

To $100 \mathrm{ml} 0.175 \mathrm{M}$ Tris $\mathrm{HCl}, \mathrm{pH} 7.5$ :

D-galactose $18 \mathrm{~g}$

Jacalin-agarose storage buffer

$0.15 \mathrm{M} \mathrm{NaCl} / 0.1 \mathrm{M} \mathrm{CaCl}_{2} / 0.02 \mathrm{M}$ galactose/0.01M HEPES/0.08\% $\mathrm{NaN}_{2}$ )

To 11 in DI H $\mathrm{H}_{2} \mathrm{O}$ :

$1 \mathrm{M}$ HEPES in DI $\mathrm{H}_{2} \mathrm{O}$

$\mathrm{NaCl}$

$\mathrm{CaCl}_{2}$

ml $\quad 10$

D-galactose

$\mathrm{NaN}_{2}$

g $\quad 8.76$

g $\quad 11.1$

g 3.6

g $\quad 0.8$ 


\section{IgG PURIFICATION ON COMPOSITE GEL FILTRATION/ION EXCHANGE} COLUMN

Stock solutions of phosphate buffers
$0.5 \mathrm{MNa}_{2} \mathrm{HPO}_{4}$
$0.5 \mathrm{MNaH}_{2} \mathrm{PO}_{4}$
To 11 in DI $\mathrm{H}_{2} \mathrm{O}$ :
$\mathrm{Na}_{2} \mathrm{HPO}_{4} \cdot 2 \mathrm{H}_{2} \mathrm{O}$
$89 \mathrm{~g}$
$\mathrm{NaH}_{2} \mathrm{PO}_{4} \cdot 2 \mathrm{H}_{2} \mathrm{O}$
$78 \mathrm{~g}$

Working solutions of phosphate buffers

$0.2 M$ phosphate buffer, $\mathrm{pH} 7.2$

Approximately 4 parts $0.5 \mathrm{M} \mathrm{Na}_{2} \mathrm{HPO}_{4}$ and 1 part $\mathrm{NaH}_{2} \mathrm{PO}_{4}$, to adjust $\mathrm{pH}$ to 7.2 , then diluted 1:2.5 in $\mathrm{DI} \mathrm{H}_{2} \mathrm{O}$ to adjust molarity.

$0.02 M$ phosphate buffer, pH7.2

Approximately 4 parts $0.5 \mathrm{M} \mathrm{Na}_{2} \mathrm{HPO}_{4}$ and 1 part $\mathrm{NaH}_{2} \mathrm{PO}_{4}$, to adjust $\mathrm{pH}$ to 7.2 , then diluted 1:25 in DI $\mathrm{H}_{2} \mathrm{O}$ to adjust molarity.

$0.02 \mathrm{M}$ phosphate/1M $\mathrm{KCl}$

To 11 in $0.02 \mathrm{M}$ phospahte buffer, $\mathrm{pH} 7.2$ :

$\mathrm{KCl} \quad 74.6 \mathrm{~g}$

CELL SEPARATION BY DENSITY GRADIENT CENTRIFUGATION AND MAGNETIC BEADS

HBSS

HBSS/1OMM HEPES

To 500ml HBSS (Life Technologies) :

1M HEPES (Life Technologies) $5 \mathrm{ml}$

HBSS/10mM HEPES/1\% FCS

To $500 \mathrm{ml}$ HBSS/10mM HEPES :

FCS (Life Technologies) 


\section{STAINING OF CYTOSPIN CELL PREPARATIONS}

Acetone/methanol fixative

$50 \%$ acetone $/ 50 \%$ methanol

$\begin{array}{ll}\text { Acetone } & 10 \mathrm{ml} \\ \text { Methanol } & 10 \mathrm{ml}\end{array}$

Tris buffered saline (TBS)

$0.05 M T B S, p H 7.6$

To 11 in DI $\mathrm{H}_{2}$ O :

Tris base $\quad \mathrm{g} \quad 6.56$

$\begin{array}{lll}\mathrm{NaCl} & \mathrm{g} & 8.52\end{array}$

$1 \mathrm{M} \mathrm{HCl} \quad \mathrm{ml} \quad 480$

AP substrate buffer

0.IM Tris $\mathrm{HCl}, \mathrm{pH} 8.2$

To 11 in DI $\mathrm{H}_{2} \mathrm{O}$ :

Tris base $\mathrm{g} \quad 12.1$

$1 \mathrm{M} \mathrm{HCl} \quad \mathrm{ml} \quad 48$

\section{AP substrate}

Naphthol AS-MX phosphate/Fast Red substrate

Naphthol AS-MX phosphate $\quad$ g $\quad 0.02$

$\mathrm{N}, \mathrm{N}$ dimethyl formamide

$\mathrm{ml} 2$

Dissolved in a polypropylene tube, and then added to :

$0.1 \mathrm{M}$ Tris $\mathrm{HCl}, \mathrm{pH} 8.2$

$1 \mathrm{M}$ levamisole in DI $\mathrm{H}_{2} \mathrm{O}$

$\mathrm{ml} \quad 98$

$\mathrm{ml} \quad 0.1$

Immediately before use :

Fast Red TR salt

Filtered and protected from light. 


\section{Haematoxylin solution}

$10 \% \mathrm{w} / \mathrm{v}$ haematoxylin (Gurr Certistain; BDH)

in absolute ethanol

$\mathrm{ml} \quad 50$

$10 \% \mathrm{w} / \mathrm{v}$ potassium alum in

hot DI $\mathrm{H}_{2} \mathrm{O}$

$\mathrm{ml} \quad 1000$

This solution was brought to boiling point, removed from the heat and the following added :

Yellow mercuric oxide (while still hot)

g $\quad 2.5$

Glacial acetic acid (when solution had cooled)

ml 40

The haematoxylin was filtered and stored at RT.

\section{$\boldsymbol{\beta} 1,3 G T$ ASSAY}

Reaction buffer ( $4 x$ concentration)

ImM UDP-Gal/8OmM $\mathrm{CaCl}_{2}$ in PBS

To $10 \mathrm{ml} \mathrm{PBS}$ :

UDP-Gal $\mu \mathrm{g} \quad 6$

$\mathrm{CaCl}_{2} \cdot 2 \mathrm{H}_{2} \mathrm{O} \quad \mathrm{mg} \quad 118$ 
APPENDIX III

Suppliers 
Appleton Woods Ltd

Birmingham B29 6EN

Amersham International Ltd Little Chalfont

Buckinghamshire HP7 9NA

\section{BDH/Merck Ltd}

Lutterworth

Leicestershire LE17 4XN

Bio-Rad Laboratories Ltd

Hemel Hempstead

Hertfordshire HP2 7TD

\section{Dako Ltd}

High Wycombe

Buckinghamshire HP13 5RE

Denley Ltd

Billingshurst

Sussex RH14 9EY

Dynal (UK) Ltd

Wirral

Merseyside L62 3PW

Gelman Sciences Ltd

Northampton NN4 0EZ

\section{ICN Flow Ltd}

Rickmansworth

Hertfordshire WD3 IPQ

Jencons Scientific Ltd

Leighton Buzzard

Bedfordshire LU7 8UA

Life Sciences International

Basingstoke

Hampshire RG21 2YH

Life Technologies/Gibco Ltd

Paisley PA3 4EF

Scotland

Sigma Chemical Company Ltd

Poole

Dorset BH17 7BR

The Binding Site Ltd

Birmingham B15 2SQ

Vector Laboratories Ltd

Peterborough PE3 8RF

Whatman International Ltd

Maidstone

Kent ME16 0LS 


\section{APPENDIX IV}

Publications and Presentations arising

from this work 


\section{Invited Editorial}

AC Allen. Abnormal glycosylation of $\operatorname{Ig} A$ - is it related to the pathogenesis of $\operatorname{Ig} A$ nephropathy? Nephrol Dial Transplant 1995:10(7):1121-1124.

\section{Peer reveiwed publications}

AC Allen, PS Topham, SJ Harper and J Feehally. Leucocyte $\beta 1,3$ galactosyltransferase activity in IgA nephropathy. Clin Exp Immunol 1996 (in press).

AC Allen, SJ Harper and J Feehally. Galactosylation of N- and O-linked Carbohydrate Moieties of IgAl and IgG in IgA Nephropathy. Clin Exp Immunol 1995:100(3);470-474 .

\section{Published abstracts}

AC Allen, PS Topham, SJ Harper and J Feehally. Reduced $\beta 1,3$ galactosyltransferase activity in the B cells of patients with IgA nephropathy. J Am Soc Nephrol 1995;6(3):820.

AC Allen, SJ Harper, J Feehally. Reduced IgAl galactosylation and increased $\beta 1,3$ galactosyltransferase activity in IgA nephropathy. J Am Soc Nephrol 1994:5(3):739.

AC Allen, SJ Harper and J Feehally. Reduced terminal galactosylation of the O-linked carbohydrates of IgA1 with raised peripheral blood mononuclear cell $\beta 1,3$ galactosyl transferase activity in IgA nephropathy. Glycosylation and Disease 1994;1(3):215.

AC Allen, L Layward, SJ Harper and J Feehally. IgA1 in IgA nephropathy (IgAN) has increased hinge region N-acetyl galactosamine. J Am Soc Nephrol 1993:4(3);592.

AC Allen, HR Griffiths, L Layward, SJ Harper and J Feehally. Serum IgA in IgA nephropathy has altered terminal oligosaccharide profile. Ann Rheum Dis 1992:51;1283. 


\section{Presentations at national and international conferences}

AC Allen, PS Topham, SJ Harper and J Feehally. Reduced $\beta 1,3$ galactosyltransferase activity in the B cell of patients with IgA nephropathy. Poster presentation, British Renal Association Spring Meeting, Oxford, March 1996.

AC Allen, SJ Harper, J Feehally. Reduced IgAl galactosylation and increased $\beta 1,3$ galactosyltransferase activity in $\operatorname{IgA}$ nephropathy. Oral presentation, American Society of Nephrology, Orlando FL, October 1994.

AC Allen, SJ Harper and J Feehally. Abnormal O-linked galactosylation of $\operatorname{IgAl}$ in $\operatorname{IgA}$ nephropathy. Oral presentation, British Renal Association Autumn Meeting, London, October 1994.

AC Allen, SJ Harper and J Feehally. Reduced terminal galactosylation of the O-linked carbohydrates of IgA1 with raised peripheral blood mononuclear cell $\beta 1,3$ galactosyl transferase activity in IgA nephropathy. Poster presentation, 3rd Jenner International Glycoimmunology Meeting, Italy, October 1994.

AC Allen, SJ Harper, L Layward and J Feehally. Increased O-linked $\mathrm{N}$-acetyl galactosamine in the hinge region of $\operatorname{IgAl}$ in IgA nephropathy. Oral presentation, IgA Nephropathy International Symposium, Adelaide, Australia, February 1994.

AC Allen, L Layward, SJ Harper and J Feehally. Altered O-linked glycosylation in the hinge region of $\operatorname{IgA} 1$ in $\operatorname{IgA}$ nephropathy. Poster presentation, British Society for Immunology First Annual Congress, Brighton, December 1993.

AC Allen, L Layward, SJ Harper and J Feehally. IgAl in IgA nephropathy (IgAN) has increased hinge region N-acetyl galactosamine. Poster presentation, American Society of Nephrology 26th Annual Meeting, Boston MA, November 1993. 
AC Allen, L Layward, SJ Harper and J Feehally. Altered terminal galactosylation of the N-linked carbohydrate moieties of IgA in IgA nephropathy. Poster presentation, British Renal Association Spring Meeting, Leicester, April 1993.

AC Allen, HR Griffiths, L Layward, SJ Harper and J Feehally. Serum IgA in IgA nephropathy has altered terminal oligosaccharide profile. Poster presentation, 2nd Jenner International Glycoimmunology Symposium, London, November 1992.

AC Allen, HR Griffiths, L Layward, SJ Harper and J Feehally. Altered terminal oligosaccharide moieties of serum IgA in IgA nephropathy. Poster presentation, IgA nephropathy "The 25th Year" International Symposium, Nancy, France, September 1992. 


\section{REFERENCES}


Alamartine E, Sabatier JC, Berthoux FC (1990) Comparison of pathological lesions on repeated renal biopsies in 73 patients with primary $\operatorname{IgA}$ glomerulonephritis: value of quantitative scoring and approach to final prognosis. Clin Nephrol 34:45-51.

Alavi A, Bond A, Brown ST, Arden N, Spector TD, Hay FC, Axford JS (1994) Glycosylation changes and pregnancy associated remission in rheumatoid arthritis (abstract). Glycosylation and Disease 1:222.

Albrechtsen M, Yeaman GR, Kerr MA (1988) Characterization of the IgA receptor from human polymorphonuclear leucocytes. Immunology 64:201-205.

Allen AC, Layward L, Harper SJ, Feehally J (1994a) In vitro immunoglobulin isotype suppression in immunoglobulin A nephropathy. Exp Nephrol 2:166-170.

Allen AC, Greer MR, Combe C, Stewart WW, Harper SJ, Kerr MA, Feehally J (1994b) Binding of human IgA to human leucocytes and mesangial cells (abstract). J Am Soc Nephrol 5:739.

d'Amico G(1987) The commonest glomerulonepluritis in the world: IgA nephropathy. Q J Med 245:709-727.

d'Amico G (1988) Clinical features and natural history in adults with IgA nephropathy. Am J Kidney Dis 12:353-357.

Andre C, Berthoux FC, Andre F, Gillon J, Genin C, Sabatier J-C (1980) Prevalence of IgA2 deposits in IgA nephropathies. N Engl J Med 303:1343-1346.

Andire PM, le Pogamp P, Chevet D (1990) Impairment of jacalin binding to serum IgA in IgA nephropathy. J Clin Lab Anal 4:115-119.

Amdreoli SP, Bergstein JM (1989) Treatment of severe IgA nephropathy in children. Pediatr Nephrol 3:248-253.

Antonaci S, Serlenga E, Garafalo, Colizzi M, Schena FP (1989) Imbalance of T cell immunoregulatory subsets in primary IgA nephropathy. Cytobios 59:95-100.

Ashwell G, Harford J (1982) Carbohydrate-specific receptors of the liver. Ann Rev Biochem 51:531-554.

Aucouturier P, Pineau N, Brugier J-C, Mihaesco E, Duarte F, Slvaril F, Preud'homme J-L (1989) Jacalin: a new laboratory tool in immunochemistry and cellular immunology. J Clin Lab Anal 3:244-251.

Axford JS, Mackenzie L, Lydyard PM, Hay FC, Isenberg DA, Roitt IM (1987) Reduced B-cell galactosyltransferase activity in rheumatoid arthritis. Lancet ii:1486-1488. 
Axford JS, Hay FC (1991) Oligosaccharides, just the icing on the protein or are they of functional relevance? Br J Rheumatol 30:196-199.

Axford JS, Sumar N, Alavi A, Isenberg DA, Young A, Bodman KB, Roitt IM (1992a) Changes in normal glycosylation mechanisms in autoimmune theumatic disease. J Clin Invest 89:10211031.

Axford JS (1992b) Are oligosaccharides relevant to rheumatological disease? Rheumatology Now 9:19-21.

Axford JS (1994a) Glycosylation and theumatic disease: more than icing on the cake. J Rheumatol 21:1791-1795.

Axford JS, Alavi A (1994b) $\beta 1,4$ galactosyltransferase variation in rheumatoid arthritis (abstract). Glycosylation and Disease 1:221.

BBaenziger J, Kornfeld S (1974a) Structure of the carbohydrate units of IgA1 immunoglobulin.

I. Composition, glycopeptide isolation and structure of the asparagine-linked oligosaccharide units. J Biol Chem 249:7260-7269.

Baenziger J, Kornfeld S (1974b) Structure of the carbohydrate units of IgA1 immunoglobulin. II. Structure of the O-glycosidically linked oligosaccharide units. J Biol Chem 249:7270-7281. Baenziger JU, Maynard Y (1980) Human hepatic lectin. Physiochemical properties and specificity. J Biol Chem 255:4607-4613.

Baenziger JU (1994) Protein-specific glycosyltransferases: how and why they do it! FASEB J 8:1019-1025.

Baker AJ, Mooney A, Hughes J, Lombardi D, Johnson RJ, Savill J (1994) Mesangial cell apoptosis: the major mechanism for resolution of glomerular hypercellularity in experimental mesangial proliferative nephritis. J Clin Invest 94:2105-2116.

Baker DA, Sugii S, Kabat EA, Ratcliffe RM, Hermentin P, Lemieux RU (1983) Immunochemical studies on the combining sites of Forssman hapten reactive hemagglutinins from Dolichos biflorus, Helix pomatia and Wisteria floribunda. Biochem 22:2741-2750.

Ballardie FW, Brenchley PEC, Williams S, O'Donoghue DJ (1988) Autoimmunity in IgA nephropathy. Lancet ii:588-591.

MBannister KM, Drew PA, Clarkson AR, Woodroffe AJ (1983) Immunoregulation in glomerulonephritis, Henoch-Schonlein purpura and lupus nephritis. Clin Exp Immunol 53:384390. 
Baud L, Hagege J, Sraer J, Rondeau E, Perez J, Ardaillou R (1983) Reactive oxygen production by cultured rat glomerular mesangial cells during phagocytosis is associated with stimulation of lipoxygenase activity. J Exp Med 158:1836-1852.

Thazzi C, Sinico RA, Petrini C, Rizza V, Torpia R, Arrigo G, Ragui A, d'Amico G (1992) Low doses of drugs able to alter intestinal mucosal permeability to food antigens (5-aminosalicylic acid and sodium cromoglycate) do not reduce proteinuria in patients with $\operatorname{Ig} A$ nephropathy: a preliminary noucontrolled trial. Nephron 61:192-195.

TBene M-C, Faure G, Duheille J (1982) IgA nephropathy: characterization of the polymeric nature of mesangial deposits by in vitro binding of free secretory component. Clin Exp Immunol 47:527 534.

MBene M-C, Faure G (1988) Mesangial IgA in IgA nephropathy arises from the mucosa. Am J Kidney Dis 12:406-409.

Bene M-C, Canton P, Amiel C, May T, Faure G (1991a) Absence of mesangial IgA in AIDS: A postmortem study (letter). Nephron 58:240-241.

BBene M-C, Hurault de Ligny B, Kessler M, Faure GC (1991b) Confirmation of tonsillar anomalies in $\operatorname{Ig}$ A nephropathy: a multicenter study. Nephron 58:425-428.

㢳ennett WM, Walker RG, Kincaid-Smith P (1989) Treatment of IgA nephropathy with eicosapentanoic acid (EPA): a two-year prospective trial. Clin Nephrol 31:128-131.

罪erger EG, Kozdrowski I (1978) Permanent mixed-field polyagglutinability exythrocytes lack galactosyltransferase activity. FEBS Lett 93:105-108.

Berger J, Hinglais N (1967) Les dépôts intercapillaires d'IgA-IgG. J Urol Nephrol (Paris) 74:694-695.

BRerger J (1969) IgA glomerular deposits in renal disease. Transplant Proc 1:939-944.

Berger J, Yaneva H, Nabarra B, Barbanel C (1975) Recurrenec of mesangial IgA deposition of IgA after renal transplantation. Kidney Int 7:232-241.

BRerger J (1988) Recurrence of IgA nephropathy in renal allografts. Am J Kidney Dis 12:371372.

Bergh MLE, Hooghwinkel GJM, van den Eijnden DH(1983) Biosynthesis of the O-glycosidically linked oligosaccharide chains of fetuin: indications for an $\alpha-\mathrm{N}$-acetyl galactosaminide $\alpha 2-6$ sialyltransferase with a narrow acceptor specificity in fetal calf liver. J Biol Chem 258:7430-7436. 
BBerthoux FC, Alamartine E, Laurent B, Berthoux P, Vacherot C, Lambert C, le Petit J-C (1993) Primary IgA glomerulonephritis and MHC revisited. In: IgA Nephropathy: The 25th Year. Bene M-C, Faure GC, Kessler M (Eds) Contrib Nephrol 104:54-60.

Biewenga J, Hiemstra PS, Steneker I, Daha MR (1989) Binding of human IgA1 and IgA1 fragments to jacalin. Mol Immunol 26:275-281.

Blumenfeld OO, Lalezari P, Khorshidi M, Puglia K, Fukada M (1992) O-linked oligosaccharides of glycophorins A and B in erythrocytes of two individuals with the Tn polyagglutinability syndrome. Blood 80:2388-2395.

Bock SC, Skriver K, Nielsen E, Thogersen H-C, Wiman B, Donaldson VH, Eddy RL, Marrinan J, Radziejewska E, Huber R, Shows TB, Magnusson S (1986) Human C1 inhibitor: primary structure, cDNA cloning, and chromosomal localization. Biochem 25:4292-4301.

Bzodman K, Sumar N, Sinclair H, Roitt I, Isenberg D, Young A (1994) The value of serum analysis of of agalactosyl IgG (Gal[0]) as a predictor of disease course in recent onset rheumatoid arthritis (abstract). Glycosylation and Disease 1:219.

BBogers WMJM, Stad R-K, van Es LA, Daha MR (1991) Immunoglobulin A: Interaction with complement, phagocytic cells and endothelial cells. Complement Inflamm 8:347-358.

BBoland CR, Chen Y-F, Rinderle SJ, Resau JH, Luk GD, Lynch HT, Goldstein IJ (1991) Use of the lectin from Amaranthus caudatus as a histochemical probe of proliferating colonic epithelial cells. Cancer Res 51:657-665.

BBond A, Arden N, Alavi A, Spector TD, Axford JS, Hay FC (1994) Remission in preguant rheumatoid arthritis patients is associated with decreased $\mathrm{IgG} \mathrm{N}$-acetylglucosamine expression (abstract). Glycosylation and Disease 1:218.

Borén T, Falk P, Roth KA, Larson G, Normark S (1993) Attachment of Helicobacter pylori to human gastric epithelium mediated by blood group antigens. Science 262:1892-1895.

BBreitfeld PP, Simmons CF, Strous GJAM, Geuze HJ, Schwartz AL (1985) Cell biology of the asialoglycoprotein receptor system: a model of receptor-mediated endocytosis. Int Rev Cytol 97:47-95.

MRurtom DR, Woof JM (1992) Human antibody effector function. Adv Immunol 51:1-84.

de Caestecker MP, Bottomley M, Telfer BA, Hutchinson IV, Vose BM, Ballardie FW (1993) Detection of abnormal peripheral blood mononuclear cell cytkine networks in human IgA nephropathy. Kidney Int 44:1298-1308. 
Cagnoli L, Beltrandi E, Pasquali S, Biagi R, Casadei-Maldini M, Rossi L, Zucchelli P (1985) B and $\mathrm{T}$ cell abnormalities in aptients with primary IgA nephropathy. Kidney Int 28:646-651.

Carlssom SR, Sasaki H, Fukuda M (1986) Structural variations of O-linked oligosaccharides present in leukosialin isolated from erythroid, myeloid and T-lymphoid cell lines. J Biol Chem 261:12787-12795.

Cartton J-P, Andreu G, Cartron J, Bird GWG, Salmon C, Gerbal A (1978) Demonstration of Ttransferase deficiency in Tn-polyagglutiuable blood samples. Eur J Biochem 92:111-119.

Cartron J-P, Nurden AT (1979) Galactosyltransferase and membrane glycoprotein abnormality in human platelets from Tn-syndrome donors. Nature 282:621-623.

Casanueva B, Rodriguez-Valverde V, Arias M, Vallo A, Garcia-Fuentes M, Rodriguez-Soriano J (1986) Immunoglobulin-producing cells in IgA nephropathy. Nephron 43:33-37.

Casanueva B, Rodriguez-Valverde V, Farinas MC, Vallo A, Rodriguez-Soriano J (1990) Autologous mixed lymphocyte reaction and T-cell suppressor activity in aptients with HenochSchonlein purpura and IgA nephropathy. Nephron 54:224-228.

de Caterina R, Endres S, Kristensen SD, Schmidt EB (1994) 11-3 Fatty acids and renal disease. Am J Kidney Dis 24:397-415.

Cedlerholm B, Wieslander J, Bygren P, Heinegard D (1986) Patients with IgA nephropathy have circulating anti-basement membrane antibodies reacting with structures common to collagen $I$, II and IV. Proc Natl Acad Sci USA 83:6151-6155.

Cederholm B, Wieslander J, Bygren P, Heinegard D (1988) Circulating complexes containing IgA and fibronectin in patients with primary IgA nephropathy. Proc Natl Acad Sci USA 85:48654868.

Chen A, Chen W-P, Sheu L-F, Lin C-Y (1994) Pathogenesis of IgA mephropathy: in vitro activation of human mesangial cells by $\operatorname{IgA}$ immune complex leads to cytokine secretion. J Pathol 173:119-126.

Chen N, Nusbaum P, Halbwechs-Mecarelli L, Lesavre P (1991) Light-chain composition of serum IgA1 and in vitro IgA1 production in IgA nephropathy. Nephrol Dial Transplant 6:846850.

Childers NK, Bruce MG, McGhee JR (1989) Molecular mechanisms of immunoglobulin A defense. Ammu Rev Microbiol 43:503-536. 
Clarkson AR, Seymour AE, Woodroffe AJ, McKenzie PE, Chan Y-L, Wootton AM (1980) Controlled trial of phenytoin therapy in IgA nephropathy. Clin Nephrol 13:215-218.

Coppo R, Basolo B, Martina G, Rollino C, de Marchi M, Giacchino F, Mazzucco G, Messina M, Piccoli G (1982) Circulating immune complexes containing IgA, IgG and IgM in patients with primary $\operatorname{IgA}$ nephropathy and with Henoch-Schoenlein nephritis. Correlation with clinical and histologic signs of activity. Clin Nephrol 18:230-239.

Coppo R, Basolo B, Bulzomi MR, Piccoli G (1984) Ineffectiveness of phenytoin treatment on IgA-containing circulating immune complexes in IgA nephropathy (letter). Nephron 36:275-276. Coppo RR, Basolo B, Rollino C, Roccatello D, Martana G, Amore A, Bongiorno G, Piccoli G (1986a) Mediterranean diet and IgA nephropathy. Clin Nephrol 26:72-82.

Coppo R, Basolo B, Rollino C, Roccatello D, Martina G, Amore A, Piccoli G (1986b) Dietary gluten and primary IgA nephropathy (letter). N Engl J Med 315:1167-1168.

Coppo R (1988) The pathogenic potential of environmental antigens in IgA nephropathy. Am J Kidney Dis 12:420-424.

Coppo R, Amore A, Roccatello D (1992) Dietary antigens and primary immunoglobulin A mephropathy. J Am Soc Nephrol 2:S173-S180.

Coppo R, Amore A, Gianoglio B, Reyna A, Peruzzi L, Roccatello D, Alessi D, Sena LM (1993) Serum $\operatorname{IgA}$ and macromolecular $\operatorname{IgA}$ reacting with mesangial matrix components. In: $\operatorname{IgA}$ Nephropathy: The 25th Year. Bene M-C, Faure GC, Kessler M(Eds) Contrib Nephrol 104:162171.

Coppo R, Emancipator S (1994) Pathogenesis of IgA nephropathy: established observations, new insights and perspectives in treatment. J Nephrol 7:5-15.

Cosio FG, Lam S, Folami AO, Couley ME, Michael AF (1982) Immune regulation of immunoglobulin production in IgA nephropathy. Clin Immunol Immunopathol 23:430-436.

Czerkinsky C, Koopman WJ, Jackson S, Collins JE, Crago SS, Schrohenloher RE, Julian BA, Galla JH, Mestecky J (1986) Circulating immune complexes and immunoglobulin A rheumatoid factor in patients with mesangial imunoglobulin A nephropathies. J Clin Iuvest 77:1931-1938. Delacroix DL, Elkon KB, Geubel AP, Hodgson HF, Dive C (1983) Changes in size, subclass, and metabolic proerties of serum immunoglobulin $\mathrm{A}$ in liver diseases and in other diseases with high serum immunoglobulin A. J Clin Invest 71:358-367. 
Delves PJ, Lund T, Axford JS, Alavi-Sadrieh A, Lydyard PM, Mackenzie L, Smith MD, Kidd VJ (1990) Polymorphism and expression of the galactosyltransferase-associated protein kinase gene in normal individuals and galactosylation-defective rheumatoid arthritis patients. Arthritis Rheum 33:1655-1664.

Denmis R (1994) Personal communication. van Djik W, Turner GA, Mackiewicz A (1994) Changes in glycosylation of acute-phase proteins in health and disease: occurrence, regulation and function. Glycosylation and Disease 1:5-14. van den Dobbelsteen MEA, van den Woude FJ, Schroeijers WEM, van den Wall Bake AWL, van Es LA, Daha MA (1994) Binding of dimeric and polymeric IgA to rat renal mesangial cells enhances the release of interleukin 6. Kidney Int 46:512-519.

Dijukanovic L, Majster Z, Kostic M, Popovic-Rolovic M (1991) Innvitro immunoglobulin production in children and adults with primary IgA nephropathy (letter). Clin Nephrol 36:209. 210.

Dueymes M, Baharaki D, Youinou P (1994) IgA glycosylation and disease (abstract). Glycosylation and Disease 1:217.

Edge CJ, Joao HC, Woods RJ, Wormald MR (1993) The conformational effects of N-linked glycosylation. Biochem Soc Trans 21:452-455.

Egido J, Blasco R, Sancho J, Lozano L, Sanchez-Crespo M, Hernando L (1982) Increased rates of polymeric IgA synthesis by circulating lymphoid cells in $\operatorname{IgA}$ mesangial glomerulonephritis. Clin Exp Immunol 47:309-316.

Egido J, Blasco R, Sancho J, Lozano L (1983) T-cell dysfunctions in IgA nephropathy: specific abnormalities in the regulation of $\operatorname{IgA}$ synthesis.

सgido J, Sancho J, Rivera F, Hernando L (1984) The role of IgA and IgG immune complexes in IgA nephropathy. Nephron 36:52-59.

Egido J, Lozano L Garcia-Hoyo R, de Nicolas R (1987) Regulation of the immune response in peripheral blood and in tonsillar lymphocytes from patients with $\operatorname{IgA}$ nephropathy. Adv Exp Med Biol 216B: 1523-1536.

Emancipator SN, Gallo GR, Lamm ME (1985) IgA nephropathy: perspectives on pathogenesis and classification. Clin Nephrol 24:161-179.

Emancipator SN, Lamm ME (1989) IgA nephropathy: Pathogenesis of the most common form of glomerulonephritis. Lab Invest 60:168-183. 
Emancipator SN (1990) Immunoregulatory factors in the pathogenesis of $\operatorname{IgA}$ nephropathy.

Kidney Int 38:1216-1229.

Emancipator SN, Rao CS, Amore A, Coppo R, Nedrud JG (1992) Macromolecular properties that promote mesangial binding and mesangiopathic nephritis. J Am Soc Nephrol 2:S149-S158. Endoh M, Sakai H, Suga T, Miura M, Tomino Y, Nomoto Y (1983) Increase of peripheral blood B cells with Fc receptor for IgA in patients with IgA nephropathy. Scand J Immunol 17:437-441.

Fndoh M, Suga T, Miura M, Tomino Y, Nomoto Y, Sakai H (1984) In vivo alteration of antibody production in patients with igAS nephropathy. Clin Exp Immunol 57:564-570.

van Es LA (1992) Pathogenesis of IgA nephropathy. Kidney Int 41:1720-1729.

Ezekowitz RAB (1995) Agalactosyl IgG and mamose-binding proteins: Biochemical nicety or pathophysiological paradigm? Nature Med 1:207-208.

Feelhally J (1988) Immune mechanisms in glomerular IgA deposition. Nephrol Dial Transplant 3:361-378.

Feehally J, Beattie TJ, Brenchley PEC, Coupes BM, Mallick NP, Postlethwaite RJ (1986) Sequential study of the IgA system in relapsing IgA nephropathy. Kidney Int 30:924-931.

Feehally J, Beattie TJ, Brenchley PEC, Coupes BM, Mallick NP, Postlethwaite RJ (1987) Response of circulating immune complexes to food challenge in relapsing $\operatorname{Ig} \mathrm{A}$ nephropathy. Pediatr Nephrol 1:581-586.

Theehally J, O'Donoghue DJ, Ballardie FW (1989) Current nephrological practice in the investigation of haematuria: relationship to incidence of IgA nephropathy. J Royal Col Phys London 23:228-231.

Field MC, Dwek RA, Edge CJ, Rademacher TW (1989) O-linked oligosaccharides from human serum immunoglobulin A1. Biochem Soc Trans 17:1034-1035.

Field MC, Amatayakul-Chantler S, Rademacher TW, Rudd PM, Dwek RA (1994) Structural analysis of the $\mathrm{N}$-glycans from human immunoglobulin $\mathrm{Al}$ : comparison of normal serum immunoglobulin Al with that isolated from patients with rheumatoid arthritis. Biochem $\mathrm{J}$ 299:261-275.

Floege J, Eitner F, Schulze M, Brunckhorst R, Schmidt RE, Koch KM (1993) Plasma IgAfibronectin complexes (IgA-FN-C) in IgA nephropathy patients: an artefact? (abstract) J Am Soc Nephrol 4:677. 
Fortune F, Courteau M, Williams DG, Lehner T (1992) T and B cell responses following immunization with tetanus toxoid in IgA nephropathy. Clin Exp Immunol 88:62-67.

Frangiome B, Wolfenstein-Todel C (1972) Partial duplication in the "hinge" region of IgA1 myeloma proteins. Proc Natl Acad Sci 12:3673-3676.

Trujii K, Muller KD, Clarkson AR, Woodroffe AJ (1990) The effect of IgA immune complexes on the proliferation of cultured human mesangial cells. Am J Kidney Dis 16:207-210.

Turuse A, Hiramatsu M, Adachi N, Karashima S, Hattori S, Matsuda I (1985) Dramatic response to corticosteroid therapy of nephrotoc syndrome associated with IgA nephropathy. Int J Pediatr Nephrol 6:205-208.

Garcia-Hilloyo R, Egido J, Lozano L, de Nicolas R, Hernando L (1987) Disturbances of IgA immune regulation in lymphocytes from mucosae and peripheral blood in patients with $\operatorname{IgA}$ nephropathy. Semin Nephrol 7:301-305.

Gesualdo L, Lamm ME, Emancipator SN (1990) defective oral tolerance promotes nephritogenesis in experimental IgA nephropathy induced by oral immunization. J Immunol 145:3684-3691.

Gomez-Guerrero C, Gonzalez E, Egido J (1993) Evidence for a specific IgA receptor in rat and human mesangial cells. J Immunol 151:7172-7181.

Gomez-Guerrero C, Lopez-Armada MJ, Gonzalez E, Egido J (1994) Soluble IgA and IgG aggregates are catabolized by cultured rat mesangial cells and induce production of TNF- $\alpha$ and IL-6, and proliferation. J Immunol 153:5247-5255.

Gonzalez-Cabrero J, Egido J, Barat A, Gonzalez E (1990) Detection and characterization of circulating and glomerular immune complexes in experimental IgA nephropathy. Immunology 70:296-302.

Goshen E, Livne A, Nagy J, Sarov I, Shoenfeld Y (1990) Antinuclear autoantibodies in sera of patients with IgA nephropathy. Nephron 55:33-36.

Gregory MC, Hammond ME, Brewer ED (1988) Renal deposition of cytomegalovirus antigen in immunoglobulin A nephropathy. Lancet i:11-14.

Griffiths HR, Lunec J (1989) The effects of oxygen free radicals on the carbohydrate moiety of IgG. FEBS Lett 245:95-99.

Griffiths HR (1991) Personal communication. 
Hale GM, McIntosh SL, Hiki Y, Clarkson AR, Woodroffe AJ (1986) Evidence for IgA-specific B cell hyperactivity in patients with IgA nephropathy. Kidney Int 29:718-724.

Hammarstrom S, Kabat EA (1969) Purification and characterisation of a blood group A reactive hemagglutinin from the snail Helix pomatia and a study of its combining site. Biochem 8:26962705.

Hilammarstrom S, Westoo A, Bjork I (1972) Subunit structure of Helix pomatia A hemagglutinin. Scand J Immunol 1:295-309.

Hirara T, Hobby P, Courteau M, Knight JF, Williams DG (1989) Charge distribution of plasma IgA in IgA nephropathy. Clin Exp Immunol 77:211-214.

Hardy MR, Reid Townsend R, Parkhurst SM, Lee YC (1985) Different modes of ligand binding to the hepatic galactose/ $\mathrm{N}$-acetylgalactosamine lectin on the surface of rabbit hepatocytes. Biochem 24:22-28.

Fllarper SJ, Feehally J (1993) The pathogenic role of immunoglobulin A polymers in immunoglobulin A nephropathy. Nephron 65:337-345.

Hirper SJ, Pringle JH, Wicks ACB, Hattersley J, Layward L, Allen A, Gillies A, Lauder I, Feehally J (1994a) Expression of J chain mRNA in duodenal plasma cells in IgA nephropathy. Kidney Int 45:836-844.

H耳arper SJ, Allen AC, Layward L, Hattersley JM, Veitch PS, Feehally J (1994b) Increased immunoglobulin A and immunoglobulin A1 cells in bone marrow trephine biopsy specimens in immunoglobulin A nephropathy. Am J Kidney Dis 24:888-892.

Hirper SJ, Allen AC, Bene M-C, Pringle JH, Faure G, Lauder I, Feehally J (1995a) Increased dimeric $\operatorname{Ig}$ A producing $B$ cells in tonsils in $\operatorname{Ig} A$ nephropathy determined by in situ hybridisation for J chain mRNA. Clin Exp Immunol 101:442-448.

Hllarper SJ, Allen AC, Pringle JH, Feehally J (1995b) Increased dimeric IgA producing B cells in the bone marrow in IgA nephropathy determined by in situ hybridisation for $J$ chain mRNA. J Clin Pathol (in press).

Hart GW (1992) Glycosylation. Curr Opin Cell Biol 4:1017-1023.

Hitaun M, Incledon B, Alles P, Wasi S (1989) A rapid procedure for the purification of IgA1 and IgA2 subclasses from normal human serum using protein $G$ and jackfruit lectin (jacalin) affinity chromatography. Immunol Lett 22:273-280. 
Hay FC, Jones MG, Bond A, Soltys AJ (1991) Rheumatoid factors and complex formation: the role of light-chain framework sequences and glycosylation. Clin Orthopaedics and Related Res 265:54-62.

Hené RJ, Schuurman H-J, Kater L (1988) Immunoglobulin A subclass-containing plasma cells in the jejunum in primary IgA nephropathy and in Henoch-Schonlein purpura. Nephron 48:4-7. Hienastra PS, Gorter A, Stuurman ME, van Es LA, Daha MR (1987) The IgA-binding lectin jacalin induces complement activation by inhibition of C1-inactivator function. Scand J Immunol 26:111-117.

Hilki Y, Saitoh M, Kobayashi Y (1991) Serum IgA class anti-IgA antibody in IgA nephropathy. Nephron 59:552-560.

Bliki Y, Iwase H, Saitoh M, Ishi-Karakasa I, Urata T, Hotta K, Kobayashi Y (1992) O-linked oligosaccharide (Galß1-3GalNAc) on IgA hinge region in IgA nephropathy (IgA-N) (abstract) IgA Nephropathy: The 25th Year International Symposium, Nancy, France.

Hortin GL, Trimpe BL (1990) Lectin affinity chromatography of proteins bearing O-linked oligosaccharides: application of jacalin-agarose.

Hounsell EF, Davies MJ (1993) Role of protein glycosylation in immune regulation. Annals Rheumatic Dis 52:\$22-\$29.

Imai H, Chen A, Wyatt RJ, Rifai A (1988) Lack of complement activation by human IgA immune complexes. Clin Exp Immunol 73:479-483.

Hsenberg D (1994) Abnormalities in the glycosylation of IgG - its clinical utility (abstract). Glycosylation and Disease 1:217.

甚zkowitz SH, Yuan M, Montgomery CK, Kjeldsen T, Takahashi HK, Bigbee WL, Kim YS (1989) Expression of Tn, sialosyl-Tn and T antigens in human colon cancer. Cancer Res 49:197204.

Jackson S, Montgomery RI, Julian BA, Galla JH, Czerkinsky C (1987) Aberrant synthesis of antibodies directed at the Fab fragment of $\operatorname{IgA}$ in patients with $\operatorname{IgA}$ nephropathies. Clin Immunol Immunopathol 45:208-213.

Jackson S (1988) Immunoglobulin-antiimmunoglobulin interactions and immune complexes in IgA nephropathy. Am J Kidney Dis 12:425-429. 
Jackson S, Moldoveanu Z, Kirk KA, Julian BA, Patterson TF, Mullins AL, Jilling T, Mestecky J, Galla JH (1992) IgA-containing immune complexes after challenge with food antigens in patients with IgA nephropathy. Clin Exp Immunol 89:315-320.

Jefferis R (1993) The glycosylation of antibody molecules: functional significance. Glycoconjugate J 10:358-361.

Jennette JC, Wall SD, Wilkman AS (1985) Low incidence of IgA nephropathy in blacks. Kidney Int 28:944-950.

Jennette JC (1988) The immunohistology of IgA nephropathy. Am J Kidney Dis 12:348-352. Jemnette JC, Wieslander J, Tuttle R, Falk RJ and the Glomerular Disease Collaborative Network (1991) Serum IgA-fibronectin aggregates in aptients with IgA nephropathy and HenochSchonlein purpura: diagnostic value and pathogenic implications. Am J Kidney Dis 18:466-471. Jentoft N (1990) Why are proteins O-glycosylated? Trends in Biochemical Sciences 15:291-294. Jessen RH, Emancipator SN, Jacobs GH, Nedrud JG (1992) Experimental IgA-IgG nephropathy induced by a viral respiratory pathogen. Dependence on antigen form and immune status. Lab Invest 67:379-386.

Jones BM, Cheng IKP, Wong RWS (1991) Aberrant T-regulation in rheumatoid arthritis and IgA nephropathy affects CD5+ and CD5- B lymphocytes equally. Clin Exp Immunol 86:212-218. Jones C, Mermelstein N, Kincaid-Smith P, Powell H, Roberton D (1988) Quantitation of human serum polymeric $\operatorname{IgA}, \operatorname{IgA} 1$ and $\operatorname{IgA} 2$ immunoglobulin by enzyme immunoassay. Clin Exp Immunol 72:344-349.

Jones CL, Powell HR, Kincaid-Smith P, Roberton D (1990) Polymeric IgA and immune complex concentrations in IgA-related renal disease. Kidney lut 38:323-331.

Joziasse DH (1992) Mammalian glycosyltransferases: genomic organisation and protein structure. Glycobiol 2:271-277.

Irameda A, Yoshikawa N, Shiozawa S, Doi K, Nakamura H (1991) Lymphocyte subpopulations and function in childhood IgA nephropathy. Nephron 59:546-551.

Kashem A, Endoh M, Nomoto Y, Sakai H, Nakazawa H (1994) FcaR expression on polymorphonuclear leukocyte and superoxide generation in IgA nephropathy. Kidney Int 45:868875.

Kratz A, Bargman JM, Miller DC, Guo J-W, Saleh Ghali V, Schoeneman MJ (1992) IgA nephritis in HIV-positive patients: a new HIV-associated nephropathy? Clin Nephrol 38:61-68. 
Kawaguchi M, Sakai T, Sakamaki A, Ishizawa S, Baba Y, Masuda Y, Koizumi F (1993) Expanded primary $\mathrm{T}$ nodules in the palatine tonsils from patients with $\operatorname{IgA}$ nephropathy. Acta Otolaryngol (Stockh) Suppl 508:36-42.

IKerr MA (1990) The structure and function of human IgA. Biochem J 271:285-296.

KKeidan I, Laufer J, Shor R, Farzam N, Gitel S, Passwell JH (1995) Activation of monocytes via their Fc $\alpha$ R increases procoagulant activity. J Lab Clin Med 125:72-78.

KKimmel PL, Phillips TM, Ferreira-Centeno A, Farkas-Szallasi T, Abraham AA, Garrett CT (1992) Idiotypic IgA nephropathy in patients with human immunodeficiency virus infection. N Engl J Med 327:702-706.

King M-J, Chan A, Roe R, Warren BF, Dell A, Morris HR, Bartolo DCC, Durdey P, Corfield AP (1994) Two different glycosyltransferase defects that result in Gal Nac $\alpha$-O-peptide (Tn) expression. Glycobiology 4:267-279.

Kleene R, Berger EG (1993) The molecular and cell biology of glycosyltransferases. Biochimica Biophysica Acta 1154:283-325.

Kondoh H, Kobayashi K, Hagiwara K, Kajii T (1986) Jacalin, a jackfruit lectin, precipitates IgA1 but not IgA2 subclass on gel diffusion reaction. J Immunol Methods 88:171-173.

KKottgen E, Hell B, Kage A, Tauber R (1992) Lectin specificity and binding characteristics of human C-reactive protein. J Immunol 149:445-453.

KKuskari C, Takasaka T, Nose M, Kyogoku M (1992) IgA1 localization in follicular dendritic cells is characteristic of IgA nephropathy. Adv Otorhinolaryngol 47:222-226.

Lai KN, Lai FM, Ho CP, Chan KW (1986) Corticosteroid therapy in IgA nephropathy with nephrotic syndrome: a long-term controlled trial. Clin Nephrol 26:174-180.

Lai KN, Lai FM-M, Leung ACT, Ho CP, Vallence-Owen J (1987a) Plasma exchange in patients with rapidly progressive idiopathic $\operatorname{Ig} A$ nephropathy: a report of two cases and review of the literature. Am J Kidney Dis 10:66-70.

Lai KN, Lai FM, Chui SH, Chan YM, Tsao GSW, Leung KN, Lam CWK (1987b) Studies of lymphocyte subpopulations and immunoglobulin production in IgA nephropathy. Clin Nephrol 28:281-287.

Lai KN, Lai FM-M, Vallence-Owen J (1988a) A short-term coutrolled trial of cyclosporine A in IgA nephropathy. Transplant Proc 20 (Suppl 4):297-303. 
Lai KN, Leung JCK, Lai FM-MI (1988b) In vitro study of expression of interleukin-2 receptors in T-lymphocytes from patients with IgA nephropathy. Clin Nephrol 30:330-334.

Lai KN, Leung JCK, Lai FM-M, Tam JS (1989) T-lymphocyte activation in IgA nephropathy: serum-soluble interleukin 2 receptor level, interleukin 2 production and interleukin 2 receptor expression by cultured lymphocytes. J Clin Immunol 9:485-92.

Lai KN, Leung JCK, Li PKT, Lui SF (1991) Cytokine production by peripheral blood mononuclear cells in IgA nephropathy. Clin Exp Immunol 85:240-245.

Lai KN, Ho R, Leung J, Li P (1992) CD4+ cells from patients with IgA nephropathy demonstrate increased mRNA of cytokines that induce in IgA switch and differentiation (abstract). J Am Soc Nephrol 3 (3):657.

Lai KN, Leung JCK (1993) Heat-aggregated IgA prepared from patients with IgA nephropathy increases calcium mobilization and superoxide production of human neutrophils in vitro. Nephron 64:129-135.

Lai KN, Chui SH, Lewis WHP, Poon ASY, Lam CWK (1994) Charge distribution of IgAlambda in IgA nephropathy. Nephron 66:38-44.

Lam CWK, Chui SH, Leung NWY, Li EKIM, Lai KN (1991) Light chain ratios of serum immunoglobulius in disease. Clin Biochem 24:283-287.

Layward L, Hattersley JM, Patel HR, Tanner MS, Feehally J (1990) Gut permeability in IgA nephropathy. Nephrol Dial Transplant 5:569-571.

Layward L, Allen AC, Harper SJ, Hattersley JM, Feehally J (1992) Increased and prolonged production of specific polymeric IgA after systemic immunisation with tetanus toxoid in $\operatorname{IgA}$ nephropathy. Clin Exp Immunol 88:394-398.

Layward L, Allen AC, Harper SJ, Hattersley JM, Feehally J (1993a) Deficiency of IgG subclass antibody response to tetanus toxoid associated with high serum $\operatorname{IgA}$ levels in $\operatorname{Ig} \mathrm{A}$ nephropathy. Clin Nephrol 40:131-136.

Layward L, Finnemore A-M, Allen AC, Harper SJ, Feehally J (1993b) Systemic and mucosal IgA responses to systemic antigen challenge in IgA nephropathy. Clin Immunol Immunopathol 69:306-313.

Layward L, Allen AC, Hattersley JM, Harper SJ, Feehally J (1993c) Elevation of IgA in IgA nephropathy is localised in the serum and not saliva and is restricted to the $\operatorname{IgA1}$ subclass. Nephrol Dial Transplant 8:25-28. 
Layward L, Allen AC, Hattersley JM, Harper SJ, Feehally J (1994a) Low antibody affinity restricted to the IgA isotype in IgA nephropathy. Clin Exp Immunol 95:35-41.

Layward L, Allen AC, Harper SJ, Feehally J (1994b) Increased IgA and decreased IgG production by Epstein-Barr virus transformed B cells in culture in IgA nephropathy. Exp Nephrol 2:24-29.

Lee LT, Frank S, de Jongh DS, Howe C (1981) Immunochemical studies on Tn erythrocyte glycoprotein. Blood 58:1228-1231.

Lee RT, Lin P, Lee YC (1984) New synthetic cluster ligands for galactose/N-acety1 galactosamine-specific lectin of mammalian liver. Biochem 23:4255-4261.

Lee T-W, Ahn J-H, Park J-K, Ihm C-G, Kim M-J (1994) Tumor necrosis factor $\alpha$ from the peripheral blood mononuclear cells of IgA nephropathy and mesangial cell proliferation. Kor J Int Med 9:1-8.

Lee YC, Townsend RR, Hardy MR, Lonngren J, Arnarp J, Haraldsson M, Lonn H (1983) Binding of synthetic oligosaccharides to the hepatic Gal/GalNAc lectin. J Biol Chem 258:199202.

Levy M (1993) Multiplex families in IgA nephropathy. In: IgA Nephropathy: The 25th Year. Bene M-C, Faure GC, Kessler M (Eds) Contrib Nephrol 104:46-53.

Li PK-T, Burns AP, So AKL, Lai KN, Rees AJ (1992) Familial IgA nephropathy: a study of HLA Class II allogenotypes in a Chinese kindred. Am J Kidney Dis 20:458-462.

Linne T, Wasserman J (1985) Lymphocyte subpopulations and immunoglobulin production in IgA nephropathy. Clin Nephrol 23:109-111.

Lis H, Sharon N (1993) Protein glycosylation. Structural and functional aspects. Eur J Biochem 218:1-27.

Loomes LM, Stewart WW, Mazengera RL, Senior BW, Kerr MA (1991) Purification and characterisation of human immunoglobulin $\operatorname{IgA1}$ and $\operatorname{IgA2}$ isotypes from serum. J Immunol Methods 141:209-218.

Lopez Trasaca M, Egido J, Sancho J, Hernando L (1980) IgA glomerulonephritis (Berger's disease): evidence of high serum levels of polymeric IgA. Clin Exp Immunol 42:247-254.

Lowry OH, Rosebrough NJ, Farr AL, Randall RJ (1951) Protein measurement with the folin phenol reagent. J Biol Chem 193:265-275. 
IVagyarlaki T, Davin JC, Szabados E, Kocsis B, Nagy J (1990) Peripheral B-lymphocyte markers and function in IgA nephropathy. Clin Nephrol 33:123-129.

IMalhotra R, Wormald MR, Rudd PM, Fischer PB, Dwek RA, Sim RB (1995) Glycosylation changes of IgG associated with rheumatoid arthritis can activate complement via the mannosebinding protein. Nature Med 1:237-243.

Marcen R, Pascual J, Felipe C, Mampaso F, Gonzalo A, Orofino L, Ortuno J (1991) Recurrence of IgA nephropathy with nephrotic syndrome after kidney transplantation. Nephron 59:486-489. Marx M, Weber M, Schafranek D, Wandel E, Meyer zum Buschenfelde K-H, Kohler H (1989) Secretory immunoglobulin A in urinary tract infection, chronic glomerulonephritis, and renal transplantation. Clin Immunol Immunopathol 53:181-191.

Matsiota P, Dosquet P, Louzir H, Druet E, Druet P, Avrameas S (1990) IgA polyspecific autoantibodies in IgA nephropathy. Clin Exp Immunol 79:361-366.

Nazengera RL, Kerr MA (1990) The specificity of the human IgA receptor purified from human neutrophils. Biochem J 272:159-165.

MICGuire EJ, Kerlin R, Cebra JJ, Roth S (1989) A human milk galactosyltransferase is specific for secreted, but not plasma, IgA. J Immunol 143:2933-2938.

Meleg-Smith S, Yu GSM, Tsukamoto H (1990a) IgA nephropathy in alcohol abuse. An animal model. Lab Invest 62:179-183.

Meleg-Smith S (1990b) IgA nephropathy: characterization of the light chains (letter). Clin Nephrol 34:93-94.

Meleg-Smith S, Wheeher C, Hoy WE (1991) Viral antigens in IgA nephropathy (letter). Clin Nephrol 36:152-153.

Mellis SJ, Baenziger JU (1983) Structures of the O-glycosidically linked oligosaccharides of human IgD. J Biol Chem 258:11557-11563.

Mene P, Simonson MS, Dunn MJ (1989) Physiology of the mesangial cell. Physiological Rev 69:1347-1424.

Mestecky J, McGhee JR (1987) Immunoglobulin A (IgA): Molecular and cellular interactions involved in IgA biosynthesis and immune respouse. Adv Immunol 40:153-245.

Mesteclky J (1988) Immunobiology of IgA. Am J Kidney Dis 12:378-383. 
Mestecky J, Tomana M, Crowley-Nowick PA, Moldoveanu Z, Julian BA, Jacksou S (1993) Defective galactosylation and clearance of $\operatorname{IgA} 1$ molecules as a possible etiopathogenic factor in IgA nephropathy. In: IgA Nephropathy: The 25th Year. Bene M-C, Faure GC, Kessler M (Eds) Contrib Nephrol 104:172-182.

Minura M, Endoh M, Nomoto Y, Sakai H (1989) Long-term effect of urokinase therapy in IgA nephropathy. Clin Nephrol 32:209-216.

Moldoveanu Z, Moro I, Radl J, Thorpe SR, Komiyama K, Mestecky J (1990) Site of catabolism of autologous and heterologous IgA in non-human primates. Scand J Immunol 32:577-583.

Monteiro RC, Halbwachs-Mecarelli L, Roque-Barreira MC, Noel L-H, Berger J, Lesavre P (1985) Charge and size of mesangial IgA in IgA nephropathy. Kidney Int 28:666-671.

Monteiro RC, Chevailler A, Noel L-H, Lesavre P (1988) Serum IgA preferentially binds to cationic polypeptides in IgA nephropathy. Clin Exp Immunol 73:300-306.

Monteiro RC, Noel L-H, Chevailler A, Halbwachs-Mecarelli L, Lesavre P (1989) Immune regulation in IgA nephropathy. Néphrologie 10:147-150.

Monteiro RC, Kubagawa H, Cooper MD (1990) Cellular distribution, regulation and biochemical nature of an Fc $\alpha$ receptor in humans. J Exp Med 171:597-613.

Montinaro V, Esparza AR, Cavallo T, Rifai A (1991) Antigen as mediator of glomerular injury in experimental $\operatorname{Ig} A$ nephropathy. Lab Invest 64:508-519.

Mlontreuil J, Bouquelet S, Debray H, Fournet B, Spik G, Strecker G (1982) Glycoproteins. In: Carbohydrate analysis: a practical approach. Eds. Chaplin IMF, Kennedy JF. IRL Press (UK): 143-204.

Montreuil J (1984) Spatial conformation of glycans and glycoproteins. Biol Cell 51:115-132. Moore R (1993) MHC gene polymorphism in primary IgA nephropathy. Kidney Int 43 (Suppl 39):S9-S12.

Muller GA, Muller CA, Engler-Blum G, Kuhn W, Risler T, Bohle A, Markovic-Lipkovski J (1992) Human cytomegalovirus in immunoglobulin A nephropathy: detection by polymerase chain reaction. Nephron 62:389-393.

IMlustonen J, Pasternack A, Helin H, Rilva A, Penttinen K, Wager O, Harmoinen A (1981) Circulating immune complexes, the concentration of serum IgA and the distribution of HLA antigens in IgA nephropathy. Nephron 29:170-175. 
Nagy J, Uj M, Szucs G, Trinn Cs, Burger T (1984) Herpes virus antigens and antibodies in kidney biopsies and sera of IgA glomerulonephritic patients. Clin Nephrol 21:259-262.

Nagy J, Brantzaeg P (1988) Tonsillar distribution of IgA and IgG immunocytes and production of IgA subclasses and $\mathrm{J}$ chain in tonsillitis vary with the presence or absence of $\operatorname{Ig} A$ nephropathy. Scand J Immunol 27:393-399.

Narimatsu H (1994) Recent progress in molecular cloning of glycosyltransferase genes of eukaryotes. Microbiol Immunol 38:489-504.

Newkirk MIV, Klein MH, Katz A, Fisher MIM, Underdown BJ (1983) Estimation of polymeric $\operatorname{IgA}$ in luman serum: and assay based on binding of radiolabelled human secretory component with applications in the study of $\operatorname{IgA}$ nephropathy, $\operatorname{Ig} A$ monoclonal gammopathy, and liver disease. J Immunol 130:1176-1181.

Newkirk MM, Rauch J (1993) Binding of human monoclonal IgG rheumatoid factors to Fc is influenced by carbohydrate. J Rheumatol 20:776-780.

Nicholls K, Kincaid-Smith P (1984) Defective in vivo Fc- and C3b-receptor function in IgA nephropathy. Am J Kidney Dis 4:128-134.

Nishimura M, Okamura M, Konishi Y, Umetani N, Negoro N, Kanayama Y, Takeda T (1992) Enhanced gene expression of platelet derived growth factor in IgA nephropathy. J Am Soc Nephrol 3(3):660.

Nishiyama T, Matsumoto Y, Watanabe H, Fujiwara M, Sato S (1987) Detection of Tn antigen with Vicia villosa agglutinin in urinary bladder cancer: its relevance to the patient's clinical course. JNCI 78:1113-1118.

Nose M, Wigzell H (1983) Biological significance of carbohydrate chains on monoclonal antibodies. Proc Natl Acad Sci USA 80:6632-6636.

O'Domoghue DJ, Darvill A, Ballardie FW (1991) Mesangial cell autoantigens in immunoglobulin A nephropathy and Henoch-Schonlein purpura. J Clin Invest 88:1522-1530.

O'Donoghue DJ, Nusbaum P, Noel L-H, Halbwechs-Mecarelli L, Lesavre P (1992) Antineutrophil cytoplasmic antibodies in $\operatorname{IgA}$ nephropathy and Henoch-Schonlein purpura. Nephrol Dial Transplant 7:534-538.

Opdenakker G, Rudd PM, Ponting CP, Dwek RA (1993) Concepts and principles of glycobiology. FASEB J 7:1330-1337. 
Osawa T, Tsuji T (1987) Fractionation and structural assessment of oligosaccharides and glycopeptides by use of immobilized lectins. Ann Rev Biochem 56:21-42.

Palcic MM (1994) Glycosyltransferases in glycobiology. In : Methods in Enzymology (Lennarz WJ, Hart GW eds) 230:300-316. Academic Press, San Diego.

Parekh RB, Dwek RA, Sutton BJ, Fernandes DL, Leung A, Stanworth D, Rademacher TW, Mizuochi T, Taniguchi T, Matsuta K, Takeuchi F, Nagano Y, Miyamoto T, Kobata A (1985) Association of rheumatoid arthritis and primary osteoarthritis with changes in the glycosylation pattern of total serum IgG (letter). Nature 316:452-457.

Parekh RB, Roitt IM, Isenberg DA, Dwek RA, Ansell BM, Rademacher TW (1988a) Galactosylation of IgG associated oligosaccharides: reduction in patients with adult and juvenile onset rheumatoid arthritis and relation to disease activity. Lancet i:966-969.

Parekh RB, Dwek RA, Rademacher TW (1988b) Rheumatoid arthritis as a glycosylation disorder. Br J Rheumatol 27(suppl II):162-169.

Parekh RB, Roitt I, Isenberg D, Dwek R, Rademacher T (1988c) Age-related galactosylation of the N-linked oligosaccharides of human serum IgG. J Exp Med 167:1731-1736.

PPark JS, Song JH, Yang WS, Cho H, Kim YK, Kim DH, Hong CD (1992) Cytomegalovirus (CMV) is not specifically associated with IgA nephropathy (IgAN) (abstract). J Am Soc Nephrol 3(3):661.

Pastermack A, Mustonen J, Leinikki P (1986) Humoral immune response in patients with IgA and IgM glomerulonephritis. Clin Exp Immunol 63:228-233.

Pemberton RT (1969) Studies on the human red cell agglutinins of the swan mussel (Adonata cygnea). Vox Sang 16:457-464.

Pierce-Cretel A, Pamblanco M, Strecker G, Montreuil J, Spik G (1981) Heterogeneity of the glycans O-glycosidically linked to the hinge region of secretory immunoglobulins from human milk. Eur J Biochem 114:169-178.

Bilatte Y, Hammer CH, Frank MM, Fries LF (1989) A new simplified procedure for C1 inbibitor purification. A novel use for jacalin-agarose. J Imumol Methods 120:37-43.

Piller F, Piller V, Fox RI, Fukuda M (1988) Human T-lymphocyte activation is associated with changes in O-glycan biosynthesis. J Biol Chem 263:15146-15150.

Piller V, Piller F, Fukada M (1990) Biosynthesis of truncated O-glycans in the T cell line Jurkat. Localization of O-glycan initiation. J Biol Chem 265:9264-9271. 
Prokop O, Uhlenbruck G, Kohler W (1968) A new source of antibody-like substances having anti-blood group specificity. A discussion on the specificity of Helix agglutinins. Vox Sang 14:321-333.

Rademacher TW (1991) Network theory of glycosylation - etiologic and pathogenic implications of changes in IgG glycoform levels in autoimmunity. Seminars in Cell Biology 2:327-337.

Rifai A (1988) Characteristics of nepluritogenic IgA immune complexes. Am J Kidney Dis 12:402-405.

Rifai A, Schena FP, Montinaro V, Mele M, d'Addabbo A, Nitti L, Pezzullo JC (1989) Clearance kinetics and fate of macromolecular $\operatorname{IgA}$ in patients with $\operatorname{IgA}$ nephropathy. Lab Invest 61:381388.

Rinderle SJ, Goldstein IJ, Matta KL, Ratcliffe RM (1989) Isolation and characterization of amaranthin, a lectin present in the seeds of Amaranthus caudatus, that recognises the T- (or cryptic T-) antigen. J Biol Chem 264:16123-16131.

Roccatello D, Picciotto G, Coppo R, Piccoli G, Molino A, Cacace G, Amore A, Amoroso A, Quattrocchio G, Sena LM (1989) Clearance of polymeric IgA aggregates in humans. Am J Kidney Dis 14:354-360.

Roccatello D, Picciotto G, Torchio M, Ropolo R, Ferro M, Franceschini R, Quattroccchio G, Cacace G, Coppo R, Sena LM, de Filippi PG, Piccoli G (1993) Removal systems of immunoglobulin A and immunoglobulin A containing complexes in IgA nephropathy and cirrhosis patients. The role of asialoglycoprotein receptors. Lab Invest 69:714-723.

Roitt IM, Dwek RA, Parekh RB, Rademacher TW, Alavi A, Axford JS, Bodman KB, Bond A, Cooke A, Hay FC, Isenberg DA, Lydyard PM, Mackenzie L, Rook G, Smith M, Sumar N (1988) The role of antigen in autoimmune responses with special reference to changes in carbohydrate structure of IgG in rheumatoid arthritis. J Autoimmunity 1:499-506.

Roitt IM, Sumar N (1990) IgG and theumatoid factor at a glance. Clin Exp Rheumatol 8(Supp1 5):89-91.

Roque-Barreira MC, Campos-Neto A (1985) Jacalin: an IgA-binding lectin. J Immunol 134:1740-1743.

RRostoker G, Pech M-A, del Prato S, Petit-Phar M, BenMaadi A, Dubert J-M, Lang P, Weil B, Lagrue G (1989) Serum IgG subclasses and IgM imbalances in adult IgA mesangial glomerulowephritis and idiopathic Henoch-Schoenlein purpura. Clin Exp Immunol 75:30-34. 
Rostoker G, Pech MA, Petit-Plaar M, BenMaadi A, Cholin S, lang P, Dubert JM, Weil B, Lagiue G (1990) Mucosal immunity in adult primary glomerulonephritis. I. Evaluation of salivary IgA subclasses and components. Nephron 54:42-46.

Rostoker G, Terzidis H, Petit-Phar M, Meillet D, Lang P, Dubert JM, Lagrue G, Weil B (1992) Secretory $\operatorname{IgA}$ is elevated in both saliva and serum of patients with various types of primary glomerulonephritis. Clin Exp Immunol 90:305-311.

Roth S (1985) Are glycosyltransferases the evolutionary antecedents of the immunoglobulius? Q Rev Biol 60:145-153.

Rothschild E, Chatenoud L (1984) T cell subset modulation of immunoglobulin production in IgA nephropathy and membranous glomerulonephritis. Kidney Int 25:557-564.

Rudd PM, Fortune F, Patel T, Parelk RB, Dwek RA, Lehner T (1994) A human T-cell receptor recognises O-linked sugars from the hinge region of human IgA1 and IgD. Immunology 83:99106.

Rudd PM (1995); personal communication.

Russell MW, Mestecky J, Julian BA, Galla JH (1986) IgA-associated renal diseases: antibodies to envirommental antigens in sera and deposition of immunoglobulins and antigens in glomeruli. J Clin Immunol 6:74-86.

Saitoh O, Piller F, Fox RI, Fukuda M (1991) T-lymphocytic leukaemia expresses complex, branched O-linked oligosaccharides on a major sialoglycoprotein, leukosialin. Blood 77:14911499.

Sakai H, Endoh M, Tomino Y, Nomoto Y (1982) Increase of IgA specific helper T $\alpha$ cells in patients with IgA nephropathy. Clin Exp Immunol 50:77-82.

Sakai H, Miyazaki M, Endoh M, Nomoto Y (1989) Increase of IgA-specific switch T cells in patients with IgA nephropathy. Clin Exp Immunol 78:378-382.

Santillippo F, Croker BP, Bollinger RR (1982) Fate of four cadaveric donor renal allografts with mesangial IgA deposits. Transplantation 33:370-376.

Santiago A, Satriano J, deCandido S, Holthofer H, Schreiber R, Unkeless J, Schloudorff D (1989) A specific Fc $\gamma$ receptor on cultured rat mesangial cells. J Immunol 143:2575-2582.

Schena FP, Mastrolitti G, Fracasso AR, Pastore A, Ladisa N (1986) Increased immunoglobulinsecreting cells in the blood of patients with active idiopathic IgA nephropathy. Clin Nephrol 26:163-168. 
Schena FP, Pastore A, Sinico RA, Montinaro V, Fornasieri A (1988a) Polymeric IgA and IgA rhematoid factor decrease the capacity of sexum to solubilize circulating immune complexes in patients with primary IgA nephropathy. J Immunol 141:125-130.

Schena FP, Pastore A, Montinaro V (1988b) Thr role of polymeric IgA in complement-mediated solubilization of IgG and IgA immune complexes. Am J Kiduey Dis 12:433-436.

Schena FP, Pastore A, Ludovico N, Sinico RA, Benuzzi S, Montinaro V (1989a) Increased serum levels of $\operatorname{IgAl}-\operatorname{IgG}$ immune complexes and anti-F( $\left.\mathrm{ab}^{\prime}\right) 2$ antibodies in patients with primary IgA nephropathy. Clin Exp Immunol 77:15-20.

Schena FP, Mastrolitti G, Jirillo E, Munno I, Pellegrino N, Fracasso AR, Aventaggiato L (1989b) Increased production of interleulan- 2 and $\mathrm{L}-2$ receptor in primary $\operatorname{Ig} A$ nephropathy. Kidney Int 35:875-879.

Schena FP (1990a) A retrospective analysis of the natural history of primary IgA nephropathy worldwide. Am J Med 89:209-215.

Schena FP, Montenegro M, Scivittaro V (1990b) Meta-analysis of randomised controlled trials in patients with primary IgA nephropathy (Berger's disease). Nephrol Dial Transplant Suppl 1:4752.

Schena FP, Gesualdo L, Montinaro V (1992) Immunopathological aspects of immunoglobulin A nephropathy and other mesangial proliferative glomerulonephritides. J Am Soc Nephrol 2:S167-172.

Schena FP, Scivittaro V, Ranieri E (1993a) IgA nephropathy: pros and cons for a familial disease. In: IgA Nephropathy: The 25th Year. Bene M-C, Faure GC, Kessler M (Eds) Contrib Nephrol 104:36-45.

Schena FP, Scivittaro V, Ranieri E, Sinico R, Benuzzi S, di Cillo M, Aventaggiato L (1993b) Abnormalities of the IgA immune system in members of unrelated pedigrees from patients with IgA nephropathy. Clin Exp Immunol 92:139-144.

Scivittaro V, Amore A, Emancipator SN (1993) Animal models as a means to study IgA nephropathy. In: IgA Nephropathy: The 25th Year. Bene M-C, Faure GC, Kessler M (Eds) Contrib Nephrol 104:65-78.

Shaper NL, Harduin-Lepers A, Rajput B, Shaper JH (1994) Murine $\beta 1$,4-galactosyltransferase: analysis of the regulation of a gene that serves both a housekeeping and cell-specific function (abstract). Glycosylation \& Disease 1:201. 
Sharon N, Lis H (1989) Lectins. 1st Edition, Chapman and Hall Ltd, UK.

Shia MA, Lodish HF (1989) The two subunits of the human asialoglycoprotein receptor have different fates when expressed alone in fibroblasts. Proc Nat1 Acad Sci USA 86:1158-1162.

Shimkai Y, Karai M, Osawa G, Sato M, Koshikawa S (1990) Antimouse laminin antibodies in IgA nephropathy and various glomerular diseases. Nephron 56:285-296.

Shur BD (1994) Molecular analysis of cell surface $\beta 1,4$-galactosyltransferase expression and function (abstract). Glycosylation \& Disease 1:202.

Silva FG, Chander P, Pirani CL, Hardy MA (1982) Disappearance of glomerular mesangial IgA deposits after renal allograft transplantation. Transplantation 33:214-216.

Sinico RA, Fornasieri A, Oreni N, Benuzzi S, d'Amico G (1986) Polymeric IgA rheumatoid factor in idiopathic IgA mesangial nephropathy (Berger's disease). J Immunol 137:536-541.

Sinico RA, Fornasieri A, Maldifassi P, Colasanti G, d'Amico G (1988) The clinical significance of IgA rheumatoid factor in idiopathic IgA mesangial nephropathy (Berger's disease). Clin Nephrol 30:182-186.

Soltys AJ, Hay FC, Bond A, Axford JS, Jones MG, Randen I, Thompson KM, Natvig JB (1994) The binding of synovial tissue-derived human monoclonal immunoglobulin $M$ rheumatoid factor to immunoglobulin G preparations of differing galactose content. Scand J Immunol 40:135-143. Stewart WW, Kerr MA (1990) The specificity of the human neutrophil IgA receptor (Fc $\alpha$ R) determined by measurement of chemiluminescence induced by serum or secretory $\operatorname{IgA} 1$ or $\operatorname{IgA} 2$. Immunology 71:328-334.

Stockert RJ, Kressner MS, Collins JC, Sternlieb I, Morell AG (1982) IgA interaction with the asialoglycoprotein receptor. Proc Natl Acad Sci USA 79:6229-6231.

Sumar N, Bodman KB, Rademacher TW, Dwek RA, Williams P, Parekh RB, Edge J, Rook GAW, Isenberg DA, Hay FC, Roitt IM (1990) Analysis of glycosylation changes in IgG using lectins. J Immunol Methods 131:127-136.

Suzuki S, Nakatomi X, Sato H, Tsukada H, Arakawa M (1994) Haemophilus parainfluenzae antigen and antibody in renal biopsy samples and serum of patients with IgA nephropathy. Lancet 343:12-20.

Tao M-H, Morrison SL (1989) Studies of aglycosylated chimeric mouse-human IgG. Role of carbohydrate in the structure and effector functions mediated by the human IgG constant region. J Immunol 143:2595-2601. 
Taylor AK, Wall R (1988) Selective removal of $\alpha$ heavy-chain glycosylation sites causes immunoglobulin A degradation and reduced secretion. Mol Cell Biol 8:4197-4203.

Thurnher M, Clausen H, Fierz W, Lanzavecchia A, Berger EG (1992) T cell clones with normal or defective $\mathrm{O}$-galactosylation from a patient with permanent mixed-field polyagglutinability. Eur J Immunol 22:1835-1842.

Thurnher M, Rusconi S, Berger EG (1993) Persistent repression of a functional allele can be responsible for galactosyltranferase deficiency in Tn syndrome. J Clin Invest 91:2103-2110.

Tollefsen SE, Kornfeld R (1983) Isolation and characterization of lectins from Vicia villosa. Two distinct carbohydrate binding activities are present in seed extracts. J Biol Chem 258:51655171.

Tomana M, Mestecky J, Niedermeier W (1972) Studies on human secretory immunoglobulin A. IV. Carbohydrate composition. J Immunol 108:1631-1636.

Tomana M, Niedermeier W, Mestecky J, Skavaril F (1976) The differences in carbohydrate composition between the subclasses of IgA immunoglobulins. Immunochem 13:325-328.

Tomana M, Kulhavy R, Mestecky J (1988) Receptor-mediated binding and uptake of immunoglobulin A by human liver. Gastroenterology 94:762-70.

Tomana M, Zikan J, Moldoveanu Z, Kulhavy R, Bennett JC, Mestecky J (1993a) Interactions of cell-surface galactosyltransferase with immunoglobulins. Mol Immunol 30:265-275.

Tomana M, Zikan J, Kulhavy R, Bennett JC, Mestecky J (1993b) Interactions of galactosyltransferase with serum and secretory immunoglobulins and their component chains. Mol Immunol 30:277-286.

Tomino Y, Endoh M, Nomoto Y, Sakai H (1982) Specificity of eluted antibody from renal tissues of patients with IgA nephropathy. Am J Kidney Dis 1:276-280.

Tomino Y, Miura M, Suga T, Endoh M, Nomoto Y, Yagame M, Sakai H, Itoh K, Ikeda N (1984) Detection of polymeric IgA in sera from patients with IgA nephropathy determined by thin-layer gel filtration. Tokai J Exp Clin Med 9:155-160.

Tomino Y, Koide H, Yagame M, Sakai H, Tanaka S (1990) Preliminary study on specificity of $\operatorname{IgA}$ released from lymphocytes by $\mathrm{EB}$ virus transformation in patients with $\operatorname{IgA}$ nephropathy. Am J Med Sci 299:374-378.

Turner GA (1992) N-glycosylation of serum proteins in disease and its investigation using lectins. Clinica Chimica Acta 208:149-171. 
Uhlenbruck G, Prokop O (1966) An agglutinin from Helix pomatia, which reacts with terminal N-acetyl-D-galactosamine. Vox Sang 11:519-520.

Valim YML, Lachmann PJ (1991) The effect of anibody isotype and antigenic epitope density on the complement-fixing activity of immune complexes: a systematic study using chimaeric antiNIP antibodies with human Fc regions. Clin Exp Immunol 84:1-8.

Varki A (1992) Diversity in the sialic acids. Glycobiol 2:25-40.

Veis JH (1993) An overview of mesangial cell biology. In: IgA Nephropathy: The 25th Year. Bene IM-C, Faure GC, Kessler M( (Eds) Contrib Nephrol 104:115-126.

Wakui H, Imai H, Nakamoto Y, Kobayashi R, Itoh H, Miura AB (1989) Anti-histone autoantibodies in ddY mice, and animal model for spontaneous IgA nephritis. Clin Immunol Immunopathol 52:248-256.

Waldo FB (1988) Is Henoch-Schönlein purpura the systemic form of IgA nephropathy? Am J Kidney Dis 12:373-377.

Waldo FB, Britt WJ, Tomana M, Julian BA, Mestecky J (1989) Non-specific mesangial staining with antibodies against cytomegalovirus in immunoglobulin-A nephropathy. Lancet $\mathrm{i}: 129-130$. Waldo FB (1990) Role of IgA in IgA nephropathy. J Pediatrics 116:S78-S85.

Walker MR, Lund J, Thompson KM, Jefferis R (1989) Aglycosylation of human IgG1 and IgG3 monoclonal antibodies can eliminate recognition by human cells expressing Fc $\gamma R$ I and/or Fc $\gamma R I I$ receptors. Biochem J 259:347-353.

van den Wall 影ake AWL, Daha MR, van der Ark A, Hiemstra PS, Radl J, van Es LA (1988a) Serum levels and in vitro production of IgA subclasses in patients with primary IgA nephropathy. Clin Exp Immunol 74:115-120.

van den Wall Balke AWL, Daha MR, Evers-Schouten J, van Es LA (1988b) Serum IgA and the production of $\operatorname{IgA}$ by peripheral blood and bone marrow lyomphocytes in patients with primary IgA nephropathy: evidence for the bone marrow as the source of mesangial IgA. Am J Kidney Dis 12:410-414.

van den Wall BBake AWL, Beyer WEP, Evers-Schouten JH, Hermans J, Daha MR, Masurel N, van Es LA (1989) Humoral immune response to influenza vaccination in patients with primary immunoglobulin A nephropathy. An analysis of isotype distribution and size of the influenzaspecific antibodies. J Clin Invest 84:1070-1075. 
van den Wall $\mathbb{B}$ ake AWL, Kirk KA, Gay RE, Switalski LM, Julian BA, Jackson S, Gay S, Mestecky J (1992) Binding of serum immunoglobulins to collagens in IgA nephropathy and HIV infection. Kidney Int 42:374-382.

vam den Wall BBake AWL (1993a) Mechanisms of IgA deposition in the mesangium. In: IgA Nephropathy: The 25th Year. Bene M-C, Faure GC, Kessler M (Eds) Contrib Nephrol 104:138146.

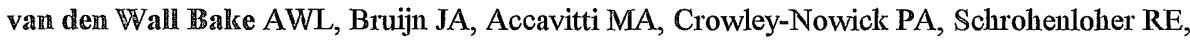
Julian BA, Jackson S, Kubagawa H, Cooper MD, Daha MR, Mestecky J (1993b) Shared idiotypes in mesangial deposits in IgA nephropathy are not disease specific. Kidney Int 44:65-74. Wilson IBH, Platt FM, Isenberg DA, Rademacher TW (1993) Aberrant control of galactosyltransferase in peripheral B lymphocytes and Epstein-Barr virus transformed B lymphoblasts from patients with rheumatoid arthritis. J Rheumatol 20:1282-1287.

Wold AE, Motas C, Svanborg C, Mestecky J (1994) Lectin receptors on IgA isotypes. Scand J Immunol 39:195-201.

Woo KT, Lee GSL, Lau YK, Chiang GSC, Lim CH (1991) Effects of triple therapy in IgA nephritis: a follow-up study 5 years later. Clin Nephrol 36:60-66.

Woof JM (1994) Personal communication; unpublished data.

Wright A, Morrison SL (1993) Antibody variable region glycosylation: biochemical and clinical effects. Springer Semin Immunopathol 15:259-273.

Wyatt RJ, Rivas ML, Schena FP, Bin J, Julian BA (1990) Regional variations in C4 phenotype in patients with IgA nephropathy. J Pediatr 116:\$72-\$77.

Wyatt RJ, Julian BA, Rivas ML (1991) Role for specific complement phenotypes and deficiencies in the clinical expression of IgA nephropathy. Am J Med Sci 301:115-123.

Yano N, Miyazaki M, Endoh M, Kuramoto T, Eguchi K, Yagame M, Nomoto Y, Sakai H (1992) Increase of CD23-positive cells in peripheral blood from patients with IgA nephropathy and nonIgA proliferative glomerulonephritis. Nephron 60:404-410.

Yasumoto Y, Suga T, Miura M, Endoh M, Nomoto H, Tomino Y, Nomoto Y, Sakai H (1989) Subpopulations of $\mathrm{T} \alpha$ cells in patients with IgA nephropathy: correlation between T $\alpha 4$ cells and in vitro IgA production. Clin Immunol Immunopathol 51:232-239.

Young NM, Jackson GED, Brisson J-R (1990) The glycopeptides of the mouse immunoglobulin A T15. Mol Inmunol 27:1083-1090. 
van $\mathbb{Z}$ eben D, Rook GAW, Hazes JMW, Zwinderman AH, Zhang Y, Ghelani S, Rademacher TW, Breedveld FC (1994) Early agalactosylation of $\mathrm{IgG}$ is associated with a more progressive disease course in patients with rheumatoid arthritis: results of a follow-up study. Br J Rheumatol 33:36-43.

Zhang W, Lachmann PJ (1994) Glycosylation of IgA is required for optimal activation of the alternative complement pathway by immune complexes. Immunology 81:137-141. 